\title{
FLORÍSTICA, FITOSSOCIOLOGIA E DINÂMICA DE DUAS FLORESTAS SECUNDÁRIAS ANTIGAS COM HISTÓRIAS DE USO DIFERENTES NO NORDESTE DO PARÁ-BRASIL
}

\author{
MARCELO SANTOS MELO
}

Dissertação apresentada à Escola Superior de Agricultura "Luiz de Queiroz", Universidade de São Paulo, para obtenção do título de Mestre em Recursos Florestais, com opção em Conservação de Ecossistemas Florestais.

P I R A C I C A B A

Estado de São Paulo -Brasil

Agosto - 2004 


\title{
FLORÍSTICA, FITOSSOCIOLOGIA E DINÂMICA DE DUAS FLORESTAS SECUNDÁRIAS ANTIGAS COM HISTÓRIAS DE USO DIFERENTES NO NORDESTE DO PARÁ-BRASIL
}

\section{MARCELOSANTOS MELO}

Engenheiro Florestal

\author{
Orientador: Prof. Dr. RICARDO RIBEIRO RODRIGUES
}

Dissertação apresentada à Escola Superior de Agricultura "Luiz de Queiroz", Universidade de São Paulo, para obtenção do título de Mestre em Recursos Florestais, com opção em Conservação de Ecossistemas Florestais.

P I R A C I C A B A

Estado de São Paulo -Brasil Agosto - 2004 
Dados Internacionais de Catalogação na Publicação (CIP)
DIVISÃO DE BIBLIOTECA E DOCUMENTAÇÃO - ESALQ/USP

Melo, Marcelo Santos

Florística, fitossociologia e dinâmica de duas florestas secundárias antigas com história de uso diferentes no nordeste do Pará-Brasil / Marcelo Santos Melo. - -

Piracicaba, 2004.

116 p. : il.

Dissertação (mestrado) - - Escola Superior de Agricultura Luiz de Queiroz, 2004.

Bibliografia.

1. Composição florística 2. Comunidades vegetais 3. Dinâmica de comunidades Florestas secundárias 5. Regeneração natural I. Título

CDD 634.9

"Permitida a cópia total ou parcial deste documento, desde que citada a fonte - O autor" 
"Nósnão cessaremos a investigação

E ofimdetodonosso investigar

Será chegar ondenós iniciamos

E conhecer olugar p\&a primeira vez"

(Shahid Naeem)

Aos meus pais Evangelista e Joselita, por todo esforço em levar o filho à universidade; ao meu irmão Genymeds pela ajuda, amizade e carinho; ao meu avô Gentil (in memorian) e todos os tios e tias que me ajudaram nesta caminhada; e especialmente à minha esposa Lia e meu filho Daniel.

Ofereço e dedico este trabalho 


\section{AGRADECIMENTOS}

- Ao Prof. Dr. Ricardo Ribeiro Rodrigues, por ter me orientado nessa importante etapa profissional, pela paciência e por ser exemplo de simplicidade e dedicação ao trabalho.

- À Prof. Lia de Oliveira Melo, pelas indispensáveis dicas, revisão do trabalho e por muito ter auxiliado na minha formação acadêmica.

- À Coordenação do Curso de Pós-Graduação em Recursos Florestais da Escola Superior de Agricultura "Luiz de Queiroz", pela oportunidade concedida.

- À Coordenação de Aperfeiçoamento de Pessoal de Nível Superior (CAPES) pela concessão da bolsa de estudos durante o período do curso.

- Ao Projeto Bosque Secundário (Projeto Capoeira) pelo apoio logístico, financeiro e por ceder o banco de dados de Bragança; sua inestimável equipe de Pesquisadores (Socorro Ferreira, Dr. Manoela Ferreira F. da Silva, Prof. Lia de Oliveira Melo, Marli Mattos e César Sabogal); aos Bolsistas (Wiliams, Regina Célia, Willen, Olegário, Paulo, Luiz Kinji, Francisco Neto, Breno e Carlinha) pela amizade e carinho; aos auxiliares de campo (Ricardinho, Joca, Izaque e Maria) pela amizade e inestimável ajuda; aos identificadores (Tio Bené, Seu Dico e Jair) pelo precioso auxílio na identificação de material botânico em campo; e ao nosso auxiliar administrativo e animador nas horas vagas, Jair Macedo.

- À Comissão Executiva do Plano da Lavoura Cacaueira, por intermédio do Chefe da Estação Experimental José Haroldo, Eng ${ }^{0} \operatorname{Agr}^{0}$ Miguel G. Martins Pina, por ceder a área e pelo apoio logístico à coleta de dados em Marituba. 
- Ao Herbário IAN, Dr. João Murça Pires, da EMBRAPA-Amazônia Oriental, pela imprescindível identificação do material botânico.

- Aos Professores da Universidade Federal Rural da Amazônia (UFRA), Luiz Gonzaga da Silva Costa, pela inestimável orientação ao longo de toda Graduação, José Augusto Santana pelo auxílio nas coletas de dados e Mário Lopes pela análise de Solos.

- À Prof ${ }^{\mathrm{a}}$. Dr. Natália Ivanauskas, pela decisiva ajuda nas análises multivariadas dos dados.

- Aos amigos Téco ${ }^{-}$Florestais (Diogo, Marcos, Alessandro e Itatimara) pelo auxílio nas coletas de dados em Marituba.

- Ao amigo Eng ${ }^{o}$ Flo. Carlos Alberto Nogueira, pelo importante auxílio nas coletas de solo.

- Aos amigos do Laboratório de Métodos Quantitativos (Jéferson, Eliza, Clarissa e Marky) pelos auxílios técnicos e operacionais.

- Aos queridos amigos do PET-Florestal da UFRA, pela amizade e pelo companheirismo nas horas difíceis da luta pela manutenção da qualidade do ensino e das bolsas (Marlon, Carlinhos, Marcus, Zilma, Patrícia, Ulisses, Farid, Andrei, Keila, Débora e Julivane).

- A todos os amigos nortistas que se encontram longe de suas terras natais, e que nesses três anos, em Piracicaba, nos ajudaram a matar a saudade da terrinha. 


\section{SUMÁRIO}

Página

LISTAS DE FIGURAS........................................................................................ ix

LISTAS DE TABELAS.................................................................................... xii

RESUMO.................................................................................................................. xiv

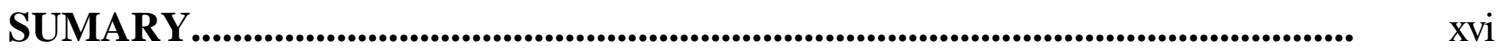

1 INTRODUÇÃ

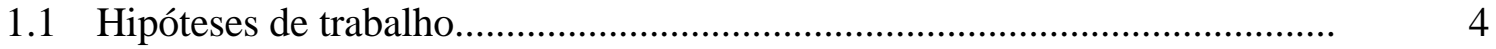

1.1.1 Objetivo geral............................................................................

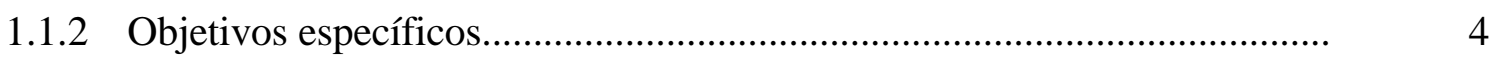

2 REVISÃO DE LITERATURA................................................................ 5

2.1 Florística e fitossociologia....................................................................

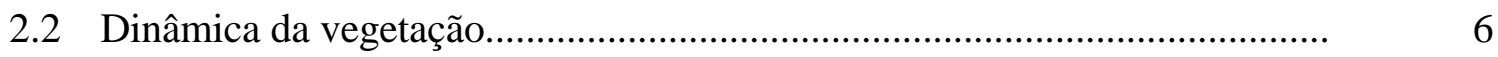

2.3 Relação entre solo e vegetação...............................................................

3 MATERIAL E MÉTODOS ......................................................................... 11

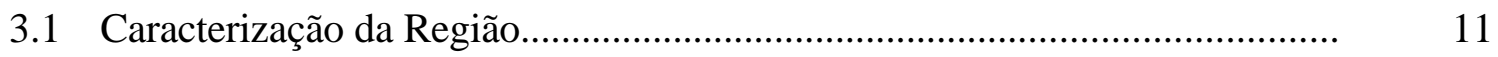

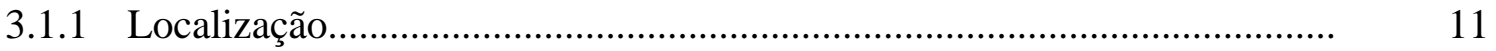

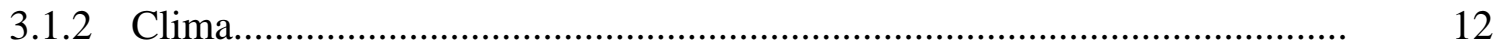

3.1.3 Geologia, relevo e solo do Nordeste do Pará............................................... 14

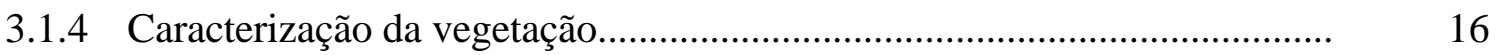

3.1.5 Histórico de ocupação.......................................................................... 17

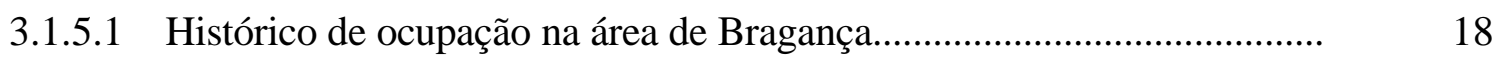

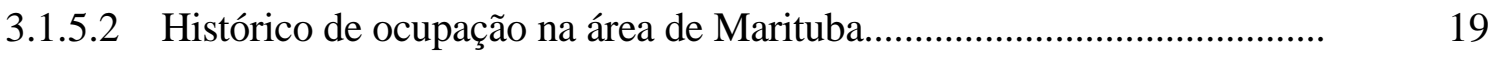

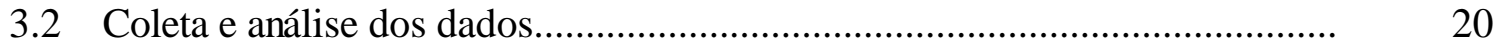




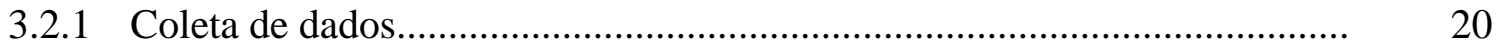

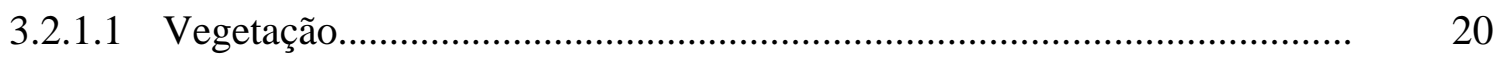

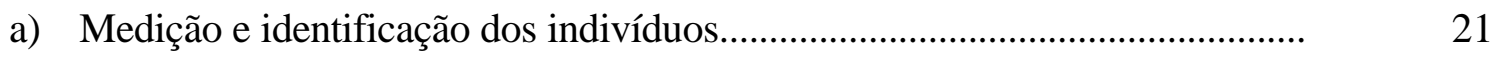

b) Classe de identificação de fuste.....................................................................

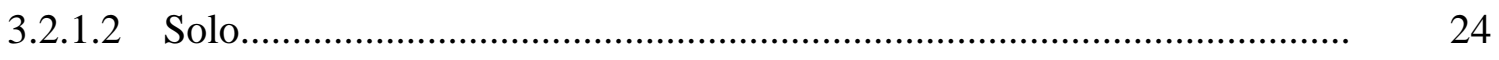

3.2.2 Análise dos dados............................................................................. 25

3.2.2.1 Parâmetros florísticos e fitossociológicos...................................................

3.2.2.2 Diversidade e Equabilidade .................................................................. 26

3.2.2.3 Similaridade Florística............................................................................. 27

3.2.2.4 Crescimento, Ingresso e Mortalidade...................................................... 29

3.2.2.5 Fertilidade e Granulometria do solo....................................................... 31

4 RESULTADOS E DISCUSSÃO........................................................................... 33

4.1 Diversidade florística..................................................................................

4.2 Similaridade florística..................................................................................

4.3 Parâmetros fitossociológicos.......................................................................

4.3.1 Famílias.....................................................................................

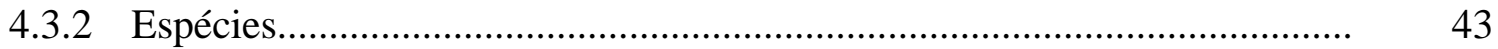

a) Índice de Valor de Importância - IVI...............................................................

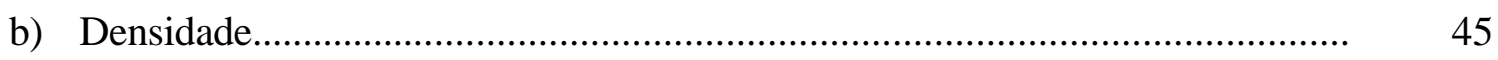

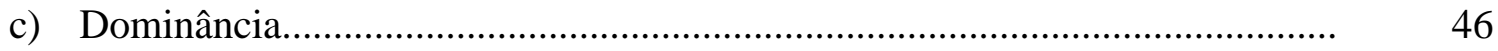

d) Distribuição nas Classes diamétricas.................................................................. 48

4.4 Descritores de regeneração............................................................................ 51

a) Taxa de incremento periódico anual (IPA) …………….................................

b) Taxas de Ingresso e Mortalidade ...................................................................

4.5 Análise dos atributos de fertilidade dos solos.......................................................... 63

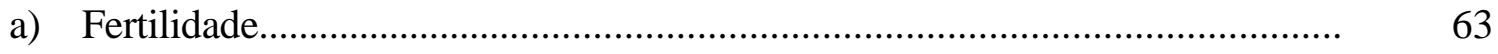

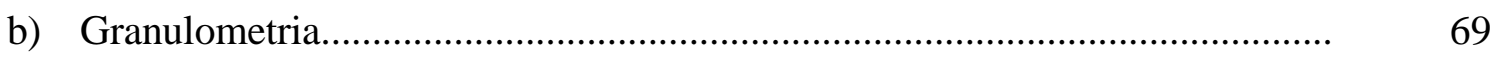

c) Análise multivariada dos principais atributos da fertilidade do solo...................

4.6 Correlação dos principais atributos da fertilidade do solo e vegetação em análises multivariadas. 


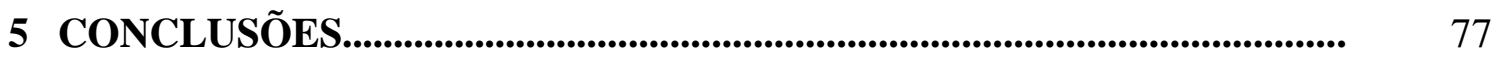

ANEXOS.............................................................................................................. 80

REFERÊNCIAS BIBLIOGRÁFICAS.............................................................. 107 


\section{LISTA DE FIGURAS}

Página

1 Localização dos municípios de Bragança e Marituba, na Zona Bragantina e Microrregião de Belém, respectivamente.

11

13

2 Diagrama climático da região de Bragança, Estado do Pará (média 1961-1991) DNM (1992)..

13 (1992)

4 Localização das formações geológicas ocorrentes no Nordeste Paraense (Adaptado, Diagnóstico Brasil, IBGE 1990)

5 Localização das unidades de Relevo predominantes no Pará (Adaptado, Atlas Nacional do Brasil, IBGE 1992).

6 Localização das unidades de Vegetação na porção norte do Nordeste Paraense (Adaptado,

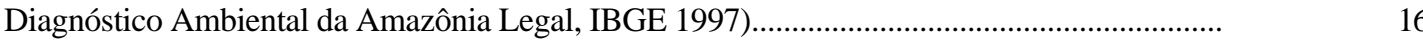

7 Entorno da área estudada em uma propriedade rural no município de Bragança-PA.................. 18

8 Entorno da área estudada em uma área de reserva da CEPLAC no município de Marituba-PA. 19

9 Croqui das parcelas estudadas nos municípios de Marituba e Bragança-PA.............................. 21

10 Medição de DAP em árvores: A- medição a 1,3m do solo; B- medição de DAP em árvores que apresentam Sapopemas (Adaptado de Pedro Bernardo Neto 2001 (não publicado))............

11 Estado físico aparente das árvores levantadas em campo e seus respectivos códigos de CIF (adaptado de SILVA et al., 1984)

12 Croqui da metodologia para coleta de amostras de solo das parcelas estudadas nos municípios de Marituba e Bragança-PA

13 "Trado Martelo" utilizado para coletar amostras de solo das parcelas estudadas nos municípios de Bragança e Marituba-PA. Onde: (A- martelo; B- cabeça; C- canhão coletor; Dcilindro coletor e; E- extensão) .

14 Dendrograma apresentando a similaridade florística, em nível específico, entre as parcelas inventariadas em Bragança e Marituba no Nordeste do Pará, utilizando como coeficiente o índice de Jaccard e agrupando as parcelas pelo método de Média de Grupo. 
15 Dendrograma apresentando a similaridade florística, em nível específico, entre as florestas inventariadas em Bragança e Marituba no Nordeste do Pará e outras áreas de florestas secundárias e primárias, utilizando como coeficiente o índice de Jaccard e agrupando as parcelas pelo método de Média de Grupo.

16 Valores de IVI para as principais espécies encontradas nos levantamentos realizados em parcelas permanentes de duas florestas secundárias antigas em Marituba e Bragança-PA........

17 Dominância Relativa para as principais espécies encontradas nos levantamentos realizados em parcelas permanentes de duas florestas secundárias antigas em Marituba e Bragança-PA..

18 Distribuição em classes de DAP do percentual de plantas encontradas nos levantamentos de 1997 e 2002 de uma floresta secundária antiga em área da CEPLAC de Marituba-PA..............

19 Distribuição em classes de DAP do percentual de plantas encontradas nos levantamentos de 1999 e 2002 de uma floresta secundária antiga em Bragança-PA

20 Crescimento médio anual em diâmetro por classe de DAP em duas florestas secundárias antigas de Marituba e Bragança-PA.

21 Crescimento médio anual em diâmetro por período e por classe de DAP em duas florestas secundárias antigas de Marituba e Bragança-PA

22 Espécies que apresentaram os maiores valores de incremento médio anual em diâmetro em duas florestas secundárias antigas de Marituba e Bragança-PA.

23 Taxa de mortalidade anual nas classes diamétricas nos levantamentos realizados em parcelas permanentes de duas florestas secundárias antigas de Marituba e Bragança-PA.......................

24 Valor médio geral de $\mathrm{C}$ e MO das amostras coletadas nas profundidades de $0-5 \mathrm{~cm}, 5-15 \mathrm{~cm}$ e 15-25cm para as parcelas estudadas em Marituba e Bragança-PA.

25 Valor geral médio da acidez potencial $\left(\mathrm{H}^{+}+\mathrm{Al}^{+3}\right)$ e capacidade de troca de cátions (CTC) das amostras coletadas nas profundidades de $0-5 \mathrm{~cm}, 5-15 \mathrm{~cm}$ e $15-25 \mathrm{~cm}$ para as parcelas estudadas em Marituba e Bragança-PA

26 Valor geral médio da saturação por bases $(\% \mathrm{~V})$ e da toxidez do alumínio $(\% \mathrm{Al})$ das amostras coletadas nas profundidades de $05 \mathrm{~cm}, 5-15 \mathrm{~cm}$ e $15-25 \mathrm{~cm}$ para as parcelas estudadas em Marituba e Bragança-PA.

27 Percentagem das frações granulométricas do solo (Areia Grossa, Areia Fina, Silte e Argila) do solo das parcelas amostradas numa floresta secundária oriunda de exploração de madeira para lenha, no município de Marituba-PA, nas profundidades de 0-5cm, $5-15 \mathrm{~cm}$ e $15-25 \mathrm{~cm} . .$.

28 Percentagem das frações granulométricas do solo (Areia Grossa, Areia Fina, Silte e Argila) do solo das parcelas amostradas numa floresta secundária oriunda de agricultura de corte e queima no município de Bragança-PA, nas profundidades de $0-5 \mathrm{~cm}, 5-15 \mathrm{~cm}$ e $15-25 \mathrm{~cm} . . . \ldots \ldots . .$. 
29 Dendrograma apresentado a Distância Euclidiana Simples entre as parcelas das áreas de Marituba e Bragança-PA, considerando os principais atributos da fertilidade e granulometria do solo e agrupando as parcelas pelo método de Média de Grupo.............................................

30 Ordenação por Análise de Componentes Principais (PCA - Correlação) dos principais atributos químicos e granulométricos do solo, para amostras coletadas na profundidade de 0$5 \mathrm{~cm}$, de floretas secundárias antigas em Marituba e Bragança-PA. Onde: Marituba corresponde aos caracteres 1, 2, 3 e 4 e Bragança 5, 6, 7 e 8

31 Ordenação pela CCA das unidades amostrais, baseada nas principais variáveis indicadores de fertilidade do solo ( $\mathrm{pH}, \mathrm{MO}, \mathrm{P}, \% \mathrm{~V}, \% \mathrm{Al}, \mathrm{CTC}$ e Argila) coletadas na proundidade de 0-5cm, e em variáveis biofísicas da vegetação $\left(C \_D A P=\right.$ incremento em diâmeto, N_IND = densidade e ABTOT = área basal total) em uma floresta secundária em Marituba-PA..............

32 Ordenação pela CCA das unidades amostrais, baseada nas principais variáveis indicadores de fertilidade do solo ( $\mathrm{pH}, \mathrm{MO}, \mathrm{P}, \% \mathrm{~V}, \% \mathrm{Al}, \mathrm{CTC}$ e Argila) coletadas na proundidade de 0-5cm, e em variáveis biofísicas da vegetação (C_DAP = incremento em diâmeto, N_IND = densidade e ABTOT = área basal total) em uma floresta secundária em Bragança-PA............... 


\section{LISTA DE TABELAS}

Página

1 Parâmetros de riqueza e diversidade do estrato arbóreo (DAP $\geq 5,0 \mathrm{~cm}$ ), nos levantamentos florísticos e fitossociológicos realizados em florestas secundárias de Marituba e Bragança no Nordeste Pará

2 Matriz de similaridade florística, em nível específico, entre as parcelas inventariadas em Bragança e Marituba no Nordeste do Pará, utilizando como coeficiente o índice de Jaccard em matriz binária com 250 espécies

3 Matriz de similaridade florística, em nível específico, entre as florestas inventariadas em Bragança e Marituba no Nordeste do Pará e outras áreas de florestas secundárias e primárias, utilizando como coeficiente o índice de Jaccard em matriz binária com 550 espécies.

4 Famílias mais importantes amostradas em 1,0ha entre os anos de 1997 e 2002 em uma floresta secundária oriunda de exploração de madeira para lenha, no município de MaritubaPA

5 Famílias mais importantes amostradas em 1,0ha entre os anos de 1999 e 2002 em uma floresta secundária oriunda de agricultura de corte e queima no município de BragançaPA.

6 Crescimento anual em diâmetro nos períodos de acompanhamento, por Classes de Identificações de Fuste (CIF - Figura 11) e para o número total de árvores numa floresta secundária oriunda de exploração de madeira para lenha, no município de Marituba-PA..........

7 Crescimento anual em diâmetro nos períodos de acompanhamento, por Classes de Identificações de Fuste (CIF - Figura 11) e para o número total de árvores numa floresta secundária antiga oriunda de agricultura de corte e queima no município de Bragança-PA.......

8 Taxas anuais de ingresso e mortalidade nos períodos de acompanhamento em uma floresta secundária oriunda de exploração de madeira para lenha, no município de Marituba-PA...........

9 Taxas anuais e números totais de ingresso e mortalidade nos períodos de acompanhamento em uma floresta secundária antiga oriunda de agricultura de corte e queima no município de Bragança-PA. 
10 Espécies com maior número de ingressos no período de 1997-2002, em uma floresta secundária oriunda de exploração seletiva de madeira para lenha, no município de MaritubaPA

11 Espécies com maior número de ingressos no período de 1999-2002, em uma floresta secundária antiga oriunda de agricultura de corte e queima no município de Bragança-PA........

12 Espécies que apresentaram maior mortalidade no período de 1997-2002, em uma floresta secundária oriunda de exploração de madeira para lenha, no município de Marituba-PA...........

13 Espécies que apresentaram maior mortalidade no período de 1999-2002, em uma floresta secundária antiga oriunda de agricultura de corte e queima no município de Bragança-PA........

14 Comparação dos valores médios pelo teste t-Student e Coeficientes de Variação de pH, C, $\mathrm{MO}, \mathrm{Na}, \mathrm{Ca}, \mathrm{Mg}, \mathrm{P}, \mathrm{k}, \mathrm{e} \mathrm{H}+\mathrm{Al}$ nas profundidades de $0-5 \mathrm{~cm}, 5-15 \mathrm{~cm}$ e $15-25 \mathrm{~cm}$ para as áreas estudadas nos municípios de Bragança e Marituba-PA

15 Comparação dos valores médios pelo teste t-Student e Coeficientes de Variação de CTC, SB, $\% \mathrm{~V}$ e $\% \mathrm{Al}$ nas profundidades de $05 \mathrm{~cm}, 515 \mathrm{~cm}$ e $15-25 \mathrm{~cm}$ para as áreas estudadas nos municípios de Bragança e Marituba-PA

16 Comparação dos valores médios pelo teste t-Student e Coeficientes de Variação de Areia Grossa, Areia Fina, Silte e Argila do solo das parcelas amostradas em florestas secundárias nos municípios de Bragança e Marituba-PA, nas profundidades de $0-5 \mathrm{~cm}, 5-15 \mathrm{~cm}$ e $15-25 \mathrm{~cm}$

17 Síntese dos resultados da análise de correspondência canônica (CCA) baseada em sete variáveis ambientais e três variáveis de vegetação $(n=48)$ para as áreas de Marituba e Bragança-PA.

18 Coeficientes canônicos e correlações "intra-set" das três variáveis de vegetação com os eixos 1 e 2 da CCA, baseada nas sete variáveis de solo $(n=48)$ 


\section{FLORÍSTICA, FITOSSOCIOLOGIA E DINÂMICA DE DUAS FLORESTAS SECUNDÁRIAS ANTIGAS COM HISTÓRIAS DE USO DIFERENTES NO NORDESTE DO PARÁ-BRASIL}

Autor: MARCELO SANTOS MELO

Orientador: Prof. Dr. RICARDO R. RODRIGUES

\section{RESUMO}

O incremento do processo de substituição da floresta amazônica por áreas agrícolas e seu posterior abandono, têm resultado num número crescente de fragmentos de florestas secundárias. Com o objetivo de contribuir com o entendimento da dinâmica dessas áreas, analisou-se a composição florística, a fitossociologia, o ingresso, a mortalidade, o crescimento dos indivíduos arbóreos e as relações do solo com o crescimento em diâmetro, densidade e área basal total de duas florestas secundárias (Marituba e Bragança, NE, PA) com diferentes histórias de degradação e mesma idade de abandono. Foram instaladas 4 parcelas permanentes de 50x50m, subdivididas em 25 com de 10x10m, em cada área, onde amostrou-se todas as árvores com DAP $\geq 5 \mathrm{~cm}$. Em Marituba as medições foram em 1997, 2000 e 2002, e em Bragança, 1999, 2000, 2001 e 2002. O solo foi coletado nas profundidades de 0$5 \mathrm{~cm}, 5-15 \mathrm{~cm}$ e $15-25 \mathrm{~cm}$, nas subparcelas pares das áreas. No primeiro levantamento de Marituba foram encontrados 1.257 indivíduos e 185 espécies. No último levantamento houve redução de 4,1\% de indivíduos e aumento de $8,1 \%$ de espécies, com $\mathrm{H}^{\prime}=4,42$ nats/indivíduo. Em Bragança, foram encontrados em 1999, 1.819 indivíduos e 136 espécies. No último levantamento, houve redução de 6,2\% dos 
indivíduos e de 1,5\% de espécies, com $\mathrm{H}^{\prime}=4,08$ nats/indivíduo. Entre as duas áreas estudadas houve baixa similaridade florística $\left(\mathrm{J}_{\mathrm{ac}}=12 \%\right)$. Marituba apresentou incremento diamétrico de $0,23 \mathrm{~cm} / \mathrm{ano}$, ingresso de $2,1 \% / \mathrm{ano}$ e mortalidade de 3,2\%/ano. Bragança apresentou incremento em DAP de 0,25cm/ano, ingresso de 1,2\%/ano e mortalidade de 3,6\%/ano. As duas florestas apresentaram um balanço característico de comunidades em sucessão secundária com taxas de mortalidade maiores do que ingressos, indicando estádio de reconstrução. As áreas apresentaram fertilidade do solo distintas, sendo que Bragança foi maior. Bragança se diferenciou de Marituba, pelo PCA, pelos atributos CTC, P, MO, Argila e \%Al. A análise de correspondência canônica (CCA), não mostrou correlação entre a fertilidade do solo e o crescimento em diâmetro, densidade e área basal total. A dinâmica da floresta de Bragança foi mais intensa, indicando um estádio sucessional menos avançado, resultado dos sucessivos ciclos de corte-queima-plantio-pousio. Para Marituba, os valores de riqueza, diversidade e área basal foram compatíveis com os de florestas primárias, em função das características mais amenas de degradação (extrativismo seletivo de madeira). Os resultados confirmaram a hipótese de que o histórico de perturbação foi definidor das características do processo de sucessão em duas florestas secundárias, com mesma idade e sobre o mesmo tipo de solo. Portanto, a idade por si só não é um requisito adequado para prever taxas de recuperação e estádios de sucessão de florestas secundárias. 


\title{
FLORISTIC, PHITOSOCIOLOGY AND DINAMIC OF TWO OLD SECONDARY FORESTS WITH DIFFERENT HISTORY OF USE IN THE NORTHEASTERN PARÁ-BRAZIL
}

\author{
Author: MARCELO SANTOS MELO \\ Adviser: Prof. Dr. RICARDO R. RODRIGUES
}

\section{SUMMARY}

The increase of the substitution from process amazonic forest by agricultural areas and their desertation afterwards have caused an increasing number of secondary forest fragments to happen. Aiming to contributing with the understanding of the diynamics of these areas, the floristic composition, the phitosociology, the ingrowth rate, the mortality rate, the growth of the individuals, and the soil relations whith the gowth in diameter, density and total basal area from secondary forests (Marituba and Bragança, NE, Pará) whith different hystories of abandonment, were analyzed. Four permanent plots measuring 50x50m, subdivided into 25 sub-plots with $10 x 10 \mathrm{~m}$ in each area, were installed. All trees with $\mathrm{DBH} \geq 5 \mathrm{~cm}$ were sampled. The measures made in Marituba took place in 1997, 2000, 2001, and 2002; yet, in Bragança, 1999, 2000, 2001 and 2002. The soil sampled were collected at lake depth of $05 \mathrm{~cm}, 5-$ $15 \mathrm{~cm}, 15-25 \mathrm{~cm}$ on the even part of the areas. In the first survey made in Marituba, 1,257 individuals and 185 species were found. In the last survey, the was a reduction of $4.1 \%$ in the number of individuals and an increase $8.1 \%$ of the species, with $\mathrm{H}^{\prime}=$ 4.42nats/indivíduo. In Bragança, 1,819 individuals and 136 species were found in 1999. In the last survei, there was a reduction of $6,2 \%$ of the individuals and $1,5 \%$ of 
species, with $\mathrm{H}^{\prime}=4.08$ nats/indivíduo. Between both studied areas, the was a low floristic similarity $\left(\mathrm{J}_{\mathrm{ac}}=12 \%\right)$. Marituba had an increase of $0.23 \mathrm{~cm} / \mathrm{year}$, ingrowth of $2.1 \% / y e a r$, and a mortality rate of 3.2\%/year. Bragança had a increase in DBH of $0.25 \mathrm{~cm}$ ?year, ingrowth of $1.2 \% / y e a r$, and a mortality rate of $3.6 \% / y e a r$. Both forests presented a characteristic floristic balance of communities under secondary succession, whit mortality rates higher than. The ingrowth, which indicated the recovering phase. The areas showed distinct soil fertility: Bragança's soil fertility was higher. Bragança was different from Marituba, for PCA analysis, mainly in relations to $\mathrm{CTC}, \mathrm{P}, \mathrm{MO}$, Clay, and \%Al. The canonical correspondence analysis (CCA) did not show correlation between the soil fertility and the growth in diameter, density, and total basal area. The dynamiocs of the forest in Bragança was more ntense, indicating a less advanced successional phase, wich was a result of successive cutting-burningólanting-resting cycles. For Marituba, the richness values, diversity, and basal area were compatible whit those of primary forests', as a function of lighter degradation characteristics (selective logging). The results confirmed the hypotesis that the succession process characteristics in both secondary forests with the same age and on the same type of soil. However, oney the age itself is not an adequate feature for forecasting the recovering rates and the successional phases of secondary forests. 


\section{INTRODUÇÃO}

Em muitas áreas da Amazônia, a expansão agropecuária tem sido desordenada e caótica, e geralmente o Estado tem chegado tarde para controlar os processos de colonização. Essa expansão tem sido realizada principalmente em terras de vocação florestal e/ou em terras baixas (ribeirinhas) destinadas a proteção florestal (TCA, 1999).

O resultado dessa situação é o crescente aumento na substituição da floresta natural por formas alternativas de uso do solo (plantações anuais, perenes e pastagens). Estes usos, na maioria das vezes se tornam insustentáveis, pois os solos, embora possuam boa estrutura, não suportam tais pressões devido à baixa fertilidade natural. Além das características do solo, a grande oferta de novas áreas, a falta de assistência técnica, o desconhecimento e/ou falta de interesse em implantar práticas de correção dos solos contribuem para o abandono das terras pelos produtores.

Numa seqüência simplificada dos processos que ocorrem após a derrubada da floresta (corte e queima), principalmente no Nordeste Paraense, geralmente há o cultivo agrícola de subsistência. Esta prática persiste normalmente por dois ou três anos, em seguida o agricultor abandona a área (pousio) por um período médio de 3 a 5 anos para que ela possa, de forma natural, "recuperar a produtividade do sítio".

Nas áreas abandonadas inicia-se do processo de regeneração natural, através do surgimento da vegetação secundária, que é chamada de floresta secundária, também conhecida como capoeira, capoeirão, juquira ou juquirão, segundo a idade da vegetação a origem dos agricultores e seus costumes.

Ao longo de décadas de estudos, diversos autores procuraram definir um conceito para floresta secundária. Greigh-Smith (1952) e Lanly (1982), concordam que floresta secundária é a vegetação que se desenvolve depois de um corte raso. UNESCO (1978), 
diz que a capoeira é uma vegetação que coloniza áreas cuja cobertura original desapareceu parcial ou totalmente, devido a perturbações naturais ou humanas.

Há também definições, particularmente na Ásia tropical, que consideram a floresta regenerante em áreas onde houve o corte parcial das árvores, como floresta secundária, devido a intensidade do distúrbio provocar fortes mudanças na estrutura, composição e função da floresta precedente (TCA 1997).

Um conceito mais abrangente desenvolvido por Chokkalingam \& De Jong (2001), afirma que as florestas secundárias são florestas em regeneração natural após significantes distúrbios humanos e/ou naturais na vegetação da floresta original, podendo ter ocorrido uma única vez ou progressivamente por longos períodos, e a floresta resultante apresentará grandes diferenças na estrutura e na composição de espécies do dossel, quando comparada a uma floresta primária próxima, mesmo estando num sítio similar.

Por outro lado, há também o conceito defendido por Corlett (1994), de que praticamente todas as florestas tropicais podem ser consideradas como florestas secundárias, uma vez que originalmente foram formadas sobre antigos leitos de rios, antigos deslizamentos de terras, áreas desmatadas por ações vulcânicas ou pelos habitantes primitivos da região.

Como mostram os conceitos citados anteriormente, não há, ainda, um consenso sobre a definição ideal de floresta secundária, principalmente, devido a origem das pesquisas, uma vez que são realizadas em continentes e países com climas, culturas e formas de uso diferenciados. Isto é, os fenômenos (furacões, vulcões, etc.) que podem causar a derrubada de consideráveis áreas naturais na América Central, não tem a mesma importância na Amazônia, onde os distúrbios, em sua maioria, são de natureza antrópica, e às vezes, não implicam necessariamente na remoção total da vegetação original.

A grande variabilidade de situações e eventos que provocam a remoção total ou parcial da floresta nativa, ou de áreas de vegetação secundária antiga e as atividades de uso alternativo que se seguem ao distúrbio, levam a diferentes estados e graus de recuperação da área abandonada. 
A vegetação secundária que repovoa a área após o abandono (regeneração natural), pode percorrer qualquer caminho no sentido da maturidade, condicionada por fatores ou causas externas (Bakker et al., 1996; Pickett \& Ostfeld, 1995) que interagem para exercer um papel chave na recuperação da área (Smith et al., 1997), tais como: precipitação, altitude (Ewel, 1980), uso anterior da terra (Uhl et al., 1988), fertilidade do solo (Mello et al., 1989) e proximidade da fonte de sementes.

Estas causas externas podem interferir de diferentes maneiras nas causas internas da sucessão, tais como o acúmulo de matéria orgânica no solo, o empobrecimento gradual e/ou a acidificação do solo (Bakker et al., 1996). As alterações mais severas, como a limpeza total da área com o uso do fogo, podem provocar mudanças tanto na fertilidade quanto na estrutura do solo, aumentando a densidade e diminuindo a porosidade ao longo dos sucessivos ciclos de desmatamento (Guariguata \& Otertag, 2001), tornando-os susceptíveis às perdas por lixiviação (Allen, 1985), e conseqüentemente mais ácidos e menos férteis (Guariguata \& Otertag, 2001), podendo afetar a composição da comunidade regenerante por diferentes mecanismos, alterando a colonização local (Bakker et al., 1996) e o crescimento das comunidades vegetais nessas áreas.

O tipo dominante de uso da terra nos arredores pode também influenciar tanto em qualidade quanto em quantidade a população do banco de sementes do solo (Guariguata \& Otertag, 2001; Pickett, 1985). Onde a intensidade de perturbação foi baixa ou moderada o estoque de sementes no solo é mais importante (Guariguata \& Otertag, 2001). Por outro lado, onde o impacto foi elevado a força da regeneração proveniente do banco de sementes é reduzida (Uhl et al., 1981). Outra forma de regeneração muito comum em áreas de pequenos agricultores é a predominância de rebrotação dos tocos (Denich, 1986) não destruídos pelas sucessivas capinas (tratos culturais), responsáveis pela eliminação de grande parte do banco de sementes remanescentes da queima (Denich, 1991).

O impacto dos repetidos ciclos de corte-queima-cultivo no "recrescimento" da floresta e na fertilidade do solo não tem sido bem documentados (Johnson et al., 2001). Portanto, identificar os principais fatores que concorrem para o surgimento e 
desenvolvimento da vegetação secundária é primordial para entender os processos sucessionais atuantes nessas áreas, além de permitir que o manejo seja finalmente adotado como medida sustentável de uso desse recurso.

\subsection{Hipóteses de trabalho}

O desenvolvimento desta pesquisa procurou testar a seguinte hipótese básica:

a) $\mathrm{O}$ processo de regeneração natural de fragmentos florestais amazônicos próximos, e com o mesmo período de abandono, é determinado pelas características do solo e pelo histórico de perturbação.

\subsubsection{Objetivo geral}

Caracterizar a composição florística, a fitossociologia, a dinâmica do estrato arbóreo, e analisar o efeito das condições de fertilidade do solo sobre esses parâmetros da regeneração natural em duas florestas secundárias com aproximadamente 50 anos de idade no Nordeste do Pará.

\subsubsection{Objetivos específicos}

b) Analisar as mudanças ocorridas ao longo do tempo na composição florística e nos parâmetros fitossociológicos das duas áreas estudadas.

c) Analisar a dinâmica de regeneração das duas florestas estudadas durante os períodos de acompanhamento.

d) Comparar os níveis dos principais atributos de fertilidade do solo das duas áreas estudadas.

e) Correlacionar os dados de densidade, área basal total e crescimento em diâmetro do estrato arbóreo com os dados de fertilidade e granulometria do solo. 


\section{REVISÃO DE LITERATURA}

\subsection{Florística e fitossociologia}

A análise florística e estrutural baseada em levantamentos de parcelas permanentes, permite comparações dentro e entre formações florestais no espaço e no tempo, gera dados sobre a riqueza e diversidade de uma determinada área, além de possibilitar a formulação de teorias, testar hipóteses e produzir resultados que servirão de base para outros estudos.

A fitossociologia é o ramo da Ecologia Vegetal que procura estudar, descrever e compreender a associação de espécies vegetais na comunidade (Rodrigues \& Gandolfi, 1998), identificando os diferentes tipos de vegetação (Felfili \& Venturoli, 2000). Estes estudos utilizam métodos fundamentados em características fisionômicas e estruturais da vegetação, e são os que melhor atendem aos requisitos de simplicidade de aplicação e de análise de um maior número de informações conjuntas (Pantoja et al., 1997).

Os resultados das análises estruturais, principalmente a estrutura horizontal (densidade, dominância, Frequiência, índice de valor de importância e valor de cobertura), permitem fazer deduções sobre origem, características ecológicas, dinamismo e tendências do futuro desenvolvimento da floresta (Hosokawa et al., 1998).

Para Rodrigues (1991), os métodos fitossociológicos devem ser utilizados de maneira a permitir a construção de modelos que auxiliem na compreensão das relações de estrutura da vegetação com os demais fatores do ambiente, buscando auxiliar na elaboração de propostas coerentes com a conservação e manejo dessas áreas.

Diversos estudos sobre florística e fitossociologia foram realizados em florestas secundárias no nordeste do Pará. Huber (1909), por exemplo, fez uma das primeiras 
caracterizações, e Lima (1954), mencionou as alterações sofridas na composição florística e na fertilidade dos solos em função das sucessivas queimadas, constantes na região. Outras pesquisas realizadas na Amazônia têm mostrado que distúrbios tais como a exploração e a conversão podem ter um efeito significativo na estrutura e na biodiversidade dessas formações (Uhl et al., 1982; Tucker et al., 1998).

Outras indicações e descrições sobre as florestas secundárias na região, podem ser encontradas em Denich (1986 e 1991), Ferreira \& Prance (1999), Froes (1957), Jardim et al. (1997), Santana (2000), Vieira et al. (1967), Vieira (1996), entre outros.

Apesar desses trabalhos, ainda existe carência de conhecimento sobre a composição florística e fitossociológica dessas florestas e, principalmente sobre as mudanças que ocorrem nessas comunidades ao longo do tempo.

\subsection{Dinâmica da vegetação}

As florestas tropicais são dinâmicas e as mudanças ocorrem continuamente nos indivíduos e nas populações ao longo do tempo (Felfili, 1995). Portanto, os estudos sobre ingressos e mortalidade em florestas tropicais têm importância fundamental no entendimento das mudanças que ocorrem na estrutura e na composição florística de povoamentos naturais (Oliveira, 1995).

Para isso, o conhecimento das taxas de ingressos é de grande importância, tanto do ponto de vista silvicultural como do ponto de vista ecológico, uma vez que a sustentabilidade de uma população florestal, entre outros fatores, depende do processo de substituição de indivíduos, que é mais intenso no período em que a floresta está em processo de reconstrução.

Esse processo de substituição se dá em função da mortalidade de seus predecessores criando as condições necessárias para o surgimento de novos indivíduos na comunidade. O padrão de mortalidade das árvores está intimamente ligado a longevidade natural das espécies, à sua distribuição nas classes de tamanho, à sua abundância na população (Swaine, et al., 1987a), tempestades, fungos patógenos, 
herbívoros, condições ambientais adversas (secas), e senescência natural (Liberman, et al., 1985).

Além do processo de substituição, a obtenção de informações confiáveis sobre as taxas de crescimento e produção para diferentes regimes de manejo e opções silviculturais é um dos pré-requisitos fundamentais para o manejo sustentável (Silva et al., 1995). Este parâmetro é mais convenientemente medido pelo incremento em diâmetro, área basal ou mesmo em volume. As diferenças no crescimento, tanto por espécie como em grupos ecológicos são funções de importantes fatores como: disponibilidade de luz, fertilidade dos solos, regimes pluviométricos, idade da floresta, grupos ecológicos predominantes, características genéticas da espécie, grau de sanidade das árvores, entre outros.

Os estudos sobre a dinâmica têm se concentrado mais em florestas primárias, entre os quais destacam-se os trabalhos de Carvalho (1992), Higuchi (1997), Silva (1989) e Vidal (2004) na Amazônia, Lieberman \& Lieberman (1987) e Finegan et al. (1999), na Costa Rica, Swaine et al. (1987a), no Kade em Ghana e Manokaran \& Kochummen (1987) na Malaysia, entre outros.

Para florestas secundárias, principalmente na Amazônia brasileira, destacam-se os trabalhos de Oliveira (1995) que analisou dados coletados por onze anos em uma floresta secundária de 50 anos em Belterra-PA e Gomide et al. (2002), que acompanhou por 12 anos o desenvolvimento de uma floresta regenerante após exploração madeireira de corte raso no estado do Amapá.

Estudos, baseados em parcelas permanentes que analisam o desenvolvimento da vegetação quanto aos principais atributos da dinâmica (crescimento, ingresso e mortalidade) são ainda escassos na Amazônia, quando comparados a outros estudos como os de florística e estrutura. Por isso é necessário que estudos dessa natureza sejam efetivados em maior quantidade, em variados tipos vegetacionais e que possam gerar dados acerca do desenvolvimento da vegetação e de seus principais condicionantes. 


\subsection{Relação entre solo e vegetação}

A relação entre a vegetação e o solo é bastante estreita, podendo as alterações na vegetação afetar as propriedades físicas ou químicas do solo (Mather, 1990). Ou as alterações e diferenças no solo provocarem efeitos significativos no desenvolvimento da vegetação.

Uma das características marcantes nessa relação é que os solos, em regiões tropicais, são intemperizados e, em sua maioria, apresentam baixa disponibilidade de nutrientes, localizando na biomassa viva acima do solo o grande capital de elementos minerais (Fassbernder, 1984; Weidelt, 1991).

Segundo Hardy (1978), as florestas não desenvolvem sua exuberância a partir do material matriz formador do solo, e sim através da decomposição de detritos orgânicos. Esta afirmativa está de acordo com os resultados apresentados por Jordan et al. (1980), onde a entrada de nutrientes no sistema (floresta) através do dossel é maior do que a produção de nutrientes a partir do material matriz no solo e subsolo. A incorporação de Cálcio e Fósforo, por exemplo, e mais significativa através da decomposição de serrapilheira e da água da chuva que lava troncos e folhas.

Um exemplo da efêmera fertilidade da maioria dos solos tropicais intemperizados foi demonstrado por Jordan et al. (1980), onde nas florestas suprimidas pela agricultura ou práticas florestais, a produtividade declina drasticamente entre dois ou três anos, porque depois de um ciclo de corte e queima o nível de nutrientes do solo aumenta apenas nos primeiros anos.

Em Gaúcha do Norte-MT, Ivanauskas et al. (2003), mostrou que após um ano da passagem do fogo o processo de lixiviação forçou uma redução aos níveis existentes antes da queima. Uhl \& Jordan (1984), em pesquisa realizada no Rio Negro na Venezuela, mostraram que após cinco anos de abandono a combinação da lixiviação de nutrientes aliada a sua acumulação na biomassa provocou um rápido retorno aos níveis anteriores a queima. Uma das implicações dessas relações é que a floresta secundária é eficiente na restauração dos nutrientes do solo durante a sucessão (Vieira, 1996). Daí o 
seu vasto uso, no Nordeste do Pará, como fonte renovadora do solo no processo denominado de pousio.

Outra constatação, é que o suprimento de nutrientes às plantas nas florestas tropicais sobre solos de baixa fertilidade está depositado na biomassa acima do solo. A re-introdução desses nutrientes no sistema solo-vegetação se dá através da decomposição do material orgânico depositado na superfície (Tognon et al., 1998). Esse material, quando decomposto, exerce importantes efeitos benéficos sobre as propriedades do solo, contribuindo substancialmente para o crescimento e desenvolvimento das plantas, pois exerce influência sobre as propriedades físicas, químicas, físico-químicas e biológicas do solo (Kiehl, 1979). Estas características estão entre os principais fatores que condicionam o desenvolvimento da vegetação (Furtini Neto et al., 1999).

Geralmente a maior percentagem de matéria orgânica, assim como sua influência, está nas camadas superficiais do solo, entre 0 e $20 \mathrm{~cm}$, e sua quantidade sempre diminui com o aumento da profundidade (Tomé Jr., 1997).

O teor e a dinâmica da matéria orgânica do solo é um componente importante no manejo, principalmente nos latossolos de ambientes tropicais, muito intemperizados e lixiviados (Hernani et al., 1987). Sua influência nos diversos atributos do solo tem sido comprovada particularmente no manejo das cargas elétricas (Sanchez, 1976) bem como no fornecimento de nutrientes para as plantas, quando está sendo mineralizada (Tognon, 1998).

O fornecimento de nutriente para as plantas e sua absorção é dependente de condições favoráveis de acidez ou alcalinidade. $\mathrm{O} \mathrm{pH}$ com valores abaixo de 4,5, por exemplo, limita a absorção (Tomé Jr., 1997), principalmente em solos que apresentam uma baixa saturação por bases $(\% \mathrm{~V})$, nos quais, a maioria das cargas negativas está sendo neutralizada por $\mathrm{H}^{+}$e $\mathrm{Al}^{3+}$ (Mello et al., 1989).

Assim como a saturação por bases, a soma de bases (SB) e a capacidade de troca de cátions (CTC), são parâmetros essenciais para a avaliação dos níveis de fertilidade do solo, principalmente nas condições de clima tropical, onde há uma grande produção de biomassa, porém a elevada acidez potencial dos solos torna os nutrientes indisponíveis. 
É sob essas condições de baixa fertilidade e elevada acidez que se desenvolvem as florestas secundárias da Região Bragantina. As quais, segundo Moran et al. (2000), após dez anos de sucessão, apresentaram crescimento vertical menor do que as florestas secundárias que se desenvolvem em solos férteis da região da Transamazônica, no Pará. 


\section{MATERIAL E MÉTODOS}

\subsection{Caracterização da Região}

\subsubsection{Localização}

A Região do Nordeste Paraense abrange uma superfície de aproximadamente $144.000 \mathrm{~km}^{2}$. Está limitada ao Norte pelo Oceano Atlântico, ao sul e Oeste pelo rio Tocantins e a Leste pelo rio Gurupi, estando situada entre as coordenadas geográficas de $0^{\circ} 33^{\prime}$ a $5^{\circ} 21^{\prime}$ de latitude Sul e de $46^{\circ}$ a $49^{\circ} 40^{\prime}$ a Oeste de Greenwich (EMBRAPA, 1991). Os estudos de campo foram realizados no município de Bragança na

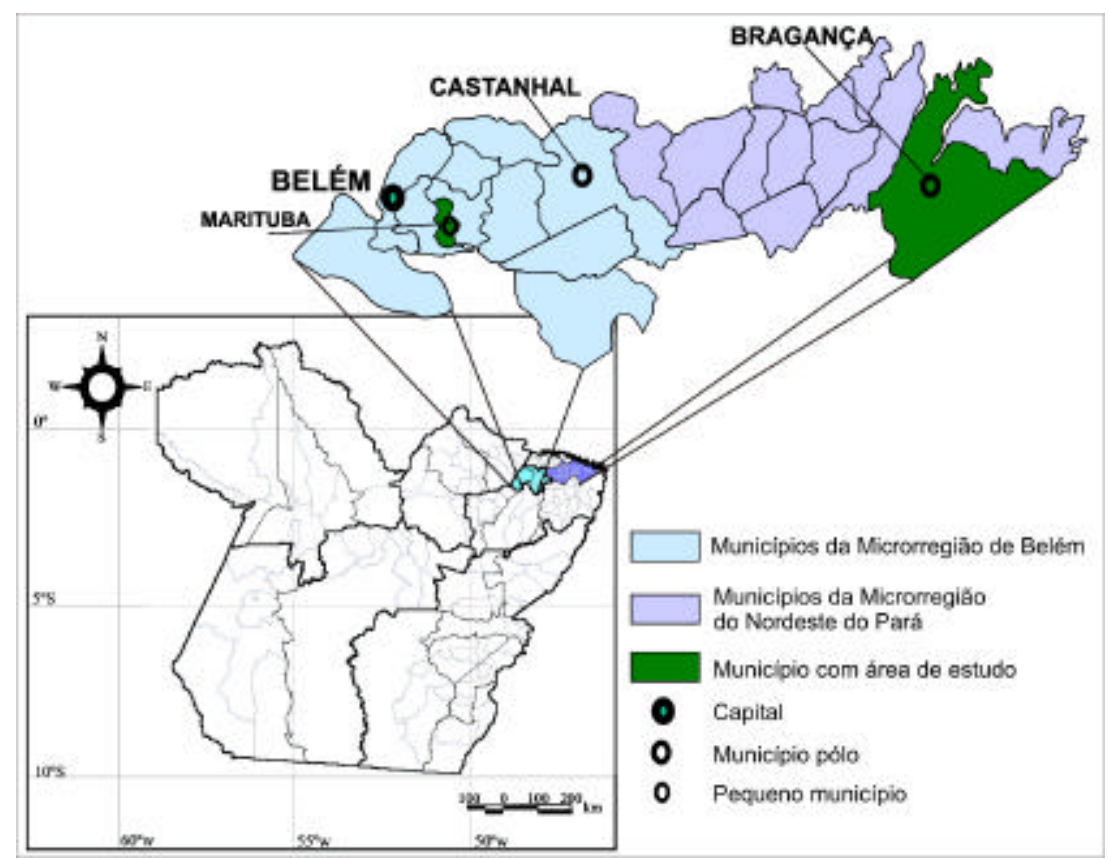

Figura 1 - Localização dos municípios de Bragança e Marituba, na Zona Bragantina e Microrregião de Belém, respectivamente 
Microrregião Nordeste paraense e no município de Marituba, na Microrregião Metropolitana de Belém, ambas situadas no Nordeste do Estado, a leste da capital Belém. A sede do município de Bragança está situada geograficamente nas coordenadas, 01 03 '15"de Latitude Sul e 4646'10" de Longitude Oeste de Greenwich (IDESP, 1998),

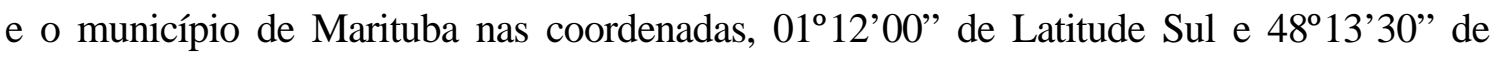
Longitude Oeste de Greenwich. As estudadas áreas distam uma da outra cerca de $240 \mathrm{~km}$.

\subsubsection{Clima}

A caracterização climática apresentada neste trabalho, foi extraída, principalmente, do trabalho realizado por Diniz em 1986, baseado no Atlas Climatológico da Amazônia Brasileira. Segundo este estudo, o regime térmico na Amazônia Oriental é caracterizado por reduzidas oscilações, considerando o espaço e tempo.

O Nordeste Paraense, pela classificação de Köppen, apresenta dois tipos climáticos, ambos com temperaturas médias anuais sempre superiores a $18^{\circ} \mathrm{C}$ (Denich, 1991). Na Microrregião Metropolitana de Belém e proximidades, segundo EMBRAPA (1991), o tipo climático predominante é o Af (Clima tropical chuvoso sem estação seca) e na Microrregião Nordeste paraense, predomina o tipo climático Am (Clima tropical chuvoso com pequeno período seco).

Esta região apresenta uma temperatura média geral em torno dos $26^{\circ} \mathrm{C}$, com máxima entre 31 e $32^{\circ} \mathrm{C}$ e mínima entre 21 e $22^{\circ} \mathrm{C}$ As temperaturas sempre elevadas na região são explicadas pela situação geográfica de proximidade do equador e pela baixa altitude, e as pequenas flutuações térmicas registradas estão associadas com o padrão de ocorrência das chuvas (Bastos \& Pacheco, 1999).

Os regimes pluviométricos encontrados, especificamente no nordeste Paraense, são caracterizados por apresentarem totais anuais bastante elevados entre $2500 \mathrm{~mm}$, na porção mais leste do Estado e 3000mm nas proximidades de Belém. 
Pelos dados apresentados pelo DNM (1992) referentes ao período de 1961 a 1990, a precipitação pluviométrica média anual é de $2.544,8 \mathrm{~mm}$, na porção mais Oeste do Nordeste Paraense (Tracuateua, próximo a Bragança) com período mais chuvoso no mês de março (467,8mm médio), e período mais seco (11,7mm médio) em novembro (Figura 2). No extremo Leste da região, próximo ao município de Marituba a média anual é mais elevada chegando aos $2.893,1 \mathrm{~mm}$. No período mais seco em novembro são registrados os menores valores, em torno de $111,8 \mathrm{~mm}$, e no mês de março ocorre a maior precipitação média com 436,2mm (Figura 3).

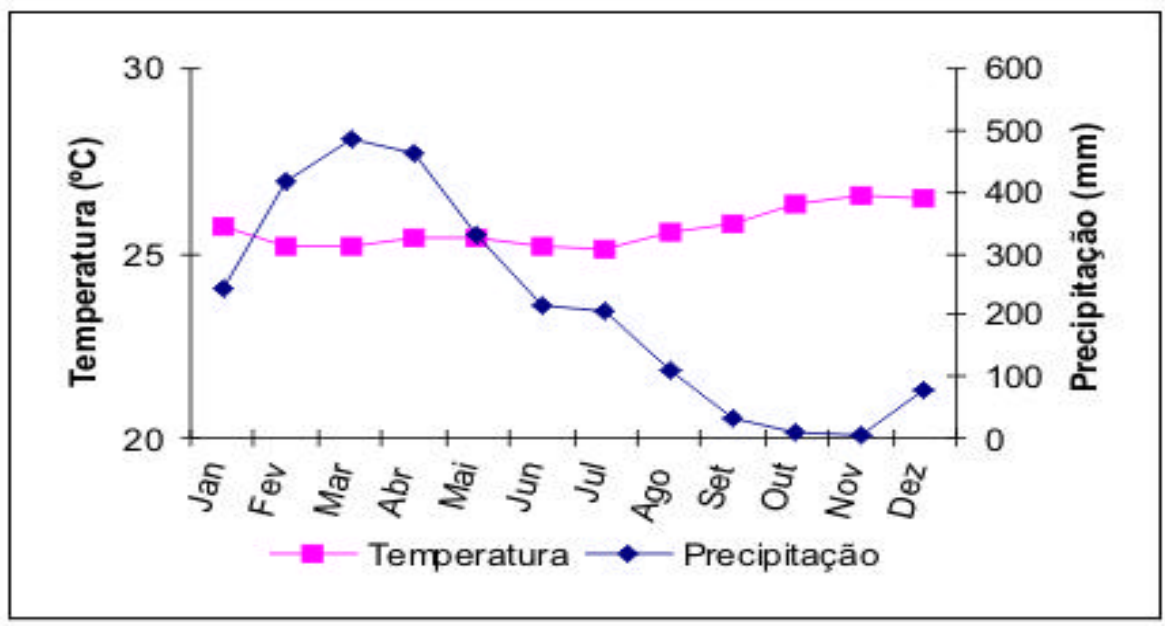

Figura 2 - Diagrama climático da região de Bragança, Estado do Pará (média 19611991) DNM (1992)

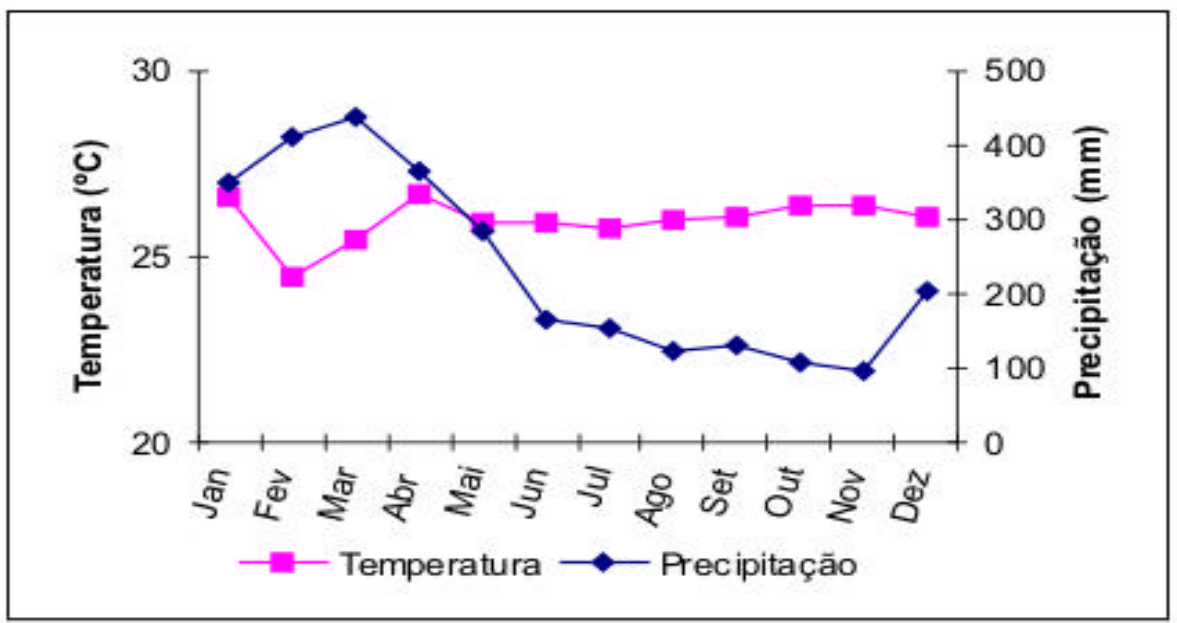

Figura 3 - Diagrama climático de Belém, Estado do Pará (média 1961-1991) DNM (1992) 


\subsubsection{Geologia, relevo e solo do Nordeste do Pará}

As áreas estudadas estão localizadas na Unidade Geológica do Terciário (Figura 4), que ocupa a maior parte do Nordeste Paraense, e encontra-se representado por duas formações: (1) pela Formação Barreiras, constituída pelas argilas de cores variegadas, vermelhas, verdes, brancas ou mosqueadas com leitos de areias inconsistentes e concreções ferruginosas, que formam blocos ou massas lenticulares; (2) Formações Pirabas, que é constituída por calcáreos creme-claro, moles, fossilíferos, associados a folhelhos vermelhos a cinza-esverdeado, normalmente lenticulares. Associados aos calcáreos e folhelhos ocorrem comumente areia quartzoza média e grosseira (EMBRAPA, 1991).

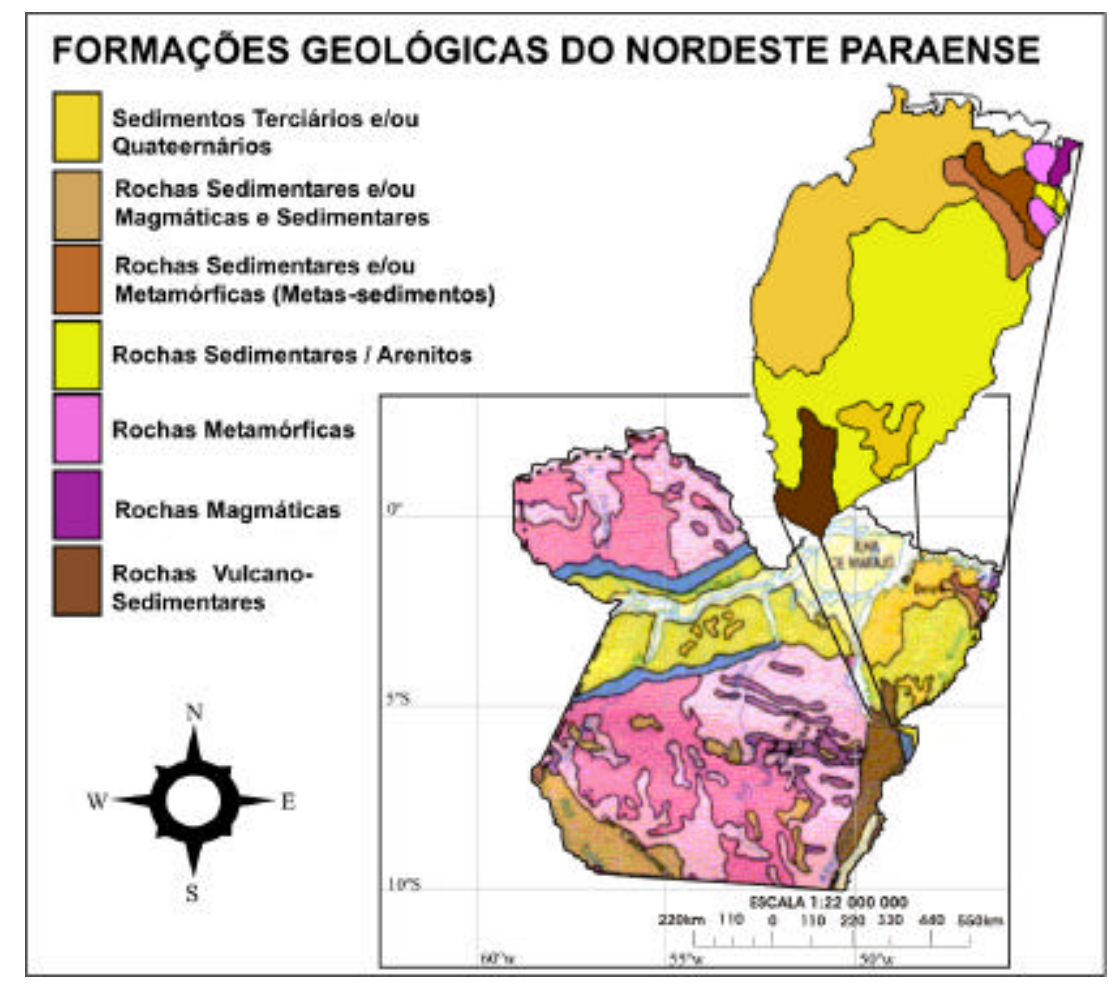

Figura 4 - Localização das formações geológicas ocorrentes no Nordeste Paraense (adaptado, Diagnóstico Brasil, Gusmão, 1990)

Segundo a classificação proposta pelo IBGE (Figura 5), o nordeste do Pará apresenta a predominância de Planícies Litorâneas e/ou Tabuleiros e Colinas (IBGE, 1992). 
Na Amazônia, predominam os Latossolos que estão representados pelos Latossolo Amarelo, Vermelho-Amarelo, Vermelho e Roxo, representando cerca de $70 \%$ dos solos amazônicos, cujas diferenças básicas referem-se a cor e ao teor de ferro total (EMBRAPA, 1991; EMBRAPA, 1991'; BRASIL, 1974).

Os solos das duas áreas estudadas (Marituba e Bragança), são solos do tipo Latossolos Amarelos distróficos (LAd) (EMBRAPA, 1999). Estes solos segundo Silva \& Carvalho (1986), ocupam uma área de $1.366 .590 \mathrm{~km}^{2}$.

Os Latossolos são solos típicos de regiões equatoriais e tropicais, são muito profundos e de evolução avançada, bastante intemperizados, com concentração relativa de argilominerais resistentes e/ou óxidos e hidróxidos de ferro e alumínio, baixa capacidade de troca de cátions e em geral, fortemente ácidos com baixa saturação de bases (EMBRAPA, 1999).

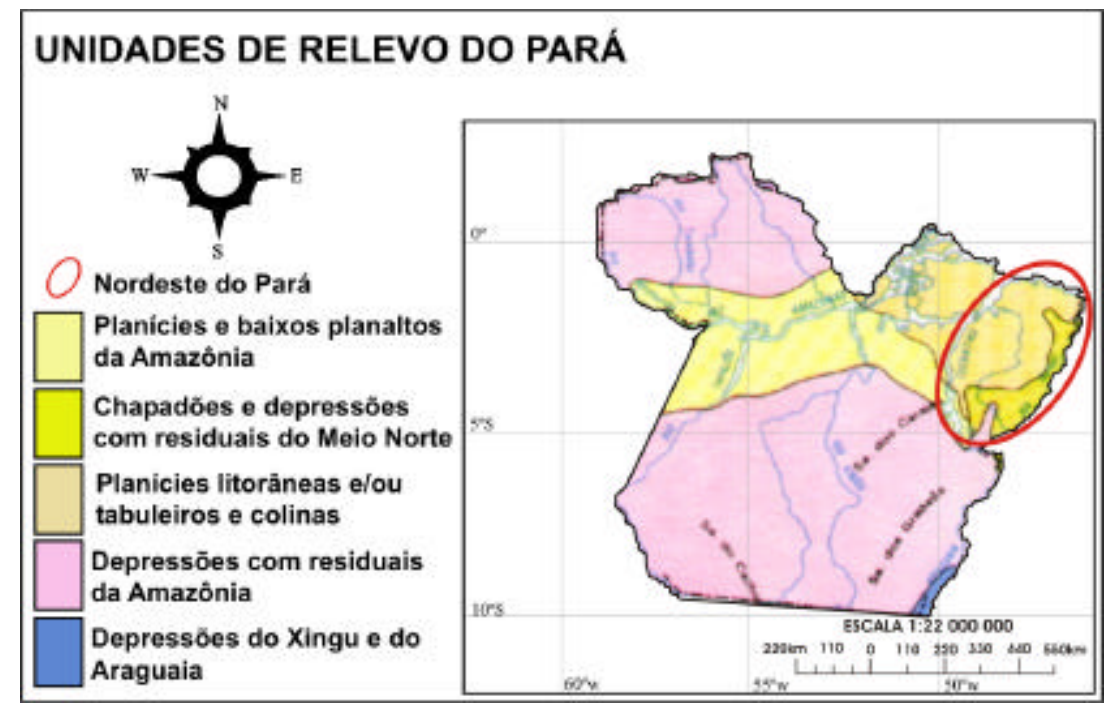

Figura 5 - Localização das unidades de Relevo predominantes no Pará (adaptado, Atlas Nacional do Brasil, IBGE 1992)

Estes solos formados no terciário e quaternário, sobretudo através dos sedimentos continentais de água doce, dada a sua origem, são solos com suprimento extremamente baixos de nutrientes (Denich, 1991).

\footnotetext{
${ }^{1}$ EMPRESA BRASILEIRA DE PESQUISA AGROPECUÁRIA - SERVIÇO NACIONAL DE LEVANTAMENTO E CONSERVAÇÃO DE SOLO. Mapa esquemático de solos do Estado do Pará, escala 1:2.000.000. Belém, EMBRAPA-SNLCS, 1991 (não publicado).
} 
Observa-se que 85\% dos solos da Amazônia são distróficos (EMBRAPA, 1991), ou seja, apresentam baixa saturação por bases $(\% \mathrm{~V}<50)$ (EMBRAPA, 1999) e são predominantemente álicos pois apresentam saturação específica com alumínio superior a $50 \%$ (Vieira \& Vieira, 1981).

\subsubsection{Caracterização da vegetação}

A vegetação predominante no Nordeste do Pará (considerando a cobertura original) é a Floresta Pluvial Equatorial, que segundo Rizzini (1963), pertence ao conjunto vegetacional homogêneo da grande Floresta Amazônica e faz parte do setor sudeste das terras baixas terciárias, porém na região há somente pequenos fragmentos da floresta de terra firme original, sendo um na região de Belém (Pires \& Salomão, 2000) (Reserva florestal do Mocambo) e outro, entre os municípios de Peixe-Boi e Nova Timboteua, entre as duas áreas estudadas no presente trabalho (Vieira, 1996).

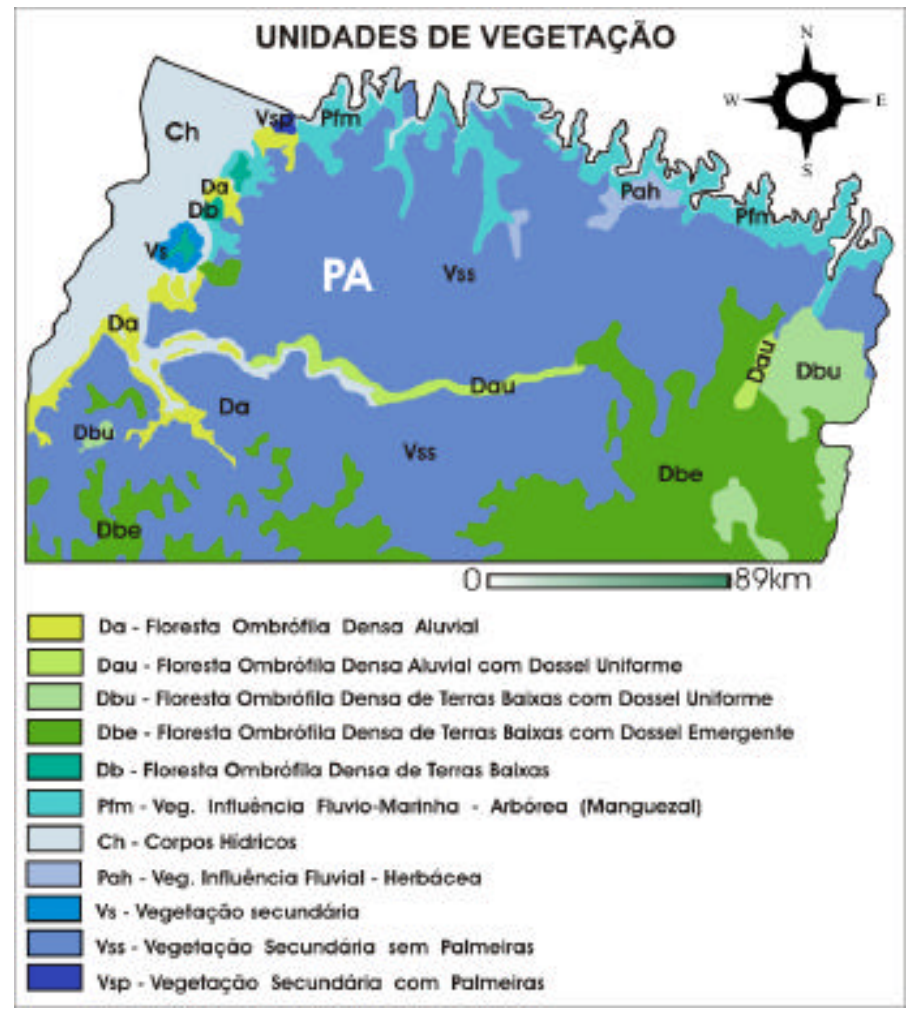

Figura 6 - Localização das unidades de Vegetação na porção norte do Nordeste Paraense (adaptado, Diagnóstico Ambiental da Amazônia Legal, IBGE 1997) 
Como mostra a Figura 6, a floresta original deu lugar, por atividades da agricultura de subsistência, a uma imensa área de vegetação secundária em diversos estágios de desenvolvimento, impossibilitando assim a identificação dos subtipos de florestas existentes anteriormente. Apesar disto, existem pequenos fragmentos (linhas estreitas) de florestas nativas ou capoeiras muito antigas, ao longo de rios e igarapés.

\subsubsection{Histórico de ocupação}

No Nordeste Paraense os projetos oficiais de colonização começaram em 1875 nas proximidades de Belém (Egler, 1961), com imigrantes açorianos (Penteado, 1967), e mais arde (1897), com a chegada dos nordestinos que fugiam da forte seca que assolou o Nordeste.

A estrada de ferro Belém-Bragança que começou a ser construída a partir de 1883 e foi concluída em 1908, foi o principal caminho de acesso às terras da região. Os colonos que eram assentados nas colônias ao longo da ferrovia foram os primeiros a começarem o processo de derrubada das florestas nativas, para cultivar gêneros alimentícios e suprir a crescente demanda da cidade de Belém. Os primeiros anos de cultivo eram produtivos, mas a partir do segundo ou terceiro ano as áreas não produziam o esperado, forçando o colono a desbravar novas áreas (Denich, 1991).

Os colonos desmatavam a floresta primária, primeiramente nas colônias às margens da ferrovia, depois, ao longo das estradas vicinais, e posteriormente com a interligação destas vicinais possibilitou a expansão das atividades de roça-queimacultivo (Denich, 1991).

Muitos dos colonos assentados permaneciam pouco tempo na propriedade, uma vez que o não funcionamento da administração, a falta de organização e principalmente a escassez de recursos (Egler, 1961), já naquela época, inviabilizavam a permanência nas colônias. Segundo a mesma autora, não há registros sobre a baixa fertilidade dos solos e problemas climáticos. Esses colonos, sem vocação agrícola, abandonavam os lotes, voltavam para seus países de origem, ou iam para Belém, onde exerciam os ofícios que costumavam praticar anteriormente (Penteado, 1967). 
Segundo Egler (1961), a Zona Bragantina transformou-se, durante os primeiros 50 anos de sua colonização, numa "paisagem-fantasma".

Atualmente, essas propriedades são um mosaico de manchas de vegetação secundária com várias idades que se formaram após sucessivos ciclos de corte-queimacultivo-pousio.

\subsubsection{Histórico de ocupação na área de Bragança}

A floresta estudada em Bragança está a aproximadamente $25 \mathrm{~km}$ da sede do município, na comunidade de Benjamim Constant, a qual foi fundada em 1894 para abrigar imigrantes espanhóis. Nessas propriedades, inicialmente era cultivada apenas a mandioca para fazer farinha, e assim abastecer os mercados de Belém e Manaus (Penteado, 1967).

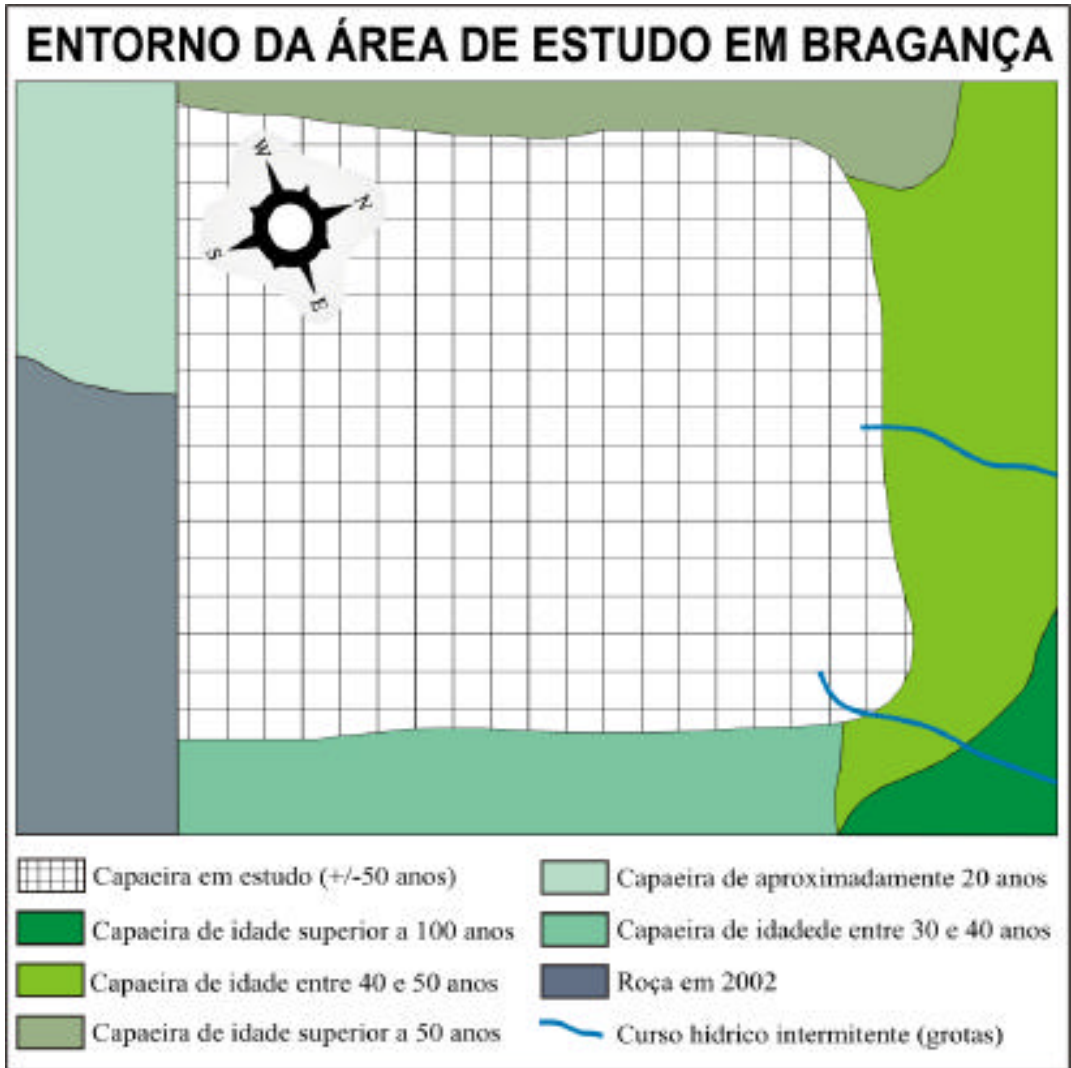

Figura 7 - Entorno da área estudada em uma propriedade rural no município de Bragança-PA 
A ocupação da área onde está localizada a capoeira em estudo apresenta um histórico de atividades agrícolas que remontam ciclos de corte-queima-cultivo-pousio, atualmente com aproximadamente 40 anos antes do abandono. Os cultivos praticados na área foram arroz, milho, feijão e principalmente mandioca, que ainda hoje é a principal fonte de recurso dos pequenos agricultores da região.

A capoeira de Bragança apresenta em seu entorno ouras florestas secundárias com diversas idades, além de áreas com recente desmatamento (Figura 7). Estas áreas possuem históricos de uso semelhantes, sempre passando pelo ciclo de corte-queimacultivo-pousio.

\subsubsection{Histórico de ocupação na área de Marituba}

$\mathrm{Na}$ região do atual município de Marituba, o processo de colonização remonta à segunda metade do século XIX, quando em 1875 nascia o primeiro núcleo colonial fundado na região (Benevides), distante $29 \mathrm{~km}$ de Belém.

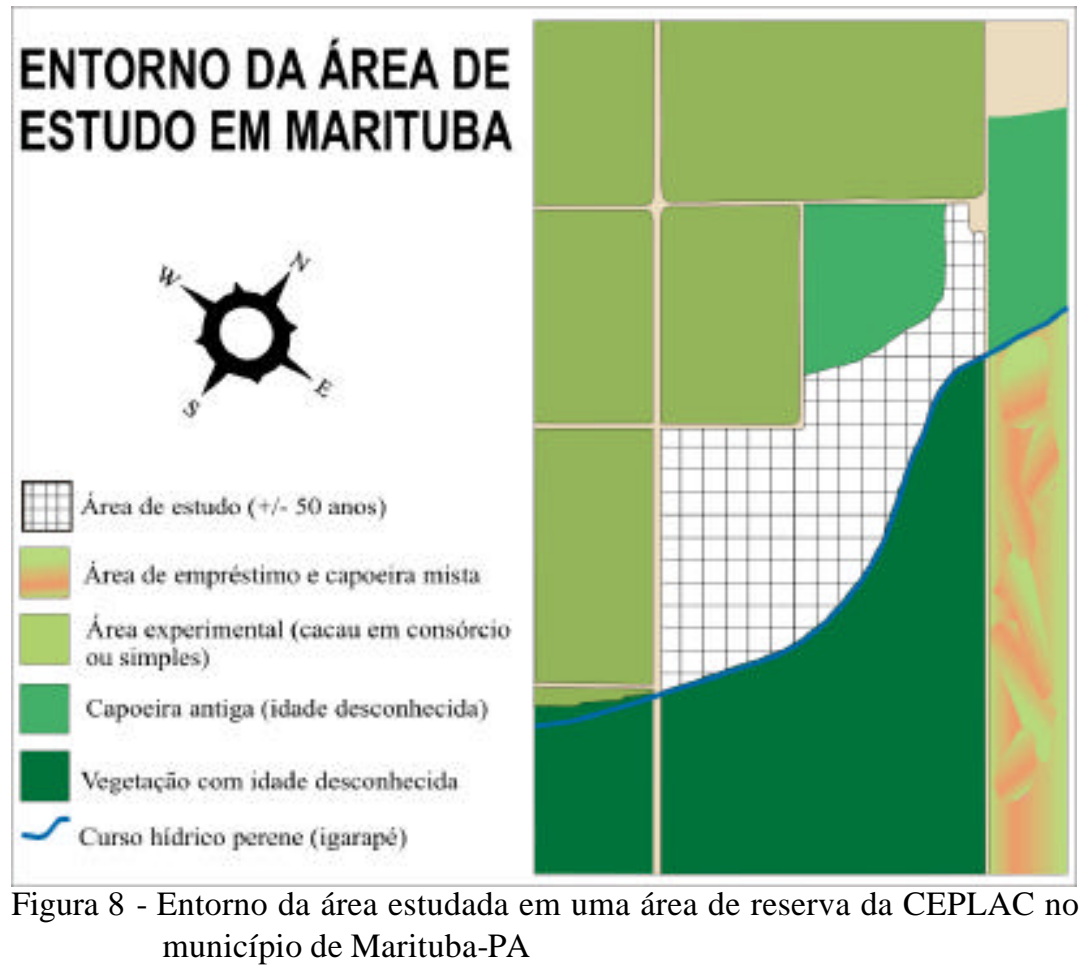


A capoeira em estudo localizada nessa região pertence a Estação de Recursos Genéticos do Cacau José Haroldo, da Comissão Executiva do Plano da Lavoura Cacaueira - CEPLAC, Marituba-PA. Essa área, no passado, era fonte de madeira para lenha, e não há registro de atividades agrícolas. Os moradores da área e funcionários mais antigos da Estação desconhecem a existência de queimadas. Por outro lado, durante os trabalhos de coleta de solos, foram encontrados restos de carvão em $12 \%$ das amostras nas profundidades de $0-5 \mathrm{~cm}$ e $5-15 \mathrm{~cm}$ e em $42 \%$ das amostras na profundidade de $15-25 \mathrm{~cm}$. Essa constatação se deve provavelmente a queimadas acidentais que ocorreram na área provenientes de atividades de limpeza de pastagens e áreas de cultivo agrícola no entorno (Figura 8). Esta área está ligada, na porção sul e sudeste, a corredores de florestas naturais preservadas que protegem os mananciais hídricos que abastecem as cidades da região.

\subsection{Coleta e análise dos dados}

\subsubsection{Coleta de dados}

\subsubsection{Vegetação}

O método de amostragem utilizado para coleta de dados de vegetação, foi o de Parcelas Permanentes de Monitoramento (PPM) instaladas de maneira sistematizada, permitindo uma melhor cobertura para detectar possíveis diferenças na estrutura da floresta.

As PPM, possuem dimensões de 50 x 50m subdivididas em 25 subparcelas de $10 \mathrm{x}$ 10m, segundo os modelos propostos por Silva \& Lopes (1984) (Figura 9).

Foram instaladas 4 PPM, com uma área amostral de 1,0ha para cada floresta secundária estudada. A área de Bragança possui aproximadamente 17ha e a de Marituba 4ha, ambas com idade aproximada de 50anos. 


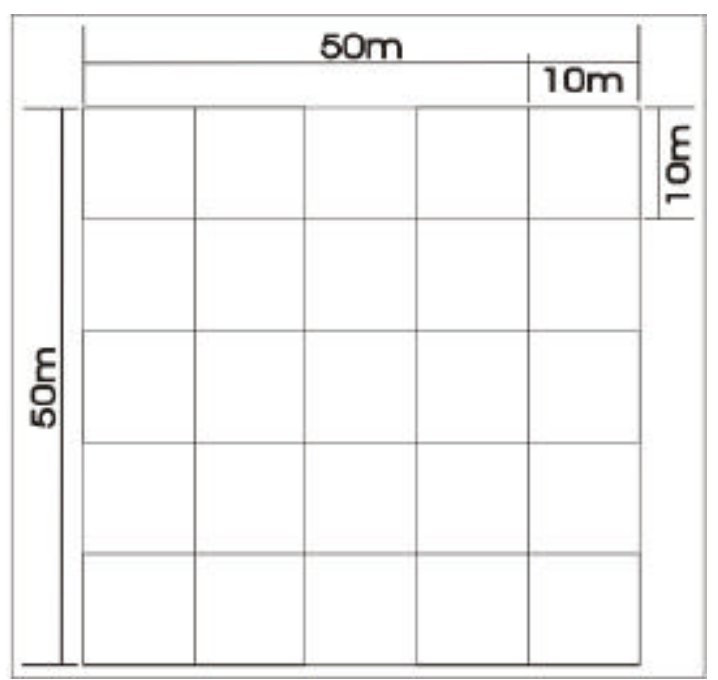

Figura 9 - Croqui das parcelas estudadas nos municípios de Marituba e Bragança-

PA

Em Marituba a instalação das PPM e o primeiro levantamento florístico/fitossociológico, foi realizado em 1997, com re-medições em 2000 e 2002. Em Bragança, a instalação das parcelas e a primeira medição do extrato arbóreo foram realizadas em 1999, com re-medições seqüenciais em 2000, 2001 e 2002.

A metodologia de coleta de dados da vegetação foi adaptada de Silva \& Lopes (1984).

\section{a) Medição, marcação e identificação dos indivíduos}

O DAP foi medido usando-se fita diamétrica, com precisão milimétrica, em todas as árvores vivas com DAP $\geq 5,0 \mathrm{~cm}$ (caídas, quebradas ou danificadas). A partir da segunda medição foram incluídas as árvores mortas no período.

As medições dessa variável deram-se no ponto de medição, estabelecido sempre que possível a 1,30m do solo (DAP) e marcado com um anel pintado com tinta vermelha à base de óleo para evitar erros de leitura em medições subseqüentes (Figura 10a). Sempre que ocorreram sapopemas ou anormalidades como danos ou deformações, o ponto de medição foi transferido para um local acima, isento de defeitos (Figura 10b). 
Todas as árvores foram etiquetadas com fita plástica numeradas com auxílio de aparelho etiquetador (DYMO). As etiquetas continham três numerações: o primeiro identificou a parcela, o segundo a subparcela e o terceiro, o número seqüencial da árvore na subparcela. Essas etiquetas foram fixadas com prego acima do ponto de medição em pelo menos $20 \mathrm{~cm}$.

Em caso de bifurcação da árvore abaixo do ponto de medição, cada galho ou perfilho foi medido como se fosse uma árvore.

Os indivíduos não identificados ou cuja identificação era duvidosa, tiveram material coletado (a maioria estéril), prensado, levado ao sol por 1 dia, e posteriormente embebido em álcool para evitar ataque de fungos ou murchamento excessivo, para depois serem acondicionados em sacos plásticos. Em seguida, esse material foi encaminhado ao Herbário IAN, Dr. João Murça Pires, da EMBRAPA Amazônia Oriental, em Belém, para secagem em estufa e posterior identificação. O sistema de classificação utilizado foi o de Cronquist (1988). Com exceção da ordem Fabales que foi considerada como família Fabaceae, segundo a classificação proposta por Gunn (1983). $\mathrm{Na}$ grafia de parte dos binômios, e seus respectivos autores, recorreu-se ao índice de espécies do Missouri Botanical Garden (MOBOT).

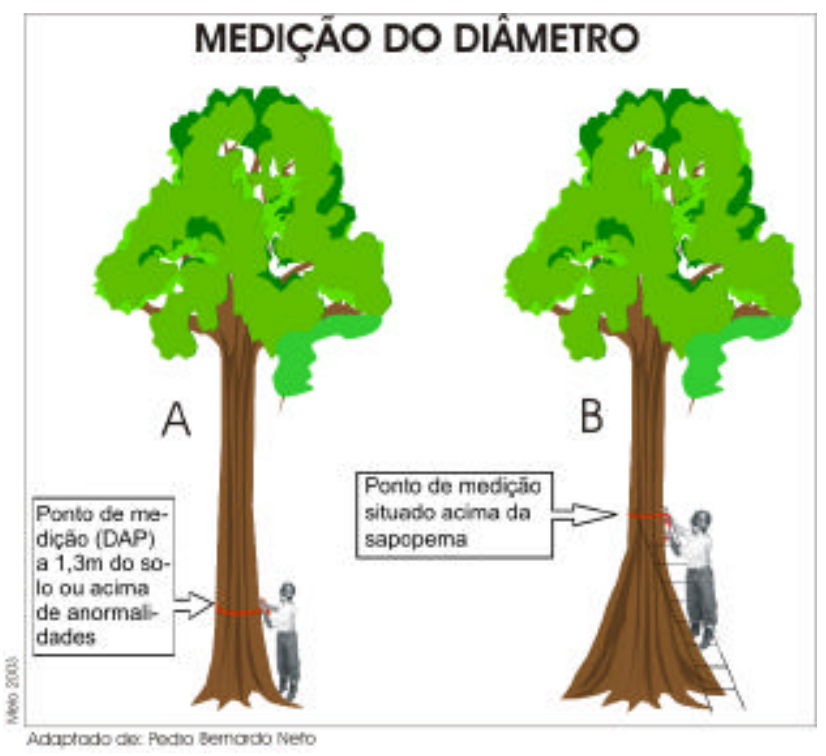

Figura 10 - Medição de DAP em árvores: A- medição a 1,3m do solo; B- medição de DAP em árvores que apresentam Sapopemas (Adaptado de Pedro Bernardo Neto 2001 (não publicado)) 


\section{b) Classe de identificação de fuste}

Procurou-se descrever os diversos estados em que podem ser encontradas as árvores em uma floresta. Esses estados são resultantes de seu próprio crescimento, ou de mudanças provocadas pelo homem ou pela natureza. O acompanhamento dessas mudanças ajuda no entendimento das relações entre as árvores e o meio ambiente ou das árvores entre si (Silva \& Lopes, 1984).

\begin{tabular}{|l|c|c|c|}
\hline \multirow{2}{*}{ Árvore } & \multirow{2}{*}{ Completa } & \multicolumn{2}{c|}{ Decapitada (sem copa) } \\
\cline { 3 - 4 } & & Fuste $>4,0 \mathrm{~m}$ & Fuste $<4,0 \mathrm{~m}$ \\
\hline Viva em pé (semente) & 111 & 112 & 113 \\
\hline Viva em pé (rebroto) & 101 & 102 & 103 \\
\hline Viva caída & \multicolumn{3}{|c|}{121} \\
\hline Morta natural (em pé e caída) & \multicolumn{3}{|c|}{131} \\
\hline
\end{tabular}

Quadro 1 - Códigos usados na identificação do fuste de árvores

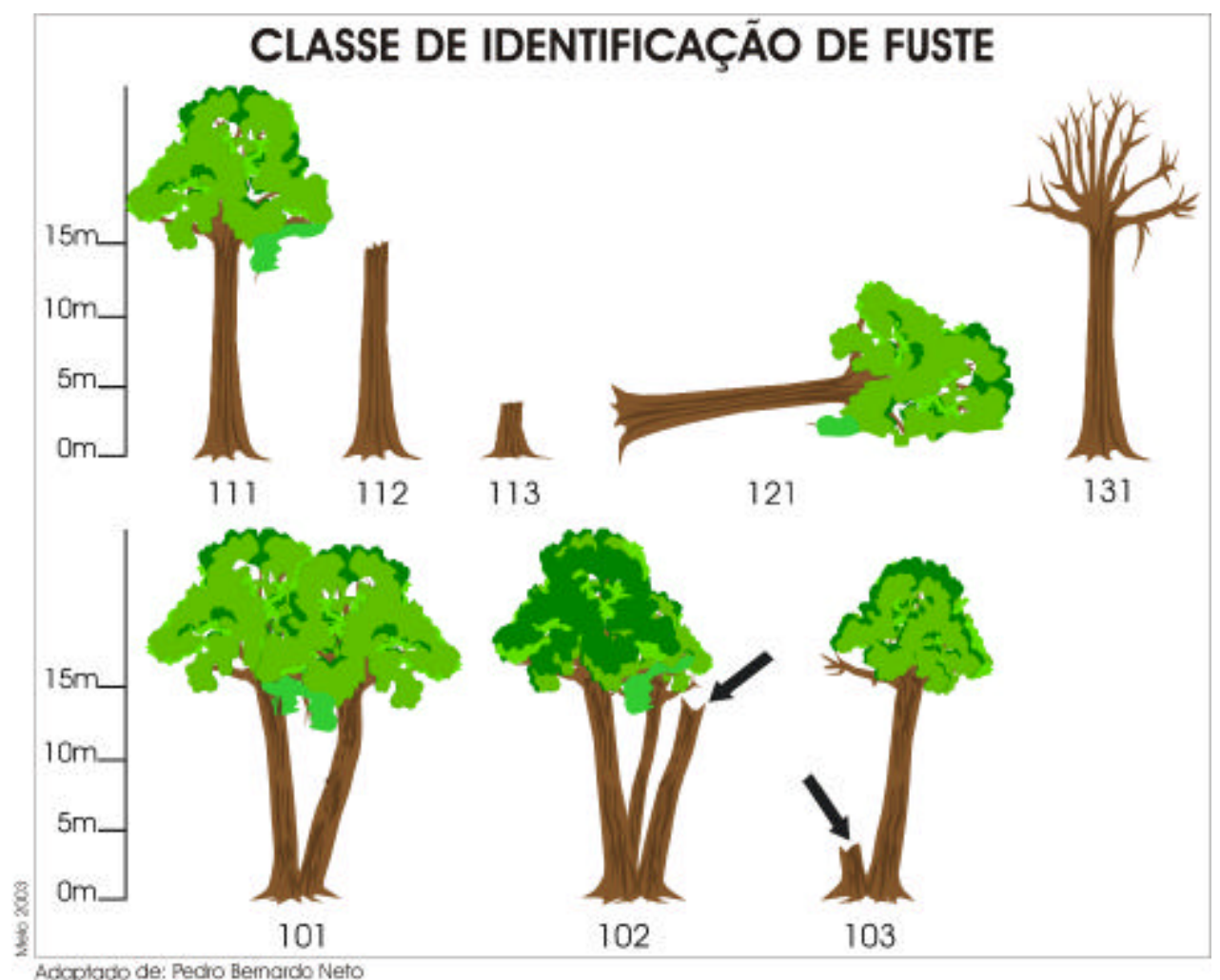

Figura 11 - Estado físico aparente das árvores levantadas em campo e seus respectivos códigos de CIF (adaptado de Silva \& Lopes, 1984) 
Para classificar o tronco das árvores, foram utilizados códigos específicos que combinam a sanidade da árvore com o estado de seu fuste (Figura 11), que pode estar completo, quebrado, morto ou mesmo não encontrado. Para cada código aplicado ao indivíduo supostamente originado de semente, existe um correspondente para o indivíduo originado de perfilhamento (rebrotação) (Quadro 1). Foram registrados códigos de CIF para todas as árvores com $\mathrm{DAP} \geq 5 \mathrm{~cm}$.

\subsubsection{Solo}

As coletas de solo foram realizadas em 2002, de maneira sistematizada em 12 subparcelas das 25 que formam cada uma das 4 parcelas de 50 x 50m, em ambas áreas estudadas (Marituba e Bragança) (Figura 12). As subparcelas escolhidas foram as de numeração par, de forma que apenas 12 parcelas foram contempladas.

$\mathrm{Na}$ profundidade de 0 a $5 \mathrm{~cm}$, as amostras compostas foram tomadas no quatro bordas das subparcelas, e para as demais profundidades (5 a $15 \mathrm{~cm}$ e 15 a $25 \mathrm{~cm}$ ), as amostras foram coletadas apenas no centro da subparcela (Figura 12). Foram coletadas, no total, 288 amostras de solos.

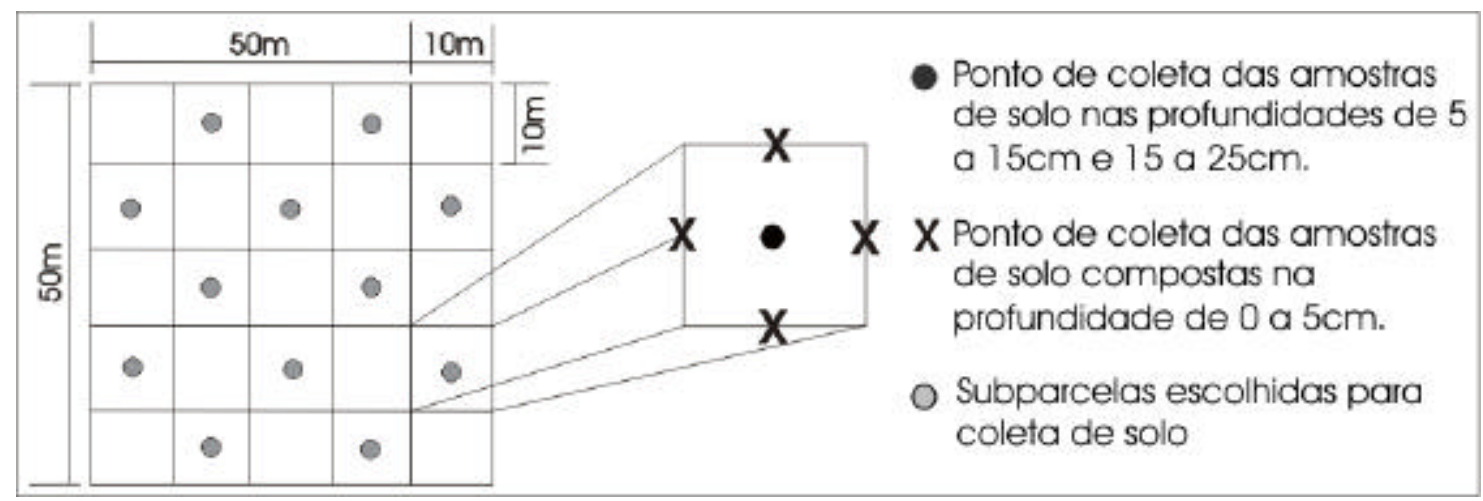

Figura 12 - Croqui da metodologia para coleta de amostras de solo das parcelas estudadas nos municípios de Marituba e Bragança-PA

Para a coleta das amostras foi utilizado um "Trado Martelo" de origem holandesa, conforme mostra a Figura 13. Este trado permite grande agilidade nas coletas, pois a cabeça (b), o canhão (c) e o cilindro coletor (d) moveis, facilitam a substituição e remoção do material, além de evitar a contaminação da amostra por outras amostras ou 
pelo contato do operador. O cilindro coletor " $D$ " é encaixado dentro do canhão " $C$ ", que é rosqueado na extremidade esquerda para fixação na cabeça "B".

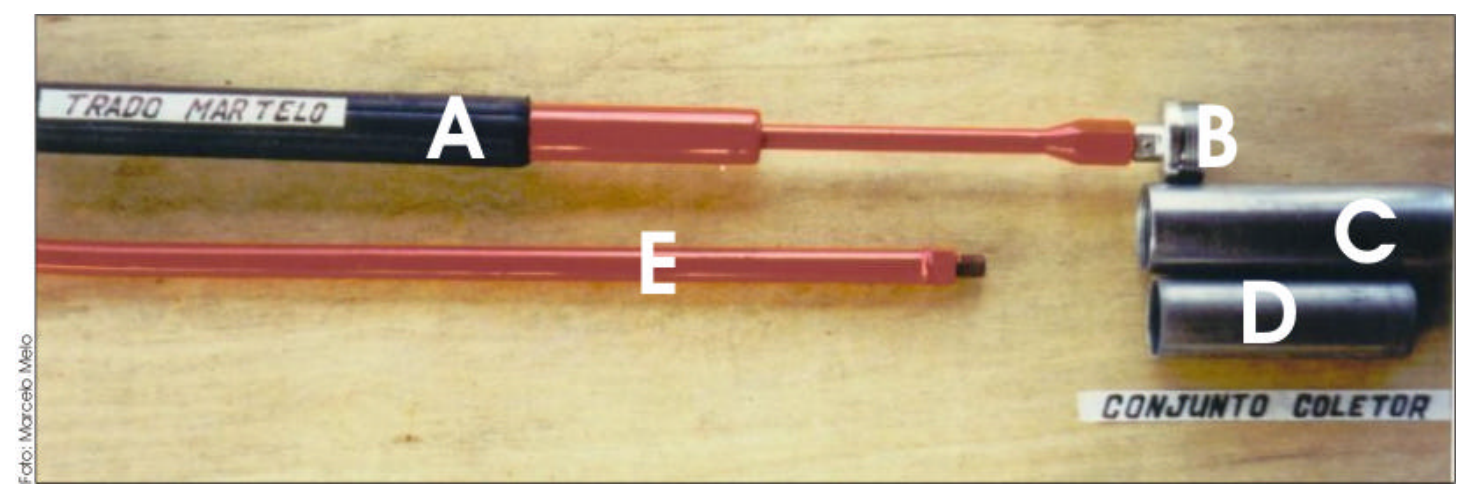

Figura 13 - "Trado Martelo" utilizado para coletar amostras de solo das parcelas estudadas nos municípios de Bragança e Marituba-PA. Onde: (A- martelo; B- cabeça; C- canhão coletor; D- cilindro coletor e; E- extensão)

\subsubsection{Análise dos dados}

\subsubsection{Parâmetros florísticos e fitossociológicos}

O processamento dos dados referentes a florística e fitossociologia, para a obtenção dos valores relativos a estrutura horizontal da floresta foi obtido com o auxílio dos programas PREPARE e PARAMS do pacote FITOPAC, desenvolvido pelo professor Shepherd (1995).

Os parâmetros da estrutura horizontal, calculados pelo FITOPAC, compreendem:

A densidade relativa, que é o número de árvores de cada espécie por hectare dividido pelo número total de árvores por hectare multiplicado por 100.

A frequiência, que é a probabilidade de se encontrar uma espécie numa unidade de amostragem e o seu valor estimado indica o número de vezes que a espécie ocorre, num dado número de amostras. O seu valor relativo é o produto da razão entre a freqüência absoluta e o somatório das freqüências absolutas multiplicados por 100.

A dominância, definida como a taxa de ocupação do ambiente pelos indivíduos de uma espécie, ou seja, a área basal, e a dominância relativa são o resultado da divisão da área basal de cada espécie pela área basal total multiplicado por 100. 
O Índice de Valor de Importância (IVI), que revela através dos pontos alcançados por uma espécie, sua posição sociológica na comunidade analisada, e é dado pelo somatório dos parâmetros relativos de densidade, frequiência e dominância, conforme descreve Mueller-Dombois \& Ellemberg (1974).

Teoricamente, a espécie mais importante em termos de IVI é aquela que apresenta o maior sucesso em explorar os recursos do seu habitat. A partir de cada parâmetro que compõe o IVI pode-se compreender se a espécie é abundante ou não, se apresenta distribuição agrupada ou dispersa e também se ela possui área basal grande, ou não, dando uma idéia sobre densidade, distribuição espacial e a dimensão alcançada pela população de uma espécie em relação às demais (Felfili \& Venturoli, 2000).

Existem algumas críticas em relação a este Índice, uma vez que o uso de parâmetros relativos pode limitar as informações, pois ambientes com vegetação densa ou esparsa podem apresentar os mesmos valores de densidade, freqüência e dominância relativa (Felfili \& Venturoli, 2000). Contudo, a literatura ainda não apresenta outras formas de cálculo que substitua o IVI, difundidas suficientemente para que possam ser feitas comparações.

\subsubsection{Diversidade e Equitabilidade}

A diversidade de espécies segundo Magurran (1988) pode ser medida pelo número de espécies, pela descrição da distribuição da abundância relativa das mesmas, ou por uma combinação desses dois componentes. Portanto, a diversidade deve ser entendida como um parâmetro da estrutura da comunidade (Martins 1990), decorrente da abundância relativa das espécies que a constituem (Martins \& Santos, 1999) e da variação espacial da estrutura comunitária.

Os modelos mais utilizados e recomendados para o cálculo dos índices de diversidade são as medidas de heterogeneidade, pois são mais simples e demandam menor tempo de cálculo.

O índice de heterogeneidade mais utilizado é o Índice de Shannon $\left(H^{\prime}\right)$, que segundo Pielou (1977), determinará a diversidade de espécies em cada área amostral. 
Esse índice assume que os indivíduos foram amostrados ao acaso, a partir de uma população infinitamente grande e que todas as espécies estão representadas na amostra. Seu valor será máximo quando cada indivíduo pertencer a uma espécie diferente, e mínimo quando todos pertencerem a mesma espécie (Fina, 1999).

Para Felfili \& Venturoli (2000), o uso deste índice induz a um resultado tendencioso, entretanto, na prática, este desvio raramente é significativo. Como uma fonte substancial de erro, cita-se a falha de incluir todas as espécies da comunidade na amostra. Erro que cresce na medida que diminui as espécies representadas na amostra. Esse índice atribui maior valor às espécies raras, e apesar disto, é um dos melhores índices usados em comparações, caso não haja interesse em separar abundância de raridade. Seu cálculo é realizado através da seguinte fórmula:

$$
\begin{aligned}
& H^{\prime}=-\sum p i \cdot \ln p i \\
& P i=n i / N
\end{aligned}
$$

onde:

$n i=$ número de indivíduos de indivíduos da espécie $i$

$N=$ número total de indivíduos amostrados

A equitabilidade foi calculada através da fórmula proposta por Pielou (1975).

$J=H^{\prime} / \ln S$

onde:

$H^{\prime}=$ índice de diversidade de Shannon

$H^{\prime}=S=$ número total das espécies amostradas

\subsubsection{Similaridade Florística}

A similaridade florística estima o grau de semelhança entre as populações entre e dentro de áreas, a partir da presença e/ou ausência dos componentes das populações amostradas. 
O índice de Jaccard trabalha com dados qualitativos. É usado tanto para comparar floras gerais de grandes áreas, como também para determinar similaridade de parcelas em termos de composição de espécies. Nesse índice a similaridade é máxima quando o valor é igual a 1 e inexistente quando for 0 . Em geral, Jaccard acima de 0,5 indica alta similaridade. Segundo Magurran (1988), uma das grandes vantagens desse método é a simplicidade, todavia, essa simplicidade também é uma desvantagem, devido o método não levar em consideração a abundância de espécies. Por exemplo, tanto faz se a espécie é rara ou abundante, seu peso será o mesmo, pois trabalha com presença e ausência de espécies.

$$
S j=a /(a+b+c)
$$

onde:

$S j=$ Coeficiente de similaridade;

$a=$ número de espécies comuns em ambas as parcelas;

$b=$ número de espécies únicas da parcela 1 ;

$c=$ número de espécies únicas da parcela 2.

Foram realizadas duas análises de similaridade florística utilizando-se o índice de Jaccard e agrupando as florestas pelo método de médias de grupo (UPGMA) com o auxílio dos programas MATRIZ e CLUSTER do pacote FITOPAC (Shepherd, 1995).

A primeira, comparou as duas áreas estudadas (Marituba e Bragança), em nível de parcelas, para verificar sua taxa de similaridade florística.

A segunda análise de agrupamento foi realizada entre as florestas secundárias do presente estudo, outras florestas secundárias de idades semelhantes e florestas naturais primárias próximas a essas áreas através da elaboração de um banco de dados com listagens de espécies arbóreas amostradas nestes levantamentos fitossociológicos.

No Nordeste do Pará utilizou-se os dados levantados por Vieira (1996), a qual, amostrou indivíduos com diâmetros a partir de $5 \mathrm{~cm}$ em 0,6ha, de um remanescente de floresta primária (200ha) no município de Peixe-Boi-PA e Pires \& Salomão (2000), que fizeram um levantamento de todos os indivíduos com diâmetros a partir de $10 \mathrm{~cm}$ em $2 \mathrm{ha}$ de uma floresta primária em Belém-PA (Reserva Mocambo-APEG). Para florestas secundárias dessa região utilizou-se os dados dos levantamentos realizados por Vieira 
(1996), que trabalhou com uma capoeira de origem agrícola com aproximadamente 40 anos em Peixe-Boi-PA (amostrando indivíduos com diâmetro a partir de $5 \mathrm{~cm}$ em 8 parcelas de $250 \mathrm{~m}^{2}$ (0,2ha)), por Santana (2000), que mediu todos os indivíduos com diâmetro a partir de $1,6 \mathrm{~cm}$ em 15 parcelas de $200 \mathrm{~m}^{2}$ (0,3ha) de uma floresta secundária com aproximadamente 35 anos em Igarapé-Açú-PA e Oliveira, L. (1997), que analisou dados coletados em 11 parcelas de $2.500 \mathrm{~m}^{2}$ (2,75ha), com medição de indivíduos com diâmetro a partir de $5 \mathrm{~cm}$, numa floresta com aproximadamente 50 anos em Belterra-PA no oeste do Pará.

Nessas análises não foi possível evitar problemas como, diferenças no tamanho da amostra, diâmetro mínimo de inclusão e distância entre áreas. Tal rigorosidade, se considerada, inviabilizaria a comparação, devido a escassez de levantamentos que se adeqüem à natureza da análise.

Das listas utilizadas, foi considerada somente a identificação em nível específico, sendo descartado as identificações incompletas (níveis de gênero, famílias ou não identificadas (Ni)).

\subsubsection{Crescimento, Ingresso e Mortalidade}

Para efeito deste estudo, foram calculados os incrementos diamétrico médios anual, a média anual de mortalidade e a média anual de ingresso para todas as árvores a partir de $5 \mathrm{~cm}$ de DAP nas duas florestas secundárias estudadas.

O cálculo do incremento médio anual em diâmetro foi realizado pela ponderação entre a média da diferença de diâmetro e o número de indivíduos em cada classes diamétrica. Esses valores foram obtidos com o auxílio do programa Sistema Florestal Contínuo - SFC, desenvolvido pela EMBRAPA Amazônia Oriental a partir da aplicação da seguinte fórmula:

$$
\bar{X}_{\text {pond }}=\sum_{i=1}^{n} \frac{\left(\left(x_{2}-x_{1}\right) \cdot n_{i=1}\right) / \sum n_{i=1}}{t}
$$

Onde:

$x_{2}=$ diâmetro da espécie $i$ no tempo 2 . 
$x_{1}=$ diâmetro da espécie $i$ no tempo 1 .

$n_{i=1}=$ número de indivíduos da espécie $i$ na classe de diâmetro $l$ que varia até $n$.

$t=$ período entre duas medições.

Para efeito dos cálculos foram desprezadas todas as árvores que por algum motivo tiveram diminuição do seu diâmetro entre os períodos analisados.

O recrutamento (ingresso) foi considerado como aqueles indivíduos jovens que atingiram o tamanho mínimo de $5 \mathrm{~cm}$ de $\mathrm{DAP}$, registrados em cada ocasião de monitoramento.

A mortalidade que é considerada como o número de árvores que morreram entre os levantamentos, foi calculada utilizando-se o modelo logarítmico proposto por Swaine \& Lieberman (1987). Os quais assumem que uma constante proporção da população sobrevivente morre em cada intervalo de tempo, apresentando um aumento exponencial (logarítmico) no declínio do número com o tempo.

A mortalidade anual foi calculada a partir da seguinte fórmula:

$m=100\left(\ln _{e} \cdot n_{0}-\ln _{e} \cdot n_{1}\right) / t$

Onde:

$n_{0}=$ número de árvores no primeiro levantamento.

$n_{1}=$ número de sobreviventes no segundo levantamento.

$n_{1} t=$ tempo em anos.

$n_{1} t$

Para a plotagem dos resultados nos gráficos de incremento, só foram consideradas as médias provenientes de, no mínimo, 10 árvores amostradas por espécie.

Primeiramente o incremento médio anual das comunidades estudadas foi calculado considerando todos os indivíduos sem distinção da classificação de fuste. Em seguida, esse incremento foi calculado, de forma separada, para todos os indivíduos com rebroto aparente, todos os indivíduos sem rebroto aparente e para todas as árvores decapitadas. 


\subsubsection{Fertilidade e Granulometria do solo}

As análises dos dados foram realizadas no Laboratório de Solos do Departamento de Solos da Universidade Federal Rural da Amazônia (UFRA).

A análise química do solo foi realizada segundo os critérios e técnicas descritos por Silva (1991). O Ph foi determinado pelo método potenciômetro, na relação de 1:2,5;

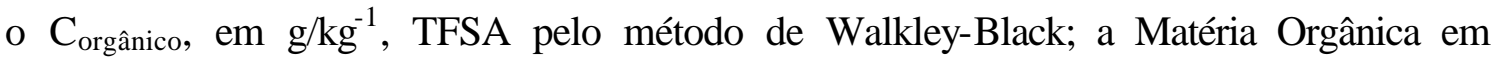
$\mathrm{g} / \mathrm{kg}^{-1}$, TFSA $\mathrm{C}_{\text {orgânico }} \mathrm{x} 1,724$; o $\mathrm{P}$ disponível em $\mathrm{mg} / \mathrm{dm}^{-3}$, TSFA pelo extrator de Mehlich - 1; o K e o Na trocáveis em $\mathrm{cmol}_{C} / \mathrm{dm}^{-3}$ pelo extrator de Mehlich - 1; o Ca e o $\mathrm{Mg}$ trocáveis em $\mathrm{cmol}_{\mathrm{C}} / \mathrm{dm}^{-3}$ pelo extrator $\mathrm{KCl}$ a $1 \mathrm{M}$; e o $\mathrm{H}^{+}$e o $\mathrm{Al}^{+}$trocáveis em cmol $_{C} / \mathrm{dm}^{-3}$ pelo extrator Acetato de Cálcio a 0,5M.

Após a análise foi determinada a capacidade de troca de cátions (CTC), que é a soma dos seguintes elementos, $\mathrm{Ca}^{+2}, \mathrm{Mg}^{+2}, \mathrm{~K}^{+}, \mathrm{Na}^{+}, \mathrm{H}^{+}$e $\mathrm{Al}^{+3}$; a soma de bases (SB) ( $\mathrm{Ca}, \mathrm{Mg}, \mathrm{K}$ e $\mathrm{Na})$; a percentagem de saturação de bases $(\% \mathrm{~V})$; e a Toxidez do alumínio $(\% \mathrm{Al})$.

Para análise granulométrica, foi utilizado o método da pipeta (EMBRAPA, 1979), para determinação dos teores de areia total $(2,00 \mathrm{~mm}$ a $0,05 \mathrm{~mm}$ de diâmetro), de silte $(0,05 \mathrm{~mm}$ a $0,002 \mathrm{~mm}$ de diâmetro) e de argila (diâmetro inferior a 0,002mm), todos expressos em percentagem. Para definição da textura foi adotada a seguinte classificação, considerando a percentagem de argila: até 14\%, considerada arenosa; de $15 \%$ a $24 \%$, média-arenora; de $25 \%$ a $34 \%$, média-argilosa; de $35 \%$ a 59\%, argilosa; e igual ou superior a $60 \%$, muito argilosa.

Para verificar possíveis diferenças entre a fertilidade e granulometria do solo das duas florestas estudadas foi aplicado o teste tStudent (nível de confiança de 95\%) com auxilio do programa estatístico "SAS-system (1987) (Statistical Analysis Systems)”. Para tal análise, assumiu-se como principal fonte de variação, a diferença entre o histórico de uso relatado para as duas áreas.

A hipótese básica $(\mathrm{H} 0)$ do teste foi que não havia diferença estatística significativa entre as médias dos atributos químicos e granulométricos do solo das áreas estudadas. O 
teste foi aplicado utilizando 48 amostras para cada atributo de fertilidade e para cada profundidade em ambas áreas.

Para a determinação de quais parâmetros (químico e granulométrtico) seriam melhores para mostrar as diferenças entre as parcelas em cada área e entre as áreas, foi realizada a Análise de Componentes Principais (PCA). As análises foram realizadas com o auxílio dos programas MATRIZ, COEF, CLUSTER e ORD do pacote FITOPAC (Shepherd, 1995). Para as análises preliminares utilizou-se uma matriz que correlacionou todas as variáveis químicas supracitadas e as variáveis granulométricas (areia grossa, areia fina e argila) para as três profundidades (0-5, 5-15 e 15-25cm de profundidade) separadamente. Em seguida foram selecionados para nova análise somente os principais atributos que melhor explicaram as diferenças entre as os grupos de parcelas formados para duas áreas.

Devido as diferenças de unidades de medidas dos diversos atributos químicos e granulométricos do solo, foi realizada uma transformação de dados pelo método do inverso da raiz ( $1 / \sqrt{x}$, onde $\boldsymbol{x}$ é o valor a ser transformado).

Para realizar a ordednação e correlação entre os principais atributos de fertilidade do solo e os dados de crescimento em diâmetro, área basal total e densidade, foi usado o método de Análise de Correspondência Canônica (CCA) (Ter Braak, 1986). O teste de Monte Carlo (99 permutações; $\mathrm{p}<0,05)$ foi utilizado na análise para informar a probabilidade dos autovalores dos eixos terem sido ou não distribuídos ao acaso.

Para a construção da matriz de variáveis ambientais foram considerados os resultados obtidos a partir da análise de PCA, que identificou os principais atributos de fertilidade e a profundidade que melhor explicaram as diferenças entre as parcelas das duas áreas. Para Marituba e Bragança, pH, MO, P, \%V, \%Al, CTC e Argila na proundidade $0-5 \mathrm{~cm}$, foram as variáveis mais importantes.

Para a matrtiz de dados de vegetação, foram usados somente os dados referentes às parcelas que tiveram valores correspondentes na matriz de variáveis ambientais. Foram 48 subparcelas em cada uma das duas áreas.

O programa utilizado para auxiliar na análise de CCA foi o programna PC-ORD versão 3.17 para Windows. 


\section{RESULTADOS E DISCUSSÃO}

\subsection{Diversidade florística}

Os resultados dos levantamentos florísticos realizados em 1997 e 2002 na floresta secundária de Marituba-PA, e em 1999 e 2002 na floresta secundária de Bragança, estão apresentados na Tabela 1 .

Das espécies encontradas durante os levantamentos em Marituba, 16 foram identificadas em nível de gênero, 4 apenas em nível família, e 1, não possui nenhuma identificação.

Em Bragança, das espécies encontradas nos dois levantamentos, 8 tiveram identificação até o nível gênero, 1 indivíduo foi identificado somente em nível de família e outro, no ultimo levantamento, não foi possível chegar a nenhuma identificação.

A identificação imprecisa de algumas espécies ocorreu pela falta de material fértil, ou mesmo a não existência de material estéril similar no herbário.

A área de Marituba apresentou maior riqueza florística do que a área de Bragança. No primeiro levantamento realizado em Marituba, a floresta secundária apresentou uma riqueza de espécies 26,5\% superior à encontrada em Bragança. Para o último levantamento, essa diferença aumentou para 33,0\% (Tabela 1).

As mudanças florísticas ocorridas ao longo dos períodos analisados foram mais acentuadas na área de Marituba. O número de famílias, gêneros e espécies, tiveram aumentos de 4,5\%, 4,3\% e 8,1\%, respectivamente (Tabela 1). Durante o período, 4 espécies (Guatteria ovalifolia, Guatteria poeppigiana, Mabea sp., Alchorneopsis trinera e Miconia sp.), não foram mais encontradas nas parcelas, considerando o diâmetro de inclusão $(5,0 \mathrm{~cm})$, e vinte novas espécies ingressaram (Duguetia stelechantha, Guatteria 
guianensis, Caryocar villosum, Vantanea guianensis, Nectandra sp., Lecythis idatimon, Parkia paraensis, Bellucia glossularioides, Brosimum lactescens Brosimum rubescens, Calyptranthes gigantifolia, Myrcia atramentifera, Myrcia deflexa, Neea oppositifolia, Talisia carinata, Talisia longifólia, Micropholis venulosa, Pouteria lasiocarpa, Rinorea racemosa e uma espécie que não teve identificação) (Anexo B).

Em Bragança, entre os levantamentos de 1999 e 2002, houve o ingresso de uma família, estabilidade do número de gêneros e diminuição do número de espécies em 1,5\% (Tabela 1). Cinco espécies não foram mais encontradas nas parcelas, (Bocageopsis multiflora, Byrsonima aerugo, Casearia javitensis, Isertia hipoleuca e Palicourea grandifolia) e três novas espécies (lnga cayennensis, Virola calophylla e uma espécie não teve nenhuma identificação) ingressaram no povoamento (Anexo C).

Quanto ao número de indivíduos, houve uma diminuição em ambas as áreas durante o período monitorado, sendo 4,1\% em Marituba e 6,2\% em Bragança (Tabela 1).

Tabela 1. Parâmetros de riqueza e diversidade do estrato arbóreo (DAP $\geq 5,0 \mathrm{~cm}$ ), nos levantamentos florísticos e fitossociológicos realizados em florestas secundárias de Marituba e Bragança no Nordeste Pará

\begin{tabular}{lrrrr}
\hline \multicolumn{1}{c}{ Variáveis } & \multicolumn{2}{c}{ Marituba } & \multicolumn{2}{c}{ Bragança } \\
& $\mathbf{1 9 9 7}$ & $\mathbf{2 0 0 2}$ & $\mathbf{1 9 9 9}$ & $\mathbf{2 0 0 2}$ \\
\hline $\mathrm{N}^{\mathbf{0}}$ de Indivíduos & 1257 & 1206 & 1819 & 1707 \\
Famílias & 44 & 46 & 39 & 41 \\
Gêneros & 115 & 120 & 86 & 86 \\
Espécies & 185 & 200 & 136 & 134 \\
Shannon $\left(\mathrm{H}^{\prime}\right)$ & 4,27 & 4,42 & 4,05 & 4,08 \\
Equabilidade $\left(\mathrm{J}^{\prime}\right)$ & 0,81 & 0,83 & 0,82 & 0,83 \\
\hline
\end{tabular}

O índice de diversidade de Shannon $\left(\mathrm{H}^{\prime}\right)$ em Marituba foi superior ao de Bragança nos dois levantamentos, já os valores de equabilidade foram muito próximos nas duas áreas durante todo o período (Tabela 1).

Os dados florísticos apresentados para ambas as áreas, foram superiores aos encontrados em outros levantamentos realizados em florestas secundárias antigas na Amazônia. Um trabalho realizado em uma capoeira de origem agrícola e com aproximadamente 40 anos na região Bragantina-PA (amostragem de indivíduos com DAP $\geq 5 \mathrm{~cm}$ em 8 parcelas de $250 \mathrm{~m}^{2}$ ), encontrou 319 indivíduos, 30 famílias 
(considerando Mimosoideae, Caesalpinioideae e Faboideae como famílias), 49 gêneros e 62 espécies (Vieira, 1996).

Um outro trabalho, também foi realizado na área da CEPLAC em Marituba (Jardim et al., 1997). No qual os autores estudaram, entre outras, uma floresta secundária com 30 anos, considerando a vegetação maior ou igual a $10 \mathrm{~cm}$ de altura em diferentes níveis de amostragem (total 0,2ha), encontraram 30 famílias, 49 gêneros e 67 espécies. Já Santana (2000), medindo todos os indivíduos com DAP $\geq 1,6 \mathrm{~cm}$ em 15 parcelas de $200 \mathrm{~m}^{2}$ (0,3ha) de uma floresta secundária com aproximadamente 35 anos em IgarapéAçú-PA, obteve 1.402 indivíduos, 42 famílias (considerando Mimosoideae, Caesalpinioideae e Faboideae como famílias), 74 gêneros e 103 espécies.

Entre os estudos realizados em florestas secundárias antigas que analisaram dados provenientes de parcelas permanentes, destaca-se o de Oliveira, L. (1997), que analisou dados coletados em 11 parcelas de $2.500 \mathrm{~m}^{2}$ (total $=2,75 \mathrm{ha}$ ), nas quais foram medidos todos indivíduos com DAP $\geq 5 \mathrm{~cm}$, de uma floresta com aproximadamente 50 anos em Belterra-PA. Este trabalho mostrou que em 10 anos de acompanhamento o número de famílias aumentou de 31 para 35, o de gêneros foi de 53 para 65 e o de espécies passou de 58 para 71 .

Considerando estes valores, isoladamente, e comparando-os com os resultados apresentados na Tabela 1, vê-se que as áreas do presente estudo apresentam maior riqueza, semelhantes às observadas em florestas primárias da região.

Um trabalho realizado em remanescente de floresta primária (200ha) no município de Peixe-Boi-PA (Vieira, 1996), no qual, foram amostrados indivíduos com DAP a partir de 5cm em 0,6ha, obteve 718 indivíduos, 47 famílias (considerando Mimosoideae, Caesalpinioideae e Faboideae como famílias), 121 gêneros e 200 espécies. Carvalho (1992) encontrou 48 famílias, 137 gêneros e 226 espécies, analisando dados de indivíduos amostrados (DAP $\geq 5 \mathrm{~cm}$ ) em 3ha de uma floresta primária na Flona do Tapajós em Santarém-PA.

Quanto a dinâmica da composição florística, os resultados apresentados no presente trabalho mostraram que, ao longo de 5 anos, o aumento na riqueza de espécies foi de $1,62 \%$ ao ano para Marituba. Para Bragança, houve diminuição de 0,5\% ao ano 
durante os 3 anos analisados. Estes valores são baixos, quando comparados aos encontrados por Oliveira, L. (1997) (aumento de 2,2\% ao ano) e Crow (1980), que encontrou um aumento médio de $2,3 \%$ ao ano na diversidade de espécies, considerando árvores com DAP $\geq 4 \mathrm{~cm}$ em 0,72 ha num período de 33 anos em floresta secundária proveniente de exploração seletiva com 39 anos de idade na região de Luquillo em Porto Rico.

Os índices de diversidade encontrados para as áreas estudadas em Marituba e Bragança são considerados altos, uma vez que são valores muito próximos aos encontrados para florestas primárias, que normalmente apresentam índices superiores a 4 (Tabela 1).

Em ambos os períodos analisados, os valores estão acima do índice encontrado por Vieira (1996), para uma floresta secundária antiga com 40 anos na região Bragantina-PA $\left(H^{\prime}=3,52\right)$, e muito próximos ao de uma floresta primária na mesma região $\left(H^{\prime}=4,43\right)$. Valores semelhantes do índice de Shannon $\left(\mathrm{H}^{\prime}=4,8\right)$ foram encontrados por Barros (1986), para uma floresta primária em Curuá-Una-PA.

Os respectivos índices de equabilidade (Tabela 1), apresentaram-se menores do que os encontrados por Vieira (1996), que foi de 0,85 para floresta secundária antiga com 40 anos e de 0,89 para floresta primária.

Comparando os trabalhos citados anteriormente, nota-se que as áreas em Marituba e Bragança embora apresentem menor ganho em riqueza de espécies, apresentam maior riqueza e diversidade total em relação às florestas secundárias de idade semelhante. Isso se deve, provavelmente, às alterações que precederam o início da recuperação dessas áreas (Uhl et al., 1988), às influências das variações climáticas regionais (Ewel, 1980), o tipo e fertilidade do solo (Guariguata \& Otertag, 2001 e Mello, et al., 1989), às atividades realizadas no entorno e à constituição e idade das florestas que as cercam.

Em Marituba, onde a floresta foi cortada para a produção madeireira, a recuperação da riqueza de espécies e a recobertura foi mais acelerada. E em Bragança, onde a área sofreu corte e queima e foi abandonada, o processo de sucessão é mais lento devido a ação do fogo (Uhl et al., 1981) e os sucessivos tratos cultirais que acabam 
reduzindo o banco de sementes do solo (Denich, 1986) e, conseqüentemente, seu poder de resiliência.

\subsection{Similaridade florística}

O dendrograma obtido para as duas áreas do presente estudo, utilizando-se o índice de similaridade de Jaccard $\left(\mathrm{J}_{\mathrm{ac}}\right)$, está apresentado na Figura 14. O dendrograma mostra a formação de dois grupos distintos com corte de similaridade em torno de 0,12 da escala de Jaccard. Esse valor de similaridade é considerado muito baixo, uma vez que a escala de Jaccard varia entre a total dissimilaridade "0" zero e a máxima similaridade "1"um.

$\mathrm{Na}$ área de Bragança a maior similaridade ocorreu entre as parcelas 3 e 4 (55\%) e a menor, entre as parcelas 1 e 3 (Tabela 2). Para a área de Marituba os índices $\left(\mathrm{J}_{\mathrm{ac}}\right)$ encontrados para a comparação entre parcelas em geral foram menores do que os apresentados em Bragança. Evidenciando a maior heterogeneidade de espécies dessa área (Tabela 2).

Tabela 2. Matriz de similaridade florística, em nível específico, entre as parcelas inventariadas em Bragança e Marituba no Nordeste do Pará, utilizando como coeficiente o índice de Jaccard em matriz binária com 250 espécies

\begin{tabular}{|c|c|c|c|c|c|c|c|c|c|}
\hline \multirow{3}{*}{ Areas } & \multirow{3}{*}{ Parcelas } & \multicolumn{8}{|c|}{ Áreas/Parcelas } \\
\hline & & \multicolumn{4}{|c|}{ Marituba } & \multicolumn{4}{|c|}{ Bragança } \\
\hline & & Par. 01 & Par. 02 & Par. 03 & Par. 04 & Par. 01 & Par. 02 & Par. 03 & Par. 04 \\
\hline \multirow{4}{*}{ 总 } & Par. 01 & 1,00 & & & & & & & \\
\hline & Par. 02 & 0,40 & 1,00 & & & & & & \\
\hline & Par. 03 & 0,41 & 0,45 & 1,00 & & & & & \\
\hline & Par. 04 & $\mathbf{0 , 3 8}$ & 0,42 & 0,45 & 1,00 & & & & \\
\hline \multirow{4}{*}{ 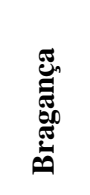 } & Par. 01 & 0,09 & 0,07 & 0,09 & 0,11 & 1,00 & & & \\
\hline & Par. 02 & 0,14 & 0,09 & 0,13 & 0,15 & $\mathbf{0 , 4 1}$ & 1,00 & & \\
\hline & Par. 03 & 0,17 & 0,14 & 0,16 & 0,18 & $\mathbf{0 , 3 7}$ & 0,46 & 1,00 & \\
\hline & Par. 04 & 0,13 & 0,12 & 0,12 & 0,15 & 0,44 & 0,49 & 0,55 & 1,00 \\
\hline
\end{tabular}

Os valores de Jaccard apresentados na Tabela 2, entre as parcelas das duas áreas, mostraram que a similaridade foi muito baixa, pois os valores ficaram entre $\mathrm{J}_{\mathrm{ac}}=7 \% \mathrm{e}$ 
18\%. Estes resultados mostraram a grande heterogeneidade florística existente entre as duas áreas estudadas.

O conjunto total de espécies encontradas nas duas áreas (incluindo as morfoespécies) soma 275 espécies, das quais 140 são exclusivas da área de Marituba, outras 75 espécies foram encontradas somente em Bragança e apenas 60 espécies são comuns às duas áreas (Anexo $\mathrm{H})$.

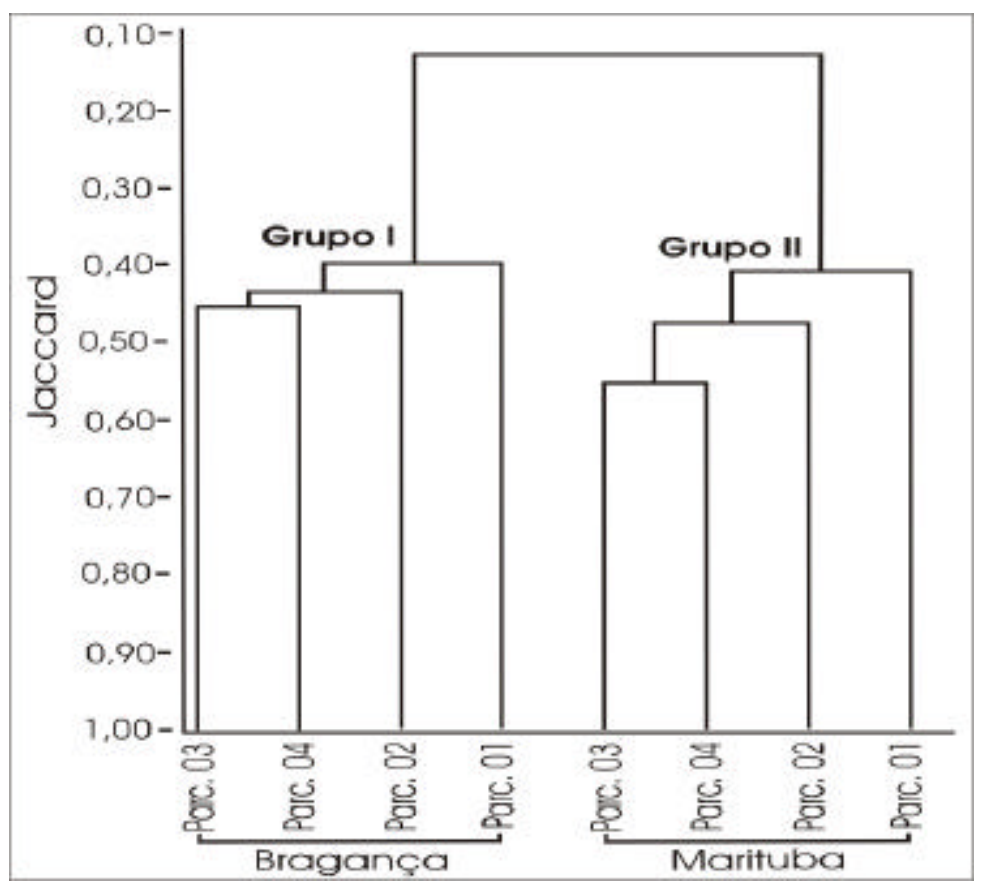

Figura 14 - Dendrograma apresentando a similaridade florística, em nível específico, entre as parcelas inventariadas em Bragança e Marituba no Nordeste do Pará, utilizando como coeficiente o índice de Jaccard e agrupando as parcelas pelo método de Média de Grupo (UPGMA)

A análise de similaridade florística entre as sete florestas comparadas, evidenciou a formação de 4 grupos (Figura 15). O grupo 4 foi o mais coeso, no qual encontram-se as duas florestas secundárias do presente estudo (MAR50 e BRA50) e as duas florestas naturais (FP01 e FP02) da região (Figura 15). Por outro lado, as outras três áreas de florestas secundárias formaram três grupos distintos e de dissimilaridade muito alta $\left(\mathrm{J}_{\mathrm{ac}}\right.$ entre $5 \%$ e $15 \%)$.

A maior similaridade florística $\left(\mathrm{J}_{\mathrm{ac}}=24 \%\right)$ foi apresentada pelas áreas MAR50 e BRA50, seguida pelas áreas de florestas naturais $\left(\mathrm{J}_{\mathrm{ac}}=23 \%\right)$. A floresta secundária de 
Marituba apresentou-se mais similar às florestas primárias do que a floresta de Bragança (Tabela 3).

Os valores de similaridade em nível de espécies para as sete florestas foram baixos quando comparados aos índices encontrados por Oliveira, A. (1997). Este autor comparou três parcelas de florestas naturais (Manaus-AM) com área de tha e distância máxima de 400 metros entre elas. Estas áreas apresentaram valores médios de similaridade $\left(\mathrm{J}_{\mathrm{ac}}\right)$ de $35 \%$ em nível específico. Este autor justifica que a baixa similaridade florística, mesmo entre áreas muito próximas, é decorrente do grande número de espécies com baixa densidade. Afirma ainda, que seria imprudência considerar áreas tão próximas, com características estruturais de solo e relevo tão semelhantes, como comunidades distintas.

Em trabalho realizado em duas florestas de interflúvio das margens esquerda e direita do Rio Pacuneiro e uma floresta periodicamente alagada na margem do mesmo Rio (Bacia do Rio Xingu) no norte do Estado do Mato Grosso (Ivanauskas, 2002), foi encontrado um valor médio de similaridade em torno de $\mathrm{J}_{\mathrm{ac}}=27 \%$ a nível específico.

Os valores encontrados por Oliveira, A. (1997) e Ivanauskas (2002), mostraram que as áreas de seus estudos são consideradas similares segundo Mueller-Dombois \& Ellemberg (1974), que consideram áreas floristicamente similares as que apresentem índice de Jaccard superior a $\mathrm{J}_{\mathrm{ac}}=25 \%$.

Tabela 3. Matriz de similaridade florística, em nível específico, entre as florestas inventariadas em Bragança e Marituba no Nordeste do Pará e outras áreas de florestas secundárias e primárias, utilizando como coeficiente o índice de Jaccard em matriz binária com550 espécies

\begin{tabular}{|c|c|c|c|c|c|c|c|}
\hline Florestas & FP 02 & FP 01 & NOP 40 & NOP 35 & MAR 50 & BRA 50 & BEL 50 \\
\hline FP 02 & 1,00 & & & & & & \\
\hline FP 01 & 0,23 & 1,00 & & & & & \\
\hline NOP 40 & 0,06 & 0,12 & 1,00 & & & & \\
\hline NOP 35 & 0,09 & 0,08 & 0,09 & 1,00 & & & \\
\hline MAR 50 & 0,22 & 0,21 & 0,07 & 0,15 & 1,00 & & \\
\hline BRA 50 & 0,12 & 0,12 & 0,14 & 0,11 & 0,24 & 1,00 & \\
\hline BEL 50 & 0,05 & 0,08 & 0,06 & 0,10 & 0,12 & 0,11 & 1,00 \\
\hline
\end{tabular}

FP 02 - Flor. Nat. Reserva do Mocambo (Belém); FP 01 - Flor. Nat. (Peixe -Boi); NO P 40-Flor. sec. Com 40 anos (Peixe -Boi); NO P 35 - Flor. sec. Com 35 anos (Igarapé-Açu); MAR 50 -Flor. sec. Com 50 anos (CEPLAC Marituba); BRA 50 - Flor. sec. Com 50 anos (Bragança) e BEL 50-Flor. sec. Com 50 anos (Belterra). 


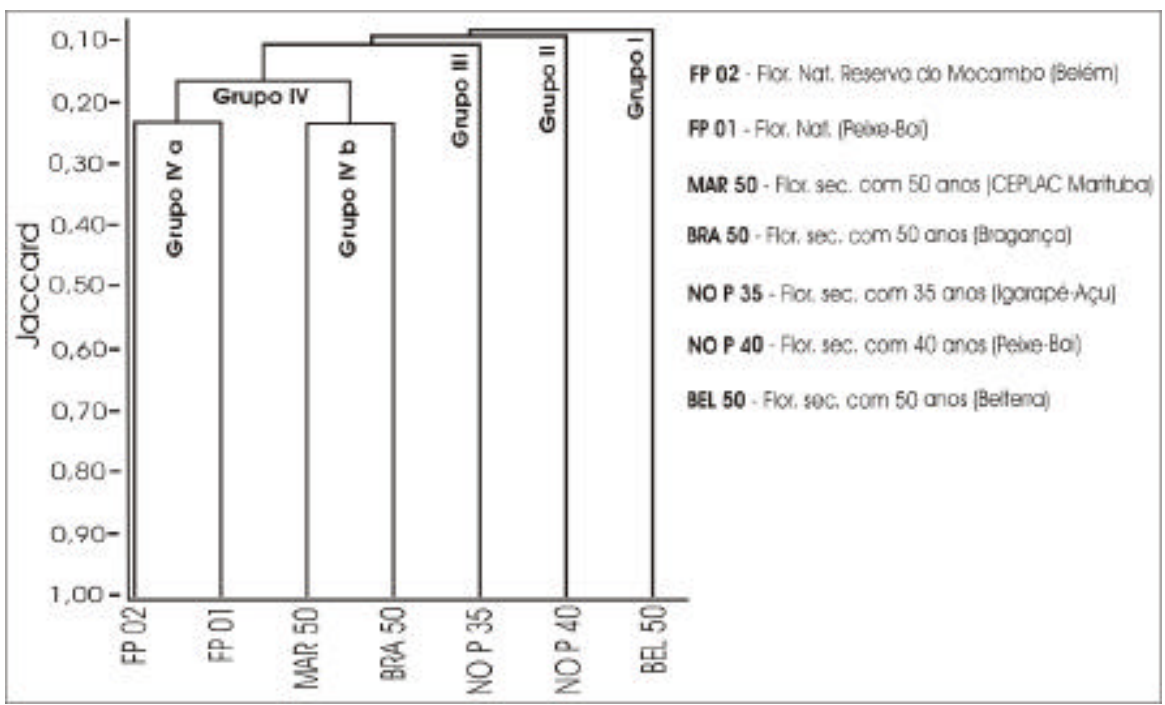

Figura 15 - Dendrograma apresentando a similaridade florística, em nível específico, entre as florestas inventariadas em Bragança e Marituba no Nordeste do Pará e outras áreas de florestas secundárias e primárias, utilizando como coeficiente o índice de Jaccard e agrupando as parcelas pelo método de Média de Grupo (UPGMA)

\subsection{Parâmetros fitossociológicos}

\subsubsection{Famílias}

As famílias com maior número de indivíduos diferem entre as duas áreas. Em Marituba predominou Moraceae e em Bragança Myrtaceae. Entre as dez principais famílias, em número de indivíduos, Fabaceae, Lecythidaceae e Euphorbiaceae são as únicas comuns entre as duas áreas (Tabelas 4 e 5).

Em Marituba no último levantamento (2002) as famílias Moraceae e Fabaceae foram as principais responsáveis pela diminuição na densidade da população $(36,1 \%$, 6,3\% respectivamente). Entre as dez famílias, 7 apresentaram aumento do número de indivíduos e Sterculiaceae permaneceu sem alteração (Tabela 4). Nessa área as famílias menos representativas foram Ebenaceae e Ulmaceae, ambas com 1 indivíduo nos dois levantamentos (Anexo A). 
Para Bragança, os dados da Tabela 5 mostraram que em relação ao levantamento de 1999, houve uma ligeira queda na densidade de indivíduos das principais famílias, entre elas Annonaceae e Euphorbiaceae tiveram as maiores reduções e apenas Lecythidaceae, teve aumento de 3,4\%. As famílias menos representativas foram Ebenaceae, Bombacaceae, Quiinaceae e Myristicaceae, todas com apenas um indivíduo (Anexo A).

Tabela 4. Famílias com maior destaque em densidade e número de espécies, amostradas em 1,0ha entre os anos de 1997 e 2002 em uma floresta secundária oriunda de exploração de madeira para lenha, no município de Marituba-PA

\begin{tabular}{|c|c|c|c|c|c|}
\hline \multirow{2}{*}{ Família } & \multicolumn{2}{|c|}{$\mathbf{N}^{\mathbf{0}}$ Ind/ha } & \multirow{2}{*}{ Família } & \multicolumn{2}{|c|}{$\mathrm{N}^{\circ} \mathrm{Spp}$} \\
\hline & 1997 & 2002 & & 1997 & 2002 \\
\hline MORACEAE & 227 & 145 & FABACEAE & 34 & 35 \\
\hline FABACEAE & 127 & 119 & SAPOTACEAE & 11 & 13 \\
\hline LECYTHIDACEAE & 119 & 129 & ANNONACEAE & 10 & 10 \\
\hline RUBIACEAE & 84 & 88 & MORACEAE & 9 & 11 \\
\hline STERCULIACEAE & 78 & 78 & BURSERACEAE & 9 & 9 \\
\hline BURSERACEAE & 75 & 77 & EUPHORBIACEAE & 9 & 7 \\
\hline MYRISTICACEAE & 69 & 73 & MYRISTICACEAE & 7 & 7 \\
\hline SAPOTACEAE & 55 & 57 & VOCHYSIACEAE & 7 & 7 \\
\hline EUPHORBIACEAE & 52 & 57 & CHRYSOBALANACEAE & 7 & 7 \\
\hline VOCHYSIACEAE & 39 & 41 & APOCYNACEAE & 7 & 7 \\
\hline Subotais (10) & $925(73,6 \%)$ & $864(71,6 \%)$ & Subotais (10) & $110(59,5 \%)$ & $113(56,5 \%)$ \\
\hline Outras (36) & $332(26,4 \%)$ & $342(28,4 \%)$ & Outras (36) & $75(40,5 \%)$ & $87(43,5 \%)$ \\
\hline Total (46) & 1.257 & 1.206 & Total (46) & 185 & 200 \\
\hline
\end{tabular}

Fabaceae foi a família que apresentou o maior número de espécies em ambas as áreas, sendo o número de espécies em Marituba cerca de 30,0\% maior do que em Bragança. Além dessa família, Sapotaceae, Annonaceae e Euphorbiaceae foram as únicas comuns as duas áreas que se destacaram entre as famílias com maior número de espécies (Tabelas 4 e 5).

Das 44 famílias encontradas no primeiro levantamento em Marituba, 75,0\% permaneceram com o mesmo número de espécies e 22,7\% tiveram aumento. Para Bragança, das 40 famílias existentes na área, em 1999, 85,0\% não tiveram alterações do número de espécies no período de três anos. Lecythidaceae e Fabaceae foram as únicas a 
ter aumento e Rubiaceae, Annonaceae, Flacourtiaceae e Malpighiaceae tiveram diminuição (Anexo A).

Tabela 5. Famílias com maior destaque em densidade e número de espécies,amostradas em 1,0ha entre os anos de 1999 e 2002 em uma floresta secundária oriunda de agricultura de corte e queima no município de Bragança-PA

\begin{tabular}{|c|c|c|c|c|c|}
\hline \multirow{2}{*}{ Família } & \multicolumn{2}{|c|}{$\mathrm{N}^{0}$ Ind/ha } & \multirow{2}{*}{ Família } & \multicolumn{2}{|c|}{$\mathrm{N}^{\circ} \mathrm{Spp}$} \\
\hline & 1999 & 2002 & & 1999 & 2002 \\
\hline MYRTACEAE & 335 & 309 & FABACEAE & 22 & 23 \\
\hline FABACEAE & 273 & 247 & LECYTHIDACEAE & 13 & 14 \\
\hline LECYTHIDACEAE & 200 & 207 & MYRTACEAE & 12 & 12 \\
\hline EUPHORBIACEAE & 145 & 122 & ANNONACEAE & 7 & 6 \\
\hline ANNONACEAE & 141 & 118 & FLACOURTIACEAE & 6 & 5 \\
\hline FLACOURTIACEAE & 121 & 107 & RUBIACEAE & 6 & 4 \\
\hline ANACARDIACEAE & 97 & 91 & EUPHORBIACEAE & 5 & 5 \\
\hline LACISTEMACEAE & 73 & 72 & SAPOTACEAE & 5 & 5 \\
\hline SAPINDACEAE & 71 & 71 & CLUSIACEAE & 5 & 5 \\
\hline APOCYNACEAE & 69 & 71 & SAPINDACEAE & 4 & 4 \\
\hline Subotais (10) & $1525(83,8 \%)$ & $1415(82,9 \%)$ & Subotais (10) & $85(62,5 \%)$ & $83(61,9 \%)$ \\
\hline Outras (31) & $294(16,2 \%)$ & $292(17,1 \%)$ & Outras (31) & $51(37,5 \%)$ & $51(38,1 \%)$ \\
\hline Total (41) & 1.819 & 1.707 & Total (41) & 136 & 134 \\
\hline
\end{tabular}

$\mathbf{N}^{\mathbf{0}}$ Ind = número de indivíduos amostrados por famílias e $\mathbf{N}^{\mathbf{0}} \mathbf{S p p}=$ número de espécies por famílias .

FABACEAE = Leguminosae com as três subfamílias (Caesalpinioideae, Faboideae e Mimosoideae)

De modo geral, Fabaceae (Leguminosae) é a família que se destaca na maioria dos levantamentos fitossociológicos realizados na Amazônia, tanto em florestas naturais primárias quanto nas florestas secundárias. Miranda (2000) em Rondônia, por exemplo, encontrou 47 espécies dessa família nos levantamentos realizados em florestas de terra firme, matas ciliares e matas alagadas. Já Vieira (1996), encontrou 29 espécies em 0,6ha de um remanescente de floresta primária no Nordeste do Pará, Pires \& Salomão (2000), 21 espécies em 2ha de uma floresta primária em Belém-PA (Reserva Mocambo-APEG) e Carvalho (1992), encontrou 49 espécies de Fabaceae em 3ha de floresta nativa em Santarém-PA. Este comportamento é também confirmado por Ramos (1994), em revisão que apresenta estudos realizados em florestas neotropicais úmidas no México, Costa Rica, Panamá, Peru e Brasil. 
Nas florestas secundárias antigas do Nordeste do Pará, Jardim et al. (1997) e Vieira (1996) encontraram 10 e 13 espécies de Fabaceae, respectivamente em 0,2ha, Santana (2000) encontrou 19 espécies em 0,3ha e Oliveira (1995), 24 espécies de Fabaceae em 2,75ha em Belterra-PA.

Portanto, os dados do presente estudo não diferem do padrão apresentado nos trabalhos citados, no qual a família Fabaceae apresenta 35 e 23 espécies em 1,0ha para Marituba e Bragança, respectivamente, no último levantamento. Deve-se considerar, no entanto, que o tamanho da área amostrada e o diâmetro de inclusão interferem no número de espécies encontradas.

\subsubsection{Espécies}

No Anexo B, estão listados os parâmetros fitossociológicos das espécies amostradas nos levantamentos realizados em 1997 e 2002 na floresta secundária de Marituba. E no Anexo $\mathrm{C}$, os parâmetros fitossociológicos referentes às espécies analisadas nas coletas de 1999 e 2002 na área de Bragança. Estes valores estão distribuídos por ordem decrescente de Índice de Valor de Importância para o primeiro ano de medição de cada área.

\section{a) Índice de Valor de Importância - IVI}

Na Figura 16 estão relacionadas às 13 espécies mais importantes em relação ao valor de IVI em seus respectivos períodos analisados para as duas áreas estudadas.

Em Marituba, após cinco anos, o mesmo grupo de espécies permaneceu em destaque, embora, oito tenham apresentado redução nos valores de IVI (Pourouma guianensis, Pourouma longipendula, Sterculia pilosa, Apeiba albiflora, Protium opacum, Pouteria guianensis, Miconia surinamensis e Inga alba) e cinco tenham apresentado aumento (Eschweilera coriacea, Coussarea paniculata, Iryantera juruensis, Eschweilera polyantha e Piptadenia suaveolens). Estas espécies representavam em 1997 47,0\% do total de indivíduos e em 2002, 42,0\% (Figura 16a). 
As mudanças que ocorreram na área de Bragança foram menos expressivas. As 13 espécies mais importantes, representavam 49,3\% do total de indivíduos em 1999 e 48,0\% em 2002. Entre elas Tapirira guianensis, foi a que apresentou o maior valor e aumento de IVI entre os dois levantamentos, Myrcia bracteata a maior perda e a espécie Sclerolobium chrysophylum após três anos foi a única a sair desse grupo (Figura 16b).

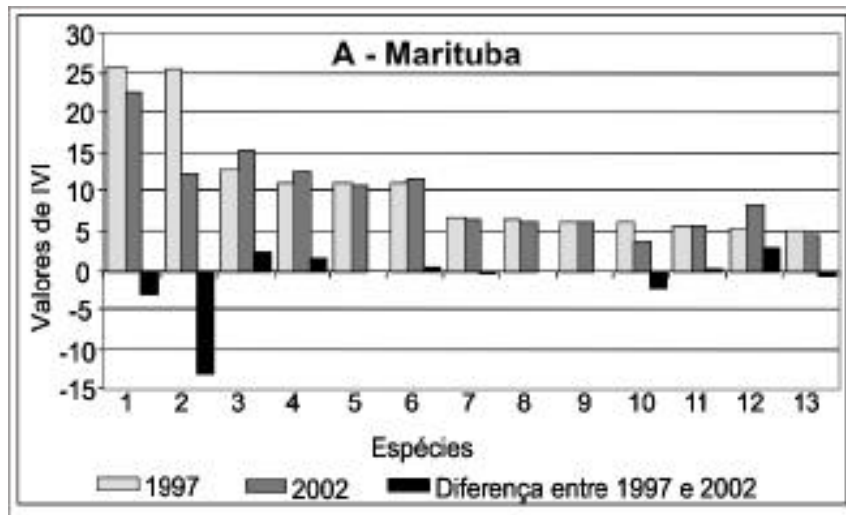

1- Pourouma longipendula

2- Pourouma guianensis

3- Eschueilera coriacea

4- Sterculia pilosa

5- Iryanthera juruensis

6- Coussarea paniculata

7- Pouteria guianensis

8- Protium opacum

9. Apeiba albiflora

10- Eschweilera polyantha

11- Miconia surinamensis

12- Mabea paniculata

13-Palicourea guianensis

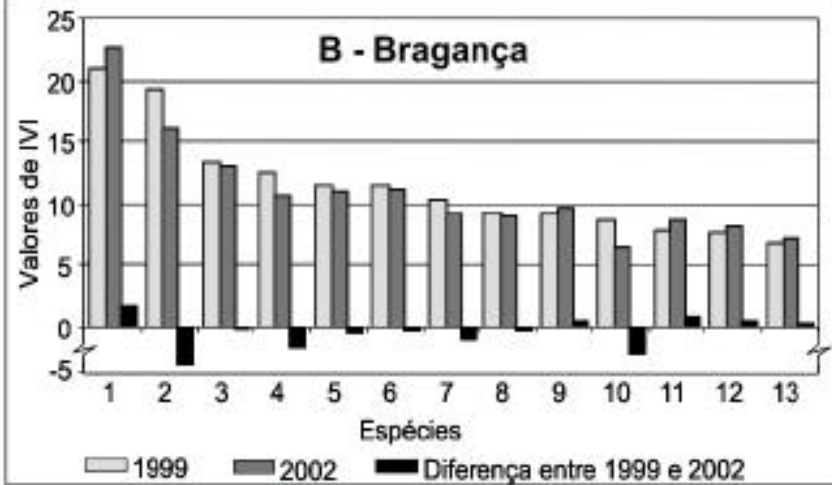

1- Tapirira guianensis

2- Myrcia bracteata

3- Casearia arorea

4- Croton matourensis

5- Inga alba

6- Maprounea guianensis

7- Guatteria poeppigiana

8- Annona paludosa

9. Eschueilera amazonica

10- Sclerolobium chrysophylum

11- Myrciaria tenella

12- Himatanthus suctuba

13- Talisia guianensis

Figura 16 - Valores de IVI para as principais espécies encontradas nos levantamentos realizados em parcelas permanentes de duas florestas secundárias antigas em Marituba e Bragança-PA

Das espécies mais importantes encontradas na área de Bragança, Croton matourensis, T. guianensis e Guatteria poeppigiana também se destacaram no trabalho de VEIRA (1996) numa capoeira antiga (40anos), assim como T. guianensis, I. alba e M. bracteata, no levantamento realizado por Santana (2000) em capoeira de 33 anos. Já no trabalho de Oliveira (1995) (capoeira 50 anos), somente $T$. guianensis e $G$. poeppigiana estão entre as mais importantes. 
Para a área de Marituba, somente E. coriacea e I. alba estavam entre as mais importantes no levantamento realizado por Vieira (1996) e E. coriacea e Iryanthera juruensis no trabalho de Pires \& Salomão (2000) em floresta primárias da região.

Dessas comparações, pôde-se observar que ao contrário do que ocorre nas áreas de florestas secundárias, a espécie T. guianensis, não está presente entre as mais importantes nas áreas de floresta primária. Esta espécie, conforme indicam Carvalho (1992), Oliveira (1995) e Vieira (1996) pertencem ao grupo ecológico das espécies pioneiras, e segundo a classificação proposta por Finegan (1992) ao grupo das heliófilas duráveis.

\section{b) Densidade}

Em cinco anos de acompanhamento em Marituba, a espécie $P$. longipendula teve redução de 52,8\% na densidade absoluta e P. guianensis, 19,1\% (Anexo B). Em Bragança, M. bracteata perdeu 25,5\% dos indivíduos da população (Anexo C).

As espécies do gênero Pourouma, mais importantes em Marituba, são espécies pioneiras e estão presentes desde as fases iniciais do processo de colonização aos estágios mais avançados em determinadas áreas. Esse fato foi constatado num trabalho de cronosequência com florestas secundárias de 6, 17 e 30 anos na área da CEPLAC de Marituba-PA (Jardim et al., 1997), onde foram encontradas espécies desse gênero nas três áreas, nas quais, passaram a ser dominantes a partir da área de 17 anos. Os mesmos autores encontraram indivíduos de $P$. guianensis somente nas classes de DAP maior que $20 \mathrm{~cm}$ nas capoeiras de 17 e 30 anos. No presente estudo essa espécie está bem distribuída em todas as classes diamétricas em ambos os levantamentos.

Das 185 espécies encontradas em Marituba em 1997, 39,0\% possuíam apenas um indivíduo. Em 2002, esse valor foi de 40,5\% das 200 amostradas. Estas espécies representavam apenas 5,7\% do total de indivíduos em 1997 e 6,8\% em 2002 (Anexo B). Em Bragança, as espécies menos representativas da área, eram equivalentes a 25,7\% do total e $2 \%$ do total de indivíduos amostrados nos dois levantamentos (Anexo C). 


\section{c) Dominância}

A área basal total para a floresta de Marituba, ou seja, a dominância absoluta foi de $27,4 \mathrm{~m}^{2} /$ ha em 1997 e 28,2 $\mathrm{m}^{2} /$ ha em 2002, o que representa um aumento de $0,16 \mathrm{~m}^{2} / \mathrm{ha} /$ ano. Em Bragança, esses valores foram menores, $16,9 \mathrm{~m}^{2} / \mathrm{ha}$ na primeira medição e $17,3 \mathrm{~m}^{2} /$ ha três anos depois, com incremento médio de $0,13 \mathrm{~m}^{2} / \mathrm{ha} /$ ano.

Crow (1980) encontrou área basal equivalente a $35,7 \mathrm{~m}^{2} /$ ha para uma floresta de 33 anos com histórico semelhante à área de Marituba. Em uma floresta secundária de 35 anos proveniente de área agrícola do Nordeste do Pará, Santana (2000) encontrou $13,4 \mathrm{~m}^{2} /$ ha. No trabalho realizado por Vieira (1996) na mesma região, foram encontrados $13,0 \mathrm{~m}^{2} /$ ha de área basal para uma capoeira antiga de 40 anos. Oliveira, L. (1997), em Belterra-PA, encontrou $18,9 \mathrm{~m}^{2} /$ ha para uma capoeira antiga de 50 anos.

Comparando os dados anteriores com os do presente trabalho, fica claro que nas áreas provenientes de agricultura os valores são semelhantes e sua variação pode ser explicada pela idade do povoamento. Por outro lado, a floresta secundária de Marituba que não é proveniente de área agrícola, apresenta área basal equivalente a florestas primárias. Por exemplo, Carvalho (1992) encontrou área basal de $30,7 \mathrm{~m}^{2}$ ha para uma floresta primária em Santarém e Vieira (1996) $25,0 \mathrm{~m}^{2} / \mathrm{ha}$ em um fragmento de floresta primária do Nordeste do Pará.

$\mathrm{Na}$ área de Marituba, entre as espécies com maior dominância relativa em 1997, Piptadenia suaveolens e Eschweilera coriacea apresentaram maior aumento entre as duas medições e a maior diminuição foi de P. longipendula (56,7\%) (Figura 17a).

Os números apresentados confirmam as observações feitas em campo, onde foi constatada a presença de grande quantidade de indivíduos de médio e grande porte $(25 \mathrm{~cm}$ a $40 \mathrm{~cm}$ de DAP) da espécie $P$. longipendula mortos ou severamente danificados. Este fato indica, que provavelmente estes indivíduos estejam em fase de senescência e, por força dos processos competitivos, comuns a povoamentos secundários, estão sendo substituídos por espécies de estágios sucessionais posteriores.

A espécie com maior destaque em dominância relativa entre os três anos de acompanhamento na área de Bragança foi Tapirira guianensis, embora tenha sido a 
terceira espécie em número de indivíduos. Essa espécie costuma dominar povoamentos secundários no Nordeste paraense, como comprovam os trabalhos de Santana (2000) e Vieira (1996). Na floresta de Bragança, as espécies que apresentaram maior redução na área basal entre os períodos analisados foram Sclerolobium chrysophylum, Myrcia bracteata e Croton matourensis (Figura 17b). Enquanto S. chrysophylum e C. matourensis apresentaram maiores perdas nas classes maiores que $20 \mathrm{~cm}$ de diâmetro, $M$. bracteata teve maior mortalidade dos indivíduos menores que $15 \mathrm{~cm}$ de diâmetro. Para o primeiro caso, é clara a força do controle genético sobre o tempo de vida dessas espécies e a menor densidade da madeira (Lieberman et al., 1985), e para M. bracteata, a competição por luz tem determinado esse comportamento. Estas espécies apresentaram tendência de saída da atual fase de sucessão, dando lugar a espécies de fases mais avançadas do processo de sucessão.

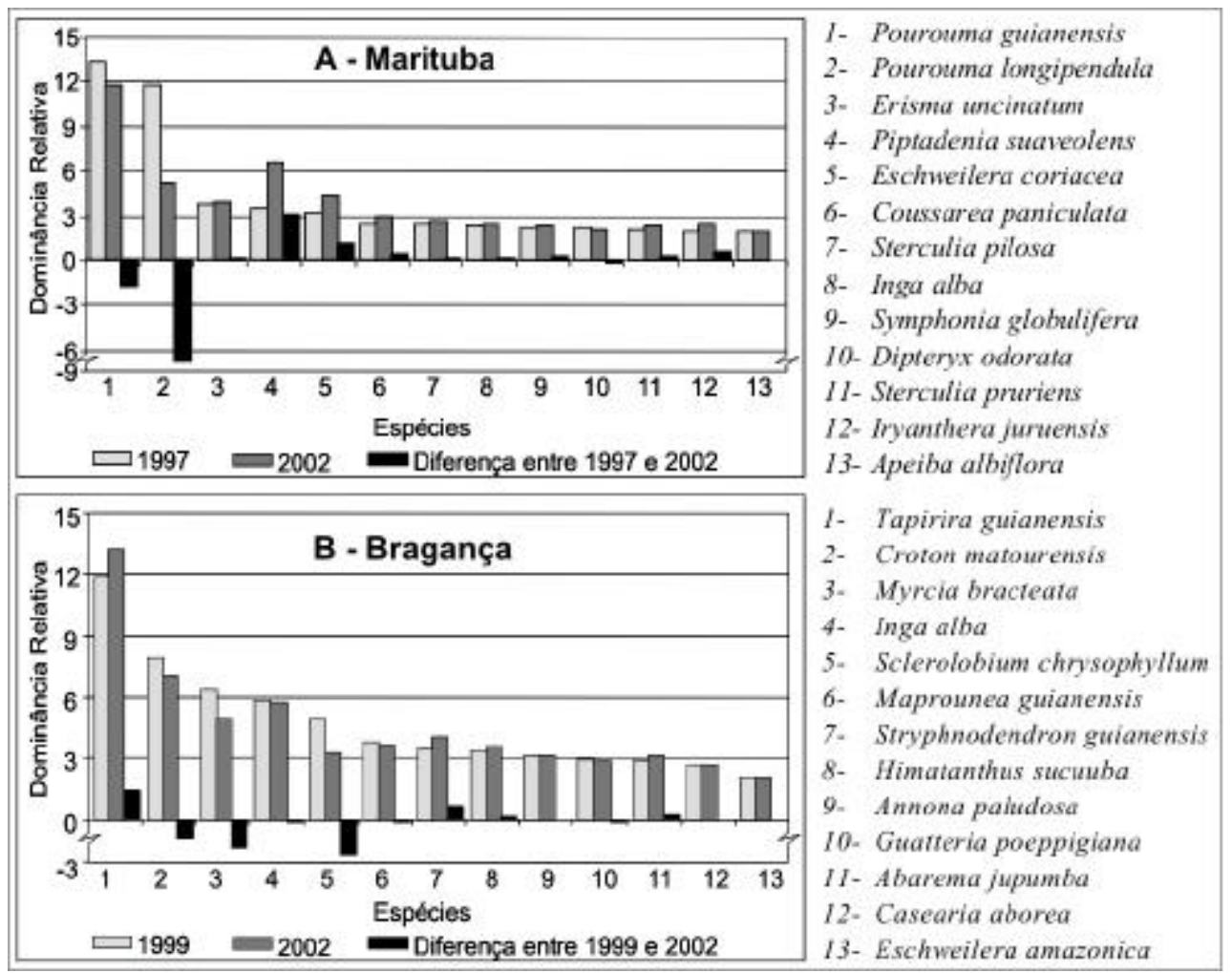

Figura 17 - Dominância Relativa para as principais espécies encontradas nos levantamentos realizados em parcelas permanentes de duas florestas secundárias antigas em Marituba e Bragança-PA 
As principais espécies dominantes $\mathrm{em}$ ambas as áreas, $(P$ guianensis, $P$. longipendula, Apeiba albiflora, Miconia surinamensis e Inga alba em Marituba e T. guianensis, C. matourensis, Guatteria poeppigiana e S. chrysophylum em Bragança) são agressivas no que se refere a ocupação do espaço físico, normalmente são adaptadas a ambientes de baixa fertilidade com altas taxas de luminosidade, produzem grandes quantidades de sementes pequenas de fácil dispersão e são consideradas espécies heliófilas pioneiras (Budowski, 1965).

Entre as treze espécies mais dominantes somente I. alba está presente em ambas áreas, e sua dominância na área de Marituba (Figura 17a) é aproximadamente o dobro da apresentada em Bragança (Figura 17b). A dominância dessa espécie é confirmada nos trabalhos de Santana (2000) em capoeira de 35 anos e por Vieira (1996) numa floresta secundária de 40 anos e em floresta primária.

\section{d) Distribuição nas Classes diamétricas}

A Figura 18 apresenta a distribuição das árvores por classes diamétrica para a área de Marituba. No primeiro levantamento 53,4\% dos 1.257 indivíduos estavam presentes na primeira classe de diâmetro, cinco anos depois esse percentual passou para 56,3\% dos 1.206 indivíduos. Pode-se observar também que a medida que aumenta o diâmetro diminui a participação dos indivíduos nas classes.

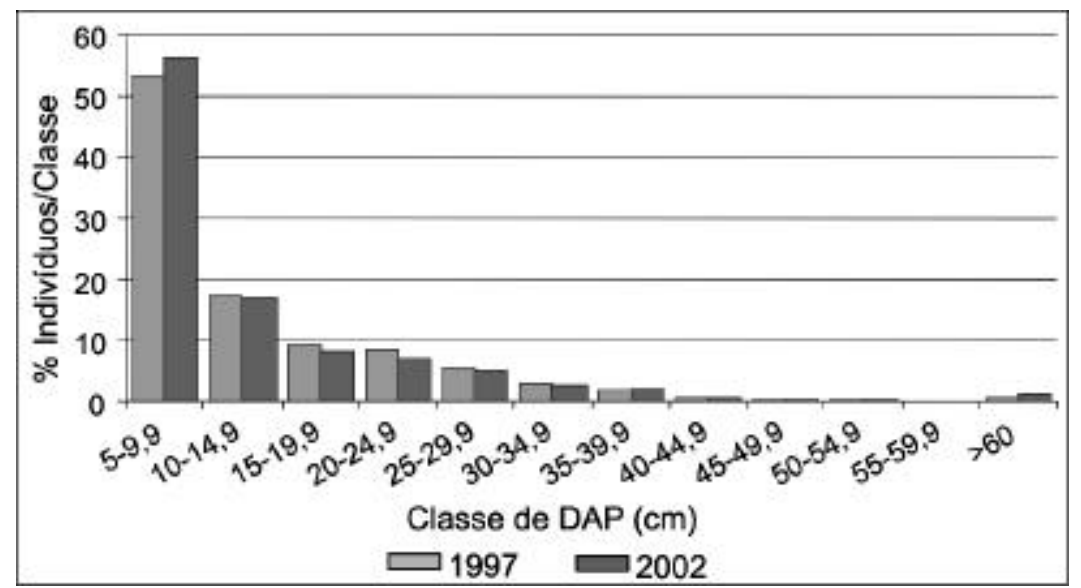

Figura 18 - Distribuição em classes de DAP do percentual de plantas encontradas nos levantamentos de 1997 e 2002 de uma floresta secundária antiga em área da CEPLAC de Marituba-PA 
As Classes situadas entre 10 e 39,9cm apresentaram diminuição do número de indivíduos ao longo do período analisado, por outro lado, a primeira classe de DAP e as superiores a 40 apresentaram aumento (Figura 18).

$\mathrm{Na}$ área de Bragança, a primeira classe de diâmetro continha aproximadamente 68,0\% das árvores nas duas ocasiões de medição em 1997 e 2002 (1.819 e 1.707 indivíduos, respectivamente).

Ao contrário do que ocorreu em Marituba, houve diminuição do percentual de indivíduos somente na segunda classe $(10-14,9 \mathrm{~cm})$, nas demais foi observada uma discreta elevação (Figura 19).

Das 570 árvores com DAP acima de $10 \mathrm{~cm}$ em Bragança por ocasião da primeira medição, 81,0\% estavam entre 10 e $20 \mathrm{~cm}$ de diâmetro, em 2002 a percentagem diminuiu para 77,4\%. Para Marituba, o percentual de indivíduos entre 10 e 19,9cm para os dois períodos analisados foi de aproximadamente 57,0\%. Considerando a mesma classe diamétrica, Vieira (1996) encontrou 76,7\% para uma floresta secundária de 40 anos. Isso mostra que a área de Bragança apresenta uma distribuição de indivíduos similar às demais florestas secundárias de mesma origem.

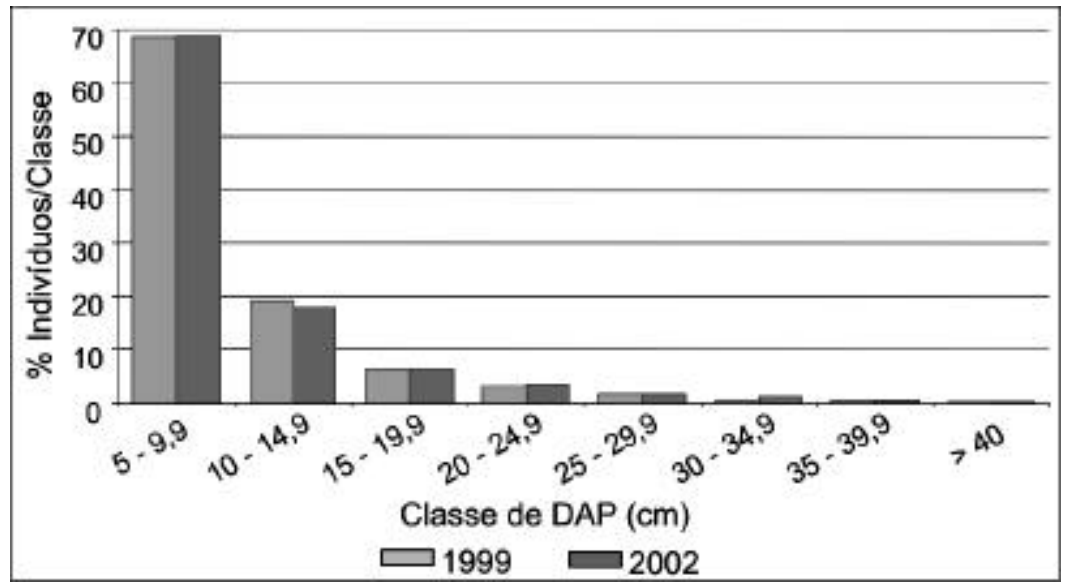

Figura 19 - Distribuição em classes de DAP do percentual de plantas encontradas nos levantamentos de 1999 e 2002 de uma floresta secundária antiga em Bragança-PA

O comportamento apresentado para a distribuição diamétrica das duas áreas estudadas (Figuras 18 e 19), segue o padrão de "J invertido", normalmente encontrado em povoamentos naturais (Hartshorn, 1978). Essa distribuição garante que o processo 
dinâmico da floresta se perpetue, pois a morte de indivíduos grandes, geralmente por senescência, dá lugar ao desenvolvimento de indivíduos jovens (Longhi, 1980).

Em Marituba a espécies Mabea caudata está presente somente na primeira classe de diâmetro $(5-9,9 \mathrm{~cm})$ com cerca de 20 indivíduos. Além desta espécie, outras como Bellucia glossularioides, Myrcia deflexa, Neea glomeruliflora, Terminalia amazônica, Guatteria poeppigiana, Inga auristellae, Parkia multijuga e Tovomita brevistaminea apresentam o mesmo comportamento, embora tenham poucos indivíduos (Anexo B). Por outro lado, várias espécies estão distribuídas em todas as classes de diâmetro (Vochysia vismiaefolia, Eschweilera coriacea, Piptadenia suaveolens, Sterculia pilosa, Erisma uncinatum, Inga alba e Dipteryx odorata). Um outro grupo de espécies como Cecropia sciadophylla, Saccoglottis amazônica, Ormosiopsis flava, Ormosia paraensis, Ampelocera edentula, Inga gracilifolia, Carapa guianensis e Chaunokiton kapleri, apresentam indivíduos somente nas maiores classes de diâmetro $(\geq 20 \mathrm{~cm})$.

Em Bragança, as principais espécies exclusivas da menor classe de diâmetro foram Pilocarpus sp., Myrciaria tenella, Ambelania acida, Lacistema pubescens, Lacistema aggregatum, Gustavia augusta e Myrciaria sp. Por outro lado, as espécies que estão presentes somente nas classes acima de $20 \mathrm{~cm}$ foram: Byrsonima crispa, Abarema jupumba, Pterocarpus amazonicus e Symphonia globulifera (Anexo C).

$\mathrm{Na}$ menor classe diamétrica $(5-9,9 \mathrm{~cm})$, em ambas as áreas, são encontrados tanto indivíduos regenerantes de espécies do dossel que passam por esse ambiente, quanto espécies exclusivas da submata.

As espécies que estão presentes somente no dossel (DAP $\geq 20 \mathrm{~cm}$ ) das duas florestas estudadas, provavelmente têm sua regeneração impedida pela falta de condições ambientais adequadas, uma vez que essas espécies demandam luz direta para germinação de seus propágulos, e no atual estágio de desenvolvimento o dossel apresenta-se parcialmente fechado e as clareiras abertas pela queda de árvores não criam condições satisfatórias para permitir a regeneração dessas espécies.

Entre as espécies distribuídas em todas as classes de DAP, nessa área destacaramse as espécies, classificadas segundo Finegan (1992), como heliófilas duráveis, ou seja, aquelas demandantes de luz que persistem no povoamento por longos períodos, são elas: 
Simarouba amara, Tapirira guianensis, Sclerolobium chrysophyllum, Inga alba, Terminalia amazônica, Himatanthus sucuba e Ocotea guianensis (Anexo C).

\subsection{Descritores de regeneração}

\section{a) Taxa de incremento periódico anual (IPA)}

A média anual de incremento entre 1997-2002 para a comunidade estudada em Marituba, considerando todas as árvores, foi de 0,23cm/ano (Tabela 6). Para Bragança, o incremento médio anual, entre os anos de 1999 e 2002, para todas as árvores foi de $0,25 \mathrm{~cm} /$ ano (Tabela 7).

$\mathrm{Na}$ área de Marituba, o crescimento médio anual das árvores sem rebrotos ou danos $(\mathrm{CIF}=111)$ foi muito próximo ao crescimento do conjunto total de árvores da comunidade (Tabela 6).

Tabela 6. Crescimento anual em diâmetro nos períodos de acompanhamento, por Classes de Identificações de Fuste (CIF - Figura 11) e para o número total de árvores numa floresta secundária oriunda de exploração de madeira para lenha, no município de Marituba-PA

\begin{tabular}{|c|c|c|c|c|c|c|c|}
\hline \multirow{2}{*}{$\begin{array}{l}\text { Código de CIF- } \\
\text { (Fig. 11) }\end{array}$} & \multirow{2}{*}{$\begin{array}{l}\text { Classe de Identificação do } \\
\text { Fuste }\end{array}$} & \multicolumn{2}{|c|}{$\begin{array}{c}1^{\circ} \text { Período } \\
\text { (1997-2001) }\end{array}$} & \multicolumn{2}{|c|}{$\begin{array}{l}2^{\circ} \text { Peníodo } \\
(2001-2002)\end{array}$} & \multicolumn{2}{|c|}{$\begin{array}{c}\text { Total } \\
(1997-2002)\end{array}$} \\
\hline & & $\mathbf{N}^{\circ}$ Arv & cm/ano & $\mathbf{N}^{0}$ Arv & cm/ano & $\mathbf{N}^{0}$ Arv & cm/ano \\
\hline$\overline{\text { Todos os CIF }}$ & Todas as árvores & 1.058 & 0,24 & 1.062 & 0,21 & 984 & 0,23 \\
\hline 111 & Árv. Sem rebroto aparente & 1.002 & 0,24 & 973 & 0,22 & 897 & 0,24 \\
\hline $101,102,103$ & Árv. Com rebroto aparente & 35 & 0,34 & 33 & 0,22 & 32 & 0,31 \\
\hline 112,113 & Árv. Quebradas (decapitadas) & 8 & 0,07 & 8 & 0,03 & 8 & 0,04 \\
\hline
\end{tabular}

$\mathrm{Na}$ área de Bragança, o crescimento médio anual das árvores sem rebrotos ou danos foi superior em todos os períodos, quando comparados as demais classificações de fuste (Tabela 7).

Em ambas áreas, as menores taxas de crescimento médio anual foram apresentadas pelas árvores quebradas ou decapitadas (Tabelas 6 e 7). Esses danos severos restringem o crescimento diamétrico das árvores pela redução da superfície fotossintética. Vidal et al. (2002), analisando o efeito das técnicas de exploração em florestas naturais no 
crescimento de árvores remanescentes, encontrou que as árvores severamente danificadas apresentam crescimento 2 vezes menor do que as árvores sem danos.

As taxas de incremento periódico anual em diâmetrto, apresentadas pelas espécies que tiveram indivíduos com rebroto aparente, foram diferentes entre as duas florestas secundárias estudadas, 0,31 cm/ano para Marituba e 0,20 cm/ano para Bragança (Tabelas 6 e 7). A estratégia de rebrotação é uma das respostas das espécies aos distúrbios provocados, principalmente, por atividades antrópicas. Em Bragança, onde as intervenções antrópicas foram mais acentuadas, com vários ciclos de corte e queima e variados tratos culturais, a percentagem de indivíduos rebrotantes foi de 23,0\%, enquanto em Maruituba, apenas 3,2\% dos indivíduos apresentaram rebrotos.

Essa característica é mais comum em espécies (não-pioneiras) pertencentes a estádios mais avançados do processo de sucessão (Putz \& Brokaw, 1989). Em Marituba, $75 \%$ das espécies rebotantes foram classificadas como tolerantes, entre as quais destacaram-se Virola melinonii, Schefflera morototoni, Sclerolobium paraense, Ambelania acida, Eschweilera coriacea e Licania densiflora. Para Bragança, 53\% das rebrotantes eram espécies tolerantes e $37 \%$ pioneiras, as demais não tiveram classificação definida. Nessa área destacaram-se, Terminalia amazônica, Croton matourensis, Saccoglottis amazônica, Eschweilera parvifolia, Eschweilera idatimon, Inga Alba, Tapirira guianensis e Inga rubiginosa com as maiores taxas de crescimento.

Tabela 7. Crescimento anual em diâmetro nos períodos de acompanhamento, por Classes de Identificações de Fuste (CIF - Figura 11) e para o número total de árvores numa floresta secundária antiga oriunda de agricultura de corte e queima no município de Bragança-PA

\begin{tabular}{|c|c|c|c|c|c|c|c|c|c|}
\hline \multirow{2}{*}{$\begin{array}{l}\text { Código de } \\
\text { CIF-(Fig. 11) }\end{array}$} & \multirow{2}{*}{$\begin{array}{c}\text { Classe de Identificação do } \\
\text { Fuste }\end{array}$} & \multicolumn{2}{|c|}{$\begin{array}{r}1^{\circ} \text { Período } \\
(1999-2000)\end{array}$} & \multicolumn{2}{|c|}{$\begin{array}{r}\mathbf{2}^{\mathbf{o}} \text { Período } \\
(2000-2001)\end{array}$} & \multicolumn{2}{|c|}{$\begin{array}{c}3^{\circ} \text { Período } \\
(2001-2002)\end{array}$} & \multicolumn{2}{|c|}{$\begin{array}{c}\text { Total } \\
(1999-2002)\end{array}$} \\
\hline & & $\mathbf{N}^{0}$ Arv & cm/ano & $\mathbf{N}^{0}$ Arv & cm/ano & $\mathbf{N}^{\circ}$ Arv & cm/ano & $\mathbf{N}^{0}$ Arv & cm/ano \\
\hline Todos os CIF & Todas as árvores & 1.156 & 0,34 & 1.661 & 0,26 & 1.376 & 0,19 & 1.206 & 0,25 \\
\hline 111 & Árv. Sem rebroto aparente & 837 & 0,36 & 1.166 & 0,28 & 936 & 0,22 & 846 & 0,28 \\
\hline $101,102,103$ & Árv. Com rebroto aparente & 259 & 0,27 & 405 & 0,21 & 344 & 0,15 & 281 & 0,20 \\
\hline 112,113 & Árv. Quebra. (decapitadas) & 37 & 0,10 & 89 & 0,08 & 51 & 0,12 & 23 & 0,09 \\
\hline
\end{tabular}

De maneira geral, as taxas de incremento periódico anual em diâmetro apresentadas na área de Bragança foram maiores do que na área de Marituba, em todas as classes de diâmetro, exceto a primeira $(5-9,9 \mathrm{~cm})$. Isso provavelmente se deve ao fato 
de que a área de Bragança possui dossel mais aberto e mais baixo, e que tal diferença pode ser atribuída, entre outros fatores, ao tipo de perturbação sofrida por essa área, pois o corte raso seguido de queima, pode ter favorecido um desenvovimeto mais uniforme dos representates das espécies que hoje formam o dossel dessa floresta. Estas características podem estar favorecendo a maior entrada de luz e conseqüentemente, o maior crescimento das árvores com diâmetro acima $10 \mathrm{~cm}$, aumentando assim, a competição na menor classe (Figura 20).

Comparando-se as médias de crescimento dos períodos (Figura 21a e 21b), observou-se, principalmente na área de Bragança, que esta taxa apresentou uma diminuição constante ao longo dos períodos analisados. Esse comportamento também foi encontrado por Felfili (1995) em florestas de galeria em Brasília, por Gomide et al. (2002) em florestas secundárias jovens no Amapá, por Ferreira et al. (1998) em florestas secundárias em Minas Gerais e Swaine et al. (1987b) em florestas naturais primárias no Kade em Ghana. Esse comportamento se deve provavelmente æ̀ variações ambientais e, principalmente ao aumento da competição entre as espécies (Swaine et al., 1987b).

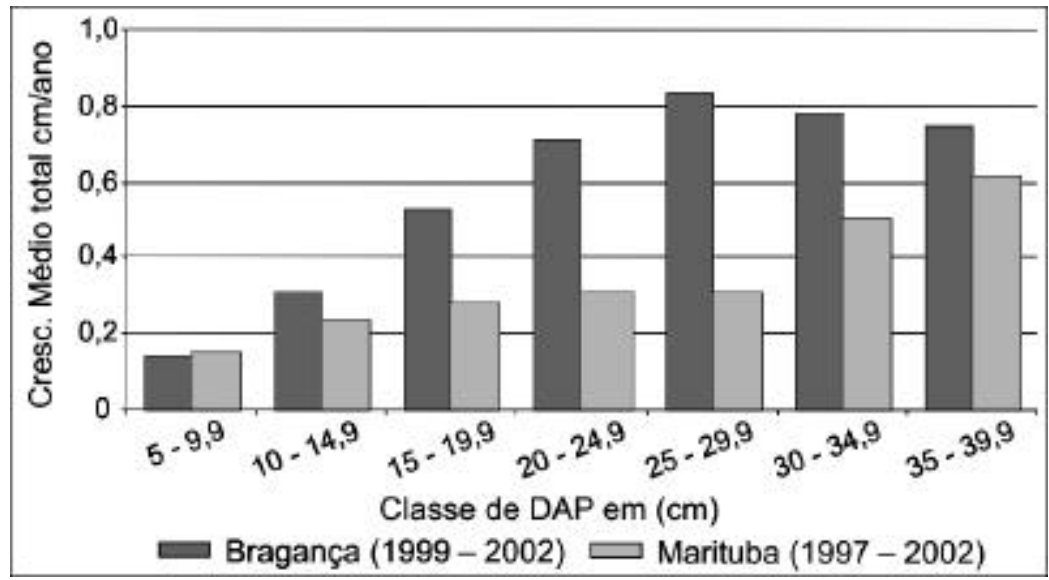

Figura 20 - Crescimento médio anual em diâmetro por classe de DAP em duas florestas secundárias antigas de Marituba e Bragança-PA

Tanto na área de Marituba quanto em Bragança, as menores médias de crescimento estão entre as menores classes de diâmetro em todos períodos analisados. A maior média de crescimento foi alcançada pelas árvores com até $35 \mathrm{~cm}$ de diâmetro (Figura 21a e 21b). 
O aumento das taxas de incremento nas maiores classes de diâmetro também foi observado por Ferreira et al. (1998), Oliveira, L. (1997), Felfili(1995), Swaine et al. (1987b) e para algumas parcelas estudadas por Bertani (2000). Uma das explicações para esse comportamento, é que a menor ou maior quantidade de luz recebida pelas copas pode determinar as diferenças nas taxas de crescimento, favorecendo assim as árvores maiores (Silva, 1989; Clark et al., 1993) que estão menos sujeitas a competição por luz e apresentam maior produtividade primária devido ao volume de suas copas (Swaine et al., 1987b).
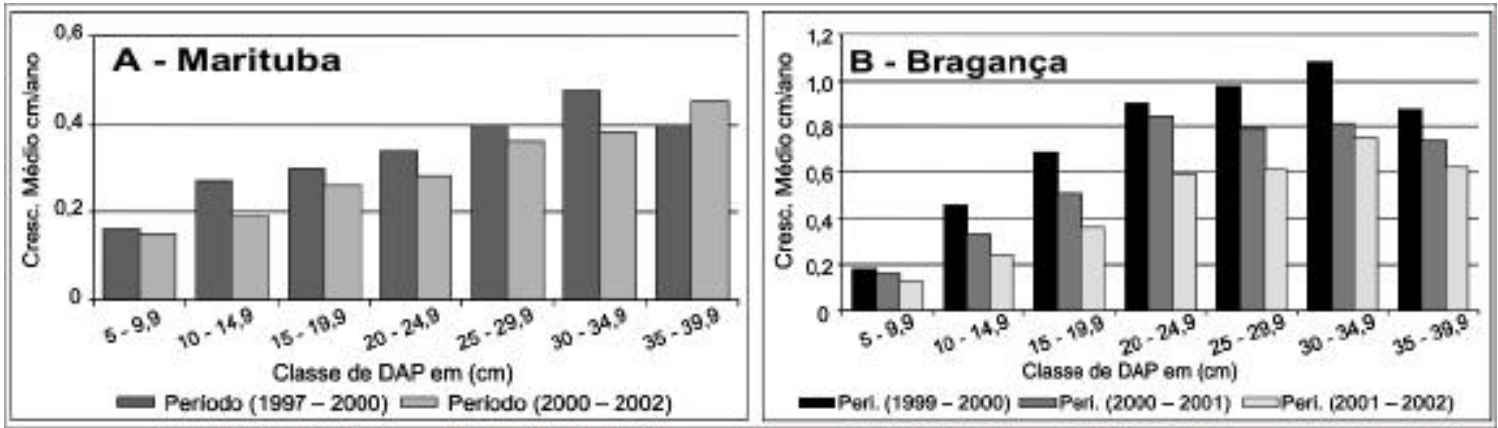

Figura 21 - Crescimento médio anual em diâmetro por período e por classe de DAP em duas florestas secundárias antigas de Marituba e Bragança-PA

A Figura 22 apresenta a comparação entre as espécies com maior crescimento médio anual para as duas áreas estudadas.

A espécie Piptadenia suaveolens apresentou a maior média de incremento periódico anual para o período na área de Marituba (Figura 22a). Em Bragança a espécie que se destacou foi Simarouba amara (Figura 22b). Ambas espécies são classificadas como pioneiras (Oliveira, 1995). Enquanto em Bragança apenas uma espécie (S. amara) se destacou das demais, em Marituba, a diferença entre as taxas de crescimento da espécie $P$. suaveolens, Inga alba e as demais, apresentou decréscimo mais gradual.

Somente a espécie I. alba destacou-se entre as que mais crescem nas duas áreas. Esta espécie está distribuída em todas as classes diamétricas, e suas maiores taxas de crescimento são apresentadas pelas árvores nas maiores classes de diâmetro. 


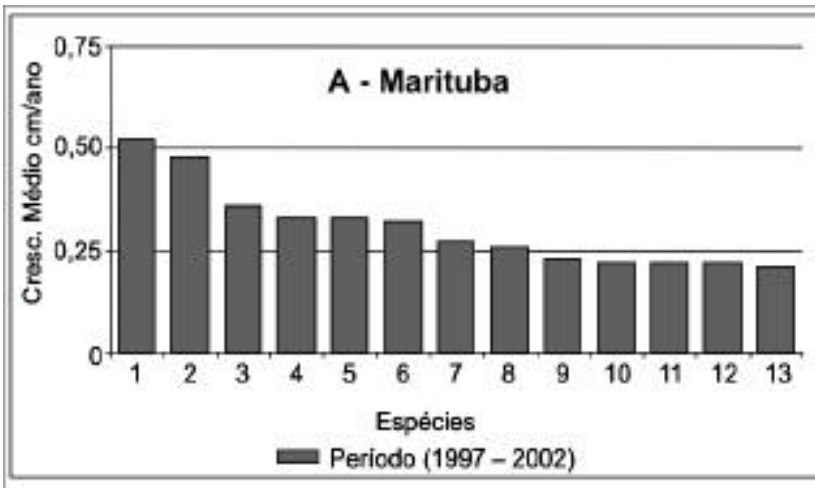

1- Piptadenia suaveolens

2- Inga alba

3- Vochysia grianensis

4- Miconia surinanensis

5- Symphonia globulifera

6. Pourouma grianensis

7- Protism pallidum

8- Palicourca guianensis

9- Pourouma longipendula

10- Iryanthera juriensis

11- Coussarea paniculata

12- Inga capitata

13- Apeiba albiflora

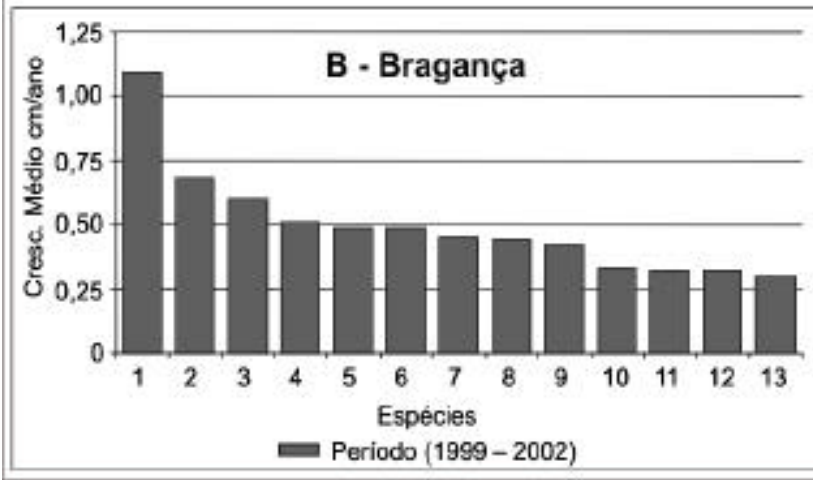

1- Sinarouba amara

2. Siryphnodendron guianensis

3. Byrsanima densa

4. Tapirira gwianensis

5. Crotan matourensis

6- Sclerolobium chrysophyllum

7- Inga alba

8- Terminalia amazonica

9. Myrcia atramentifena

10. Ouratea castaneaefolia

11- Saccoglottis amazónica

12- Inga rubiginasa

13. Annona paludosa

Figura 22 - Espécies que apresentaram os maiores valores de incremento médio anual em diâmetro em duas florestas secundárias antigas de Marituba e Bragança-PA

Das espécies que apresentaram as maiores taxas de IPA (Figuras 22a e 22b), 62,0\%, na área de Marituba também apresentaram os maiores valores de dominância (Figura 17a), para Bragança (Figura 17b) essa relação foi menor, cerca de 46,0\%. Isso conirmou que as espécies mais dominantes apresentaram maior taxa de incremento em diâmetro.

\section{b) Taxas de Ingresso e Mortalidade}

O número ingresso e mortalidade e as taxas anuais encontradas em cada período analisado e para o período total nas parcelas de Marituba e Bragança, estão apresentadas nas Tabelas 8 e 9, respectivamente. 
Tabela 8. Taxas anuais de ingresso e mortalidade nos períodos de acompanhamento em uma floresta secundária oriunda de exploração de madeira para lenha, no município de Marituba-PA

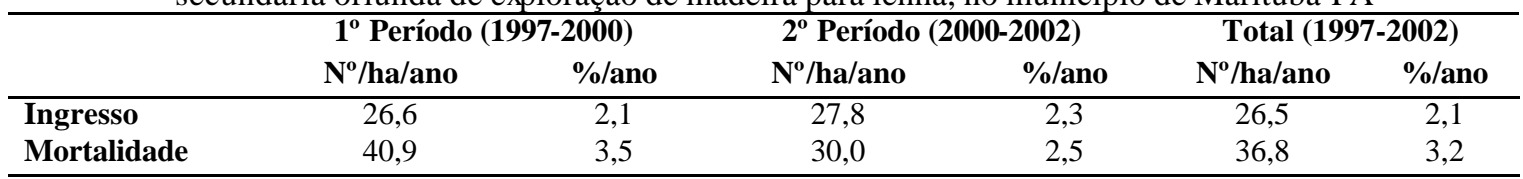

No/ha/ano: número de árvores mortas ou que ingressaram no período/n ${ }^{\circ}$ de anos do intervalo; (\% ingresso): percentagem anual de ingressos $=$ percentagem do montante de árvores vivas no primeiro período $/ \mathrm{n}^{\circ}$ de anos do intervalo; (\% mortalidade): percentagem anual de mortalidade segundo o modelo logarítmico proposto por Swaine \& Lieberman (1987).

A floresta secundária de Marituba apresentou balanço negativo em todos os períodos analisados. Entre a primeira e a última medição a mortalidade anual foi 1,4 vez superior ao número anual de ingressos (Tabela 8). As elevadas taxas de mortalidade se devem principalmente às espécies pioneiras Pourouma longipendula e Pourouma guianensis que apresentaram alta densidade no povoamento e tiveram mortalidade de 12,2 e 4,0 indivíduos/ha/ano, respectivamente. Apesar desse balanço negativo, a área basal apresentou incremento médio de $0,16 \mathrm{~m}^{2} / \mathrm{ha} / \mathrm{ano}$ (Anexo B), e o aumento na riqueza específica foi de 3,8 espécies por ano (Tabela 1).

Em Bragança o balanço entre ingresso e mortalidade também foi negativo, sendo o número de indivíduos mortos por ano, 2,7 vezes superior ao número de ingressantes (Tabela 9). As espécies que mais contribuíram para essa elevada mortalidade foram Myrcia bracteata, Guatteria poeppigiana e Casearia arborea com 12,0, 5,0 e 4,0 indivíduos mortos/ha/ano, respectivamente. As três espécies são consideradas pioneiras, muito comuns em povoamentos secundários do Nordeste do Pará. Essa perda de densidade foi acompanhada pelo aumento de $0,13 \mathrm{~m}^{2} / \mathrm{ha} /$ ano (Anexo C) na área basal e pelo incremento de 1,0 espécie por ano (Tabela 1).

As taxas de ingresso para a floresta de Marituba tiveram pouca variação mantendo-se em torno de $2,0 \%$ ao longo dos períodos analisados. As taxas de mortalidade, calculadas com base no modelo logarítmico (Swaine \& Lieberman, 1987), mostraram que o primeiro período teve mortalidade superior ao último período (Tabela 8).

Para a área de Bragança as taxas de ingressos e mortalidades, foram mais distintas no segundo período, onde a mortalidade foi cerca de 5 rezes maior do que o ingresso. 
Enquanto para os demais períodos e para o total, a mortalidade foi aproximadamente 2 vezes maior que a taxa de ingresso (Tabela 9). Essas diferenças ficaram mais evidentes com os valores de densidade, que teve redução de $2,0 \%$ ao ano para Bragança e de $0,8 \%$ ao ano para Marituba (Tabela 1).

O balanço negativo obtido para as áreas do presente estudo é contrastante com as taxas de 5,9\% para ingresso e 4,7\% para mortalidade (não logaritmizadas), encontrada por Oliveira, L. (1997), quando analisou dados referentes a 10 anos de acompanhamento de uma floresta secundária antiga em Belterra-PA.

Tabela 9. Taxas anuais e números totais de ingresso e mortalidade nos períodos de acompanhamento em uma floresta secundária antiga oriunda de agricultura de corte e queima no município de Bragança-PA

\begin{tabular}{lcccccccc}
\hline & \multicolumn{2}{c}{$\mathbf{1}^{\mathbf{o}}$ Período (1999-2000) } & \multicolumn{2}{c}{$\mathbf{2}^{\mathbf{o}}$ Período (2000-2001) } & \multicolumn{2}{c}{$\mathbf{3}^{\mathbf{o}}$ Período (2001-2002) } & \multicolumn{2}{c}{ Total (1999-2002) } \\
& $\mathbf{N}^{\mathbf{o}}$ /ha/ano & \%/ano & $\mathbf{N}^{\mathbf{o}}$ /ha/ano & \%/ano & No/ha/ano & \%/ano & $\mathbf{N}^{\mathbf{o}} / \mathbf{h a} / \mathbf{a n o}$ & \%/ano \\
\hline Ingresso & 30,0 & 1,6 & 7,0 & 0,4 & 35,0 & 1,8 & 22,7 & 1,2 \\
Mortalidade & 61,0 & 3,4 & 39,0 & 2,2 & 84,0 & 4,9 & 61,3 & 3,6 \\
\hline
\end{tabular}

No/ha/ano: número de árvores mortas ou que ingressaram no período/n ${ }^{\circ}$ de anos do intervalo; (\% ingresso): percentagem anual de ingressos $=$ percentagem do montante de árvores vivas no primeiro período $/ \mathrm{n}^{\circ}$ de anos do intervalo; (\% mortalidade): percentagem anual de mortalidade segundo o modelo logarítmico proposto por Swaine \& Lieberman (1987).

Em Bragança, atenção deve ser dada ao fato de que quanto maiores as taxas de mortalidade, tanto maiores são a taxas de ingresso (Tabela 9). Baseado em observações de campo e análise dos dados, isso pode ser explicado principalmente pela abertura no dossel da floresta, provocada pela queda de árvores senescentes de espécies como Croton matourensis, Guatteria poeppigiana, Sclerolobium chrysophyllum, Byrsonima densa e Byrsonima aerugo, com diâmetro a partir de $20 \mathrm{~cm}$, o que acaba favorecendo o melhor desenvolvimento de indivíduos mais jovens de espécies pertencentes a estádios seriais posteriores. 
Tabela 10. Espécies com maior número de ingressos no período de 19972002, em uma floresta secundária oriunda de exploração seletiva de madeira para lenha, no município de Marituba-PA

\begin{tabular}{lccc}
\hline \multicolumn{1}{c}{ Espécie } & No/ha & $\begin{array}{c}\text { Ingressos } \\
\text { No/ha/ano }\end{array}$ & $\mathbf{( \% )}$ \\
\hline Eschweilera coriacea & 11 & 2,1 & 7,9 \\
Coussarea paniculata & 7 & 1,3 & 5,0 \\
Pourouma longipendula & 7 & 1,3 & 5,0 \\
Mabea caudata & 7 & 1,3 & 5,0 \\
Theobroma subincanum & 5 & 1,0 & 3,6 \\
Virola michelii & 4 & 0,8 & 2,9 \\
Palicourea guianensis & 4 & 0,8 & 2,9 \\
Goupia glabra & 3 & 0,6 & 2,2 \\
Erisma uncinatum & 3 & 0,6 & 2,2 \\
Ambelania acida & 3 & 0,6 & 2,2 \\
Pourouma guianensis & 3 & 0,6 & 2,2 \\
Mabea paniculata & 3 & 0,6 & 2,2 \\
Ferdinandusa sp. & 3 & 0,6 & 2,2 \\
Sub-total & $\mathbf{6 3}$ & $\mathbf{1 2 , 0 0}$ & $\mathbf{4 5 , 3}$ \\
Demais espécies & $\mathbf{7 6}$ & $\mathbf{1 4 , 4 8}$ & $\mathbf{5 4 , 7}$ \\
Total & $\mathbf{1 3 9}$ & $\mathbf{2 6 , 5 0}$ & $\mathbf{1 0 0 , 0}$ \\
\hline
\end{tabular}

$\overline{\mathbf{N}} / \mathbf{h a}=$ Número total de indivíduos ingressantes; $\mathbf{N}^{\circ} / \mathbf{h a / a n o}=$ Número de indivíduos ingressantes/ano; $(\%)=$ percentagem do número total de ingressos.

A espécie responsável pela maior contribuição na taxa de ingresso em Marituba foi Eschweilera coriacea, seguida por Coussarea paniculata e Pourouma longipendula (Tabela 10). E em Bragança, as espécies Gustavia augusta, Myrciaria tenella e Pilocarpus sp., foram as que mais se destacaram (Tabela 11). Entre as espécies citadas nas duas áreas somente $C$. paniculata e $P$. longipendula são espécies consideradas pioneiras. A maior contribuição de espécies não-pioneiras indica que no atual estádio de desenvolvimento dessas florestas os eventos naturais favorecem o desenvolvimento de grupos de espécies que dominam as etapas mais avançadas da sucessão. 
Tabela 11. Espécies com maior número de ingressos no período de 19992002, em uma floresta secundária antiga oriunda de agricultura de corte e queima no município de Bragança-PA

\begin{tabular}{lccc}
\multicolumn{1}{c}{ Espécie } & No/ha & $\begin{array}{c}\text { Ingressos } \\
\text { No/ha/ano }\end{array}$ & $\mathbf{( \% )}$ \\
\hline Gustavia augusta & 5 & 1,7 & 7,1 \\
Myrciaria tenella & 5 & 1,7 & 7,1 \\
Pilocarpus sp. & 4 & 1,3 & 5,7 \\
Myrcia sp. 2 & 4 & 1,3 & 5,7 \\
Casearia arborea & 3 & 1,0 & 4,3 \\
Lacistema pubescens & 3 & 1,0 & 4,3 \\
Myrciaria sp. & 3 & 1,0 & 4,3 \\
Talisia guianensis & 3 & 1,0 & 4,3 \\
Cordia bicolor & 3 & 1,0 & 4,3 \\
Sub-total & $\mathbf{3 3}$ & $\mathbf{1 1 , 0}$ & $\mathbf{4 7 , 1 4}$ \\
Demais espécies & $\mathbf{3 7}$ & $\mathbf{1 2 , 3}$ & $\mathbf{5 2 , 8 6}$ \\
Total & $\mathbf{7 0}$ & $\mathbf{2 3 , 3}$ & $\mathbf{1 0 0 , 0 0}$ \\
\hline No/ha Número total de indivíduos
\end{tabular}

$\overline{\mathbf{N}^{\circ} / \mathbf{h a}=\text { Número total de indivíduos ingressantes; } \mathbf{N}^{\mathbf{0}} / \mathbf{h a / a n o}=\text { Número de indivíduos }}$ ingressantes/ano; $(\%)=$ percentagem do número total de ingressos.

O maior número de indivíduos mortos em Marituba foi apresentado pela espécie P. logipendula seguida por Pourouma guianensis, Miconia surinamensis e Palicourea guianensis, enquanto a maior taxa de mortalidade foi apresentada por Cecropia obtusa, a qual perdeu 22,4\% de seus indivíduos (Tabela 12). Esta espécie, segundo Gomide et al. (2002) é classificada como heliófila efêmera, comum em estágios iniciais de sucessão. Segundo estes autores, em capoeiras jovens, tal espécie começou a apresentar declínio de sua população após o quarto ano do processo de sucessão em uma área de capoeira jovem no Amapá.

Das 185 espécies existentes no primeiro levantamento (1997) em Marituba, 38,4\% apresentaram indivíduos ingressantes. Em Bragança, o percentual foi menor, 28,7\% das 136 espécies encontradas em 1999. Quanto às espécies que apresentaram mortalidade, em Marituba o percentual foi de 25,4\% e em Bragança 30,9\%. Estes resultados mostraram que há tendência de inversão dos valores relativos. Enquanto mais espécies contribuíram com o recrutamento em Marituba, em Bragança a maior percentagem de espécies contribuiu com a mortalidade. 
Tabela 12. Espécies que apresentaram maior mortalidade no período de 1997-2002, em uma floresta secundária oriunda de exploração de madeira para lenha, no município de Marituba-PA

\begin{tabular}{lrccr}
\multicolumn{1}{c}{ Espécies } & \multirow{2}{*}{$\mathbf{N}^{\mathbf{0}}$ Total } & \multicolumn{3}{c}{ Mortalidade } \\
& & $\mathbf{N}^{\mathbf{0}}$ Mort. & $\mathbf{N}^{\mathbf{0}}$ Rem. & \% Total \\
\hline Pourouma longipendula & 103 & 61 & 42 & 17,09 \\
Pourouma guianensis & 88 & 20 & 68 & 4,91 \\
Miconia surinamensis & 26 & 12 & 14 & 11,79 \\
Palicourea guianensis & 21 & 10 & 11 & 12,32 \\
Cecropia obtusa & 13 & 9 & 4 & 22,45 \\
Inga alba & 18 & 6 & 12 & 7,72 \\
Sterculia pilosa & 56 & 5 & 51 & 1,78 \\
Protium opacum & 32 & 4 & 28 & 2,54 \\
Goupia glabra & 19 & 4 & 15 & 4,50 \\
Inga sp.1 & 12 & 4 & 8 & 7,72 \\
Tapirira guianensis & 13 & 3 & 10 & 5,00 \\
Apeiba albiflora & 28 & 3 & 25 & 2,16 \\
Sub-total & $\mathbf{4 2 9}$ & $\mathbf{1 4 1}$ & $\mathbf{2 8 8}$ & $\mathbf{7 , 5 9}$ \\
Demais espécies & $\mathbf{3 7 3}$ & $\mathbf{4 3}$ & $\mathbf{3 3 0}$ & $\mathbf{2 , 3 3}$ \\
Total & $\mathbf{8 0 2}$ & $\mathbf{1 8 4}$ & $\mathbf{6 1 8}$ & $\mathbf{4 , 9 6}$ \\
\hline
\end{tabular}

$\mathbf{\mathbf { N }}^{\circ}$ total = Número de indivíduos da espécie na área; $\mathbf{N}^{\circ}$ Mort. = Número total indivíduos mortos da espécie; $\mathbf{N}^{\mathbf{0}} \mathbf{R e m} .=$ Número total de indivíduos sobreviventes e $\%$ Total $=$ percentagem média anual de mortalidade.

$\mathrm{Na}$ área estudada em Bragança, a maior mortalidade de indivíduos foi registrada para a espécie Myrcia bracteata, seguida por Guatteria poeppigiana, Casearia aborea, Croton matourensis e Maprounea guianensis e a maior taxa anual de mortalidade foi registrada para Inga edulis e Casearia decandra, ambas com taxa superior a $36 \%$ (Tabela 13).

Tabela 13. Espécies que apresentaram maior mortalidade no período de 1999-2002, em uma floresta secundária antiga oriunda de agricultura de corte e queima no município de Bragança-PA

\begin{tabular}{lcccc}
\hline \multicolumn{1}{c}{ Espécies } & $\mathbf{N}^{\mathbf{0}}$ Total & $\mathbf{N}^{\mathbf{o}}$ Mort. & $\begin{array}{c}\text { Mortalidade } \\
\mathbf{N}^{\mathbf{0}} \text { Rem. }\end{array}$ & \% Total \\
\hline Myrcia bracteata & 141 & 36 & 105 & 9,83 \\
Guatteria poeppigiana & 73 & 15 & 58 & 7,67 \\
Casearia arborea & 98 & 12 & 86 & 4,35 \\
Croton matourensis & 41 & 10 & 31 & 9,32 \\
Maprounea guianensis & 77 & 10 & 67 & 4,64 \\
Inga edulis & 13 & 9 & 4 & 39,29 \\
Tapirira guianensis & 92 & 8 & 84 & 3,03 \\
Annona paludosa & 53 & 8 & 45 & 5,45 \\
Inga alba & 53 & 7 & 46 & 4,72
\end{tabular}


Continua...

Tabela 13. Espécies que apresentaram maior mortalidade no período de 1999-2002, em uma floresta secundária antiga oriunda de agricultura de corte e queima no município de Bragança-PA

\begin{tabular}{|c|c|c|c|c|}
\hline \multirow{2}{*}{ Espécies } & \multirow{2}{*}{$\mathbf{N}^{\circ}$ Total } & \multicolumn{3}{|c|}{ Mortalidade } \\
\hline & & $\mathbf{N}^{o}$ Mort. & $\mathbf{N}^{\circ}$ Rem. & $\%$ Total \\
\hline Sclerolobium chrysophyllum & 27 & 7 & 20 & 10,00 \\
\hline Lacistema agregatum & 38 & 6 & 32 & 5,73 \\
\hline Byrsonima densa & 19 & 6 & 13 & 12,65 \\
\hline Casearia decandra & 6 & 4 & 2 & 36,62 \\
\hline Talisia guianensis & 52 & 4 & 48 & 2,67 \\
\hline Couratari oblongifolia & 15 & 3 & 12 & 7,44 \\
\hline Phyllanthus nobilis & 17 & 3 & 14 & 6,47 \\
\hline Myrcia atramentifera & 14 & 3 & 11 & 8,04 \\
\hline Abarema cochleata & 25 & 3 & 22 & 4,26 \\
\hline Cordia bicolor & 17 & 3 & 14 & 6,47 \\
\hline Sub-total & 871 & 157 & 714 & 6,63 \\
\hline Demais espécies & 266 & 27 & 239 & 3,57 \\
\hline Total & 1137 & 184 & 953 & 5,88 \\
\hline
\end{tabular}

Comparando as taxas de mortalidade por classes diamétrica (Figuras 23a e 23b), a área de Bragança mostrou-se superior somente nas duas primeiras classes. Em ambas as áreas, a taxa de mortalidade das espécies que estão entre 25 e $30 \mathrm{~cm}$ foi maior que as demais classes, ficando em torno de 8,0\%. Nessa classe de diâmetro, na área de Marituba predominou a mortalidade de indivíduos das espécies Schefflera morototoni, Eschweilera coriacea, Inga alba, Vochysia vismiaefolia, Pourouma guianensis e Pourouma longipendula. Em Bragança, o predomínio foi de Croton matourensis, Inga alba, Sclerolobium chrysophyllum, Byrsonima densa e Byrsonima aerugo, mostrando que as maiores taxas de mortalidade são atrtibuídas aos indivíduos senescentes, e que provavelmente isso seja função do controle genético sobre o tempo de vida e a menor densidade da madeira, que favorece as ações das intempéries (Lieberman et al., 1985). 


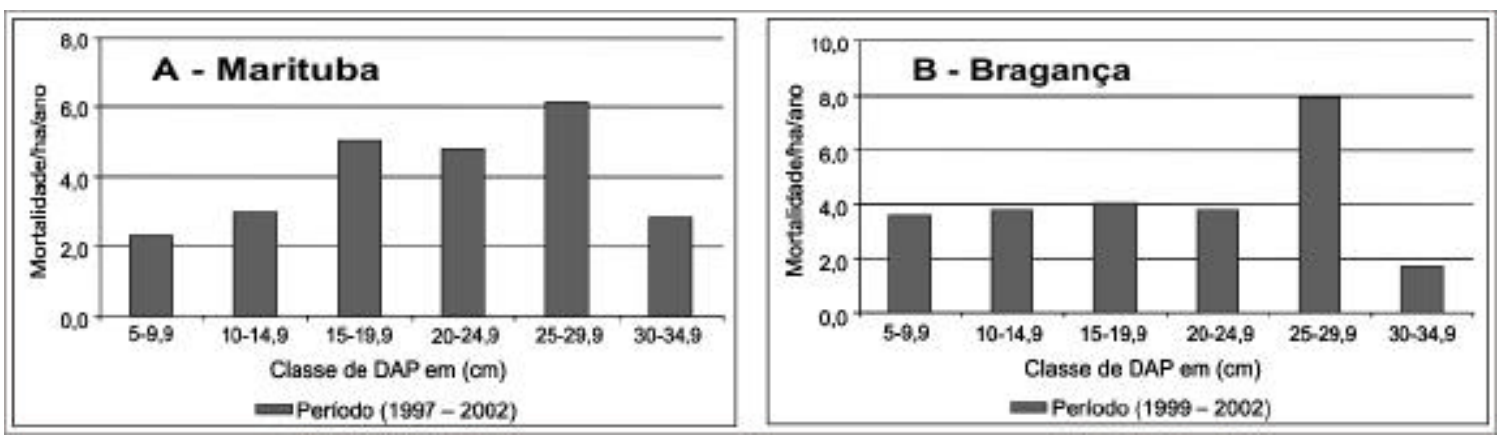

Figura 23 - Taxa de mortalidade anual nas classes diamétricas nos levantamentos realizados em parcelas permanentes de duas florestas secundárias antigas de Marituba e Bragança-PA

No atual estádio de sucessão em que se encontram os povoamentos analisados foi observada uma intensa dinâmica entre a entrada e a saída de indivíduos. $\mathrm{O}$ fato das taxas de mortalidade terem sido superiores as de ingresso, não significa que as comunidades estejam em declínio, pois esse comportamento é esperado para florestas secundárias antigas, onde a perda do número de indivíduos se dá, entre outros fatores, em função do aumento da área basal, processo definido por Brown \& Lugo (1990), como raleamento competitivo.

$\mathrm{Na}$ medida em que o processo sucessional avança, as taxas de entrada e saída de indivíduos tendem a diminuir aproximando-se de valores encontrados em florestas primárias. Por exemplo, Manokaran \& Kochummen (1987) encontraram taxas de ingresso de 1,4\%/ano e mortalidade de 2,0\%/ano em florestas naturais na Malaysia, e Swaine et al. (1987b), estudando por 12 anos uma floresta tropical úmida no Kade, em Ghana, encontrou taxas de ingresso de 1,3\%/ano e de 1,32\%/ano para mortalidade.

Considerando o período entre o primeiro e último levantamento, observou-se que a área de Bragança apresentou taxa de mortalidade maior do que a de Marituba. Por outro lado, a taxa total de ingresso foi maior em Marituba (Tabelas 8 e 9) assim como o maior incremento em área basal (Anexo B) e riqueza de espécies (Tabela 1). Essas diferenças em favor de Marituba podem ser atribuídas ao estádio mais avançado de sucessão, favorecido pela história específica do sítio que sofreu distúrbios menos severos (sem queima), além das dierenças entre as paisagens regionais (Figuras 7 e 8), que em Marituba, é mais favorável a manutenção da capacidade de resiliência, com a presença de fragmentos grandes e preservados de florestas primárias próximas. O grau 
de degradação de um ecossistema e a qualidade do seu entorno afetam sua capacidade de auto-renovação, e depende de fatores como freqüência, área e intensidade dos distúrbios a que foi submetido (Pickett, 1985; Martins \& Rodrigues, 2002).

\subsection{Análise dos atributos de fertilidade dos solos}

\section{a) Fertilidade}

A análise de fertilidade do solo das parcelas instaladas nas duas florestas secundárias de Marituba (Anexo D) e Bragança-PA (Anexo E), apresentou resultados de $\mathrm{Ph}$ muito baixos, com valores de 3,89 e 4,53, respectivamente, considerando a média das profundidades $0-5 \mathrm{~cm}$ e $5-15 \mathrm{~cm}$. Os valores encontrados, principalmente para Marituba, indicam condições desfavoráveis às plantas, como pobreza em $\mathrm{Ca}$ e $\mathrm{Mg}$, altos teores de Al, alta fixação de P e deficiência de micronutrientes (Tomé Jr. 1997).

Os valores de $\mathrm{Ph}$ encontrados nas áreas do presente estudo foram inferiores aos encontrados por Vieira (1996) para florestas secundárias com várias idades e um fragmento de floresta primária no nordeste do Pará. Nestas áreas a autora encontrou, na profundidade de $0-10 \mathrm{~cm}, \mathrm{Ph}$ de 5,92 para uma área recém-queimada, 4,54 para a floresta de 10 anos, 4,48 para uma floresta de 20 anos, 4,40 para a floresta de 40 anos de pousio e para a floresta primária, 4,16. Na mesma região Denich (1991), encontrou Ph médio de 5,14 para a profundidade de $0-10 \mathrm{~cm}$ em cinco áreas de capoeiras jovens.

Estes resultados mostraram que nas áreas mais jovens a deposição de cinzas em consequiência das queimadas, eleva os valores de Ph (Menezes, 2003) e ao longo do processo de sucessão os valores vão retornando aos níveis anteriores ao distúrbio. No presente trabalho os teores médios de Ph encontrados para Bragança foram maiores, uma vez que essa área é de origem agrícola e tal diferença provavelmente seja atribuída ao efeito residual das cinzas.

O carbono $(\mathrm{C})$ e a matéria orgânica (MO), apresentaram-se em maior quantidade nas menores profundidades de coleta para ambas as áreas. Tognon (1998), observou que 
a maior concentração de MO está nas camadas superficiais, tanto para os solos de texturas finas quanto para os de textura mais grosseira.

Os maiores teores médios de $\mathrm{C}$ e $\mathrm{MO}$ foram encontrados nas parcelas de Marituba (Anexo D). A maior concentração de MO pode ser explicada tanto pela maior concentração de biomassa aérea quanto pela umidade, que segundo Jenny (1961) é responsável pelo aumento logarítmico do teor de $\mathrm{MO}$. Tanto para o $\mathrm{C}$ quanto para a $\mathrm{MO}$ houve diferença estatisticamente significativa entre Marituba e Bragança nas profundidades de $0-5 \mathrm{~cm}$ e $15-25 \mathrm{~cm}$. (Tabela 14).

A Figura 24a mostra que a distribuição dos teores médios de carbono e matéria orgânica entre as parcelas na área de Marituba é mais homogênea, variando de 11,3g/kg a $15,5 \mathrm{~g} / \mathrm{kg}$ para $\mathrm{C}$ e de $19,4 \mathrm{~g} / \mathrm{kg}$ a $26,7 \mathrm{~g} / \mathrm{kg}$ para MO. Em Bragança (Figura 24b), estes teores variaram de 6,8g/kg a 13,8g/kg para C e de $11,8 \mathrm{~g} / \mathrm{kg}$ a 23,8g/kg para MO.

O valor médio de MO para Marituba foi de 23,0g/kg e para Bragança 17,8g/kg. Estes resultados foram próximos aos valores médios encontrados por Vieira (1996) para uma floresta secundária de 40anos $(\mathrm{MO}=13,7 / \mathrm{kg})$ na profundidade de $0-20 \mathrm{~cm}$, e inferiores aos encontrados por TOGNON (1998), que comparou os teores de MO em florestas naturais sobre Latossolo Amarelo (LA) e Latossolo Vermelho Amarelo (LV) na Amazônia. Esse autor encontrou valor médio de 32,0g/kg.

Os valores apresentados evidenciam que de acordo com o avanço do processo de sucessão há a tendência de maior acúmulo de MO nas camadas superficiais do solo. Observando-se, todavia, as peculiaridades climáticas e vegetacionais da região.
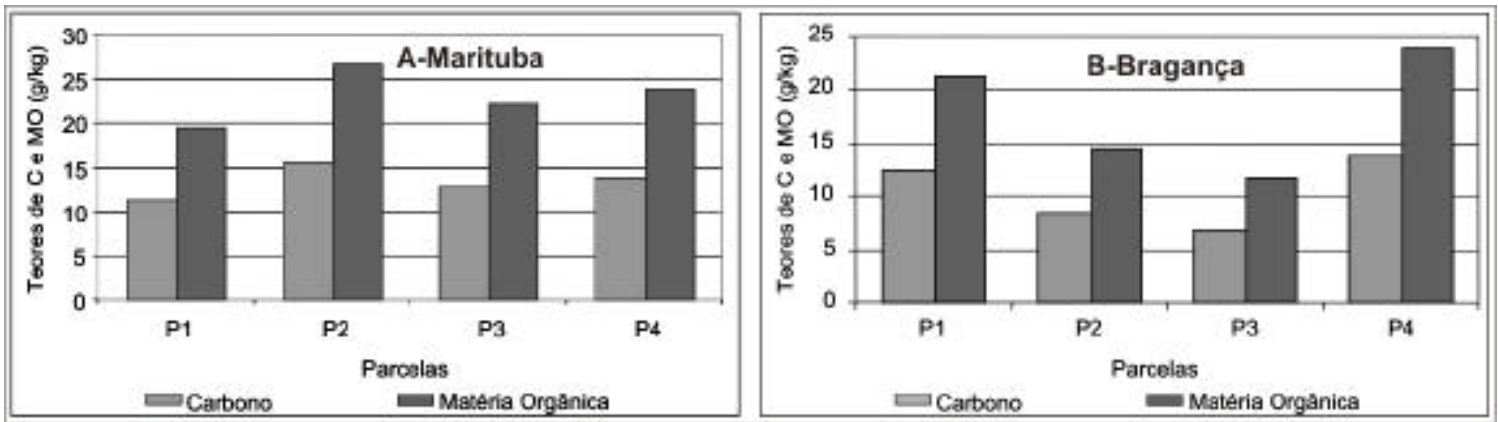

Figura 24 - Valor médio geral de $\mathrm{C}$ e $\mathrm{MO}$ das amostras coletadas nas profundidades de $0-5 \mathrm{~cm}, 5-15 \mathrm{~cm}$ e $15-25 \mathrm{~cm}$ para as parcelas estudadas em Marituba e Bragança-PA 
Tabela 14. Comparação dos valores médios pelo teste t-Student e Coeficientes de Variação de $\mathrm{Ph}, \mathrm{C}, \mathrm{MO}$, $\mathrm{Na}, \mathrm{Ca}, \mathrm{Mg}, \mathrm{P}, \mathrm{k}$, e $\mathrm{H}+\mathrm{Al}$ nas profundidades de $0-5 \mathrm{~cm}, 515 \mathrm{~cm}$ e $15-25 \mathrm{~cm}$ para as áreas estudadas nos municípios de Bragança e Marituba

\begin{tabular}{|c|c|c|c|c|c|c|c|}
\hline \multirow{3}{*}{ Elementos de fertilidade } & \multirow{3}{*}{ Área } & \multicolumn{6}{|c|}{ Profundidade (cm) } \\
\hline & & \multicolumn{2}{|c|}{$0-5$} & \multicolumn{2}{|c|}{$5-15$} & \multicolumn{2}{|c|}{$15-25$} \\
\hline & & Me & CV\% & Me & CV\% & Me & CV\% \\
\hline \multirow{3}{*}{$\mathrm{Ph}$ em $\mathrm{H}_{2} \mathrm{O}$} & Bragança & 4,27 & 5,10 & 4,80 & 3,73 & 4,26 & 3,00 \\
\hline & Marituba & 3,83 & 4,47 & 3,96 & 4,76 & 4,23 & 5,23 \\
\hline & $\operatorname{Pr}>\mathrm{T}$ & \multicolumn{2}{|c|}{$0,0000^{*}$} & \multicolumn{2}{|c|}{$0,0008^{*}$} & \multicolumn{2}{|c|}{$0,4660^{\text {ns }}$} \\
\hline \multirow{3}{*}{$\mathrm{CARBONO}-\mathrm{Cg} / \mathrm{Kg}$} & Bragança & 14,14 & 42,58 & 9,70 & 52,94 & 7,22 & 87,80 \\
\hline & Marituba & 18,78 & 34,21 & 11,82 & 33,62 & 9,41 & 43,55 \\
\hline & $\operatorname{Pr}>\mathrm{T}$ & \multicolumn{2}{|c|}{$0,0004 *$} & \multicolumn{2}{|c|}{$0,0233^{*}$} & \multicolumn{2}{|c|}{$0,0487 *$} \\
\hline \multirow{3}{*}{$\begin{array}{l}\text { MATÉRIA ORGÂNICA - } \\
\text { Mog/Kg }\end{array}$} & Bragança & 24,38 & 42,60 & 16,67 & 52,98 & 12,45 & 87,81 \\
\hline & Marituba & 32,36 & 34,25 & 20,37 & 33,69 & 16,22 & 43,52 \\
\hline & $\operatorname{Pr}>\mathrm{T}$ & \multicolumn{2}{|c|}{$0,0004^{*}$} & \multicolumn{2}{|c|}{$0,0238^{*}$} & \multicolumn{2}{|c|}{$0,0481^{*}$} \\
\hline \multirow{3}{*}{ SÓDIO - Nacmol/dm ${ }^{3}$} & Bragança & 0,11 & 50,09 & 0,06 & 51,04 & 0,03 & 48,13 \\
\hline & Marituba & 0,07 & 28,98 & 0,04 & 34,40 & 0,03 & 37,20 \\
\hline & $\operatorname{Pr}>\mathrm{T}$ & \multicolumn{2}{|c|}{$0,0001^{*}$} & \multicolumn{2}{|c|}{$0,0001^{*}$} & \multicolumn{2}{|c|}{$0,3096^{\mathrm{ns}}$} \\
\hline \multirow{3}{*}{ CÁLCIO - Cacmol/dm³ } & Bragança & 0,73 & 45,29 & 0,25 & 64,59 & 0,14 & 74,46 \\
\hline & Marituba & 0,50 & 36,51 & 0,30 & 53,97 & 0,22 & 54,89 \\
\hline & $\operatorname{Pr}>\mathrm{T}$ & \multicolumn{2}{|c|}{$0,0001 *$} & \multicolumn{2}{|c|}{$0,1888^{\mathrm{ns}}$} & \multicolumn{2}{|c|}{$0,0015^{*}$} \\
\hline \multirow{3}{*}{$\begin{array}{l}\text { MAGNÉSIO - Mg } \\
\mathrm{cmol} / \mathrm{dm}^{3}\end{array}$} & Bragança & 0,54 & 16,20 & 0,27 & 60,40 & 0,18 & 45,12 \\
\hline & Marituba & 0,31 & 31,87 & 0,19 & 49,33 & 0,17 & 56,76 \\
\hline & $\operatorname{Pr}>\mathrm{T}$ & \multicolumn{2}{|c|}{$0,0001^{*}$} & \multicolumn{2}{|c|}{$0,0032^{*}$} & & \\
\hline & Bragança & 3,12 & 30,83 & 2,00 & 31,03 & 1,52 & 44,27 \\
\hline FÓSFORO - Pcmol/ $/ \mathrm{dm}^{3}$ & Marituba & 4,08 & 27,40 & 1,96 & 46,95 & 1,16 & 26,76 \\
\hline & $\operatorname{Pr}>\mathrm{T}$ & & & & & & \\
\hline & Bragança & 0,14 & 48,53 & 0,08 & 49,47 & 0,04 & 46,32 \\
\hline POTÁSSIO - $\mathrm{kcmol} / \mathrm{dm}^{3}$ & Marituba & 0,09 & 24,72 & 0,05 & 30,86 & 0,03 & 43,42 \\
\hline & $\operatorname{Pr}>\mathrm{T}$ & & & & & & \\
\hline & Bragança & 5,60 & 16,70 & 4,70 & 22,02 & 3,74 & 21,52 \\
\hline 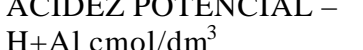 & Marituba & 8,45 & 16,12 & 6,40 & 26,72 & 5,63 & 26,64 \\
\hline & $\operatorname{Pr}>\mathrm{T}$ & & & & & & \\
\hline & Bragança & 1,18 & 27,97 & 1,41 & 17,73 & 1,28 & 21,09 \\
\hline ALUMINIO TROCAVEL & Marituba & 2,21 & 16,74 & 1,90 & 20,00 & 1,66 & 26,51 \\
\hline & $\operatorname{Pr}>T$ & & & & & & \\
\hline
\end{tabular}

$\mathbf{M e}=$ Média relativa a 48 amostras para cada profundidade; $\% \mathbf{C V}=$ Coeficiente de Variação e $\mathbf{P r}>\mathbf{T}=$ Probabilidade de aceitar a hipótese nula. O CV possui pequena variabilidade quando o coeficiente for até $10 \%$, média quando for de $10 \%$ a $20 \%$; e alta quando o valor ultrapassar 20\% (Fonseca \& Martins, 1995).

*-Diferença estatisticamente significativa (nível de confiança de 95\%).

ns-Diferença não significativa (nível de confiança de 95\%). 
Foram encontradas diferenças estatísticas significativas $(\mathrm{p}<0,05)$ em todos os atributos de fertilidade do solo entre a área de Bragança e Marituba na profundidade de 0-5cm. Na profundidade de $5-15 \mathrm{~cm}$, Cálcio e Fósforo foram estatisticamente iguais e entre 15-25cm, somente $\mathrm{Ph}$, Sódio e Magnésio apresentaram médias estatisticamente iguais (Tabela 14).

A acidez potencial $(\mathrm{H}+\mathrm{Al})$ oscilou entre $6,52 \mathrm{cmol} / \mathrm{dm}^{3}$ e $7,43 \mathrm{cmol} / \mathrm{dm}^{3}$ na área de Marituba (Anexo D), e para Bragança os valores desse atributo apresentaram-se menores $\left(3,82 \mathrm{cmol} / \mathrm{dm}^{3}\right.$ a $\left.5,28 \mathrm{cmol} / \mathrm{dm}^{3}\right)$ (Anexo E). Segundo Tomé Jr. (1997), a ocorrência de maiores teores de acidez potencial está associada a solos que apresentem maiores teores de matéria orgânica e principalmente, se estes apresentarem $\mathrm{Ph}$ muito baixos.

O principal objetivo da determinação da acidez potencial é o cálculo da capacidade de troca de cátions CTC. Como mostram as Figuras 25a e 25b a CTC foi dominada em grande parte pelos teores da acidez potencial. Estes valores confirmam os resultados apresentados por Numata (1999), quando comparou áreas de florestas naturais e de pastagens na Amazônia e no Cerrado. Essa autora afirma que em floretas naturais existe baixa proporção de bases formando a CTC, e que após as queimadas a adição de cinzas ao solo inverte esta proporção e a acidez potencial passa a ter menor influência na CTC.

Comparando as Figuras 25a e 25b, o teor de acidez potencial teve maior influência na área de Marituba do que em Bragança. Essa diferença se deve, provavelmente, pelo remanescente de cinzas na área de Bragança, uma vez que esta área é de origem agrícola com vários ciclos de corte-queima-plantio-pousio.
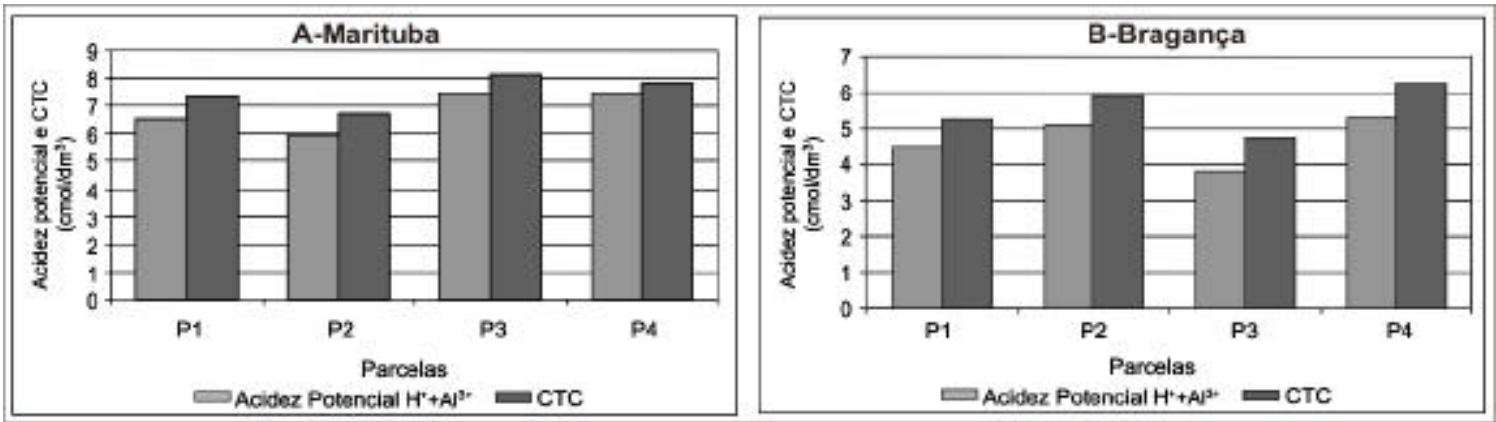

Figura 25 - Valor geral médio da acidez potencial $\left(\mathrm{H}^{+}+\mathrm{Al}^{+3}\right)$ e capacidade de troca de cátions $(\mathrm{CTC})$ das amostras coletadas nas profundidades de $0-5 \mathrm{~cm}, 5-15 \mathrm{~cm}$ e $15-25 \mathrm{~cm}$ para as parcelas estudadas em Marituba e Bragança-PA 
Os valores encontrados para a saturação por bases $(\% \mathrm{~V})$, em geral foram maiores nas parcelas de Bragança. Nessa área a relação entre \%V e a saturação por alumínio $(\% \mathrm{Al})$ foi, a grosso modo, inversa, ou seja, quanto maior $\% \mathrm{~V}$ menor foi a $\% \mathrm{Al}$ (Figura 26b). Em Marituba essa relação não foi tão evidente, pois somente as parcelas 1 e 4 confirmam o caráter proporcional entre \%V e \%Al (Figura 26a).

Segundo Tomé Jr. (1997), a saturação por bases e saturação por alumínio são um excelente indicativo das condições gerais de fertilidade do solo, pois é a partir de seus percentuais que são definidos o caráter eutrófico, distrófico e alumínico (EMBRAPA,1999) do solo.

Os resultados apresentados para os solos das presentes áreas mostraram valores de $\% \mathrm{~V}$ menores que 50\%, caracterizando-os como solos distróficos conforme Tomé Jr. (1997). A saturação por alumínio em todas as parcelas e profundidades analisadas para as duas áreas ficaram entre $25 \%$ e $28 \%$ para Marituba e $23 \%$ e $27 \%$ para Bragança. Estes valores são considerados médios e com leve capacidade prejudicial às plantas (Figura 26a e 26b). Por outro lado, considerando a classificação proposta pela EMBRAPA (1999), o solo é alumínico quando apresenta saturação por alumínio $\geq 50 \%$ e alumínio extraível $\geq 4,0 \mathrm{cmol} / \mathrm{dm}^{3}$, ou ainda quando a saturação por bases for menor que $50 \%$. Apesar do solo de ambas áreas serem classificados como Latossolo Amarelo distrófico (LAd), não podem ser considerados alumínicos, uma vez que os valores de saturação por alumínio foram inferiores a $50 \%$ e os valores Al trocável foram inferiores a $4,0 \mathrm{cmol} / \mathrm{dm}^{3}$.
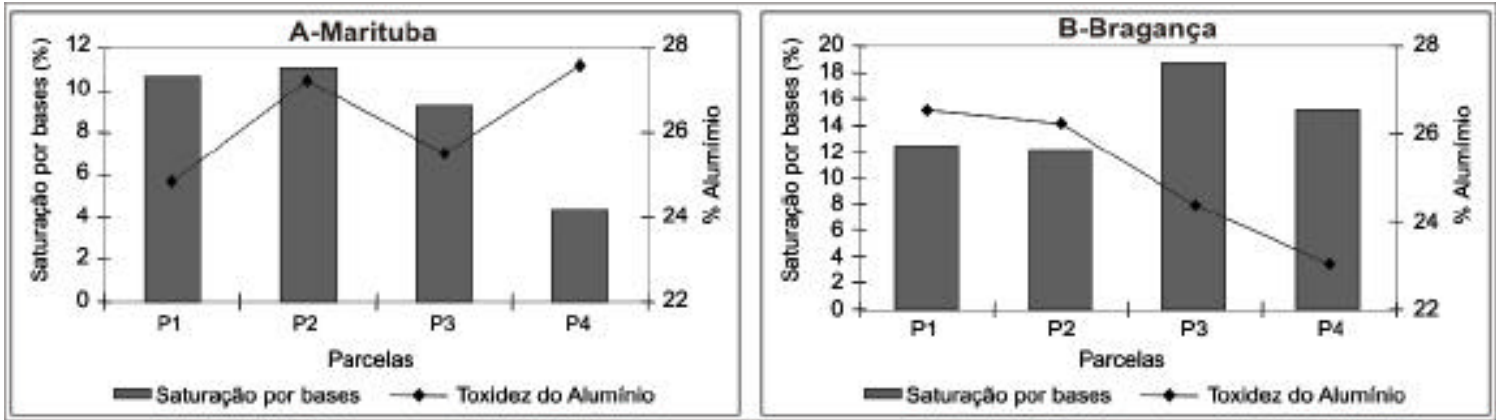

Figura 26 - Valor geral médio da saturação por bases $(\% \mathrm{~V})$ e da toxidez do alumínio (\% Al) das amostras coletadas nas profundidades de $0-5 \mathrm{~cm}, 515 \mathrm{~cm}$ e $15-25 \mathrm{~cm}$ para as parcelas estudadas em Marituba e Bragança-PA 
No Anexo F, estão apresentados os valores médios de CTC, SB, \%V e \%Al para as três profundidades de coleta nas parcelas de Marituba e Bragança.

O teste estatístico mostrou que existe diferença estatisticamente significativa entre os solos das duas florestas estudadas quanto aos principais verificadores de fertilidade do solo (CTC, SB, \%V e \%Al) na profundidade de $0-5 \mathrm{~cm}$ (Tabela 15). Nas demais profundidades, a soma de bases (SB) não apresentou diferença estatística significativa e a capacidade de troca de cátions (CTC) e a saturação por bases (\%V), apresentou diferenças estatisticamente significativas, para todas as profundidades analisadas.

Os resultados para o CV apresentados pela floresta de Bragança, são considerados médios. Já para a área de Marituba esse comportamento é observado somente na primeira profundidade enquanto que as demais apresentam alta dispersão relativa $(\mathrm{CV}>$ 20\%) em torno da média (Tabela 15).

Tabela 15. Comparação dos valores médios pelo teste t-Student e Coeficientes de Variação de CTC, SB, \%V e \%Al nas profundidades de $0-5 \mathrm{~cm}, 5-15 \mathrm{~cm}$ e $15-25 \mathrm{~cm}$ para as áreas estudadas nos municípios de Bragança e Marituba-PA

\begin{tabular}{|c|c|c|c|c|c|c|c|}
\hline \multirow{3}{*}{ Fertilidade } & \multirow{3}{*}{ Área } & \multicolumn{6}{|c|}{ Profundidade (cm) } \\
\hline & & \multicolumn{2}{|c|}{$0-5$} & \multicolumn{2}{|c|}{$5-15$} & \multicolumn{2}{|c|}{$15-25$} \\
\hline & & Me & CV\% & Me & CV\% & Me & CV\% \\
\hline \multirow{3}{*}{$\mathrm{CTC} \mathrm{cmol} / \mathrm{dm}^{3}$} & Bragança & 7,11 & 11,86 & 5,35 & 20,52 & 4,14 & 20,46 \\
\hline & Marituba & 9,45 & 14,32 & 6,95 & 24,39 & 6,07 & 24,55 \\
\hline & $\operatorname{Pr}>\mathrm{T}$ & \multicolumn{2}{|c|}{$0,0001 *$} & \multicolumn{2}{|c|}{$0,0001^{*}$} & \multicolumn{2}{|c|}{$0,0001 *$} \\
\hline \multirow{3}{*}{$\mathrm{SB} \mathrm{cmol} / \mathrm{dm}^{3}$} & Bragança & 1,51 & 22,77 & 0,65 & 38,06 & 0,40 & 39,81 \\
\hline & Marituba & 0,96 & 24,91 & 0,57 & 39,57 & 0,45 & 42,09 \\
\hline & $\operatorname{Pr}>T$ & \multicolumn{2}{|c|}{$0,0001^{*}$} & \multicolumn{2}{|c|}{$0,8110^{\mathrm{ns}}$} & \multicolumn{2}{|c|}{$0,1119^{\mathrm{ns}}$} \\
\hline \multirow{3}{*}{$\% \mathrm{~V}$} & Bragança & 21,61 & 25,36 & 12,40 & 37,07 & 9,72 & 40,71 \\
\hline & Marituba & 10,37 & 27,81 & 8,58 & 42,77 & 7,80 & 45,65 \\
\hline & $\operatorname{Pr}>T$ & \multicolumn{2}{|c|}{$0,0001 *$} & \multicolumn{2}{|c|}{$0,0001 *$} & \multicolumn{2}{|c|}{$0,0133 *$} \\
\hline \multirow{3}{*}{$\% \mathrm{Al}$} & Bragança & 16,05 & 22,84 & 26,89 & 15,01 & 32,19 & 12,67 \\
\hline & Marituba & 23,52 & 13,90 & 27,78 & 14,20 & 27,63 & 18,33 \\
\hline & $\operatorname{Pr}>T$ & \multicolumn{2}{|c|}{$0,0001 *$} & \multicolumn{2}{|c|}{$0,2730^{\mathrm{ns}}$} & \multicolumn{2}{|c|}{$0,0001 *$} \\
\hline \multicolumn{8}{|c|}{$\begin{array}{l}\mathbf{C T C}=\text { Capacidade de troca de cátions }\left(\mathrm{Ca}^{+2}, \mathrm{Mg}^{+2}, \mathrm{~K}^{+}, \mathrm{Na}^{+}, \mathrm{H}^{+} \text {e } \mathrm{Al}^{+3}\right), \mathbf{S B}=\text { Soma de bases }(\mathrm{Ca}, \mathrm{Mg}, \mathrm{Ke} \\
\mathrm{Na}), \% \mathbf{V}=\text { Percentagem de saturação de bases, \% } \mathbf{A l}=\text { Toxidez do alumínio } \mathbf{M e}=\text { Média relativa a } 48 \\
\text { amostras para cada profundidade, } \% \mathbf{C V}=\text { Coeficiente de Variação e Pr }>\mathbf{T}=\text { Probabilidade de aceitar a } \\
\text { hipótese nula. O CV possui pequena variabilidade quando o coeficiente for até } 10 \%, \text { média quando for de } \\
10 \% \text { a } 20 \% \text {; e alta quando o valor ultrapassar } 20 \% \text { (Fonseca \& Martins, 1995). } \\
\text { *-Diferença estatisticamente significativa ao nível de } 95 \% . \\
\text { ns-Diferença não significativa ao nível de } 95 \% \text {. }\end{array}$} \\
\hline
\end{tabular}




\section{b) Granulometria}

No Anexo G, são apresentados os valores médios para as frações sólidas do solo das parcelas instaladas em Marituba e Bragança-PA. As quantidades de Areia Grossa, apresentaram-se constituindo cerca de $60 \%$ na primeira área e de $49 \%$ na segunda área das frações sólidas do solo na profundidade de $0-5 \mathrm{~cm}$.

Nota-se que a quantidade de areia grossa diminuiu de acordo com o aumento da profundidade no solo (Figuras 27 e 28). O coeficiente de variação entre as médias mostrou-se baixo $(\mathrm{CV}<10 \%)$, indicando uniformidade do teor da fração Areia Grossa em todas as parcelas amostradas.

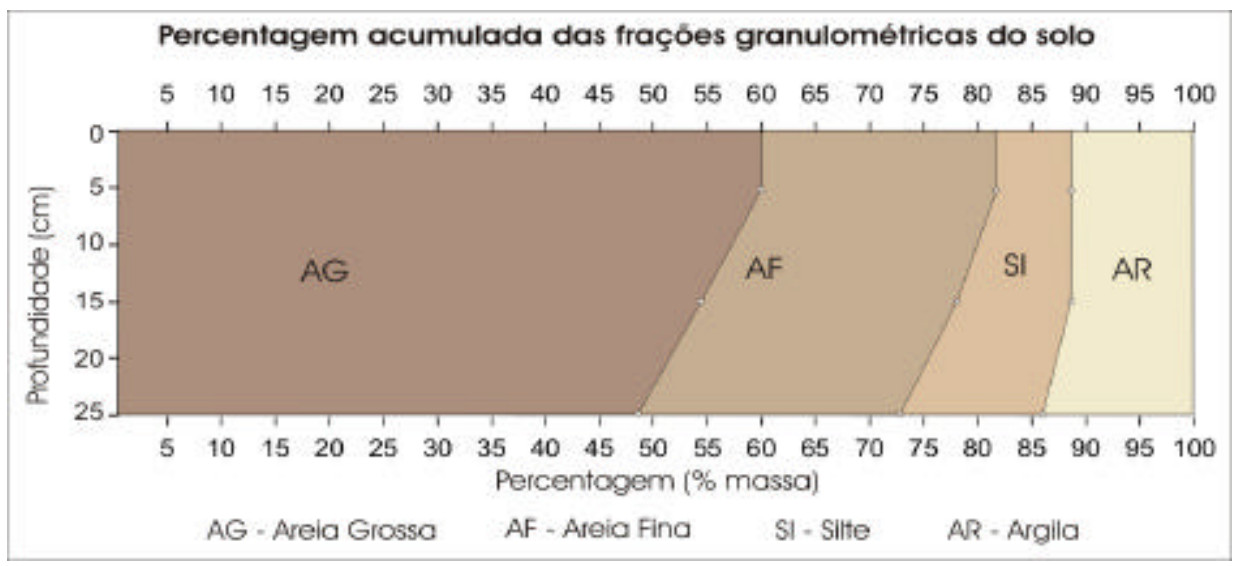

Figura 27 - Percentagem das frações granulométricas do solo (Areia Grossa, Areia Fina, Silte e Argila) do solo das parcelas amostradas numa floresta secundária oriunda de exploração de madeira para lenha, no município de Marituba$\mathrm{PA}$, nas profundidades de $0-5 \mathrm{~cm}, 5-15 \mathrm{~cm}$ e $15-25 \mathrm{~cm}$

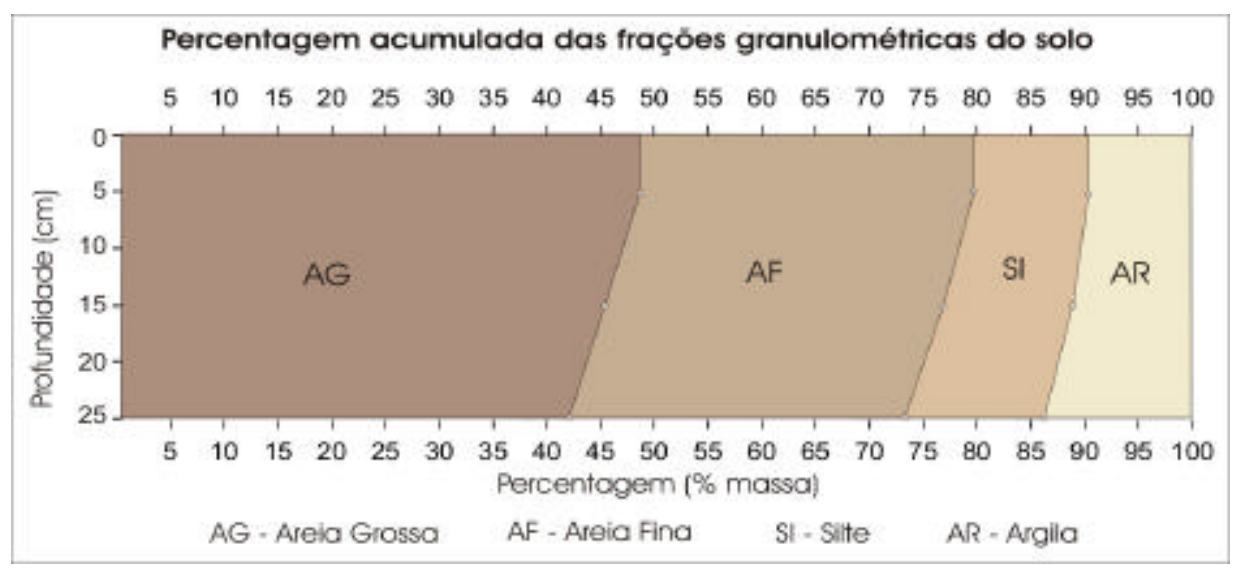

Figura 28 - Percentagem das frações granulométricas do solo (Areia Grossa, Areia Fina, Silte e Argila) do solo das parcelas amostradas numa floresta secundária oriunda de agricultura de corte e queima no município de Bragança-PA, nas profundidades de $0-5 \mathrm{~cm}, 5-15 \mathrm{~cm}$ e $15-25 \mathrm{~cm}$ 
De maneira geral, a soma dos teores de areia grossa e areia fina foi cerca de $80 \%$ das frações sólidas em Marituba e Bragança, na profundidade de $0-5 \mathrm{~cm}$. Esse comportamento pode ser melhor visualizado na Figura 27 e 28, que apresentam as percentagem acumuladas por profundidade.

A soma das médias de todas as profundidades dos teores de areia grossa e areia fina para ambas áreas foi superior a 77\%. As médias da fração argila de todas as profundidades foi inferior a 35\%. Esses teores permitem classificar os solos nas duas áreas como textura média, segundo o diagrama triangular utilizado pela EMBRAPA (1999). Segundo Tomé Jr. (1997), os solos com essas características são solos com baixa/moderada susceptibilidade à erosão e Médios a baixos valores de retenção de água.

Como mostram as Figuras 27 e 28 os teores de argila e silte apresentam comportamento inverso aos de areia, pois aumentam à medida que aumenta a profundidade de coleta.

Tabela 16. Comparação dos valores médios pelo teste t-Student e Coeficientes de Variação de Areia Grossa, Areia Fina, Silte e Argila do solo das parcelas amostradas em florestas secundárias nos municípios de Bragança e Marituba-PA, nas profundidades de 0$5 \mathrm{~cm}, 5-15 \mathrm{~cm}$ e $15-25 \mathrm{~cm}$

\begin{tabular}{|c|c|c|c|c|c|c|c|}
\hline \multirow{3}{*}{ Fertilidade } & \multirow{3}{*}{ Área } & \multicolumn{6}{|c|}{ Profundidade $(\mathrm{cm})$} \\
\hline & & \multicolumn{2}{|c|}{$0-5$} & \multicolumn{2}{|c|}{$5-15$} & \multicolumn{2}{|c|}{$15-25$} \\
\hline & & Me & CV\% & Me & CV\% & Me & CV\% \\
\hline \multirow{3}{*}{ Areia Grossa } & Bragança & 49,24 & 10,19 & 46,20 & 8,94 & 42,41 & 8,59 \\
\hline & Marituba & 60,00 & 10,53 & 54,40 & 10,93 & 48,45 & 11,33 \\
\hline & $\operatorname{Pr}>\mathrm{T}$ & \multicolumn{2}{|c|}{$0,0001^{*}$} & \multicolumn{2}{|c|}{$0,0001 *$} & \multicolumn{2}{|c|}{$0,0001 *$} \\
\hline \multirow{3}{*}{ Areia Fina } & Bragança & 30,64 & 15,91 & 31,35 & 14,35 & 32,19 & 13,43 \\
\hline & Marituba & 22,08 & 19,06 & 23,68 & 17,30 & 24,23 & 15,71 \\
\hline & $\operatorname{Pr}>\mathrm{T}$ & \multicolumn{2}{|c|}{$0,0001 *$} & \multicolumn{2}{|c|}{$0,0001 *$} & \multicolumn{2}{|c|}{$0,0001 *$} \\
\hline \multirow{3}{*}{ Argila } & Bragança & 9,14 & 22,88 & 10,18 & 24,40 & 12,76 & 22,46 \\
\hline & Marituba & 11,31 & 20,14 & 11,38 & 23,76 & 13,99 & 27,64 \\
\hline & $\operatorname{Pr}>\mathrm{T}$ & \multicolumn{2}{|c|}{$0,0001 *$} & \multicolumn{2}{|c|}{$0,0257 *$} & \multicolumn{2}{|c|}{$0,0786^{\mathrm{ns}}$} \\
\hline \multirow{3}{*}{ Silte } & Bragança & 10,97 & 24,62 & 12,33 & 24,37 & 12,66 & 20,37 \\
\hline & Marituba & 6,84 & 36,94 & 10,55 & 33,61 & 13,32 & 24,77 \\
\hline & $\operatorname{Pr}>\mathrm{T}$ & \multicolumn{2}{|c|}{$0,0001 *$} & \multicolumn{2}{|c|}{$0,0095 *$} & \multicolumn{2}{|c|}{$0,2729^{\mathrm{ns}}$} \\
\hline
\end{tabular}

\%CV = Coeficiente de Variação. CV até 10\% pequena variabilidade; $10 \%$ a $20 \%$ média variabilidade; > $20 \%$ alta variabilidade (Fonseca \& Martins, 1995). Me = Média relativa a 48 amostras para cada profundidade. Classes de textura (ver metodologia).

*-Diferença estatisticamente significativa ao nível de $95 \%$.

${ }^{\text {ns }-D i f e r e n c ̧ a ~ n a ̃ o ~ s i g n i f i c a t i v a ~ a o ~ n i ́ v e l ~ d e ~} 95 \%$. 
Na comparação dos teores médios de todos os atributos da fração sólida do solo entre as duas áreas, o teste estatístico mostrou que existem diferenças estatisticamente significativas nas profundidades de $0-5 \mathrm{~cm}$ e $5-15 \mathrm{~cm}$. Na última profundidade (15$25 \mathrm{~cm}$ ), somente argila e silte foram estatisticamente iguais (Tabela 16).

Os valores de $\mathrm{CV}$ com alta variabilidade em torno da média, sempre acima de 20\%, foram apresentados somente para as frações de argila e silte em todas as profundidades nas duas áreas (Tabela 16).

De maneira geral a área de Bragança apresentou menor quantidade de argila do que Marituba. Por outro lado, os teores de silte foram maiores na área de Marituba Tabela 16.

\section{c) Análise multivariada dos principais atributos da fertilidade do solo}

A aplicação do índice de Distância Euclidiana Simples para a identificação de possíveis diferenças entre os teores dos principais atributos da fertilidade do solo da floresta de Marituba e Bragança auxiliou na produção do dendrograma apresentado na Figura 29, agrupando as parcelas pelo método de Média de Grupo.

O dendrograma mostrou a formação de cinco grandes grupos. O grupo 1 é formado preponderantemente pelas parcelas de 5 a 8 da área de Bragança. $\mathrm{O}$ grupo 2 que é formado principalmente pelas parcelas de 1 a 3, referentes a área de Marituba. E o grupo 5, formado exclusivamente pela parcela 4 de Marituba que apresentou o maior valor da Distância Euclidiana (Figura 29). 


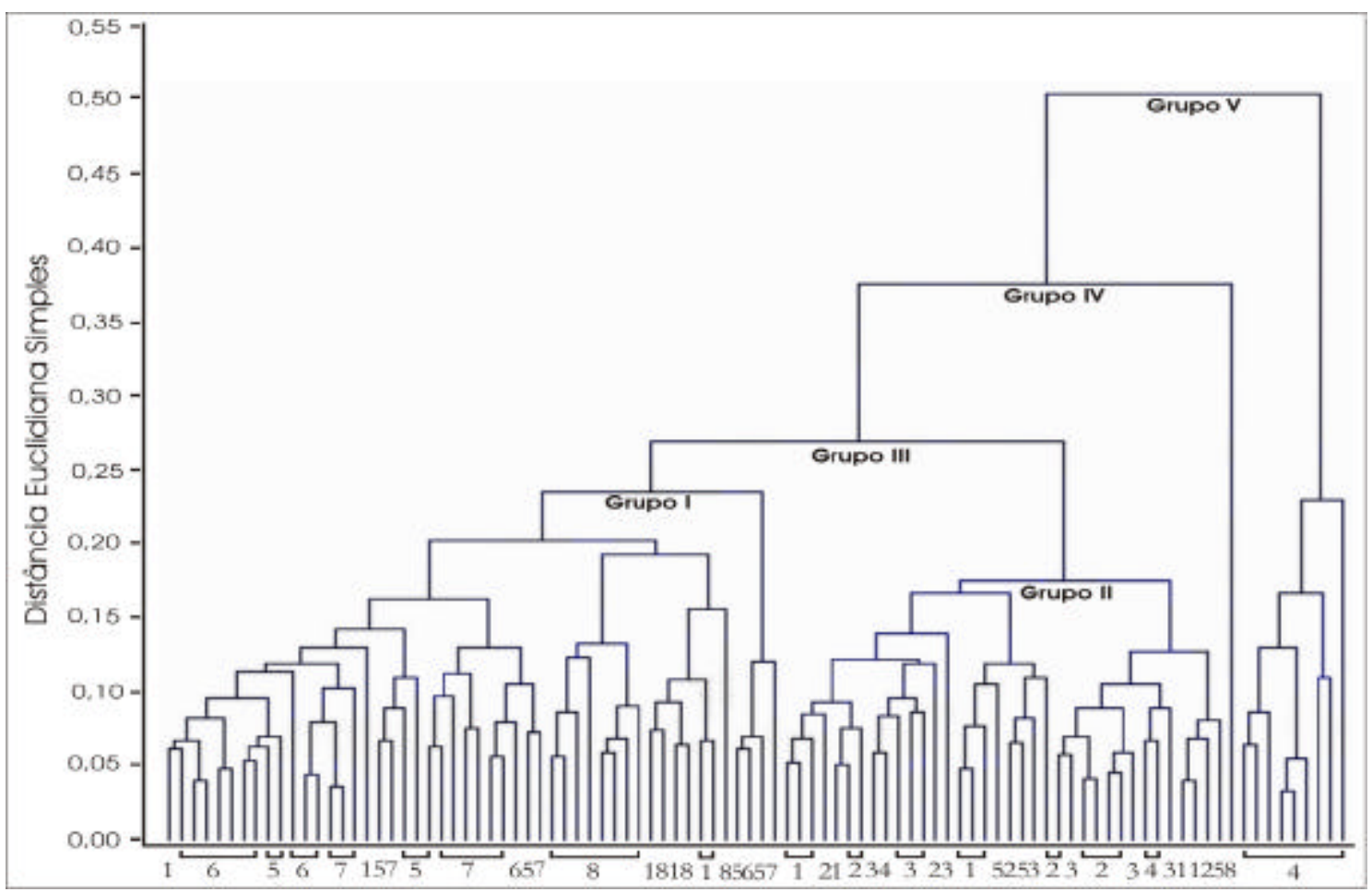

Figura 29 - Dendrograma apresentado a Distância Euclidiana Simples entre as parcelas das áreas de Marituba (1 a 4) e Bragança (5 a 8), considerando os principais atributos da fertilidade e granulometria do solo e agrupando as parcelas pelo método de Média de Grupo (UPGMA) usando o índice de Distância Euclidiana Simples

Pela Análise de Componentes Principais (PCA) pode-se ter uma melhor visualização dos principais atributos da fertilidade do solo que melhor diferenciaram as áreas estudadas, com a formação de dois grandes grupos limitados pelas linhas pontilhadas (Figura 30).

Os dois principais eixos de correlação da PCA apresentaram percentagem de variância acumulada de 67\%. Com a análise desses eixos, verificou-se que a separação das parcelas e das áreas se deu pelos menores valores dos atributos de fertilidade. No lado negativo do eixo 2, ocorreu o agrupamento das parcelas 8 (Figura 30), associadas aos menores teores de fósforo (Anexo E). O maior agrupamento das parcelas 7 no lado positivo do eixo 1 (Figura 30) pode estar associado aos menores teores de CTC efetiva, nos solos de Bragança (Anexo F). Para Marituba, a parcela 4 foi a que formou o grupo mais coeso no quadrante positivo do eixo 2 e negativo do eixo 1 (Figura 30). Essa parcela apresentou os menores valores de \% V, SB (Anexo F) e Ph (Anexo D). 


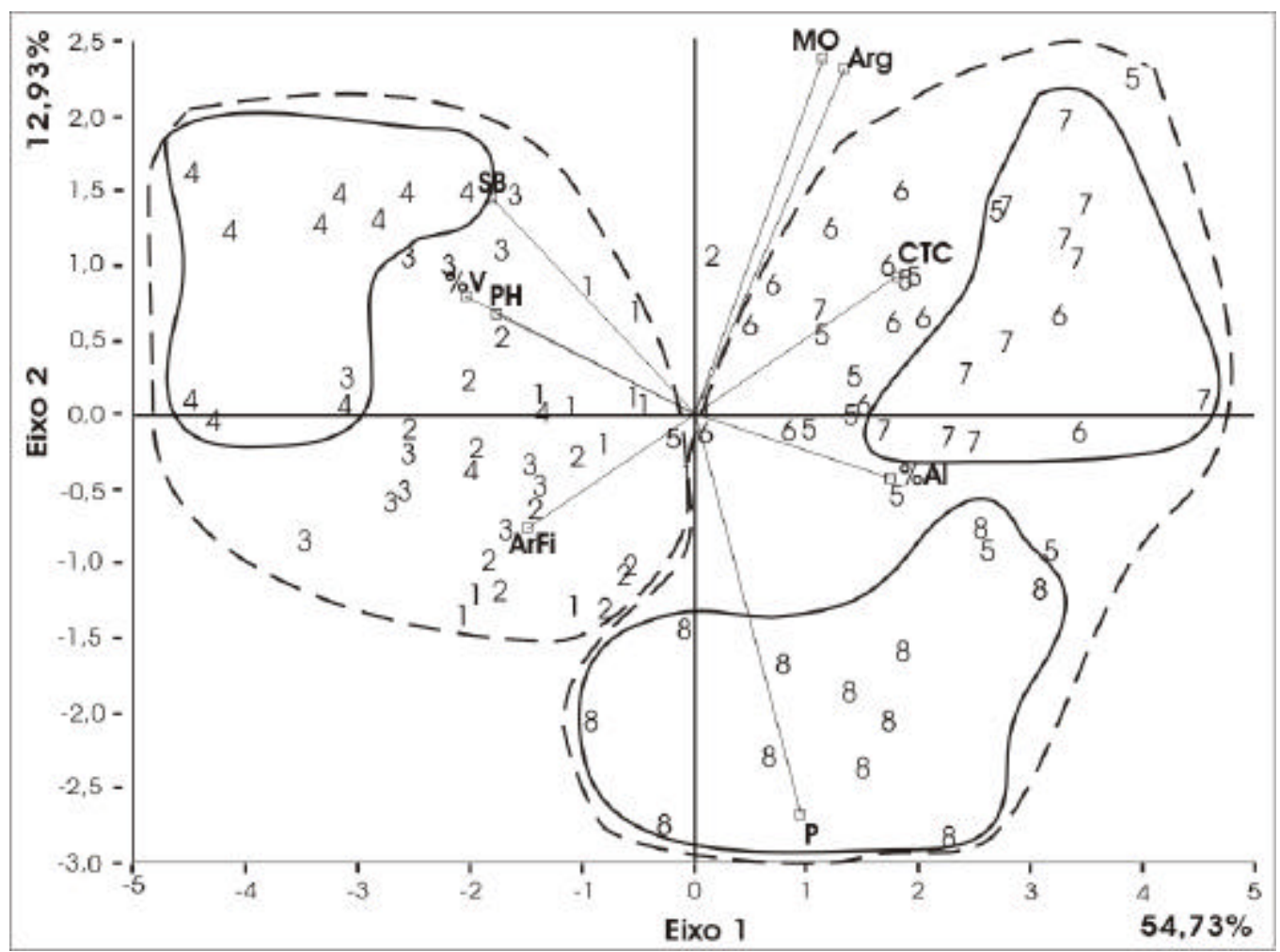

Figura 30- Ordenação por Análise de Componentes Principais (PCA - Correlação) dos principais atributos químicos e granulométricos do solo, para amostras coletadas na profundidade de $0-5 \mathrm{~cm}$, de floretas secundárias antigas em Marituba e BragançaPA. Onde: Marituba corresponde aos caracteres 1, 2, 3 e 4 e Bragança 5, 6, 7 e 8 correspondentes a 1, 2, 3 e 4 nos Anexos 5, 6 e 7

\subsection{Correlação dos principais atributos da fertilidade do solo e vegetação (Crescimento em diâmetro, densidade e área basal total) em análises multivariadas}

Os resultados das análises de correspodência canônica para as duas áreas estão apresentados nas Tabelas 17 e 18, além das Figuras 31 e 32. O teste de Monte Carlo não apresentou valores significativos $(\mathrm{p}>0,05)$ nem para os autovalores, nem para a correlação ambiente-vegetação (Tabela 17), indicando que os eventos ou o desenvolvimento da vegetação no período analisado ocorreu ao acaso, não mostrando 
relação direta entre os atributos de fertilidade do solo e as variáveis de vegetação (crescimento em diâmetro, densidade e área basal total).

Tabela 17. Síntese dos resultados da análise de correspondência canônica (CCA) baseada em sete variáveis ambientais e três variáveis de vegetação $(n=48)$ para as áreas de Marituba e Bragança-PA

\begin{tabular}{lllll}
\hline \multicolumn{1}{c}{ Parâmetros da análise } & \multicolumn{2}{c}{ Marituba } & \multicolumn{2}{c}{ Bragança } \\
& Eixo 1 & Eixo 2 & Eixo 1 & Eixo 2 \\
\hline Autovalores $(\lambda)$ & 0,001 & 0,000 & 0,001 & 0,000 \\
Porcentagem da variância explicada $(\%)$ & 8,8 & 1,3 & 7,4 & 1,1 \\
Porcentagem da variância acumulada & 8,8 & 10,1 & 7,4 & 8,5 \\
Correlação de Pearson (ambiente-vegetação) & 0,427 & 0,317 & 0,388 & 0,268 \\
Teste de Monte Carlo (p) & & & 0,1616 & 0,5758 \\
$\quad$ Autovalores & 0,0808 & 0,4444 & 0,3434 & 0,4040 \\
\hline
\end{tabular}

Os coeficientes canônicos para o eixo 1 em ambas as áreas (Tabela 18) mostraram que a densidade (N_IND), foi a variável de maior peso na ordenação. Além dessa variável, a área basal total (AB_TOT) e o incremento em diâmetro (C_DAP), também apresentaram valores significativos em Bragança (Tabela 18).

A correlação dentro dos grupos (intra-set), no eixo 1, embora tenham apresentado maiores valores para densidade (N_IND) em Marituba e Bragança (Tabela 18), eles não foram significativos, indicando que não há contribuição dessas variáveis na relação ambiente-vegetação, durante o período estudado.

Tabela 18. Coeficientes canônicos e correlações "intra-set" das três variáveis de vegetação com os eixos 1 e 2 da CCA, baseada nas sete variáveis de solo $(n=48)$

\begin{tabular}{lcccccccc}
\hline \multirow{2}{*}{ Variáveis } & \multicolumn{4}{c}{ Marituba } & \multicolumn{3}{c}{ Bragança } \\
& \multicolumn{2}{c}{ Coef. Canonico } & \multicolumn{2}{c}{ Coef. Corr. Intra-set } & \multicolumn{2}{c}{ Coef. Canonico } & \multicolumn{2}{c}{ Coef. Corr. Intra-set } \\
\cline { 2 - 9 } & Eixo 1 & Eixo 2 & Eixo 1 & Eixo 2 & Eixo 1 & Eixo 2 & Eixo 1 & Eixo 2 \\
\hline C_DAP & 0,199 & $-0,557$ & 0,209 & $-0,168$ & 0,637 & $-1,152$ & $-0,067$ & $-0,215$ \\
N_IND & $-1,042$ & $-0,544$ & $-0,402$ & 0,045 & $-1,618$ & 0,211 & $-0,239$ & 0,0137 \\
AB_TOT & 0,320 & 0,988 & $-0,104$ & 0,252 & 1,380 & 0,810 & 0,032 & $-0,61$ \\
\hline
\end{tabular}

Onde: C_DAP = incremento médio em diâmetro por subparcela; N_IND = densidade por subparcela; AB_TOT = área basal total por subparcela

Como pode ser observado nas Figuras 31 e 32, as variáveis de vegetação (Crescimento em diâmetro, densidade e área basal total) não formaram grupos específicos de parcelas. 


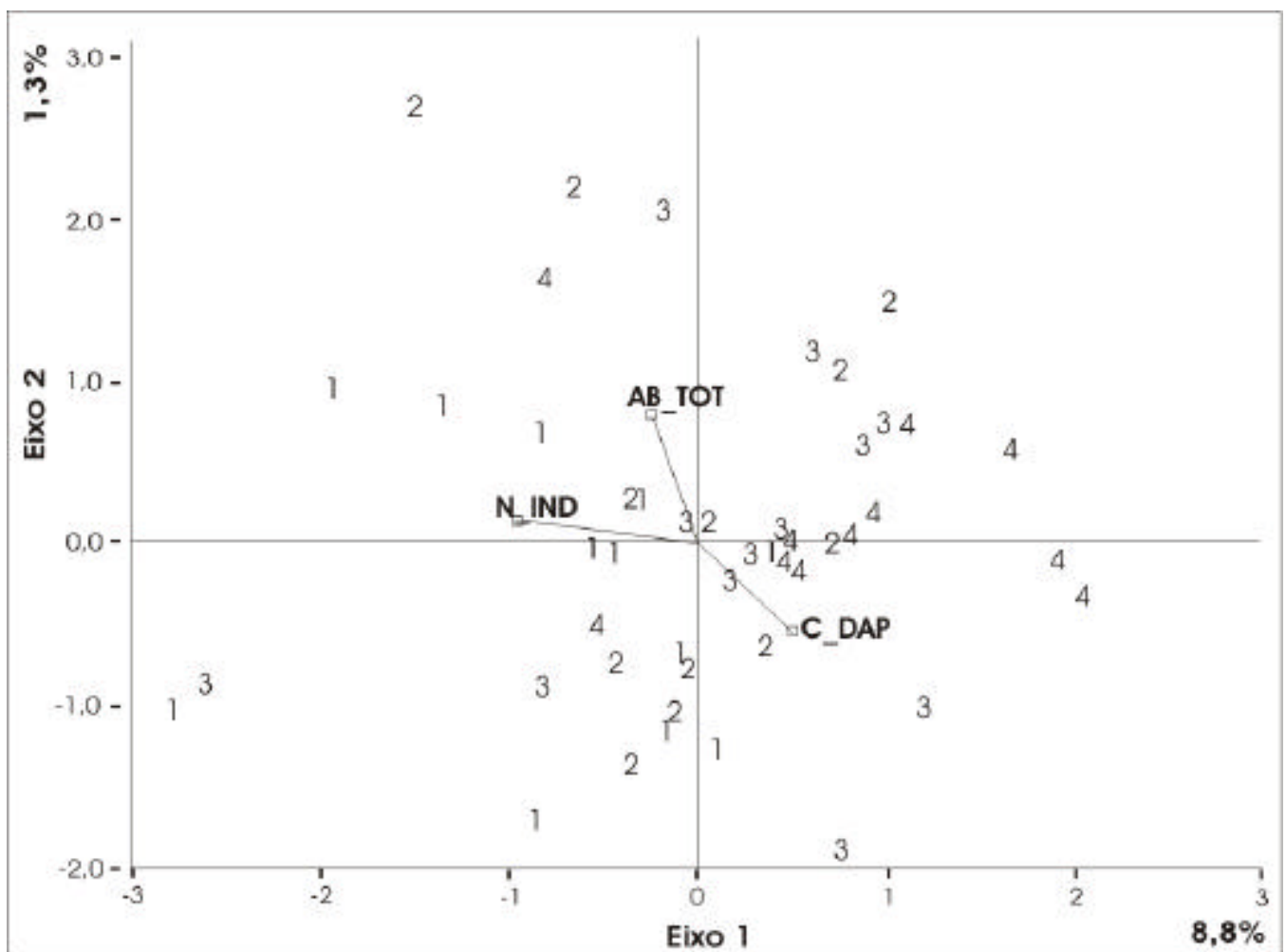

Figura 31 - Ordenação pela CCA das unidades amostrais, baseada nas principais variáveis indicadores de fertilidade do solo ( $\mathrm{pH}, \mathrm{MO}, \mathrm{P}, \% \mathrm{~V}, \% \mathrm{Al}, \mathrm{CTC}$ e Argila) coletadas na proundidade de $05 \mathrm{~cm}$, e em variáveis biofísicas da vegetação $($ C_DAP $=$ incremento em diâmetro, N_IND = densidade e AB_TOT = área basal total) em uma floresta secundária em Marituba-PA

Apesar da relatada influência dos atributos de fertilidade dos solos no desenvolvimento da vegetação (Kiehl, 1979; Mello et al., 1989; Mather, 1990; Tomé Jr., 1997; Tognon, 1998; Furtini Neto et al., 1999). No presente estudo, não foi possível demonstrar correlação com o incremento em diâmetro, nem com a distribuição do número de indivíduos (densidade) ou com a área basal total das comunidades estudadas, durante o período de acompanhamento. 
A explicação mais aceita para as diferenças entre as áreas podem ser atribuídas aos distintos históricos de degradação, - uma vez que a capacidade de regeneração natural será menor quanto maior o potencial de degradação e a duração da atividade (Uhl et al., 1988).

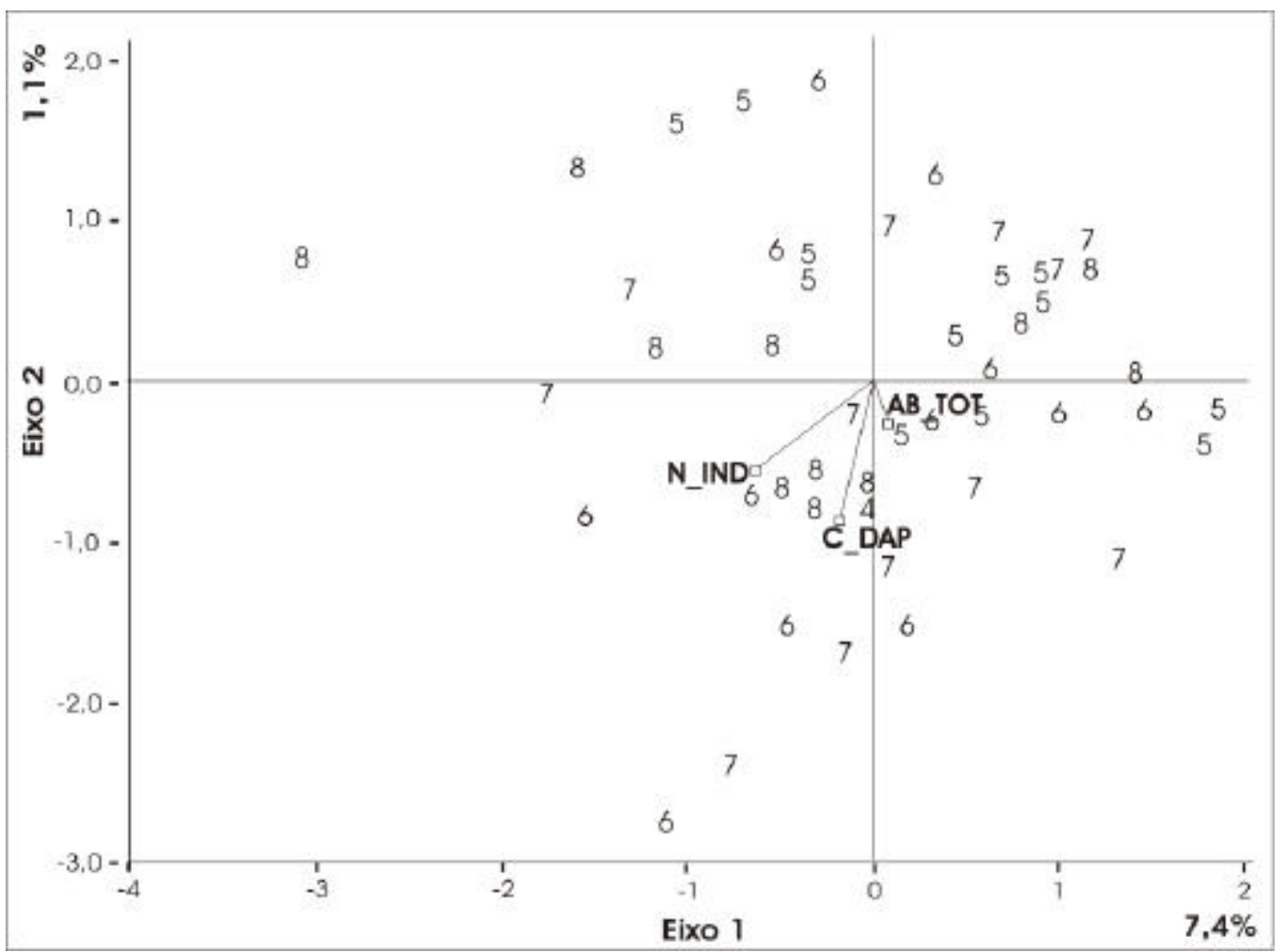

Figura 32 - Ordenação pela CCA das unidades amostrais, baseada nas principais variáveis indicadores de fertilidade do solo ( $\mathrm{pH}, \mathrm{MO}, \mathrm{P}, \% \mathrm{~V}, \% \mathrm{Al}, \mathrm{CTC}$ e Argila) coletadas na profundidade de $05 \mathrm{~cm}$, e em variáveis biofísicas da vegetação $\left(\mathrm{C} \_D A P=\right.$ incremento em diâmetro, $\mathrm{N} \_\mathrm{IND}=$ densidade e AB_TOT = área basal total) em uma floresta secundária em Bragança-PA, onde as parcelas $5,6,7$ e 8 correspondem às parcelas 1, 2, 3 e 4 nos Anexos 5, 6 e 7 


\section{CONCLUSÃO}

As duas florestas secundárias estudadas, embora possuam a mesma idade de regeneração, aproximadamente 50 anos, apresentaram expressiva diferença nos parâmetros florísticos e fitossociológicos. Estes fragmentos de floresta secundária não foram floristicamente similares entre si (Jaccard aproximadamente 12\%), nem com outros fragmentos de florestas primárias e secundárias, ocorrentes no entorno.

A floresta secundária de Marituba, após 50 anos do início do processo de regeneração, apresentou valores de riqueza, diversidade e área basal superiores aos encontrados em Bragança e comparáveis com os de florestas primárias. A área basal na floresta secundária de Marituba, no último levantamento, foi 38,7\% superior a de Bragança e a riqueza específica foi 33,0\% maior. Marituba apresentou maior capacidade de recrutamento de novas espécies (3,8/ano), enquanto Bragança, apresentou apenas 1,0 espécie/ano, ressaltando que o tempo de acompanhamento foi diferenciado, cinco e três anos, respectivamente, nessas áreas.

Os dois fragmentos de florestas secundárias, considerando o período total da pesquisa, apresentaram taxas anuais de incremento em diâmetro muito próximas, com pequena vantagem para Bragança. Esse comportamento foi confirmado nas classes diamétricas, onde o incremento médio na área de Bragança também foi superior. Diversos fatores podem ter determinado o maior crescimento das árvores nesta floresta secundária, entre eles, o estado inicial mais aberto da área de Bragança, em função das condições distintas de degradação, uma vez que esta área sofreu vários ciclos de cortequeima-plantio-pousio. Em Marituba, o processo de degradação por extrativismo seletivo, definiu uma condição mais fechada e sombreada em função das árvores remanescentes. Um outro fator é a diferença entre as espécies que ocupam o dossel 
superior nas duas áreas. Em Bragança, área mais degradada, o dossel mais baixo e mais uniforme, apresentou maior presença de espécies pioneiras de rápido crescimento e pertencentes a estádios mais iniciais de sucessão. Como consequiências do histórico de perturbação, tais condições podem ter permitido que as árvores com diâmetro superior a $10 \mathrm{~cm}$, na floresta secundária de Bragança, tivessem maior acesso à luz (Silva, 1989; Clark et al., 1993; Swaine et al., 1987b) e, conseqüentemente, maior crescimento.

As florestas secundárias estudadas apresentaram um balanço negativo entre a entrada e a saída de indivíduos, ou seja, as taxas de mortalidade foram maiores do que as de ingresso. O padrão apresentado é típico de comunidades em sucessão secundária antiga, onde a perda do número de indivíduos se dá, entre outros fatores, em função do aumento da área basal, processo definido por Brown \& Lugo (1990), como raleamento competitivo e da gradual substituição, por senescência, das espécies mais iniciais do processo de sucessão, pelas espécies de estádios sucessionais mais avançados. Isso se confirmou na constatação de que nas duas áreas as espécies pioneiras com diâmetro a partir de $20 \mathrm{~cm}$ apresentaram as maiores taxas de mortalidade.

Com relação às características edáficas, os solos, apesar de serem semelhantes quanto ao tipo, apresentaram níveis de fertilidade distintos a $5 \mathrm{~cm}$ de profundidade. A área de Bragança apresentou valores superiores para os principais atributos de fertilidade, soma de bases e saturação por bases, e menores níveis de toxidez por alumínio, além de maior $\mathrm{pH}$ e concentrações mais elevadas de $\mathrm{Na}, \mathrm{K}, \mathrm{Ca}$ e $\mathrm{Mg}$. É improvável que esta maior fertilidade seja efeito das queimadas que ocorreram a aproximadamente 50 anos, uma vez que, poucos anos (entre 1 e 5) após a passagem do fogo os níveis de fertilidade tendem a voltar a patamares iguais ou inferiores aos anteriores a queima (Uhl \& Jordan, 1984; Ivanauskas et al., 2003).

A matéria orgânica teve comportamento diferenciado para as duas áreas. Apesar de apresentarem idades de abandono semelhantes, o acúmulo médio de matéria orgânica no solo foi maior em Marituba para todas as profundidades. Essa diferença pode ser atribuída aos efeitos das sucessivas queimadas resultantes do preparo da terra na área de Bragança. Uma outra evidência, apesar das características do solo de Marituba serem menos favoráveis, é que a floresta secundária deste município apresentou estádio de 
sucessão secundária mais avançado, com maiores valores de área basal, de riqueza de espécies, de diversidade florística e de ingressos de novos indivíduos. Esse melhor desempenho é atribuído ao uso anterior dessa área para extrativismo seletivo de madeira para diversos usos e à paisagem regional mais favorável a manutenção da capacidade de resiliência, com a presença de fragmentos maiores e mais preservados de florestas primárias próximas à floresta secundária estudada.

Para a floresta de Bragança, apenas crescimento e mortalidade foram mais expressivos, mostrando que o processo dinâmico nessa área foi mais intenso, o que indica um estádio sucessional menos avançado, sendo provavelmente, resultado dos sucessivos ciclos de corte-queima-plantio-pousio. Nessa área a paisagem regional é dominada por fragmentos de florestas secundárias com várias idades e distintos graus de perturbação.

Portanto, a idade por si só não é um requisito adequado para prever taxas de recuperação ou estádios de sucessão de florestas secundárias, - sendo o processo de sucessão influenciado pela história específica do sítio, por fatores externos ao ecossistema e por fontes locais de sementes, caracterizando a sucessão como um processo estocástico e raramente determinístico (Pickett \& Ostfeld, 1995). O grau de degradação de um ecossistema afeta sua capacidade de auto-renovação e depende de fatores como freqüência, área e intensidade dos distúrbios a que foi submetido (Pickett, 1985), ou seja, a capacidade de regeneração natural será menor quanto maior o potencial de degradação e a duração da atividade (Uhl et al., 1988).

Diante do exposto, a hipótese de trabalho foi parcialmente confirmada, uma vez que as características de solo analisadas, não apresentaram correlação direta com as variáveis de vegetação (crescimento em diâmetro, densidade e área basal total), consideradas importantes no processo de regeneração; e que o histórico de perturbação foi definidor das características do processo de sucessão nas duas florestas secundárias, com mesma idade e sobre o mesmo tipo de solo. 
ANEXOS 
Anexo A. Parâmetros fitossociológicos das famílias das espécies arbóreas amostradas nos anos de 1997 e 2002 em uma floresta secundária oriunda de exploração de madeira para lenha, no município de Marituba-PA. E 1999 e 2002 em uma floresta secundária oriunda de agricultura de corte e queima no município de Bragança-PA

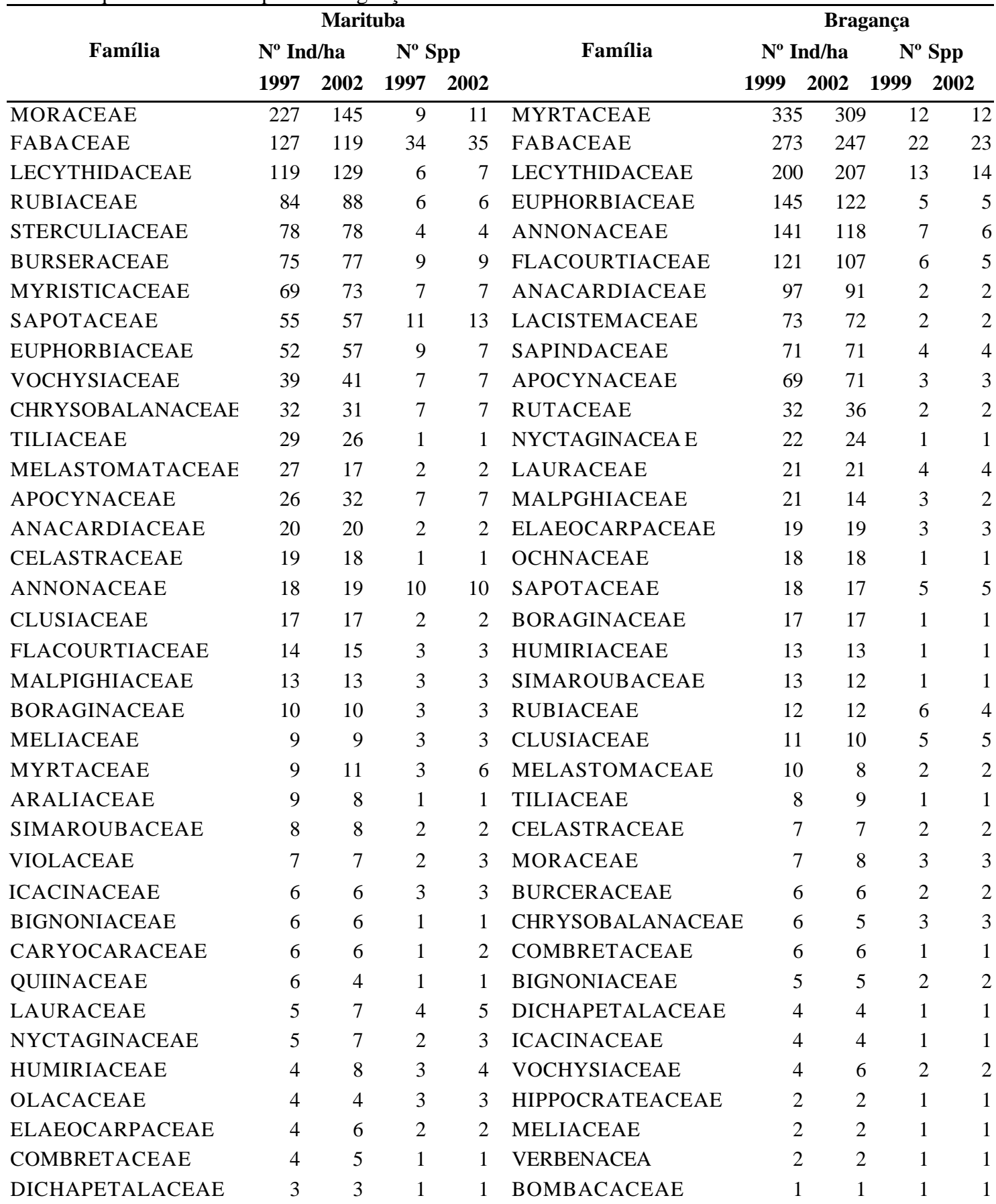


Continua... Anexo A. Parâmetros fitossociológicos das famílias das espécies arbóreas amostradas nos anos de 1997 e 2002 em uma floresta secundária oriunda de exploração de madeira para lenha, no município de Marituba-PA. E 1999 e 2002 em uma floresta secundária oriunda de agricultura de corte e queima no município de Bragança-PA

\begin{tabular}{|c|c|c|c|c|c|c|c|c|c|c|}
\hline \multirow{3}{*}{ Família } & \multicolumn{4}{|c|}{ Marituba } & \multirow{3}{*}{ Família } & \multicolumn{5}{|c|}{ Bragança } \\
\hline & \multicolumn{2}{|c|}{$\mathrm{N}^{\mathrm{o}}$ Ind/ha } & \multicolumn{2}{|c|}{$N^{o}$ Ind/ha } & & \multicolumn{2}{|c|}{$\mathbf{N}^{0}$ Ind/ha } & \multicolumn{3}{|c|}{$\mathbf{N}^{\circ} \mathrm{Spp}$} \\
\hline & 1997 & 2002 & 1997 & 2002 & & 1999 & 2002 & 1999 & & 2002 \\
\hline MEMECYLACEAE & 2 & 2 & 2 & 2 & EBENACEAE & & 1 & 1 & 1 & 1 \\
\hline RUTACEAE & 2 & 2 & 2 & 2 & NI & & 1 & 1 & 1 & 1 \\
\hline LINACEAE & 2 & 4 & 1 & 1 & QUIINACEAE & & 1 & 1 & 1 & 1 \\
\hline MONIMIACEAE & 2 & 3 & 1 & 1 & MYRISTICACEAE* & & & 1 & & 1 \\
\hline OPILIACEAE & 2 & 2 & 1 & 1 & & & & & & \\
\hline EBENACEAE & 1 & 1 & 1 & 1 & & & & & & \\
\hline ULMACEAE & 1 & 1 & 1 & 1 & & & & & & \\
\hline NI* & 0 & 2 & 0 & 1 & & & & & & \\
\hline SAPINDACEAE* & 0 & 2 & 0 & 2 & & & & & & \\
\hline TOTAL & 1257,0 & 206,0 & 185 & 200 & TOTAL & 181 & $9 \quad 17$ & & 36 & 134 \\
\hline
\end{tabular}

As células em branco na tabela representam valores menores que 0,01,

* Família ingressante ao longo do período.

$\mathbf{N}^{\mathbf{o}}$ Ind/ha = número de indivíduos por hectare; $\mathbf{N}^{\mathbf{0}} \mathbf{S p p}=$ número de espécies por famílias . 
Anexo B. Parâmetros fitossociológicos das espécies arbóreas amostradas nos anos de 1997 e 2002 (por ordem de IVI) em uma floresta secundária oriunda de exploração seletiva de madeira para lenha, no município de Marituba-PA

\begin{tabular}{|c|c|c|c|c|c|c|c|c|c|c|c|c|c|c|c|c|c|}
\hline \multirow{2}{*}{ Espécies } & \multirow{2}{*}{ Famílias } & \multicolumn{2}{|c|}{$\overline{\text { DA }}$} & \multicolumn{2}{|c|}{ DR } & \multicolumn{2}{|c|}{ DoR } & \multicolumn{2}{|c|}{ FR } & \multicolumn{2}{|c|}{ IVI } & \multicolumn{2}{|c|}{ Ar.Bas. } & \multicolumn{2}{|c|}{ DAP 1997} & \multicolumn{2}{|c|}{$\overline{\text { DAP } 2002}$} \\
\hline & & 1997 & 2002 & 1997 & 2002 & 1997 & 2002 & 1997 & 2002 & 1997 & 2002 & 1997 & 2002 & Min. & Max. & Min. & Max. \\
\hline Pourouma guianensis & IORACEAE & 89 & 72 & 7,08 & 5,97 & 13,36 & 11,71 & 5,13 & 4,72 & 25,57 & 22,40 & 3,657 & 3,306 & 5,4 & 40,5 & 7,7 & $\overline{34,3}$ \\
\hline Pourouma longipendula & IORACEAE & 106 & 50 & 8,43 & 4,15 & 11,83 & 5,12 & 5,13 & 3,02 & 25,39 & 12,28 & 3,238 & 1,447 & ,0 & 37,2 & 0 & 35,3 \\
\hline Eschweilera coriacea & LECYTHIDAC & 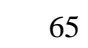 & 74 & 5,17 & 6,14 & & 4,32 & 4,42 & 4,82 & 12,88 & 15,28 & 0,899 & 1,219 &,$\sigma$ & 45,0 &, 0 & 70,0 \\
\hline Coussarea paniculata & $\mathrm{AE}$ & 52 & ( & 4,14 & 4,89 & 2,5 & 2,88 & 4,32 & 4,72 & 11,00 & 12,50 & 0,695 & 0,815 & , & 36,5 & 5,0 & 38,0 \\
\hline Sterculia pilosa & STERCULIACEAE & 56 & 52 & 4,46 & 4,31 & 2,46 & 2,63 & 4,02 & 3,82 & 10,93 & 10,76 & 0,673 & 0,743 & 5,0 & 64,5 & 5,2 & 66,6 \\
\hline Iryanthera juruensis & MYl & 54 & 54 & 4,30 & 4,48 & 1,98 & 2,46 & 4,52 & 4,42 & 10,80 & 11,36 & 0,542 & 0,694 & 5,0 & 38,2 & ,0 & 47,1 \\
\hline Apeiba albiflora & TILIACEAE & 29 & 26 & 2,31 & 2,16 & 1,90 & 1,94 & 2,31 & 2,11 & 6,52 & 6,21 & 0,521 & 0,548 & 5,0 & 39,6 & 5,0 & 40,3 \\
\hline Protium opacum & ACEAE & 32 & 30 & 2,55 & 2,49 & 1,34 & 1,38 & 2,51 & 2,31 & 6,40 & 6,17 & 0,367 & 0,388 & 5,0 & 36,0 & $\mathrm{D}, \mathrm{I}$ & 39,0 \\
\hline & CEAE & 34 & 32 & 2,70 & 2,65 & 0,94 & 1,01 & 2,51 & 2,41 & 6,16 & 6,08 & 0,258 & 0,286 &, 0 & 21,3 & 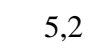 & 23,9 \\
\hline & & 6 & 16 & 2,07 & 1,33 & & 1,01 & 2,41 & & 6,06 & 3,74 & 0,434 & & 6,3 & 26,7 & , & 29,2 \\
\hline Esch & LEC & 28 & 8 & 2,23 & 2,32 & 1,22 & 1,28 & 2,01 & 2,01 & 5,45 & 5,61 & 0,333 & 0,361 & 5,3 & 28,0 & 2 & 28,2 \\
\hline Piptadenia suaveolens & $\mathrm{FAB}$ & 11 & 10 & 0,88 & 0,83 & 3,50 & 6,56 & 0,90 & 0,80 & 5,28 & 8,19 & 0,959 & 1,853 & 5,0 & 72,0 & 0 & 99,0 \\
\hline Inga alba & FABACEAE M & 18 & 12 & 1,43 & 1,00 & 2,37 & 2,44 & 1,21 & 1,01 & 5,01 & 4,44 & 0,649 & 0,688 & 5,1 & 61,5 & 5,7 & 13,0 \\
\hline uncinatum & VOCHYSIACEAE & 5 & 7 & 0,40 & 0,58 & 3,75 & 3,94 & 0,50 & 0,70 & 4,65 & 5,22 & 1,027 & 1,112 & 5,0 & 111,4 & 5,2 & 115,1 \\
\hline niculata & $\mathrm{El}$ & 4 & 5 & 1,91 & 2,07 & 0 & 0,70 & 2,11 & 2,11 & 4,47 & 4,88 & 0,124 & 97 & 0 & 27,5 & 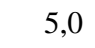 & 40,5 \\
\hline & VOCF & 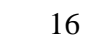 & 15 & 1,27 & 4 & & 2,10 & 1,31 & & 4,38 & 4,55 & & & & 34,3 & & 36,5 \\
\hline & ACEAE & 12 & 12 & 0,95 & 1,00 & 2,23 & 2,43 & 1,11 & 1,11 & 4,29 & 4,53 & 0,611 & 0,687 & 5,0 & 37,5 & 6,0 & 62,0 \\
\hline Goupia glabra & TRACE & 19 & 18 & 1,51 & 1,49 & 1,05 & 1,09 & 1,41 & 1,61 & 3,97 & 4,19 & 0,288 & 0,308 & 5,2 & 25,0 & 5,2 & 33,3 \\
\hline Inga capitata & FABACEAE Mimo. & 17 & 17 & 1,35 & 1,41 & 1,30 & 1,39 & 1,31 & 1,31 & 3,96 & 4,11 & 0,357 & 0,393 & 5,5 & 35,5 & 5,1 & 35,8 \\
\hline Eschweilera blanchetiana & ГHIDACEAE & 18 & 18 & 1,43 & 1,49 & 1,13 & 1,08 & 1,31 & 1,31 & 3,87 & 3,88 & 0,309 & 0,306 & 0 & 32,4 & ,0 & 26,8 \\
\hline Licania logistyla & CHRYSOBALANACEAE & 17 & 17 & 1,35 & 1,41 & 1,01 & 1,04 & 1,51 & 1,51 & 3,87 & 3,95 & 0,277 & 0,292 & 5,8 & 38,3 & 2 & 38,7 \\
\hline Protium pallidum & BURSERACEAE & 15 & 16 & 1,19 & 1,33 & 1,16 & 1,31 & 1,41 & 1,61 & 3,76 & 4,25 & 0,317 & 0,371 & 5,0 & 44,6 & 5,0 & 47,9 \\
\hline Palicourea guianensis & RUBIACEAE & 21 & 15 & 1,67 & 1,24 & 0,32 & 0,29 & 1,61 & 1,21 & 3,60 & 2,74 & 0,087 & 0,081 & 5,0 & 12,4 & 5,3 & 15,2 \\
\hline Theobroma subincanum & STERCULIACEAE & 20 & 24 & 1,59 & 1,99 & 0,45 & 0,54 & 1,51 & 1,71 & 3,55 & 4,23 & 0,122 & 0,151 & 5,0 & 15,6 & 5,2 & 16,9 \\
\hline Cecropia obtusa & MORACEAE & 13 & 4 & 1,03 & 0,33 & 1,05 & 0,57 & 1,01 & 0,40 & 3,09 & 1,30 & 0,289 & 0,160 & 5,0 & 27,0 & 6,6 & 17,6 \\
\hline Tapirira guianensis & ANACARDIACEAE & 13 & 11 & 1,03 & 0,91 & 0,96 & 0,96 & 1,01 & 1,01 & 3,00 & 2,88 & 0,263 & 0,272 & 5,0 & 35,7 & 5,0 & 15,1 \\
\hline
\end{tabular}


Continua...

Anexo B. Parâmetros fitossociológicos das espécies arbóreas amostradas nos anos de 1997 e 2002 (por ordem de IVI) em uma floresta secundária oriunda de exploração seletiva de madeira para lenha, no município de Marituba-PA

\begin{tabular}{|c|c|c|c|c|c|c|c|c|c|c|c|c|c|c|c|c|c|}
\hline \multirow{2}{*}{ Espécies } & \multirow{2}{*}{ Famílias } & \multicolumn{2}{|c|}{ DA } & \multicolumn{2}{|c|}{ DR } & \multicolumn{2}{|c|}{ DoR } & \multicolumn{2}{|c|}{ FR } & \multicolumn{2}{|c|}{ IVI } & \multicolumn{2}{|c|}{ Ar.Bas. } & \multicolumn{2}{|c|}{ DAP 1997} & \multicolumn{2}{|c|}{ DAP 2002} \\
\hline & & 1997 & 2002 & 1997 & 2002 & 1997 & 2002 & 1997 & 2002 & 1997 & 2002 & 1997 & 2002 & Min. & Max. & Min. & Max. \\
\hline Mabea caudata & PHORBIACEAE & 15 & 21 & 1,19 & 1,74 & 0,16 & 0,20 & 1,51 & 2,01 & 2,86 & 3,96 & 0,044 & 0,058 & 5,0 & 9,4 & 5,0 & $\overline{9,1}$ \\
\hline Inga spl & BACEAE Mimo. & 12 & 8 & 0,95 & 0,66 & 0,85 & 0,83 & 1,01 & 0,70 & 2,81 & 2,20 & 0,234 & 0,235 & 5,0 & 36,6 & 7,5 & 29,2 \\
\hline Abarema jupumba & FABACEAE Mimo. & 9 & 9 & 0,72 & 0,75 & 1,27 & 1,37 & 0,80 & 0,80 & 2,79 & 2,92 & 0,347 & 0,387 & 5,7 & 38,0 & 6,0 & 39,4 \\
\hline Dipteryx odorata & FABACEAE Pap. & 2 & 2 & 0,16 & 0,17 & 2,23 & 2,07 & 0,20 & 0,20 & 2,59 & 2,44 & 0,611 & 0,585 & 6,2 & 88,0 & 6,8 & 7,9 \\
\hline Schefflera morototoni & ARALIACEAE & 9 & 8 & 0,72 & 0,66 & 0,90 & 0,88 & 0,80 & 0,70 & 2,42 & 2,25 & 0,246 & 0,248 & 5,0 & 31,8 & 5,0 & 37,3 \\
\hline Qualea eximia & OCHYSIACEAE & 5 & 5 & 0,40 & 0,41 & 1,61 & 1,80 & 0,40 & 0,40 & 2,41 & 2,62 & 0,442 & 0,510 & 9,2 & 57,3 & 5,5 & 9,6 \\
\hline Protium subserr & BURSERACEAE & 10 & 12 & 0,80 & 1,00 & 0,7 & 0,94 & 0,80 & 1,01 & 2,39 & 2,94 & 0,217 & 0,265 & J, & 23,5 & 5,3 & 27,4 \\
\hline Cecropia sciadophylla & MOR & 6 & 6 & 0,48 & 0,50 & 1,27 & 1,32 & 0,60 & 0,60 & 2,35 & 2,42 & 0,347 & 0,373 & 22,3 & 31,5 & 22,6 & 32,1 \\
\hline dlia pruriens & LIACEAE & 1 & 1 & 0,08 & 0,08 & 2,15 & 2,41 & 0,10 & 0,10 & 2,33 & 2,59 & 0,588 & 0,679 & 86,5 & 86,5 & 9,1 & 9,1 \\
\hline Laetia procera & FLACOURTIACEAE & 12 & 13 & 0,95 & 1,08 & 0,33 & 0,38 & 1,01 & 1,11 & 2,29 & 2,56 & 0,091 & 0,106 & 5,2 & 20,7 & 5,0 & 23,0 \\
\hline Vochysia vismiaefolia & VOCHYSIACEAE & 5 & 6 & 0,40 & 0,50 & 1,32 & 1,65 & 0,50 & 0,60 & 2,22 & 2,75 & 0,362 & 0,465 & 11,0 & 44,0 & 5,0 & 51,3 \\
\hline Vochysia inundata & $\mathrm{VOCH}$ & 4 & 4 & 0,32 & 0,33 & 1,39 & 1,78 & 0,30 & 0,30 & 2,01 & 2,42 & 0,380 & 0,504 & 9,7 & 42,0 & 11,7 & 19,3 \\
\hline ianensis & MELIACEAE & 2 & 2 & 6 & 0,17 & 8 & & 20 & 0 & 1,94 & 2,12 & 0,431 & 0,495 & 32,1 & 66,8 & 5,4 &, 5 \\
\hline Cordia bicolor & E & 8 & 8 & 0,64 & 0,66 & 0,44 & 0,49 & 0,80 & 0,80 & 1,88 & 1,96 & 0,121 & 0,138 & 7,1 & 28,3 & 5,6 & 37,1 \\
\hline Protium spruceanum & ACEAE & 6 & 6 & 0,48 & 0,50 & 0,78 & 0,84 & 0,60 & 0,60 & 1,86 & 1,94 & 0,213 & 0,237 & 5,5 & 35,0 & 7,0 & 35,2 \\
\hline Byrsonima aerugo & MALPIGHIACEAE & 8 & 7 & 0,64 & 0,58 & 0,38 & 0,49 & 0,80 & 0,70 & 1,82 & 1,78 & 0,104 & 0,139 & 5,8 & 18,2 & 6,2 & 20,7 \\
\hline Inga heterophylla & FABACEAE Mimo. & 4 & 2 & 0,32 & 0,17 & 1,10 & 0,34 & 0,30 & 0,20 & 1,71 & 0,70 & 0,300 & 0,095 & 5,1 & 53,0 & 5,8 & 6,1 \\
\hline Ambelania acida & APOCYNACEAE & 9 & 12 & 0,72 & 1,00 & 8 & 0 & 80 & 1 & 1,70 & 34 & 50 & 68 & ,4 & 12,6 & 5,2 & 40,0 \\
\hline Caryocar glabrum & CARYOCARACEA & 6 & 5 & 0,48 & 0,41 & 0,62 & 0 , & 0,60 & 0 , & 1,70 & 1,08 & 0,171 & 0,045 & 7,0 & 40,0 & 7,3 & 14,7 \\
\hline Vatairea sericea & FABACEAE Pap. & 5 & 5 & 0,40 & 0,41 & 0,72 & 0,75 & 0,50 & 0,50 & 1,62 & 1,67 & 0,198 & 0,213 & 10,6 & 35,3 & 9,5 & 60,2 \\
\hline Tachigali sp. & FABACEAE Caes. & 1 & 1 & 0,08 & 0,08 & 1,41 & 2,28 & 0,10 & 0,10 & 1,59 & 2,46 & 0,385 & 0,643 & 70,0 & 70,0 & 5,2 & 5,2 \\
\hline Thyrsodium paraense & ANACARDIACEAE & 7 & 9 & 0,56 & 0,75 & 0,42 & 0,48 & 0,60 & 0,80 & 1,58 & 2,03 & 0,116 & 0,137 & 5,0 & 25,4 & 5,4 & 27,0 \\
\hline Lacmellea sculeata & APOCYNACEAE & 8 & 9 & 0,64 & 0,75 & 0,22 & 0,25 & 0,70 & 0,80 & 1,56 & 1,80 & 0,060 & 0,071 & 5,0 & 18,5 & 6,0 & 18,5 \\
\hline Ferdinandusa sp. & RUBIACEAE & 8 & 11 & 0,64 & 0,91 & 0,13 & 0,18 & 0,70 & 0,90 & 1,47 & 1,99 & 0,037 & 0,050 & 5,0 & 14,4 & 5,6 & 36,5 \\
\hline Ormosiopsis flava & FABACEAE Pap. & 2 & 2 & 0,16 & 0,17 & 1,02 & 0,99 & 0,20 & 0,20 & 1,38 & 1,36 & 0,280 & 0,281 & 24,3 & 54,5 & 24,4 & 54,6 \\
\hline Simarouba amara & SIMAROUBACEAE & 6 & 6 & 0,48 & 0,50 & 0,21 & 0,24 & 0,60 & 0,60 & 1,29 & 1,34 & 0,057 & 0,066 & 7,0 & 18,1 & 7,5 & 19,6 \\
\hline Rinorea guianensis & VIOLACEAE & 5 & 4 & 0,40 & 0,33 & 0,38 & 0,06 & 0,50 & 0,40 & 1,28 & 0,79 & 0,105 & 0,017 & 5,4 & 33,8 & 5,9 & 11,0 \\
\hline Jacaranda copaia & BIGNONIACEAE & 6 & 6 & 0,48 & 0,50 & 0,19 & 0,27 & 0,60 & 0,60 & 1,27 & 1,37 & 0,051 & 0,077 & 5,0 & 19,0 & 5,0 & 24,3 \\
\hline
\end{tabular}


Continua

Anexo B. Parâmetros fitossociológicos das espécies arbóreas amostradas nos anos de 1997 e 2002 (por ordem de IVI) em uma floresta secundária oriunda de exploração seletiva de madeira para lenha, no município de Marituba-PA

\begin{tabular}{|c|c|c|c|c|c|c|c|c|c|c|c|c|c|c|c|c|c|}
\hline \multirow{2}{*}{ Espécies } & \multirow{2}{*}{ Famílias } & \multicolumn{2}{|c|}{$\overline{\mathbf{D A}}$} & \multicolumn{2}{|c|}{ DR } & \multicolumn{2}{|c|}{ DoR } & \multicolumn{2}{|c|}{ FR } & \multicolumn{2}{|c|}{ IVI } & \multicolumn{2}{|c|}{ Ar.Bas. } & \multicolumn{2}{|c|}{ DAP 1997} & \multicolumn{2}{|c|}{ DAP 2002} \\
\hline & & 1997 & 2002 & 1997 & 2002 & 1997 & 2002 & 1997 & 2002 & 1997 & 2002 & 1997 & 2002 & Min. & Max. & Min. & Max. \\
\hline Lacunaria jenmani & UIINACEAE & 6 & 4 & 0,48 & 0,33 & 0,16 & 0,14 & 0,60 & 0,40 & 1,24 & 0,87 & 0,044 & 0,039 & 5,5 & 18,5 & 18,0 & 28,2 \\
\hline Trichilia lecointei & ELIACEAE & 6 & 6 & 0,48 & 0,50 & 0,12 & 0,13 & 0,60 & 0,60 & 1,20 & 1,23 & 0,034 & 0,038 & 5,4 & 11,8 & 5,1 & 12,5 \\
\hline Eschweilera amara & LECYTHIDACEAE & 6 & 6 & 0,48 & 0,50 & 0,29 & 0,31 & 0,40 & 0,40 & 1,17 & 1,21 & 0,080 & 0,087 & 5,8 & 18,5 & 6,1 & 19,6 \\
\hline Virola michelii & IYRISTICACEAE & 6 & 10 & 0,48 & 0,83 & 0,09 & 0,17 & 0,60 & 0,90 & 1,17 & 1,90 & 0,025 & 0,048 & 6,0 & 10,0 & 5,0 & 13,4 \\
\hline Chaunokiton kapleri & DPILIACEAE & 2 & 2 & 0,16 & 0,17 & 0,76 & 0,87 & 0,20 & 0,20 & 1,12 & 1,24 & 0,209 & 0,247 & 32,5 & 40,1 & 16,2 & 30,8 \\
\hline Sclerolobium paraense & ABACEAE Caes. & 4 & 4 & 0,32 & 0,33 & 0,54 & 0,68 & 0,20 & 0,20 & 1,06 & 1,21 & 0,147 & 0,191 & 9,5 & 33,4 & 5,0 & 15,7 \\
\hline Trattinickia rhoifolia & BURSERACEAE & 6 & 6 & 0,48 & 0,50 & 0,17 & 0,18 & 0,40 & 0,40 & 1,05 & 1,08 & 0,047 & 0,051 & 6,5 & 14,2 & 6,6 & 14,6 \\
\hline Licania heteromorpha & CHRYSOBALANACEAE & 5 & 4 & 0,40 & 0,33 & 0,13 & 0,07 & 0,50 & 0,40 & 1,03 & 0,80 & 0,035 & 0,019 & 5,3 & 15,0 & 5,1 & 8,2 \\
\hline Vouacapoua americana & FABACEAE Caes. & 5 & 6 & 0,40 & 0,50 & 0,09 & 0,14 & 0,50 & 0,60 & 0,99 & 1,24 & 0,025 & 0,039 & 5,1 & 11,7 & 5,6 & 13,7 \\
\hline Guatteria poeppigiana & ANNONACEAE & 5 & 7 & 0,40 & 0,58 & 0,07 & 0,09 & 0,50 & 0,70 & 0,97 & 1,38 & 0,018 & 0,026 & 5,1 & 8,3 & 5,0 & 8,7 \\
\hline Tovomita brevistaminea & $\mathrm{AE}$ & 5 & 5 & 0,40 & 0,41 &, 06 & 0,06 & 0,50 & 0,50 & 0,96 & 0,98 & 0,016 & 0,018 & 5,0 & 8,4 & 5,5 & 15,2 \\
\hline Poraqueiba guianensis & ICACINACEAE & 4 & 4 & 0,32 & 0,33 & 0,23 & 0,24 & 0,40 & 0,40 & 0,95 & 0,97 & 0,062 & 0,068 & 11,4 & 18,1 & 5,1 & 14,4 \\
\hline Sloanea froesii & ELAEOCARPACEAE & 3 & 4 & 0,24 & 0,33 & 0,37 & 0,35 & 0,30 & 0,40 & 0,91 & 1,09 & 0,101 & 0,100 & 10,2 & 25,0 & 5,0 & 25,3 \\
\hline Sclerolobium chrysophyllum & FABACEAE Caes. & 1 & 1 & 0,08 & 0,08 & 0,70 & 1,03 & 0,10 & 0,10 & 0,88 & 1,21 & 0,191 & 0,290 & 49,3 & 49,3 & 6,0 & 6,0 \\
\hline Tapura singularis & DICHAPETALACEAE & 3 & 3 & 0,24 & 0,25 & 32 & 0,32 & 0,30 & 30 & 0,86 & 0,87 & 0,088 & 0,090 & 8,2 & 25,3 & 5,4 & 13,1 \\
\hline Myrcia spl & MYRTACEAE & 4 & 4 & 0,32 & 0,33 & 0,13 & 0,13 & 0,40 & 0,40 & 0,85 & 0,86 & 0,035 & 0,037 & 5,5 & 18,0 & 5,8 & 18,1 \\
\hline Neea guianensis & NYCTAGINACEAE & 4 & 4 & 0,32 & 0,33 & 0,08 & 0,09 & 0,40 & 0,40 & 0,80 & 0,82 & 0,021 & 0,025 & 5,4 & 11,4 & 7,3 & 11,1 \\
\hline Eugenia patrisii & MYRTACEAE & 4 & 3 & 0,32 & 0,25 & 0,07 & 0,04 & 0,40 & 0,30 & 0,79 & 0,59 & 0,020 & 0,012 & 5,1 & 10,2 & 8,3 & 22,2 \\
\hline Brosimum guianensis & MORACEAE & 3 & 3 & 0,24 & 0,25 & 0,17 & 0,18 & 0,30 & 0,30 & 0,71 & 0,73 & 0,048 & 0,051 & 7,2 & 21,0 & 5,2 & 9,3 \\
\hline Licania blanchiiprance & CHRYSOBALANACEAE & 3 & 3 & 0,24 & 0,25 & 0,17 & 0,19 & 0,30 & 0,30 & 0,71 & 0,74 & 0,045 & 0,053 & 12,4 & 16,9 & 12,8 & 18,1 \\
\hline Inga rubiginosa & FABACEAE Mimo. & 3 & 3 & 0,24 & 0,25 & 0,16 & 0,07 & 0,30 & 0,30 & 0,70 & 0,62 & 0,045 & 0,020 & 8,8 & 19,1 & 6,1 & 11,8 \\
\hline Protium paniculatum & BURSERACEAE & 3 & 2 & 0,24 & 0,17 & 0,16 & 0,16 & 0,30 & 0,20 & 0,70 & 0,53 & 0,044 & 0,045 & 9,2 & 17,9 & 33,4 & 72,0 \\
\hline Drypetes variabilis & EUPHORBIACEAE & 4 & 5 & 0,32 & 0,41 & 0,06 & 0,08 & 0,30 & 0,30 & 0,68 & 0,79 & 0,015 & 0,022 & 6,0 & 8,3 & 5,1 & 12,3 \\
\hline Sapium scelerantum & EUPHORBIACEAE & 3 & 2 & 0,24 & 0,17 & 0,24 & 0,10 & 0,20 & 0,20 & 0,68 & 0,47 & 0,065 & 0,029 & 11,1 & 22,9 & 37,9 & 41,3 \\
\hline Terminalia amazonica & COMBRETACEAE & 4 & 5 & 0,32 & 0,41 & 0,06 & 0,05 & 0,30 & 0,40 & 0,67 & 0,86 & 0,015 & 0,014 & 5,1 & 8,9 & 5,0 & 7,6 \\
\hline
\end{tabular}


Continua...

Anexo B. Parâmetros fitossociológicos das espécies arbóreas amostradas nos anos de 1997 e 2002 (por ordem de IVI) em uma floresta secundária oriunda de exploração seletiva de madeira para lenha, no município de Marituba-PA

\begin{tabular}{|c|c|c|c|c|c|c|c|c|c|c|c|c|c|c|c|c|c|}
\hline \multirow{2}{*}{ Espécies } & \multirow{2}{*}{ Famílias } & \multicolumn{2}{|c|}{$\overline{\text { DA }}$} & \multicolumn{2}{|c|}{$\overline{\text { DR }}$} & \multicolumn{2}{|c|}{ DoR } & \multicolumn{2}{|c|}{ FR } & \multicolumn{2}{|c|}{ IVI } & \multicolumn{2}{|c|}{ Ar.Bas. } & \multicolumn{2}{|c|}{ DAP 1997} & \multicolumn{2}{|c|}{ DAP 2002} \\
\hline & & 1997 & 2002 & 1997 & 2002 & 1997 & 2002 & 1997 & 2002 & 1997 & 2002 & 1997 & 2002 & Min. & Max. & Min. & Max. \\
\hline Ni ni4 & TACEAE & 3 & 4 & 0,24 & 0,33 & 0,07 & 0,09 & 0,30 & 0,40 & 0,61 & 0,82 & 0,020 & 0,024 & 5,5 & 13,0 & 9,6 & 37,9 \\
\hline Pourouma paraen & $\mathrm{AE}$ & 3 & 2 & 0,24 & 0,17 & 0,07 & 0,05 & 0,30 & 0,20 & 0,61 & 0,42 & 0,019 & 0,014 & 8,3 & 9,2 & 6,8 & 13,4 \\
\hline Xylopia nítida & NNONACEAE & 3 & 2 & 0,24 & 0,17 & 0,17 & 0,06 & 0,20 & 0,20 & 0,61 & 0,43 & 0,019 & 0,018 & 6,6 & 19,8 & 6,8 & 86,0 \\
\hline Batesia floribunda & ABACEAE Caes. & 1 & 1 & 0,08 & 0,08 & 0,41 & 0,44 & 0,10 & 0,10 & 0,59 & 0,62 & 0,014 & 0,123 & 38,0 & 38,0 & 5,0 & 5,0 \\
\hline Inga thibaudiana & ABACEAE Mimo. & 3 & 3 & 0,24 & 0,25 & 0,05 & 0,06 & 0,30 & 0,30 & 0,59 & 0,61 & 0,013 & 0,016 & 6,6 & 8,1 & 7 , & 9,4 \\
\hline Tachigali guianensis & AE Caes. & 3 & 5 & 0,24 & 0,41 & 0,05 & 0,08 & 0,30 & 0,40 & 0,59 & 0,90 & 0,014 & 0,023 & 5,4 & 10,5 & 11,0 & 35,9 \\
\hline Couma guian & YNACEAE & 3 & 5 & 0,24 & 0,41 & 0,04 & 0,08 & 0,30 & 0,50 & 0,58 & 0,99 & 0,010 & 0,021 & 5,4 & 8,6 & 5,0 & 9,0 \\
\hline Vantanea parviflora & UMIRIACEAE & 2 & 4 & 0,16 & 0,33 & 0,21 & 0,23 & 0,20 & 0,40 & 0,57 & 0,97 & 0,057 & 0,066 & 7,6 & 25,9 & 9,7 & 51,7 \\
\hline Parinarium barbatum & HRYSOBALANACI & 2 & 2 & 0,16 & 0,17 & 0,18 & 0,22 & 0,20 & 0,20 & 0,54 & 0,59 & 0,050 & 0,063 & 15,6 & 19,9 & 19,2 & 20,9 \\
\hline Byrsonima crispa & IIACEAE & 3 & 4 & 0,24 & 0,33 & 0,09 & 0,22 & 0,20 & 0,20 & 0,53 & 0,75 & 0,026 & 0,062 & 8,3 & 11,5 & 5,7 & 8,5 \\
\hline Virol & & 3 & 3 & 24 & 0,25 & 08 & 1 & 0,20 & 0 & 0,52 & 0,56 & 0,023 & 0,031 & 9,1 & 11,0 & 6,1 & 10,2 \\
\hline Manilkara paraens & $\mathrm{E}$ & 1 & 1 & 0,08 & 0,08 & 0,33 & 0,40 & 0,10 & 0 & 0,51 & 0,59 & 0,041 & 0,114 & 34,0 & 34,0 & 15,5 & 15,5 \\
\hline Inga gracilifolia & AE Mimo. & 1 & 1 & 0,08 & 0,08 & 0,29 & 0,27 & 0,10 & 0,10 & 0,47 & 0,45 & 0,079 & 0,076 & 31,8 & 31,8 & 5,6 & 5,6 \\
\hline Xylopia benthamii & ACEAE & 2 & 2 & 0,16 & 0,17 & 0,06 & 0,07 & 0,20 & 0,20 & 0,43 & 0,43 & 0,018 & 0,018 & 5,5 & 14,0 & 5,8 & 7,7 \\
\hline Virola $s p$ & CACEAD & 2 & 1 & 0,16 & 0 , & 06 & 0,01 & 0,20 & & 0,42 & 19 & 0,017 & 0,002 & 5,5 & 13,5 & 26,2 & 26,2 \\
\hline Byrsonima densa & MALPIGHIACEAE & 2 & 2 & 0,16 & 0,17 & 0,05 & 0,06 & 0,20 & 0,20 & 0,41 & 0,43 & 0,013 & 0,018 & 7,4 & 10,5 & 5, & 6,3 \\
\hline Micropholis guyan & SAPOTACEAE & 2 & 2 & 0,16 & 0,17 & 0,05 & 0,07 & 0,20 & 0,20 & 0,41 & 0,44 & 0,013 & 0,021 & 5,1 & 12,7 & 5,0 & 5,2 \\
\hline Ocotea costulata & ACEAE & 2 & 2 & 0,16 & 0,17 & 0,05 & 0,06 & 0,20 & 0,20 & 0,41 & 0,43 & 0,013 & 0,017 & 8,7 & 9,4 & 10,1 & 10,8 \\
\hline Pradosia praeato & SAPOTACEAE & 2 & 2 & 0,16 & 0,17 & 0,05 & 0,06 & 0,20 & 0,20 & 0,41 & 0,43 & 0,013 & 0,017 & 7,2 & 10,5 & 8,4 & 10,3 \\
\hline Pseudopiptadenia psilostachya & FABACEAE Mimo. & 2 & 2 & 0,16 & 0,17 & 0,05 & 0,06 & 0,20 & 0,20 & 0,41 & 0,42 & 0,015 & 0,016 & 5,4 & 11,4 & 10,1 & 10,8 \\
\hline Parinari $s p$ & CHRYSOBALANACEAE & 2 & 2 & 0,16 & 0,17 & 0,04 & 0,04 & 0,20 & 0,20 & 0,40 & 0,41 & 0,011 & 0,013 & 8,2 & 8,3 & 8,0 & 9,8 \\
\hline Zanthoxylum rh & RUTACEAE & 1 & 1 & 0,08 & 0,08 & 0,22 & 0,23 & 0,10 & 0,10 & 0,40 & 0,41 & 0,061 & 0,064 & 27,8 & 27,8 & 19,9 & 19,9 \\
\hline Inga stipularis & FABACEAE Mimo. & 2 & 2 & 0,16 & 0,17 & 0,03 & 0,03 & 0,20 & 0,20 & 0,39 & 0,40 & 0,008 & 0,009 & 6,7 & 7,8 & 7,0 & 14,8 \\
\hline Minquartia guianensis & OLACACEAE & 2 & 2 & 0,16 & 0,17 & 0,03 & 0,03 & 0,20 & 0,20 & 0,39 & 0,40 & 0,008 & 0,010 & 5,6 & 8,7 & 5,2 & 5,4 \\
\hline Qualea albiflora & VOCHYSIACEAE & 2 & 2 & 0,16 & 0,17 & 0,03 & 0,03 & 0,20 & 0,20 & 0,39 & 0,39 & 0,007 & 0,008 & 5,9 & 7,6 & 13,5 & 19,8 \\
\hline
\end{tabular}


Continua...

Anexo B. Parâmetros fitossociológicos das espécies arbóreas amostradas nos anos de 1997 e 2002 (por ordem de IVI) em uma floresta secundária oriunda de exploração seletiva de madeira para lenha, no município de Marituba-PA

\begin{tabular}{|c|c|c|c|c|c|c|c|c|c|c|c|c|c|c|c|c|c|}
\hline \multirow{2}{*}{ Espécies } & \multirow{2}{*}{ Famílias } & \multicolumn{2}{|c|}{ DA } & \multicolumn{2}{|c|}{$\overline{\text { DR }}$} & \multicolumn{2}{|c|}{ DoR } & \multicolumn{2}{|c|}{ FR } & \multicolumn{2}{|c|}{ IVI } & \multicolumn{2}{|c|}{ Ar.Bas. } & \multicolumn{2}{|c|}{ DAP 1997} & \multicolumn{2}{|c|}{ DAP 2002} \\
\hline & & 1997 & 2002 & 1997 & 2002 & 1997 & 2002 & 1997 & 2002 & 1997 & 2002 & 1997 & 2002 & Min. & Max. & Min. & Max. \\
\hline Rinorea flavescens & VIOLACEAE & 2 & 2 & 0,16 & 0,17 & 0,02 & 0,03 & 0,20 & 0,20 & 0,39 & 0,39 & 0,007 & 0,007 & 5,4 & 7,6 & 6,3 & $\overline{7,6}$ \\
\hline Hebepetalum humiriifolium & INACEAE & 2 & 4 & 6 & 0,33 & 0,02 & 0,05 & 0,20 & 0,40 & 0,38 & 0,78 & 0,005 & 013 & 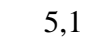 &, 5 & 0 & 26,6 \\
\hline Simaba cedron & CEA & 2 & 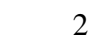 & 0,16 & 0,17 & 0,02 & 0,03 & 0,20 & 0,20 & 0,38 & 0,39 & 0,006 & 0,008 & 5,6 & 6,4 & 12,3 & 19,7 \\
\hline Siparuna decipiens & ONIMIACEAE & 2 & 3 & 0,16 & 0,25 & 0,02 & 0,03 & 0,20 & 0,30 & 0,38 & 0,58 & 0,006 & 0,008 & 5,5 & 6,5 & 8,2 & 25,4 \\
\hline Himatanthus sucuuba & POCYNACEAE & 3 & 3 & 0,24 & 0,25 & 0,03 & 0,03 & 0,10 & 0,10 & 0,37 & 0,38 & 0,008 & 0,010 & 5,0 & 7,0 & 5,5 & 7,9 \\
\hline Ormosia paraensis & ABACEAE Pap. & 1 & 1 & 0,08 & 0,08 & 0,15 & 0,19 & 0,10 & 0,10 & 0,33 & 0,37 & 0,041 & 0,052 & 22,5 & 22,5 & 7,3 & 7,3 \\
\hline Licania lata & BALANACEAE & - & 1 & 0,08 & 0,08 & 0,14 & 0,18 & 0,10 & 0,10 & 0,32 & 0,36 & 0,038 & 0,050 & 22,0 & 22,0 & 0 & 5,0 \\
\hline accoglottis amo & - & 1 & 1 & 8 & 0,08 & 0,13 & & 0,10 & & 31 & 0,34 & 0,036 & 0,043 & 21,4 & 21,4 & 2 & 5,2 \\
\hline Richardella $\mathrm{m}$ & $E$ & 1 & 1 & 0,08 & 0,08 & 0,11 & 1 & 0,10 & 0,10 & 0,29 & 0,29 & 0,030 & 0,031 & 19,5 & 19,5 & 5,0 & 5,0 \\
\hline Annona Montana & NNONACEAE & 2 & 2 & 0,16 & 0,17 & 0,02 & 0,02 & 0,10 & 0,10 & 0,28 & 0,29 & 0,005 & 0,006 & 5,7 & 5,7 & 6,9 & 9,8 \\
\hline Heisteria acuminata & UPHORBIACEAE & 2 & 2 & 0,16 & 0,17 & 0,02 & 0,02 & 0,10 & 0,10 & 0,28 & 0,29 & 0,006 & 0,005 & 5,2 & 6,3 & 9,8 & 13,1 \\
\hline Licania densiflora & HRYSOBALA & 2 & 2 & 0,16 & 0,17 & 0,02 & 0,07 & 0,10 & 0,10 & 0,28 & 0,34 & 0,005 & 0,021 & 5,7 & 7,0 & 6,0 & 9,2 \\
\hline Iryanthera paraen & IYRISTICACE & 1 & 1 & 0,08 & 0,08 & 0,08 & 0,09 & 0,10 & 0,10 & 0,26 & 0,27 & 0,022 & 0,024 & 16,9 & 16,9 & 15,9 & 15,9 \\
\hline Heisteria sessilis & LACACEAE & 1 & 1 & 0,08 & 0,08 & 0,07 & 0,07 & 0,10 & 0,10 & 0,25 & 0,25 & 0,019 & 0,020 & 15,6 & 15,6 & 14,1 & 14,1 \\
\hline Aspidosperma rig & ACEA & 1 & 1 & 0,08 & 0,08 & 0,06 & 0,09 & 0,10 & 0,10 & 0,24 & 0,27 & 0,016 & 0,024 & 14,3 & 14,3 & 39,6 & 39,6 \\
\hline Inga crassiflora & CEAE Mimo. & 1 & 1 & 0,08 & 0,08 & 0,06 & 0,07 & 0,10 & 0,10 & 0,24 & 0,25 & 0,017 & 0,019 & 14,6 & 14,6 & ,5 & 5,5 \\
\hline Emmotum fagifolium & ICACINACEAE & 1 & 1 & 0,08 & 0,08 & 0,04 & 0,06 & 0,10 & 0,10 & 0,22 & 0,24 & 0,012 & 0,016 & 12,0 & 12,0 & ,5 & 9,5 \\
\hline Geissospermum sericeum & APOCYNACEAE & 1 & 1 & 0,08 & 0,08 & 0,04 & 0,04 & 0,10 & 0,10 & 0,22 & 0,23 & 0,012 & 0,012 & 12,1 & 12,1 & 8,8 & 8,8 \\
\hline Pithecelobium racemosum & FABACEAE Mimo. & 1 & 1 & 0,08 & 0,08 & 0,04 & 0,04 & 0,10 & 0,10 & 0,22 & 0,22 & 0,010 & 0,012 & 11,1 & 11,1 & 9,3 & 9,3 \\
\hline Guatteria ovalifolia* & ANNONACEAE & 1 & & 0,08 & & 0,04 & & 0,10 & & 0,22 & & 0,011 & & 12,3 & 12,3 & & \\
\hline Annona paludosa & ANNONACEAE & 1 & 1 & 0,08 & 0,08 & 0,03 & 0,03 & 0,10 & 0,10 & 0,21 & 0,21 & 0,007 & 0,008 & 9,5 & 9,5 & 7,6 & 7,6 \\
\hline Endicheria sp & LAURACEAE & 1 & 2 & 0,08 & 0,17 & 0,03 & 0,04 & 0,10 & 0,20 & 0,21 & 0,41 & 0,007 & 0,011 & 9,5 & 9,5 & 13,3 & 13,7 \\
\hline Stryphnodendron & FABACEAE Mimo. & 1 & 1 & 0,08 & 0,08 & 0,03 & 0,03 & 0,10 & 0,10 & 0,21 & 0,21 & 0,009 & 0,009 & 10,5 & 10,5 & 25,8 & 25,8 \\
\hline Theobroma speciosum & STERCULIACEAE & 1 & 1 & 0,08 & 0,08 & 0,03 & 0,03 & 0,10 & 0,10 & 0,21 & 0,22 & 0,009 & 0,009 & 10,5 & 10,5 & 12,1 & 12,1 \\
\hline Aspidosperma auriculatum & APOCYNACEAE & 1 & 1 & 0,08 & 0,08 & 0,02 & 0,02 & 0,10 & 0,10 & 0,20 & 0,20 & 0,007 & 0,005 & 7,5 & 7,5 & 17,5 & 17,5 \\
\hline
\end{tabular}


Continua..

Anexo B. Parâmetros fitossociológicos das espécies arbóreas amostradas nos anos de 1997 e 2002 (por ordem de IVI) em uma floresta secundária oriunda de exploração seletiva de madeira para lenha, no município de Marituba-PA

\begin{tabular}{|c|c|c|c|c|c|c|c|c|c|c|c|c|c|c|c|c|c|}
\hline \multirow{2}{*}{ Espécies } & \multirow{2}{*}{ Famílias } & \multicolumn{2}{|c|}{ DA } & \multicolumn{2}{|c|}{ DR } & \multicolumn{2}{|c|}{ DoR } & \multicolumn{2}{|c|}{ FR } & \multicolumn{2}{|c|}{ IVI } & \multicolumn{2}{|c|}{ Ar.Bas. } & \multicolumn{2}{|c|}{ DAP 1997} & \multicolumn{2}{|c|}{$\overline{\text { DAP } 2002}$} \\
\hline & & 1997 & 2002 & 1997 & 2002 & 1997 & 2002 & 1997 & 2002 & 1997 & 2002 & 1997 & 2002 & Min. & Max. & Min. & Max. \\
\hline Conceveiba guianensis & EUPHORBIACEAE & 1 & 1 & 0,08 & 0,08 & 0,02 & 0,03 & 0,10 & 0,10 & 0,20 & 0,22 & 0,005 & 0,009 & 9,3 & $\overline{9,3}$ & 5,6 & $\overline{5,6}$ \\
\hline Cordia scabrifolia & BORAGINACEAE & 1 & 1 & 0,08 & 0,08 & 0,02 & 0,01 & 0,10 & 0,10 & 0,20 & 0,20 & 0,006 & 0,004 & 7,3 & 7,3 & 7,6 & 7,6 \\
\hline Couratari guianensis & LECYTHIDACEAE & 1 & 1 & 0,08 & 0,08 & 0,02 & 0,02 & 0,10 & 0,10 & 0,20 & 0,21 & 0,004 & 0,007 & 9,2 & 9,2 & 7,7 & 7,7 \\
\hline Dimorphandra glabrifol & FAB ACEAE Caes. & 1 & 1 & 0,08 & 0,08 & 0,02 & 0,03 & 0,10 & 0,10 & 0,20 & 0,21 & 0,004 & 0,007 & 8,9 & 8,9 & 7,2 & 7,2 \\
\hline Diplotropis guianensis & FABACEAE Pap. & 1 & 1 & 0,08 & 0,08 & 0,02 & 0,02 & 0,10 & 0,10 & 0,20 & 0,20 & 0,005 & 0,006 & 8,8 & 8,8 & 6,1 & 6,1 \\
\hline Mouriri sp. & MEMECYLACEAE & 1 & 1 & 0,08 & 0,08 & 0,02 & 0,02 & 0,10 & 0,10 & 0,20 & 0,21 & 0,005 & 0,007 & 8,8 & 8,8 & 5,7 & 5,7 \\
\hline Myrciaria sp. & MYRTACEAE & 1 & 1 & 0,08 & 0,08 & 0,02 & 0,03 & 0,10 & 0,10 & 0,20 & 0,21 & 0,005 & 0,007 & 9,0 & 9,0 & 8,8 & 8,8 \\
\hline Ni ni2 & ANNONACEAE & 1 & 1 & 0,08 & 0,08 & 0,02 & 0,02 & 0,10 & 0,10 & 0,20 & 0,20 & 0,004 & 0,005 & 7,4 & 7,4 & 9,0 & 9,0 \\
\hline Ocotea sp.1 & LAURACEAE & 1 & 1 & 0,08 & 0,08 & 0,02 & 0,02 & 0,10 & 0,10 & 0,20 & 0,21 & 0,004 & 0,007 & 7,3 & 7,3 & 10,8 & 10,8 \\
\hline Protium sp. & BURSERACEAE & 1 & 1 & 0,08 & 0,08 & 0,02 & 0,02 & 0,10 & 0,10 & 0,20 & 0,20 & 0,006 & 0,005 & 7,8 & 7,8 & 5,0 & 5,0 \\
\hline Protium trifoliolatum & BURSERACEAE & 1 & 3 & 0,08 & 0,25 & 0,02 & 0,06 & 0,10 & 0,30 & 0,20 & 0,61 & 0,006 & 0,017 & 9,1 & 9,1 & 9,8 & 13,4 \\
\hline saccoglottis guianensis & HUMIR & 1 & 1 & 0,08 & 0,08 & 0,02 & 0,03 & 0,10 & 0,10 & 0,20 & 0,21 & 0,006 & 0,008 & 7,5 & 7,5 & 6,4 & 6,4 \\
\hline Sclerolobium guianense & FABACEA & 1 & 1 & 0,08 & 0,08 & 0,02 & 0,02 & 0,10 & 0,10 & 0,20 & 0,20 & 0,007 & 0,006 & 7,4 & 7,4 & 5,7 & 5,7 \\
\hline Sloanea grandifolia & ELAEOCARPACEAE & 1 & 2 & 0,08 & 0,17 & 0,02 & 0,05 & 0,10 & 0,20 & 0,20 & 0,41 & 0,005 & 0,013 & 7,9 & 7,9 & 6,4 & 6,5 \\
\hline Xylopia benthamiana & ANNONACEAE & 1 & 1 & 0,08 & 0,08 & 0,02 & 0,02 & 0,10 & 0,10 & 0,20 & 0,20 & 0,007 & 0,005 & 7,9 & 7,9 & 7,9 & 7,9 \\
\hline Guatteria amazonica* & ANNONACEAE & 1 & & 0,08 & & 0,02 & & 0,10 & & 0,20 & & 0,004 & & 8,8 & 8,8 & & \\
\hline Mabea sp.* & EUPHORBIACEA E & 1 & & 0,08 & & 0,02 & & 0,10 & & 0,20 & & 0,006 & & 7,8 & 7,8 & & \\
\hline Miconia sp.* & MELASTOMATACEAE & 1 & & 0,08 & & 0,02 & & 0,10 & & 0,20 & & 0,004 & & 8,0 & 8,0 & & \\
\hline Brosimum parinarioides & MORACEAE & 1 & 1 & 0,08 & 0,08 & 0,01 & 0,01 & 0,10 & 0,10 & 0,19 & 0,20 & 0,003 & 0,003 & 6,8 & 6,8 & 5,5 & 5,5 \\
\hline Casearia spruceana & FLACOURTIACEAE & 1 & 1 & 0,08 & 0,08 & 0,01 & 0,01 & 0,10 & 0,10 & 0,19 & 0,19 & 0,003 & 0,003 & 6,4 & 6,4 & 6,5 & 6,5 \\
\hline Chimarrhis turbinata & RUBIACEAE & 1 & 1 & 0,08 & 0,08 & 0,01 & 0,02 & 0,10 & 0,10 & 0,19 & 0,20 & 0,002 & 0,005 & 6,9 & 6,9 & 5,8 & 5,8 \\
\hline Cordia sp. & BORAGINACEAE & 1 & 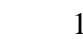 & 0,08 & 0,08 & 0,01 & 0,02 & 0,10 & 0,10 & 0,19 & 0,20 & 0,004 & 0,005 & 5,4 & 5,4 & 6,4 & 6,4 \\
\hline Dendrobangia boliviana & ICACINACEAE & 1 & 1 & 0,08 & 0,08 & 0,01 & 0,01 & 0,10 & 0,10 & 0,19 & 0,19 & 0,002 & 0,003 & 5,4 & 5,4 & 10,9 & 10,9 \\
\hline Diospyros melinonii & EBENACEAE & 1 & 1 & 0,08 & 0,08 & 0,01 & 0,02 & 0,10 & 0,10 & 0,19 & 0,20 & 0,004 & 0,004 & 5,7 & 5,7 & 8,3 & 8,3 \\
\hline Diploon venezuelanum & SAPOTACEAE & 1 & 1 & 0,08 & 0,08 & 0,01 & 0,02 & 0,10 & 0,10 & 0,19 & 0,20 & 0,003 & 0,005 & 6,4 & 6,4 & 9,2 & 9,2 \\
\hline Ferdinandusa guianensis & RUBIACEAE & 1 & 1 & 0,08 & 0,08 & 0,01 & 0,01 & 0,10 & 0,10 & 0,19 & 0,20 & 0,003 & 0,004 & 5,5 & 5,5 & 7,4 & 7,4 \\
\hline Ferdinandusa paraensis & RUBIACEAE & 1 & 1 & 0,08 & 0,08 & 0,01 & 0,01 & 0,10 & 0,10 & 0,19 & 0,19 & 0,004 & 0,003 & 5,2 & 5,2 & 7,6 & 7,6 \\
\hline Guarea kunthiana & MELIACEAE & 1 & 1 & 0,08 & 0,08 & 0,01 & 0,01 & 0,10 & 0,10 & 0,19 & 0,19 & 0,004 & 0,002 & 5,4 & 5,4 & 5,1 & 5,1 \\
\hline
\end{tabular}


Continua...

Anexo B. Parâmetros fitossociológicos das espécies arbóreas amostradas nos anos de 1997 e 2002 (por ordem de IVI) em uma floresta secundária oriunda de exploração seletiva de madeira para lenha, no município de Marituba-PA

\begin{tabular}{|c|c|c|c|c|c|c|c|c|c|c|c|c|c|c|c|c|c|}
\hline \multirow{2}{*}{ Espécies } & \multirow{2}{*}{ Famílias } & \multicolumn{2}{|c|}{ DA } & \multicolumn{2}{|c|}{ DR } & \multicolumn{2}{|c|}{ DoR } & \multicolumn{2}{|c|}{ FR } & \multicolumn{2}{|c|}{ IVI } & \multicolumn{2}{|c|}{ Ar.Bas. } & \multicolumn{2}{|c|}{ DAP 1997} & \multicolumn{2}{|c|}{ DAP 2002} \\
\hline & & 1997 & 2002 & 1997 & 2002 & 1997 & 2002 & 1997 & 2002 & 1997 & 2002 & 1997 & 2002 & Min. & Max. & Min. & Max. \\
\hline Heisteria sp. & OLACACEAE & 1 & 1 & 0,08 & 0,08 & 0,01 & 0,01 & 0,10 & 0,10 & 0,19 & 0,19 & 0,002 & 0,003 & 6,0 & 6,0 & 6,8 & 6,8 \\
\hline Hymenolobium excelsum & FABACEAE Pap. & 1 & 2 & 0,08 & 0,17 & 0,01 & 0,02 & 0,10 & 0,20 & 0,19 & 0,38 & 0,002 & 0,005 & 5,1 & 5,1 & 6,7 & 7,2 \\
\hline Inga auristellae & FABACEAE Mimo. & 1 & 1 & 0,08 & 0,08 & 0,01 & 0,01 & 0,10 & 0,10 & 0,19 & 0,19 & 0,002 & 0,002 & 5,0 & 5,0 & 6,1 & 6,1 \\
\hline Inga cayennensis & FABACEAE Mimo. & 1 & 1 & 0,08 & 0,08 & 0,01 & 0,01 & 0,10 & 0,10 & 0,19 & 0,20 & 0,003 & 0,003 & 5,0 & 5,0 & 12,3 & 12,3 \\
\hline Lecythis usitata & LECYTHIDACEAE & 1 & 1 & 0,08 & 0,08 & 0,01 & 0,02 & 0,10 & 0,10 & 0,19 & 0,20 & 0,002 & 0,006 & 7,2 & 7,2 & 6,3 & 6,3 \\
\hline Manilkara huberi & APOTACEAE & 1 & 1 & 0,08 & 0,08 & 0,01 & 0,02 & 0,10 & 0,10 & 0,19 & 0,21 & 0,002 & 0,006 & 7,1 & 7,1 & 6,6 & 6,6 \\
\hline Maquira guianensis & IORACEAE & 1 & 1 & 0,08 & 0,08 & 0,01 & 0,01 & 0,10 & 0,10 & 0,19 & 0,19 & 0,002 & 0,003 & 6,7 & 6,7 & 31,0 & 31,0 \\
\hline Mouriri apiranga & MEMECYLACEAE & 1 & 1 & 0,08 & 0,08 & 0,01 & 0,01 & 0,10 & 0,10 & 0,19 & 0,20 & 0,004 & 0,004 & 6,4 & 6,4 & 17,5 & 17,5 \\
\hline Neea glomeruliflora & NYCTAGINACEAE & 1 & 2 & 0,08 & 0,17 & 0,01 & 0,01 & 0,10 & 0,20 & 0,19 & 0,38 & 0,002 & 0,004 & 5,0 & 5,0 & 5,5 & 11,7 \\
\hline Ni nil & ANNONACEAE & 1 & 1 & 0,08 & 0,08 & 0,01 & 0,01 & 0,10 & 0,10 & 0,19 & 0,19 & 0,003 & 0,003 & 5,5 & 5,5 & 25,1 & 25,1 \\
\hline Ni ni3 & FLACOURTIACEAE & 1 & 1 & 0,08 & 0,08 & 0,01 & 0,01 & 0,10 & 0,10 & 0,19 & 0,19 & 0,003 & 0,003 & 5,1 & 5,1 & 38,1 & 38,1 \\
\hline Ocotea canaliculata & LAURACEAE & 1 & 1 & 0,08 & 0,08 & 0,01 & 0,01 & 0,10 & 0,10 & 0,19 & 0,19 & 0,002 & 0,003 & 5,5 & 5,5 & 6,4 & 6,4 \\
\hline Protium pilosum & ACEAE & 1 & 1 & 0,08 & 0,08 & 0,01 & 0,01 & 0,10 & 0,10 & 0,19 & 0,19 & 0,003 & 0,002 & 5,1 & 5,1 & 5,3 & 5,3 \\
\hline Pterocarpus amazo & ABACEAE Pap. & 1 & 1 & 0,08 & 0,08 & 0,01 & 0,01 & 0,10 & 0,10 & 0,19 & 0,19 & 0,002 & 0,003 & 5,7 & 5,7 & 9,5 & 9,5 \\
\hline Sagotia racemosa & EUPHORBIACEAE & 1 & 1 & 0,08 & 0,08 & 0,01 & 0,02 & 0,10 & 0,10 & 0,19 & 0,20 & 0,002 & 0,005 & 6,7 & 6,7 & 7,6 & 7,6 \\
\hline Vataireopsis speciosa & FABACEAE Pap. & 1 & 1 & 0,08 & 0,08 & 0,01 & 0,01 & 0,10 & 0,10 & 0,19 & 0,19 & 0,004 & 0,003 & 5,9 & 5,9 & 5,3 & 5,3 \\
\hline Virola surinamensis & MYRISTICACEAE & 1 & 1 & 0,08 & 0,08 & 0,01 & 0,03 & 0,10 & 0,10 & 0,19 & 0,21 & 0,002 & 0,007 & 5,7 & 5,7 & 5,4 & 5,4 \\
\hline Zanthoxylum pentandra & RUTACEAE & 1 & 1 & 0,08 & 0,08 & 0,01 & 0,01 & 0,10 & 0,10 & 0,19 & 0,19 & 0,003 & 0,003 & 5,3 & 5,3 & 6,0 & 6,0 \\
\hline Alchorneopsis trinera* & EUPHORBIACEAE & 1 & & 0,08 & & 0,01 & & 0,10 & & 0,19 & & 0,002 & & 5,7 & 5,7 & & \\
\hline Bellucia glossularioides $* *$ & MELASTOMATACEAE & & 1 & & 0,08 & & 0,01 & & 0,1 & & 0,19 & & 0,002 & & & 5,1 & 5,1 \\
\hline Brosimum lactescens $* *$ & MORACEAE & & 1 & & 0,08 & & 0,01 & & 0,1 & & 0,19 & & 0,0024 & & & 23,4 & 23,4 \\
\hline Brosimum rubescens $* *$ & MORACEAE & & 1 & & 0,08 & & 0,01 & & 0,1 & & 0,19 & & 0,0026 & & & 10,2 & 10,2 \\
\hline Calyptranthes gigantifolia $* *$ & MYRTACEAE & & 1 & & 0,08 & & 0,01 & & 0,1 & & 0,19 & & 0,0025 & & & 7,9 & 7,9 \\
\hline Caryocar villosum $* *$ & CARYOCARACEAE & & 1 & & 0,08 & & 0,02 & & 0,1 & & 0,2 & & 0,0045 & & & 60,8 & 60,8 \\
\hline Duguetia stelechantha** & ANNONACEAE & & 1 & & 0,08 & & 0,01 & & 0,1 & & 0,19 & & 0,002 & & & 8,4 & 8,4 \\
\hline Guatteria guianensis $* *$ & ANNONACEAE & & 1 & & 0,08 & & 0,01 & & 0,1 & & 0,19 & & 0,0025 & & & 93 & 93 \\
\hline Lecythis idatimon** & LECYTHIDACEAE & & 1 & & 0,08 & & 0,01 & & 0,1 & & 0,19 & & 0,0026 & & & 10,6 & 10,6 \\
\hline Micropholis venulosa** & SAPOTACEAE & & 1 & & 0,08 & & 0,03 & & 0,1 & & 0,22 & & 0,0092 & & & 90,5 & 90,5 \\
\hline
\end{tabular}


Anexo B. Parâmetros fitossociológicos das espécies arbóreas amostradas nos anos de 1997 e 2002 (por ordem de IVI) em uma floresta secundária oriunda de exploração seletiva de madeira para lenha, no município de Marituba-PA

\begin{tabular}{|c|c|c|c|c|c|c|c|c|c|c|c|c|c|c|c|c|c|}
\hline \multirow{2}{*}{ Espécies } & \multirow{2}{*}{ Famílias } & \multicolumn{2}{|c|}{ DA } & \multicolumn{2}{|c|}{ DR } & \multicolumn{2}{|c|}{ DoR } & \multicolumn{2}{|c|}{ FR } & \multicolumn{2}{|c|}{ IVI } & \multicolumn{2}{|c|}{ Ar.Bas. } & \multicolumn{2}{|c|}{ DAP 1997} & \multicolumn{2}{|c|}{$\overline{\text { DAP 2002 }}$} \\
\hline & & 1997 & 2002 & 1997 & 2002 & 1997 & 2002 & 1997 & 2002 & 1997 & 2002 & 1997 & 2002 & Min. & Max. & Min. & Max. \\
\hline Myrcia atramentifera** & MYRTACEAE & & 1 & & 0,08 & & 0,01 & & 0,1 & & 0,19 & & 0,0022 & & & 5,3 & $\overline{5,3}$ \\
\hline Myrcia deflexa** & MYRTACEAE & & 1 & & 0,08 & & 0,01 & & 0,1 & & 0,19 & & 0,002 & & & 5,2 & 5,2 \\
\hline Nectandra sp. ${ }^{* *}$ & LAURACEAE & & 1 & & 0,08 & & 0,01 & & 0,1 & & 0,19 & & 0,002 & & & 10,7 & 10,7 \\
\hline Neea oppositifolia** & NYCTAGINACEAE & & 1 & & 0,08 & & 0,01 & & 0,1 & & 0,19 & & 0,0021 & & & 6,1 & 6,1 \\
\hline Ni ni5** & NI & & 2 & & 0,17 & & 0,02 & & 0,2 & & 0,38 & & 0,0044 & & & 6,8 & 13,7 \\
\hline Parkia paraensis** & FABACEAE Mimo & & 1 & & 0,08 & & 0,01 & & 0,1 & & 0,19 & & 0,0021 & & & 5 & 5 \\
\hline Pouteria lasiocarpa** & SAPOTACEAE & & 1 & & 0,08 & & 0,01 & & 0,1 & & 0,19 & & 0,0022 & & & 9,6 & 9,6 \\
\hline Rinorea racemosa** & VIOLACEAE & & 1 & & 0,08 & & 0,01 & & 0,1 & & 0,19 & & 0,002 & & & 7,9 & 7,9 \\
\hline Talisia carinata** & SAPINDACEAE & & 1 & & 0,08 & & 0,01 & & 0,1 & & 0,19 & & 0,0022 & & & 5,7 & 5,7 \\
\hline Talisia longifólia** & SAPINDACEAE & & 1 & & 0,08 & & 0,01 & & 0,1 & & 0,19 & & 0,0021 & & & 28,6 & 28,6 \\
\hline Vantanea guianensis $* *$ & HUMIRIACEAE & & 2 & & 0,17 & & 0,02 & & 0,2 & & 0,39 & & 0,0065 & & & 9,5 & 11,9 \\
\hline
\end{tabular}

As células em branco na tabela representam valores menores que 0,01 .

*Espécies presentes somente no primeiro ano de medição.

**Espécies que ingressaram no último período.

$\mathbf{D A}=$ abundância absoluta; $\mathbf{D R}=$ abundância relativa; $\mathbf{D o R}=$ dominância relativa; $\mathbf{F R}=$ freqüência relativa; $\mathbf{I V I}=$ índice de valor de importância e

Ar.Bas. = área basal.

Anexo C. Parâmetros fitossociológicos das espécies arbóreas amostradas nos anos de 1999 e 2002 (por ordem de IVI 1999) em uma floresta secundária oriunda de agricultura de corte e queima no município de Bragança-PA

\begin{tabular}{|c|c|c|c|c|c|c|c|c|c|c|c|c|c|c|c|c|c|}
\hline \multirow{2}{*}{ Especies } & \multirow{2}{*}{ Famílias } & \multicolumn{2}{|c|}{ DA } & \multicolumn{2}{|c|}{ DR } & \multicolumn{2}{|c|}{ DoR } & \multicolumn{2}{|c|}{ FR } & \multicolumn{2}{|c|}{ IVI } & \multicolumn{2}{|c|}{ Ar.Bas. } & \multicolumn{2}{|c|}{ DAP 1999} & \multicolumn{2}{|c|}{ DAP 2002} \\
\hline & & 1999 & 002 & 1999 & 2002 & 1999 & 2002 & 1999 & 2002 & 999 & 002 & 999 & 2002 & & [AX. & & MAX. \\
\hline apt & $\bar{E}$ & 92 & $\overline{6}$ & 5,0 & 5,04 & 11,82 & & 4,12 & 4,30 & 0 & & 93 & 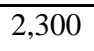 & $\overline{0}$ & 36,4 & 5,0 & 37 , \\
\hline Myr & & 141 & 5 & 7,75 & 6,15 & & 4,97 & & 4,94 & 5 & 06 & 57 & 0,8 & & & & \\
\hline & & & & & & & & & & & & & & & & & \\
\hline Croton $n$ & $\mathrm{AE}$ & 4 & 31 & 2 , & 1 , & 7,94 & 7 & & 1,74 & & 59 & 39 & 1,217 & & 5 & & 40 \\
\hline nga alba & mo. & 53 & 46 & 2 , & 2 & 5,86 & 5,78 & 2 & 2,47 & & 10,95 & 8 & 1,000 & & 35,0 & & \\
\hline Maprouned & EAE & 77 & 68 & 4,23 & 3 , & 8 & 3 & 3,42 & 3,39 & +3 & 11,02 & 38 & 0,631 & & 24,5 & 5,0 & \\
\hline & $\mathrm{E}$ & 73 & 60 & 4,01 & 3,51 & 5 & & 4 & 2,74 &, 21 & ,08 & 98 & 0,488 & 0 & 23,5 & & \\
\hline Annona paludosa & ANNONACEAE & 53 & 46 & 2,91 & 2,69 & 3,15 & 3,15 & 3,24 & 3,11 & 9,31 & 8,95 & 0,531 & 0,545 & 6,0 & 16,8 & 6,4 & 17 \\
\hline
\end{tabular}


Continua...

Anexo C. Parâmetros fitossociológicos das espécies arbóreas amostradas nos anos de 1999 e 2002 (por ordem de IVI 1999) em uma floresta secundária oriunda de agricultura de corte e queima no município de Bragança-PA

\begin{tabular}{|c|c|c|c|c|c|c|c|c|c|c|c|c|c|c|c|c|c|}
\hline \multirow{2}{*}{ species } & \multirow{2}{*}{ Famílias } & \multicolumn{2}{|c|}{ DA } & \multicolumn{2}{|c|}{ DR } & \multicolumn{2}{|c|}{ DoR } & \multicolumn{2}{|c|}{ FR } & \multicolumn{2}{|c|}{ IVI } & \multicolumn{2}{|c|}{ Ar.Bas. } & \multicolumn{2}{|c|}{ DAP 1999} & \multicolumn{2}{|c|}{ DAP 2002} \\
\hline & & 1999 & 2002 & 1999 & 2002 & 1999 & 2002 & 1999 & 2002 & 1999 & 2002 & 1999 & 2002 & MI & IAX. & IN. & IAX. \\
\hline Eschweilera & LECYTHI & 76 & 5 & 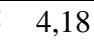 & 9 & 95 & 06 & 89 & (2) & - & 56 & 0,346 & t & 5,0 & 6,5 & 0 & 16,5 \\
\hline Sclerolobium chry & & 27 & 21 & & & 4,98 & & & & & 6,29 & 0,840 & & & & 5,0 & 36,3 \\
\hline Myrciaria tenella & MYRTACEAE & 74 & 年 & , & (, & 1,05 & & & & & 8,56 & 0,178 & 0 & & , & 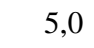 & 8,3 \\
\hline Himatanthus sucu & APOCYNACI & 39 & 40 & 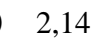 & 4 & 3,36 & 2 & 2 & 2 & 7,52 & 7,97 & 0,567 & 0 & & 20,0 & 0 & 30,0 \\
\hline Talisia guianensis & SAPINDACEAE & 52 & 51 & 2,8 & 9 & 0,99 & 1,06 & 9 & 3,02 & 6,74 & 7,07 & 0,167 & 0 & 0 & (10, & , & 10,7 \\
\hline Lecythis lurida & ECYTHIDACEAE & 43 & 4 & 2,36 & 2,58 & 1,25 & 1,34 & 7 & 2,47 & 5,98 & 6,38 & 0,210 & 0,2 & 0 & 14,2 & 0 & 14,5 \\
\hline Lacistema aggr & LACISTEMAC & 50 & 4 & 2,09 & 1,99 & 0,66 & 0,63 &, 80 & 2,56 & 5,56 & 5,18 & 0,112 & 0,108 & 0 & 9,0 & ,0 & 9,5 \\
\hline Stryphnodendron guian & FABACEAE Mimo. & 15 & 15 & 0,82 & 0,88 & 3,47 & 4,10 & 14 & 1,19 & 5,43 & 6,17 & 0,585 & 0,709 & 0 & 40,5 & 9,2 & 44,1 \\
\hline Lacistema pubescens & LACISTEMACEAE & 35 & 38 & 1,92 & 2,23 & 0,68 & 0,73 &, 19 & 2,38 & 4,80 & 5,34 & 0,115 & 0,127 & 0 & 9,0 & 5,0 & 9,4 \\
\hline Ormosiopsis flava & FABACEAE Pap. & 33 & 35 & 1,81 & 2,05 & 1,82 & 1,90 & 0,96 & 1,10 & 4,60 & 5,05 & 0,307 & 0,329 & 0 & 18,0 & 5,2 & 18,5 \\
\hline Inga rubiginosa & FAB ACEAE Mimo. & 26 & 26 & 1,43 & 1,52 & 1,75 & 1,97 & 1,40 & 1,46 & 4,59 & 4,95 & 0,296 & 0,340 & 7 & 23,0 & 5,3 & 25,9 \\
\hline Myrciaria sp & MYRTACEAE & 3 & 38 & 2,03 & 2,23 & 0,59 & 0,60 & 1,75 & 2,01 & 4,38 & 4,84 & 0,100 & 0 & 0 & 8,2 & 50 & 8,5 \\
\hline Byrsonima de & MALPIGHIACl & 19 & 3 & 1, & 0,76 & 1,91 & 1,36 & 1,40 & 1,10 & 4,36 & 3,22 & 0,323 & 0 , & 0 & 28,0 & 4 & 23,7 \\
\hline Myr & 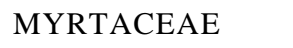 & 40 & 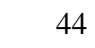 & 2 & 2 , & 0 & 0 , & 0 & 1 & 4,32 & 39 & 0 & 0 & & 8,0 & 5,0 & 3,6 \\
\hline Inga macrophylla & FABACEAE Mi & 26 & 26 & 1,43 & 1,52 & 1,27 & 1,43 & 1,40 & 1,46 & 4,10 & 4,41 & 0,215 & 0,2 & 0 & 20,5 & 0 & 22,4 \\
\hline Abarema cochleata & FABACEAE Mimo. & 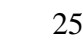 & 22 & 1,37 & 1,29 & 0,72 & 0,58 & 1,93 & 1,92 & 4,02 & 3,79 & 0,122 & 0,1 & 0 & 11,5 & 5,0 & 11,3 \\
\hline & RUTACEAE & 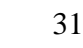 & 35 & 1,70 & 2,05 & 0,44 & 0,55 & 1,67 & 1,92 & 3,81 & 4,52 & 0,074 & 0,095 & & 8,0 & , & 8,0 \\
\hline & & 7 & 6 & 0,38 & 0,35 & & 3,10 & & 0,37 & 3,62 & 3,82 & 0,487 & & 15,0 & 41,5 & 25,6 & 44,4 \\
\hline & NYCTAGINACEAE & 22 & 24 & & 1,41 & & 0,72 & 1,75 & 1,92 & 3,60 & 4,04 & 0,108 & & & 12,5 & 5,0 & 12,9 \\
\hline Ambelania acida & APO & 27 & & & 1, & & 0, & & 1,65 & 3,49 & 3,80 & & & & 9,0 & 0 & 8,9 \\
\hline Simarouba amara & $\operatorname{SIM}$ & 1 & 12 & 0 & 0,70 & 1,98 & 2,76 & 0,79 & & 3,49 & 4,20 & & & 0 & 35,7 & 0 & 42,2 \\
\hline Ouratea castaneaefolia & OCHNACEAE & 18 & 18 & 0,99 & 1,05 & 0,95 & 1,01 & 1,14 & 1,19 & 3,08 & 3,25 & 0,161 & 0,175 & 8 & 16,5 &, 5 & 17,9 \\
\hline Couratari guianensis & LECYTHIDACEAE & 19 & 21 & 1,04 & 1,23 & 0,49 & 0,49 & 1,49 & 1,74 & 3,02 & 3,45 & 0,082 & 0,084 & 0 & 14,0 & 0 & 14,0 \\
\hline Phyllanthus nobilis & EUPHORBIACEAE & 17 & 14 & 0,93 & 0,82 & 0,83 & 0,67 & 1,23 & 1,01 & 3,00 & 2,49 & 0,141 & 0,116 & 0 & 16,0 & 5,2 & 15,8 \\
\hline Gustavia a & LECYTHIDACEAE & 25 & 30 & 1,37 & 1,76 & 0,37 & 0,42 & 1,23 & 1,46 & 2,97 & 3,64 & 0,062 & 0,072 & 0 & 6,8 & 5,0 & 6,5 \\
\hline Cordia bicolor & BORAGINACEAE & 17 & 17 & 0,93 & 1,00 & 0,77 & 0,74 & 1,23 & 1,37 & 2,93 & 3,10 & 0,129 & 0,128 & 5,0 & 17,0 & 5,1 & 18,2 \\
\hline
\end{tabular}


Continua...

Anexo C. Parâmetros fitossociológicos das espécies arbóreas amostradas nos anos de 1999 e 2002 (por ordem de IVI 1999) em uma floresta secundária oriunda de agricultura de corte e queima no município de Bragança-PA

\begin{tabular}{|c|c|c|c|c|c|c|c|c|c|c|c|c|c|c|c|c|c|}
\hline \multirow{2}{*}{ Especies } & \multirow{2}{*}{ Famílias } & \multicolumn{2}{|c|}{$\overline{\mathbf{D A}}$} & \multicolumn{2}{|c|}{$\overline{\text { DR }}$} & \multicolumn{2}{|c|}{ DoR } & \multicolumn{2}{|c|}{ FR } & \multicolumn{2}{|c|}{ IVI } & \multicolumn{2}{|c|}{ Ar.Bas. } & \multicolumn{2}{|c|}{ DAP 1999} & \multicolumn{2}{|c|}{ DAP 2002} \\
\hline & & 1999 & 2002 & 1999 & 2002 & 1999 & 2002 & 1999 & 2002 & 1999 & 2002 & 1999 & 2002 & MIN. & MAX. & MIN. & MAX. \\
\hline Myrcia atrame & MYRTAC & 14 & 11 & 0,77 & 0,64 & 0,87 & 75 & $\overline{14}$ & 0,91 & 2,78 & 2,31 & 0,146 & 0,130 & 6,0 & 17,0 & 5 & $\overline{19,5}$ \\
\hline Xylopia nitida & 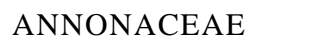 & 8 & 6 & 44 & 0,35 & 1,38 & 65 & 0,70 & 0,55 & 2,52 & 2,55 & 0,232 & 0,286 & 8,0 & 29,0 & 11,0 & 33,3 \\
\hline Inga edulis & ABACEAE Mimo. & 13 & 5 & 0,71 & 0,29 & 0,68 & 0,44 & 0 & 0,27 & 2,27 & 1,01 & 0,115 & 0,076 & ,5 & 17,7 & 0 & 18,1 \\
\hline Sloanea froesii & LAEC & 15 & 15 & 0,82 & 0,88 & 0,36 & 0,33 & 1,05 & 1,10 & 2,23 & 2,31 & 0,060 & 0,058 & 0 & 11,5 & 0 & 11,0 \\
\hline Saccoglottis amazonica & UMIR & 13 & 13 & 0,71 & 0,76 & 0,75 & 0,87 & 0,61 & 0,64 & 2,08 & 2,27 & 0,127 & 0,151 & 5 & 18,0 & 5 & 19,4 \\
\hline Couratari oblongifolia & LECYTHIDACEAE & 15 & 12 & 0,82 & 0,70 & 0,52 & 0,47 & 0,70 & 0,64 & 2,05 & 1,81 & 0,088 & 0,081 & 5,5 & 14,4 & 5,5 & 14,9 \\
\hline Sclerolobium paraense & FABACEAE Caes. & 5 & 4 & 0,27 & 0,23 & 1,15 & 1,19 & 0,44 & 0,37 & 1,86 & 1,79 & 0,193 & 0,206 & 10,0 & 36,5 & 11,0 & 38,2 \\
\hline Pouteria guianensis & SAPOTACEAE & 14 & 13 & 0,77 & 0,76 & 0,38 & 0,43 & 0,61 & 0,55 & 1,77 & 1,74 & 0,065 & 0,074 & 5,6 & 11,8 & 5,8 & 12,1 \\
\hline Licaria canella & LAURACEAE & 10 & 10 & 0,55 & 0,59 & 0,43 & 0,45 & 0,70 & 0,73 & 1,68 & 1,77 & 0,072 & 0,078 & 5,7 & 13,8 & 5,7 & 14,2 \\
\hline Diplotropis guianensis & FABACEAE Pap. & 8 & 8 & 0,44 & 0,47 & 0,51 & 0,59 & 0,70 & 0,73 & 1,65 & 1,79 & 0,087 & 0,102 & 6,5 & 19,0 & 6,2 & 21,9 \\
\hline Eugenia tapacumensis & MYRTACEAE & 10 & 11 & 0,55 & 0,64 & 0,36 & 0,39 & 0,70 & 0,82 & 1,61 & 1,86 & 0,061 & 0,068 & 6,0 & 11,0 & 5,5 & 11,0 \\
\hline Terminalia amazonica & COMBRETACEAE & 6 & 6 & 0,33 & 0,35 & 0,99 & 1,19 & 0,26 & 0,27 & 1,58 & 1,82 & 0,167 & 0,207 & 5,0 & 29,3 & 5,0 & 31,8 \\
\hline Cupania hirsuta & SAPINDACEAE & 10 & 11 & 0,55 & 0,64 & 0,23 & 0,25 & 0,79 & 0,91 & 1,56 & 1,81 & 0,038 & 0,043 & 5,0 & 9,0 & 5,2 & 9,3 \\
\hline Tachigali guianensis & FABACEAE Caes. & 4 & 4 & 0,22 & 0,23 & 0,90 & 1,07 & 0,35 & 0,37 & 1,47 & 1,67 & 0,151 & 0,186 & 7,0 & 34,0 & 7,5 & 34,5 \\
\hline Bellucia glossularioides & MELASTOMACEAE & 9 & 7 & 0,49 & 0,41 & 0,16 & 0,14 & 0,79 & 0,64 & 1,45 & 1,20 & 0,028 & 0,025 & 5,0 & 9,0 & 5,4 & 8,8 \\
\hline Casearia grandiflora & FLACOURTIACEAF & 9 & 9 & 0,49 & 0,53 & 0,22 & 0,22 & 0,70 & 0,73 & 1,41 & 1,48 & 0,037 & 0,038 & 5,3 & 9,0 & 6,1 & 9,5 \\
\hline Apeiba albiflora & TILIACEAE & 8 & 9 & 0,44 & 0,53 & 0,41 & 0,54 & 0,53 & 0,64 & 1,38 & 1,71 & 0,069 & 0,094 & 6,5 & 14,0 & 6,3 & 16,9 \\
\hline Pogonophora schomburgkiana & $a$ EUPHORBIACEAE & 8 & 7 & 0,44 & 0,41 & 0,17 & 0,17 & 0,44 & 0,46 & 1,05 & 1,03 & 0,029 & 0,029 & $5,2>>$ & 9,6 & 5,5 & 10,1 \\
\hline Talisia longifolia & SAPINDACEAE & 7 & 7 & 0,38 & 0,41 & 0,13 & 0,15 & 0,53 & 0,55 & 1,04 & 1,11 & 0,022 & 0,026 & 5,0 & 9,0 & 5,1 & 10,3 \\
\hline Dipteryx odorata & FABACEAE Pap. & 6 & 6 & 0,33 & 0,35 & 0,33 & 0,30 & 0,35 & 0,37 & 1,01 & 1,02 & 0,055 & 0,052 & 5,5 & 19,4 & 5,0 & 19,1 \\
\hline Casearia acuminata & FLACOURTIACEAF & 6 & 1 & 0,33 & 0,06 & 0,17 & 0,01 & 0,44 & 0,09 & 0,94 & 0,16 & 0,028 & 0,003 & 5,0 & 10,0 & 5,7 & 5,7 \\
\hline Swartzia arborescens & FABACEAE Pap. & 6 & 5 & 0,33 & 0,29 & 0,10 & 0,07 & 0,44 & 0,46 & 0,87 & 0,82 & 0,017 & 0,013 & 5,3 & 6,4 & 5,0 & 6,2 \\
\hline Stryphnodendron barbatimam & FABACEAE Mimo. & 6 & 5 & 0,33 & 0,29 & 0,13 & 0,11 & 0,35 & 0,37 & 0,81 & 0,77 & 0,022 & 0,019 & 5,0 & 11,0 & 5,0 & 11,0 \\
\hline Eschweilera parvifolia & LECYTHIDACEAE & 6 & 6 & 0,33 & 0,35 & 0,20 & 0,24 & 0,26 & 0,27 & 0,80 & 0,87 & 0,034 & 0,042 & 5,1 & 11,1 & 5,1 & 12,3 \\
\hline Psychotria racemosa & RUBIACEAE & 4 & 4 & 0,22 & 0,23 & 0,20 & 0,20 & 0,35 & 0,37 & 0,77 & 0,80 & 0,034 & 0,034 & 5,0 & 13,0 & 5,0 & 12,7 \\
\hline Lecythis usitata & LECYTHIDACEAE & 6 & 6 & 0,33 & 0,35 & 0,16 & 0,18 & 0,26 & 0,27 & 0,76 & 0,81 & 0,028 & 0,032 & 5,2 & 12,0 & 5,5 & 13,7 \\
\hline Brosimum guianensis & MORACEAE & 5 & 6 & 0,27 & 0,35 & 0,12 & 0,14 & 0,35 & 0,46 & 0,74 & 0,95 & 0,020 & 0,024 & 5,5 & 10,0 & 5,5 & 10,6 \\
\hline
\end{tabular}


Continua...

Anexo C. Parâmetros fitossociológicos das espécies arbóreas amostradas nos anos de 1999 e 2002 (por ordem de IVI 1999) em uma floresta secundária oriunda de agricultura de corte e queima no município de Bragança-PA

\begin{tabular}{|c|c|c|c|c|c|c|c|c|c|c|c|c|c|c|c|c|c|}
\hline \multirow{2}{*}{ Especies } & \multirow{2}{*}{ Famílias } & \multicolumn{2}{|c|}{ DA } & \multicolumn{2}{|c|}{ DR } & \multicolumn{2}{|c|}{ DoR } & \multicolumn{2}{|c|}{ FR } & \multicolumn{2}{|c|}{ IVI } & \multicolumn{2}{|c|}{ Ar.Bas. } & \multicolumn{2}{|c|}{ DAP 1999} & \multicolumn{2}{|c|}{ DAP 2002} \\
\hline & & 1999 & 2002 & 1999 & 2002 & 1999 & 2002 & 1999 & 2002 & 1999 & 2002 & 1999 & 2002 & MIN. & MAX. & MIN. & MAX. \\
\hline Maytenus pruinosa & CELASTRACEAE & 5 & 5 & 0,27 & 0,29 & 0,20 & 0,18 & 0,26 & 0,27 & 0,73 & 0,75 & 0,033 & 0,031 & 5,5 & 12,0 & 6,5 & $\overline{11,4}$ \\
\hline Myrcia cf. tomentosa & MYRTACEAE & 5 & 5 &, 27 & 0,29 & 0,10 & 0,10 & 0,35 & 0,37 & 0,73 & 0,76 & 0,017 & 0,017 & 5,5 & 8,3 & 5,5 & 8,6 \\
\hline Thyrsodium paraense & ANACARDIACEAE & 5 & 5 & 0,27 & 0,29 & 0,10 & 0,11 & 0,35 & 0,37 & 0,73 & 0,77 & 0,018 & 0,020 & 5,0 & 8,8 &, 7 & 9,2 \\
\hline Lindackeria paraensis & FLACOURTIACEAE & 6 & 6 & 0,33 & 0,35 & 0,13 & 0,15 & 0,26 & 0,27 & 0,72 & 0,77 & 0,021 & 0,025 & 5,7 & 9,2 & 5,5 & 9,9 \\
\hline Trattinickia rhoifolia & BURCERACEAE & 3 & 3 & 0,16 & 0,18 & 0,27 & 0,28 & 0,26 & 0,27 & 0,70 & 0,73 & 0,046 & 0,049 & 7,0 & 18,5 & 7,2 & 18,8 \\
\hline Ocotea guianensis & LAURACEAE & 3 & 3 & 0,16 & 0,18 & 0,34 & 0,55 & 0,18 & 0,18 & 0,68 & 0,90 & 0,057 & 0,094 & 6,0 & 25,5 & 5,5 & 33,3 \\
\hline Inga paraensis & FABACEAE Mimo. & 4 & 4 & 0,22 & 0,23 & 0,09 & 0,06 & 0,35 & 0,37 & 0,66 & 0,66 & 0,016 & 0,011 & 5,0 & 9,0 & 5,0 & 7,2 \\
\hline Rheedia acuminata & CLUSIACEAE & 4 & 3 & 0,22 & 0,18 & 0,08 & 0,06 & 0,35 & 0,27 & 0,65 & 0,51 & 0,013 & 0,010 & 5,1 & 8,0 & 5,5 & 7,7 \\
\hline Tabebuia serratifolia & BIGNONIACEAE & 4 & 4 & 0,22 & 0,23 & 0,07 & 0,07 & 0,35 & 0,37 & 0,65 & 0,67 & 0,013 & 0,012 & 5,2 & 7,8 & 5,2 & 7,6 \\
\hline Tapura singularis & DICHAPETALACEAE & 4 & 4 & 0,22 & 0,23 & 0,15 & 0,14 & 0,26 & 0,27 & 0,63 & 0,65 & 0,025 & 0,025 & 5,0 & 13,8 & 5,0 & 14,0 \\
\hline Ocotea sp2 & LAURACEAE & 5 & 5 & 0,27 & 0,29 & 0,15 & 0,16 & 0,18 & 0,18 & 0,60 & 0,63 & 0,026 & 0,027 & 5,0 & 10,0 & 5,0 & 10,3 \\
\hline Symphonia globulifera & CLUSIACEAE & 1 & 1 & 0,05 & 0,06 & 0,45 & 0,51 & 0,09 & 0,09 & 0,59 & 0,66 & 0,076 & 0,089 & 31,0 & 31,0 & 33,6 & 33,6 \\
\hline Xylopia frutescens var frutescens & ANNONACEAE & 3 & 3 & 0,16 & 0,18 & 0,13 & 0,19 & 0,26 & 0,27 & 0,56 & 0,64 & 0,022 & 0,032 & 8,5 & 10,5 & 9,5 & 13,3 \\
\hline Licania lata & CHRYSOBALANACEAE & 3 & 3 & 0,16 & 0,18 & 0,12 & 0,14 & 0,26 & 0,27 & 0,55 & 0,59 & 0,021 & 0,024 & 7,2 & 10,5 & 7,2 & 12,3 \\
\hline Vochysia inundata & VOCHYSIACEAE & 3 & 5 & 0,16 & 0,29 & 0,11 & 0,21 & 0,26 & 0,46 & 0,54 & 0,96 & 0,019 & 0,036 & 5,0 & 13,5 & 5,1 & 17,6 \\
\hline Eugenia sp2 & MYRTACEAE & + & 5 & 0,22 & 0,29 & 0,05 & 0,07 & 0,26 & 0,37 & 0,53 & 0,73 & 0,009 & 0,012 & 5,0 & 5,7 & 5,0 & 6,1 \\
\hline Ferdinandusa paraensis & RUBIACEAE & 3 & 4 & 0,16 & 0,23 & 0,10 & 0,13 & 0,26 & 0,37 & 0,53 & 0,73 & 0,017 & 0,022 & 7,0 & 10,5 & 6,8 & 10,9 \\
\hline Ormosia discolor & FABACEAE Pap. & 2 & 2 & 0,11 & 0,12 & 0,33 & 0,36 & 0,09 & 0,09 & 0,53 & 0,56 & 0,055 & 0,061 & 18,0 & 19,5 & 17,4 & 21,9 \\
\hline Sloanea grandifolia & ELAEOCARPACEAE & 3 & 3 & 0,16 & 0,18 & 0,10 & 0,13 & 0,26 & 0,27 & 0,53 & 0,58 & 0,017 & 0,023 & 6,0 & 10,0 & 7,2 & 11,2 \\
\hline Licaria multiflora & LAURACEAE & 3 & 3 & 0,16 & 0,18 & 0,08 & 0,08 & 0,26 & 0,27 & 0,51 & 0,53 & 0,014 & 0,013 & 6,0 & 10,0 & 5,8 & 9,8 \\
\hline Eschweilera coriacea & LECYTHIDACEAE & 3 & 3 & 0,16 & 0,18 & 0,08 & 0,08 & 0,26 & 0,27 & 0,50 & 0,53 & 0,013 & 0,014 & 5,0 & 9,0 & 6,1 & 9,1 \\
\hline Lacmellea sculeata & APOCYNACEAE & 3 & 3 & 0,16 & 0,18 & 0,06 & 0,05 & 0,26 & 0,27 & 0,49 & 0,50 & 0,011 & 0,008 & 5,5 & 7,5 & 5,0 & 6,7 \\
\hline Clusia amazonica & CLUSIACEAE & 2 & 2 & 0,11 & 0,12 & 0,20 & 0,19 & 0,18 & 0,18 & 0,48 & 0,49 & 0,033 & 0,033 & 6,5 & 19,5 & 6,4 & 19,5 \\
\hline Emmotum fagifolium & ICACINACEAE & 4 & 4 & 0,22 & 0,23 & 0,08 & 0,08 & 0,18 & 0,18 & 0,48 & 0,50 & 0,014 & 0,014 & 5,4 & 7,0 & 5,9 & 7,1 \\
\hline Byrsonima aerugo* & MALPIGHIACEAE & 1 & & 0,05 & & 0,31 & & 0,09 & & 0,46 & & 0,053 & & 26,0 & 26,0 & & \\
\hline Pterocarpus amazonicus & FABACEAE Pap. & 1 & 1 & 0,05 & 0,06 & 0,31 & 0,38 & 0,09 & 0,09 & 0,46 & 0,53 & 0,053 & 0,065 & 26,0 & 26,0 & 28,8 & 28,8 \\
\hline Calophyllum brasiliense & CLUSIACEAE & 3 & 3 & 0,16 & 0,18 & 0,10 & 0,09 & 0,18 & 0,18 & 0,44 & 0,45 & 0,016 & 0,016 & 5,5 & 11,0 & 5,7 & 10,6 \\
\hline
\end{tabular}


Continua...

Anexo C. Parâmetros fitossociológicos das espécies arbóreas amostradas nos anos de 1999 e 2002 (por ordem de IVI 1999) em uma floresta secundária oriunda de agricultura de corte e queima no município de Bragança-PA

\begin{tabular}{|c|c|c|c|c|c|c|c|c|c|c|c|c|c|c|c|c|c|}
\hline \multirow{2}{*}{ Especies } & \multirow{2}{*}{ Famílias } & \multicolumn{2}{|c|}{ DA } & \multicolumn{2}{|c|}{ DR } & \multicolumn{2}{|c|}{ DoR } & \multicolumn{2}{|c|}{ FR } & \multicolumn{2}{|c|}{ IVI } & \multicolumn{2}{|c|}{ Ar.Bas. } & \multicolumn{2}{|c|}{ DAP 1999} & \multicolumn{2}{|c|}{ DAP 2002 } \\
\hline & & 1999 & 2002 & 1999 & 2002 & 1999 & 2002 & 1999 & 2002 & 1999 & 2002 & 1999 & 2002 & MIN. & MAX. & MIN. & MAX. \\
\hline Myrcia sylvatica & MYRTACEAE & 5 & 5 & 0,27 & 0,29 & 0,07 & 0,08 & 0,09 & 0,09 & 0,43 & 0,46 & 0,012 & 0,013 & 5,0 & 6,5 & 5,0 & $\overline{6,8}$ \\
\hline Annona aff. Excellens & ANNONACEAE & 2 & 2 & 0,11 & 0,12 & 0,13 & 0,14 & 0,18 & 0,18 & 0,42 & 0,44 & 0,023 & 0,024 & 12,0 & 12,0 & 11,6 & 13,1 \\
\hline Couepia bracteosa & CHRYSOBALANACEAE & 2 & 1 & 0,11 & 0,06 & 0,12 & 0,10 & 0,18 & 0,09 & 0,40 & 0,25 & 0,020 & 0,017 & 6,3 & 14,5 & 14,6 & 14,6 \\
\hline Protium pallidum & BURCERACEA E & 3 & 3 & 0,16 & 0,18 & 0,06 & 0,07 & 0,18 & 0,18 & 0,40 & 0,43 & 0,010 & 0,012 & 5,6 & 8,0 & 6,1 & 8,5 \\
\hline Inga heterophylla & FABACEAE Mimo. & 2 & 1 & 0,11 & 0,06 & 0,11 & 0,09 & 0,18 & 0,09 & 0,39 & 0,24 & 0,018 & 0,015 & 5,2 & 14,2 & 14,0 & 14,0 \\
\hline Myrcia spl & MYRTACEAE & 3 & 3 & 0,16 & 0,18 & 0,05 & 0,04 & 0,18 & 0,18 & 0,39 & 0,40 & 0,009 & 0,008 & 5,0 & 7,0 & 5,0 & 6,1 \\
\hline Sapindus saponaria & SAPINDACEAE & 2 & 2 & 0,11 & 0,12 & 0,05 & 0,05 & 0,18 & 0,18 & 0,34 & 0,35 & 0,009 & 0,008 & 6,0 & 8,7 & 5,1 & 9,0 \\
\hline Duroia sprucei & RUBIACEAE & 2 & 2 & 0,11 & 0,12 & 0,05 & 0,05 & 0,18 & 0,18 & 0,33 & 0,35 & 0,008 & 0,008 & 5,0 & 9,0 & 5,0 & 8,7 \\
\hline Eschweilera micrantha & LECYTHIDACEAE & 2 & 3 & 0,11 & 0,18 & 0,05 & 0,06 & 0,18 & 0,18 & 0,33 & 0,42 & 0,008 & 0,010 & 5,9 & 8,0 & 5,3 & 7,9 \\
\hline Byrsonima crispa & MALPIGHIACEAE & 1 & 1 & 0,05 & 0,06 & 0,17 & 0,19 & 0,09 & 0,09 & 0,32 & 0,34 & 0,029 & 0,032 & 19,3 & 19,3 & 20,2 & 20,2 \\
\hline Mabea paniculata & EUPHORBIACEAE & 2 & 2 & 0,11 & 0,12 & 0,04 & 0,04 & 0,18 & 0,18 & 0,32 & 0,34 & 0,006 & 0,007 & 6,0 & 6,5 & 6,2 & 6,7 \\
\hline Inga stipularis & FABACEAE Mimo. & 2 & 2 & 0,11 & 0,12 & 0,03 & 0,03 & 0,18 & 0,18 & 0,31 & 0,33 & 0,005 & 0,005 & 5,0 & 6,0 & 5,0 & 6,0 \\
\hline Maytenus myrsinoides & CELASTRACEAE & 2 & 2 & 0,11 & 0,12 & 0,11 & 0,12 & 0,09 & 0,09 & 0,31 & 0,33 & 0,018 & 0,020 & 10,0 & 11,5 & 9,9 & 12,6 \\
\hline Trichilia lecointei & MELIACEAE & 2 & 2 & 0,11 & 0,12 & 0,03 & 0,04 & 0,18 & 0,18 & 0,31 & 0,34 & 0,005 & 0,007 & 5,5 & 5,7 & 6,4 & 7,0 \\
\hline Vitex triflora & VERBENACEA & 2 & 2 & 0,11 & 0,12 & 0,06 & 0,07 & 0,09 & 0,09 & 0,26 & 0,28 & 0,010 & 0,012 & 7,2 & 9,0 & 7,4 & 9,8 \\
\hline Eschweilera idatimon & LECYTHIDACEAE & 2 & 2 & 0,11 & 0,12 & 0,03 & 0,05 & 0,09 & 0,09 & 0,23 & 0,26 & 0,006 & 0,008 & 5,0 & 7,0 & 6,3 & 8,2 \\
\hline Cheiloclinium cognatum & HIPPOCRATEACEAE & 2 & 2 & 0,11 & 0,12 & 0,03 & 0,02 & 0,09 & 0,09 & 0,22 & 0,23 & 0,004 & 0,004 & 5,0 & 5,5 & 5,1 & 5,3 \\
\hline Dialium guianense & FABACEAE Caes. & 1 & 1 & 0,05 & 0,06 & 0,08 & 0,11 & 0,09 & 0,09 & 0,22 & 0,26 & 0,014 & 0,019 & 13,1 & 13,1 & 15,6 & 15,6 \\
\hline Sloanea guianensis & ELAEOCARPACEAE & 1 & 1 & 0,05 & 0,06 & 0,06 & 0,06 & 0,09 & 0,09 & 0,21 & 0,21 & 0,011 & 0,011 & 11,7 & 11,7 & 11,6 & 11,6 \\
\hline Casearia decandra & FLACOURTIACEAE & 1 & 2 & 0,05 & 0,12 & 0,06 & 0,08 & 0,09 & 0,18 & 0,20 & 0,38 & 0,010 & 0,014 & 11,0 & 11,0 & 8,4 & 10,1 \\
\hline Pouteria reticulata & SAPOTACEAE & 1 & 1 & 0,05 & 0,06 & 0,05 & 0,07 & 0,09 & 0,09 & 0,20 & 0,22 & 0,009 & 0,011 & 10,8 & 10,8 & 12,0 & 12,0 \\
\hline Bocageopsis multiflora* & ANNONACEAE & 1 & & 0,05 & & 0,04 & & 0,09 & & 0,18 & & 0,006 & & 9,0 & 9,0 & & \\
\hline Bombax faroense & BOMBACACEAE & 1 & 1 & 0,05 & 0,06 & 0,04 & 0,04 & 0,09 & 0,09 & 0,18 & 0,19 & 0,006 & 0,007 & 9,0 & 9,0 & 9,2 & 9,2 \\
\hline Palicourea grandifolia* & RUBIACEAE & 1 & & 0,05 & & 0,03 & & 0,09 & & 0,18 & & 0,006 & & 8,4 & 8,4 & & \\
\hline Zanthoxylum rhoifolia & RUTACEAE & 1 & 1 & 0,05 & 0,06 & 0,04 & 0,04 & 0,09 & 0,09 & 0,18 & 0,19 & 0,006 & 0,007 & 9,0 & 9,0 & 9,1 & 9,1 \\
\hline Eugenia spl & MYRTACEAE & 1 & 2 & 0,05 & 0,12 & 0,02 & 0,04 & 0,09 & 0,18 & 0,17 & 0,34 & 0,004 & 0,007 & 7,3 & 7,3 & 5,4 & 7,4 \\
\hline Isertia hipoleuca* & RUBIACEAE & 1 & & 0,05 & & 0,03 & & 0,09 & & 0,17 & & 0,005 & & 8,3 & 8,3 & & \\
\hline
\end{tabular}


Continua...

Anexo C. Parâmetros fitossociológicos das espécies arbóreas amostradas nos anos de 1999 e 2002 (por ordem de IVI 1999) em uma floresta secundária oriunda de agricultura de corte e queima no município de Bragança-PA

\begin{tabular}{|c|c|c|c|c|c|c|c|c|c|c|c|c|c|c|c|c|c|}
\hline \multirow{2}{*}{ Especies } & \multirow{2}{*}{ Famílias } & \multicolumn{2}{|c|}{ DA } & \multicolumn{2}{|c|}{ DR } & \multicolumn{2}{|c|}{ DoR } & \multicolumn{2}{|c|}{ FR } & \multicolumn{2}{|c|}{ IVI } & \multicolumn{2}{|c|}{ Ar.Bas. } & \multicolumn{2}{|c|}{ DAP 1999} & \multicolumn{2}{|c|}{ DAP 2002} \\
\hline & & 1999 & 2002 & 1999 & 2002 & 1999 & 2002 & 1999 & 2002 & 1999 & 2002 & 1999 & 2002 & MIN. & MAX. & MIN. & MAX. \\
\hline Jacaranda copaia & BIGNONIACEAE & 1 & 1 & 0,05 & 0,06 & 0,03 & 0,06 & 0,09 & 0,09 & 0,17 & 0,21 & 0,005 & 0,010 & 7,8 & 7,8 & 11,5 & $\overline{11,5}$ \\
\hline Lecythis micrantha & LECYTHIDACEAE & 1 & 2 & 20,05 & 0,12 & 0,02 & 0,05 & 0,09 & 0,18 & 0,17 & 0,35 & 0,004 & 0,009 & 7,0 & 7,0 & 5,5 & 8,9 \\
\hline Perebea guianensis & MORACEAE & 1 & 1 & 0,05 & 0,06 & 0,02 & 0,02 & 0,09 & 0,09 & 0,17 & 0,17 & 0,004 & 0,003 & 7,0 & 7,0 & 6,3 & 6,3 \\
\hline Vochysia guianensis & VOCHYSIACEAE & 1 & 1 & 0,05 & 0,06 & 0,02 & 0,04 & 0,09 & 0,09 & 0,17 & 0,19 & 0,004 & 0,008 & 7,1 & 7,1 & 9,9 & 9,9 \\
\hline Casearia javitensis* & FLACOURTIACEAE & 1 & & 0,05 & & 0,02 & & 0,09 & & 0,16 & & 0,003 & & 5,7 & 5,7 & & \\
\hline Chrysophillum argenteum & $\imath$ SAPOTACEAE & 1 & 1 & 0,05 & 0,06 & 0,02 & 0,02 & 0,09 & 0,09 & 0,16 & 0,17 & 0,003 & 0,003 & 6,3 & 6,3 & 6,2 & 6,2 \\
\hline Diospyros plaetermissa & EBENACEAE & 1 & 1 & 0,05 & 0,06 & 0,02 & 0,02 & 0,09 & 0,09 & 0,16 & 0,17 & 0,003 & 0,003 & 6,5 & 6,5 & 6,1 & 6,1 \\
\hline Duroia guianensis & RUBIACEAE & 1 & 2 & 0,05 & 0,12 & 0,02 & 0,03 & 0,09 & 0,09 & 0,16 & 0,23 & 0,003 & 0,004 & 6,0 & 6,0 & 5,1 & 5,5 \\
\hline Eschweilera apiculata & LECYTHIDACEAE & 1 & 1 & 0,05 & 0,06 & 0,02 & 0,02 & 0,09 & 0,09 & 0,16 & 0,17 & 0,004 & 0,004 & 6,8 & 6,8 & 6,8 & 6,8 \\
\hline Helicostylis sp & MORACEAE & 1 & 1 & 0,05 & 0,06 & 0,02 & 0,01 & 0,09 & 0,09 & 0,16 & 0,16 & 0,003 & 0,003 & 6,2 & 6,2 & 5,7 & 5,7 \\
\hline Lacunaria jenmani & QUIINACEAE & 1 & 1 & 0,05 & 0,06 & 0,01 & 0,02 & 0,09 & 0,09 & 0,16 & 0,17 & 0,002 & 0,003 & 5,4 & 5,4 & 5,9 & 5,9 \\
\hline Licania densiflora & CHRYSOBALANACEAE & 1 & 1 & 0,05 & 0,06 & 0,02 & 0,02 & 0,09 & 0,09 & 0,16 & 0,17 & 0,003 & 0,004 & 6,5 & 6,5 & 6,9 & 6,9 \\
\hline Ni ni5 & $\mathrm{NI}$ & 1 & 1 & 0,05 & 0,06 & 0,02 & 0,02 & 0,09 & 0,09 & 0,16 & 0,17 & 0,003 & 0,003 & 5,8 & 5,8 & 5,9 & 5,9 \\
\hline Ormosia paraensis & FABACEAE Pap. & 1 & 1 & 0,05 & 0,06 & 0,02 & 0,01 & 0,09 & 0,09 & 0,16 & 0,16 & 0,003 & 0,003 & 6,0 & 6,0 & 5,7 & 5,7 \\
\hline Pouteria torta & SAPOTACEAE & 1 & 1 & 0,05 & 0,06 & 0,02 & 0,01 & 0,09 & 0,09 & 0,16 & 0,16 & 0,003 & 0,002 & 6,0 & 6,0 & 5,5 & 5,5 \\
\hline Richardella macrophylla & SAPOTACEAE & 1 & 1 & 0,05 & 0,06 & 0,02 & 0,02 & 0,09 & 0,09 & 0,16 & 0,17 & 0,003 & 0,004 & 6,2 & 6,2 & 6,7 & 6,7 \\
\hline Guatteria amazonica & ANNONACEAE & 1 & 1 & 0,05 & 0,06 & 0,01 & 0,01 & 0,09 & 0,09 & 0,15 & 0,16 & 0,002 & 0,002 & 5,0 & 5,0 & 5,0 & 5,0 \\
\hline Lecythis idatimon & LECYTHIDACEAE & 1 & 1 & 0,05 & 0,06 & 0,01 & 0,01 & 0,09 & 0,09 & 0,15 & 0,16 & 0,002 & 0,003 & 5,0 & 5,0 & 5,6 & 5,6 \\
\hline Miconia eriodonta & MELASTOMACEAE & 1 & 1 & 0,05 & 0,06 & 0,01 & 0,01 & 0,09 & 0,09 & 0,15 & 0,16 & 0,002 & 0,002 & 5,0 & 5,0 & 5,0 & 5,0 \\
\hline Platonia insignis & CLUSIACEAE & 1 & 1 & 0,05 & 0,06 & 0,01 & 0,01 & 0,09 & 0,09 & 0,15 & 0,16 & 0,002 & 0,002 & 5,0 & 5,0 & 5,0 & 5,0 \\
\hline Psidium guajava & MYRTACEAE & 1 & 1 & 0,05 & 0,06 & 0,01 & 0,01 & 0,09 & 0,09 & 0,15 & 0,16 & 0,002 & 0,002 & 5,0 & 5,0 & 5,3 & 5,3 \\
\hline Inga cayennensis & FABACEAE Mimo. & & 1 & & 0,06 & & 0,01 & & 0,09 & & 0,16 & & 0,002 & & & 5,5 & 5,5 \\
\hline NI Ni6** & LECYTHIDACEAE & & 1 & & 0,06 & & 0,01 & & 0,09 & & 0,16 & & 0,002 & & & 5,3 & 5,3 \\
\hline Virola calophylla** & MYRISTICACEAE & & 1 & 1 & 0,06 & & 0,01 & & 0,09 & & 0,16 & & 0,002 & & & 5,4 & 5,4 \\
\hline
\end{tabular}

As células em branco na tabela representam valores menores que 0,01

*Espécies presentes somente no primeiro ano de medição.

**Espécies que ingressaram no último período.

DA = densidade absoluta; $\mathbf{D R}=$ abundância relativa; $\mathbf{D o R}=$ dominância relativa $; \mathbf{F R}=$ freqüência relativa; $\mathbf{I V I}=$ índice de valor de importância e Ar.Bas. $=$ área basal. 
Anexo D. Valores médios (Me) do pH, Carbono (C), Matéria Orgânica (MO), Fósforo (P), Potássio (k), Sódio (Na), Cálcio (Ca), Magnésio (Mg), Alumínio $(\mathrm{Al})$ e da Acidez $(\mathrm{H})$ para o solo das parcelas amostradas numa floresta secundária antiga oriunda de exploração de madeira para lenha, no município de Marituba-PA, nas profundidades de $0-5 \mathrm{~cm}, 5-15 \mathrm{~cm}$ e $15-25 \mathrm{~cm}$.

\begin{tabular}{|c|c|c|c|c|c|c|c|c|c|c|c|c|c|c|c|c|c|c|c|}
\hline \multirow{3}{*}{ Parc. } & \multirow{3}{*}{$\operatorname{Pr}(\mathbf{c m})$} & \multirow{2}{*}{\multicolumn{2}{|c|}{$\begin{array}{c}\text { pH } \\
\mathrm{H}_{2} \mathrm{O}\end{array}$}} & \multirow{2}{*}{\multicolumn{4}{|c|}{ C }} & \multicolumn{2}{|c|}{$\mathbf{P}$} & \multicolumn{2}{|c|}{$\mathbf{K}$} & \multicolumn{2}{|c|}{$\mathrm{Na}$} & \multicolumn{2}{|c|}{$\mathrm{Ca}$} & \multicolumn{2}{|c|}{ Mg } & \multicolumn{2}{|c|}{$\mathbf{H}+\mathbf{A l}$} \\
\hline & & & & & & & & & & & & & cm & & & & & & \\
\hline & & Me & CV\% & Me & CV\% & Me & CV\% & Me & CV\% & Me & CV\% & Me & CV\% & Me & CV\% & Me & CV\% & Me & CV\% \\
\hline Par 01 & $0-5$ & 3,83 & 4,19 & 16,31 & 46,37 & 28,13 & 46,38 & 3,04 & 13,33 & 0,09 & 21,1 & 0,06 & 21,71 & 0,67 & 22,46 & 0,32 & 37,08 & 7,97 & 15,50 \\
\hline Par 02 & $0-5$ & 3,93 & 5,53 & 22,57 & 16,86 & 38,91 & 16,85 & 4,01 & 21,18 & 0,09 & 27,53 & 0,08 & 29,62 & 0,53 & 22,46 & 0,35 & 13,78 & 7,96 & 13,78 \\
\hline Par 03 & $0-5$ & 3,78 & 2,20 & 16,32 & 31,40 & 28,12 & 31,41 & 4,61 & 31,64 & 0,10 & 26,81 & 0,06 & 32,31 & 0,48 & 13,94 & 0,34 & 32,03 & 8,88 & 13,97 \\
\hline Par 04 & $0-5$ & 3,78 & 4,04 & 19,82 & 34,12 & 34,15 & 34,26 & 4,94 & 10,48 & 0,08 & 13,69 & 0,06 & 18,94 & 0,31 & 53,49 & 0,24 & 34,91 & 9,20 & 18,11 \\
\hline Par 01 & $5-15$ & 3,98 & 3,74 & 10,17 & 40,96 & 17,52 & 40,95 & 1,74 & 24,66 & 0,05 & 30,75 & 0,04 & 31,49 & 0,41 & 36,96 & 0,20 & 41,29 & 6,08 & 16,59 \\
\hline Par 02 & $5-15$ & 3,98 & 4,49 & 13,24 & 26,65 & 22,83 & 26,64 & 1,72 & 54,78 & 0,04 & 30,84 & 0,04 & 40,53 & 0,32 & 15,02 & 0,23 & 31,95 & 5,11 & 17,81 \\
\hline Par 03 & $5-15$ & 3,95 & 7,72 & 12,53 & 30,16 & 21,57 & 30,07 & 2,33 & 54,48 & 0,05 & 30,62 & 0,03 & 30,84 & 0,36 & 37,35 & 0,24 & 31,05 & 7,27 & 33,91 \\
\hline Par 04 & $5-15$ & 4,00 & 4,26 & 11,58 & 35,42 & 19,97 & 35,4 & 2,13 & 36,38 & 0,05 & 30,76 & 0,04 & 30,35 & 0,1 & 34,88 & 0,08 & 46,71 & 7,14 & 13,03 \\
\hline Par 01 & $15-25$ & 4,20 & 3,93 & 7,33 & 71,01 & 12,65 & 71,04 & 1,33 & 24,75 & 0,04 & 38,53 & 0,04 & 33,36 & 0,32 & 34,18 & 0,16 & 54,29 & 5,50 & 16,51 \\
\hline Par 02 & $15-25$ & 4,23 & 3,78 & 10,58 & 31,68 & 18,24 & 31,64 & 0,82 & 27,81 & 0,03 & 48,68 & 0,03 & 49,3 & 0,26 & 10,76 & 0,21 & 30,75 & 4,83 & 26,70 \\
\hline Par 03 & $15-25$ & 4,18 & 7,42 & 9,69 & 30,39 & 16,71 & 30,37 & 1,75 & 71,69 & 0,03 & 42,91 & 0,03 & 37,53 & 0,25 & 24,49 & 0,24 & 21,23 & 6,11 & 34,20 \\
\hline Par 04 & $15-25$ & 4,32 & 4,62 & 10,11 & 41,18 & 17,43 & 41,03 & 1,13 & 27,36 & 0,03 & 30,87 & 0,03 & 22,60 & 0,05 & 0,00 & 0,05 & 0,00 & 6,07 & 19,35 \\
\hline
\end{tabular}

$\mathbf{n}=12$ em cada parcela/profundidade. $\% \mathbf{C V}=$ Coeficiente de Variação. CV até $10 \%$ pequena variabilidade; $10 \%$ a $20 \%$ média variabilidade; > $20 \%$ alta variabilidade (Fonseca \& Martins, 1995). 
Anexo E. Valores médios (Me) do pH, do Carbono (C), da Matéria Orgânica (MO), do Fósforo (P) e do Potássio (k) para o solo das parcelas amostradas numa floresta secundária oriunda de agricultura de corte e queima no município de Bragança-PA, nas profundidades de $0-5 \mathrm{~cm}, 5-15 \mathrm{~cm}$ e 15 -

\begin{tabular}{|c|c|c|c|c|c|c|c|c|c|c|c|c|c|c|c|c|c|c|c|}
\hline \multirow[b]{2}{*}{ Parc. } & \multirow[b]{2}{*}{$\operatorname{Pr}(\mathbf{c m})$} & \multirow{2}{*}{\multicolumn{2}{|c|}{$\begin{array}{c}\text { pH } \\
\mathrm{H}_{2} \mathrm{O}\end{array}$}} & \multicolumn{2}{|c|}{ C } & \multicolumn{2}{|c|}{ MO } & \multicolumn{2}{|c|}{$\mathbf{P}$} & \multicolumn{2}{|c|}{$\mathbf{K}$} & \multicolumn{2}{|c|}{$\mathbf{N a}$} & \multicolumn{2}{|c|}{$\mathrm{Ca}$} & \multicolumn{2}{|c|}{ Mg } & \multicolumn{2}{|c|}{$\mathbf{H}+\mathbf{A l}$} \\
\hline & & & & & $\mathrm{g} /$ & $\mathrm{kg}$ & & & & & & & cmo & $\mathrm{dm}^{3}$ & & & & & \\
\hline Par 01 & $0-5$ & 4,37 & 4,72 & 15,61 & 44,98 & 26,91 & 44,92 & 3,70 & 12,83 & 0,17 & 14,87 & 0,14 & 16,32 & 0,70 & 56,20 & 0,50 & 15,18 & 5,46 & 12,15 \\
\hline Par 02 & $0-5$ & 4,24 & 4,76 & 12,41 & 28,03 & 21,38 & 28,17 & 3,45 & 12,70 & 0,21 & 21,39 & 0,16 & 24,08 & 0,51 & 66,03 & 0,55 & 12,63 & 6,23 & 13,49 \\
\hline Par 04 & $0-5$ & 4,33 & 5,67 & 18,47 & 32,28 & 31,84 & 32,33 & 2,14 & 14,96 & 0,07 & 24,02 & 0,06 & 26,96 & 0,82 & 32,33 & 0,58 & 17,59 & 5,97 & 16,32 \\
\hline Par 01 & $5-15$ & 4,08 & 4,02 & 11,61 & 48,87 & 20,03 & 48,89 & 2,54 & 21,71 & 0,09 & 27,86 & 0,07 & 39,38 & 0,16 & 74,77 & 0,16 & 48,24 & 4,55 & 23,10 \\
\hline Par 02 & $5-15$ & 4,09 & 4,10 & 8,03 & 29,13 & 13,87 & 29,25 & 2,33 & 16,07 & 0,11 & 21,60 & 0,08 & 29,73 & 0,13 & 49,73 & 0,27 & 32,89 & 5,01 & 13,16 \\
\hline Par 03 & $5-15$ & 4,02 & 2,97 & 6,98 & 62,17 & 12,05 & 62,37 & 1,72 & 23,28 & 0,06 & 68,28 & 0,04 & 62,18 & 0,33 & 35,23 & 0,32 & 83,64 & 3,77 & 8,16 \\
\hline Par 04 & $5-15$ & 4,13 & 3,62 & 12,03 & 48,75 & 20,73 & 48,79 & 1,42 & 26,89 & 0,05 & 44,84 & 0,04 & 56,83 & 0,40 & 40,47 & 0,33 & 28,84 & 5,46 & 20,27 \\
\hline Par 01 & $15-25$ & 4,28 & 3,47 & 9,78 & 95,69 & 16,85 & 95,60 & 2,09 & 29,50 & 0,05 & 33,03 & 0,03 & 44,73 & 0,05 & 26,65 & 0,10 & 60,76 & 3,51 & 14,19 \\
\hline Par 02 & $15-25$ & 4,23 & 2,10 & 4,76 & 58,82 & 8,23 & 58,19 & 1,90 & 21,53 & 0,06 & 15,66 & 0,03 & 29,54 & 0,05 & 26,65 & 0,16 & 49,73 & 4,08 & 15,07 \\
\hline Par 03 & $15-25$ & 4,28 & 3,47 & 3,42 & 88,65 & 5,85 & 88,76 & 1,16 & 45,00 & 0,03 & 65,40 & 0,02 & 73,70 & 0,21 & 40,29 & 0,21 & 22,71 & 2,98 & 21,66 \\
\hline Par 04 & $15-25$ & 4,27 & 3,05 & 10,97 & 43,56 & 18,89 & 43,82 & 0,92 & 24,98 & 0,03 & 38,56 & 0,02 & 42,20 & 0,25 & 28,39 & 0,27 & 24,43 & 4,42 & 14,49 \\
\hline
\end{tabular}

$\mathbf{n}=12$ em cada parcela/profundidade. \%CV = Coeficiente de Variação. CV até $10 \%$ pequena variabilidade; $10 \%$ a $20 \%$ média variabilidade; > $20 \%$ alta variabilidade (Fonseca \& Martins, 1995. 
Anexo F. Valores médios (Me) de CTC, SB, \%V e \%Al para o solo das parcelas amostradas em florestas secundárias nos municípios de Marituba e Bragança-PA, nas profundidades de $0-5 \mathrm{~cm}, 5-15 \mathrm{~cm}$ e $15-25 \mathrm{~cm}$.

\begin{tabular}{|c|c|c|c|c|c|c|c|c|c|c|c|c|c|c|c|c|c|}
\hline \multirow{3}{*}{ Parcelas } & \multirow{3}{*}{ Profun $(\mathrm{cm})$} & \multicolumn{8}{|c|}{ Marituba } & \multicolumn{8}{|c|}{ Bragança } \\
\hline & & \multicolumn{2}{|c|}{$\begin{array}{c}\text { CTC } \\
{\mathrm{cmol} / \mathrm{dm}^{3}}^{3}\end{array}$} & \multicolumn{2}{|c|}{$\mathrm{SB} \mathrm{cmol} / \mathrm{dm}^{3}$} & \multicolumn{2}{|c|}{$\% \mathrm{~V}$} & \multicolumn{2}{|c|}{$\% \mathrm{Al}$} & \multicolumn{2}{|c|}{$\begin{array}{c}\text { CTC } \\
\mathrm{cmol} / \mathrm{dm}^{3}\end{array}$} & \multicolumn{2}{|c|}{$\mathrm{SB} \mathbf{c m o l} / \mathrm{dm}^{3}$} & \multicolumn{2}{|c|}{$\% \mathrm{~V}$} & \multicolumn{2}{|c|}{$\% \mathrm{Al}$} \\
\hline & & Me & $\% \mathrm{CV}$ & Me & $\% \mathrm{CV}$ & Me & $\% \mathrm{CV}$ & Me & $\% \mathrm{CV}$ & Me & $\% \mathrm{CV}$ & Me & $\% \mathrm{CV}$ & Me & $\% \mathrm{CV}$ & Me & $\% \mathrm{CV}$ \\
\hline Par 01 & $0-5$ & 9,11 & 14,40 & 1,14 & 14,72 & 12,61 & 13,79 & 22,46 & 24,38 & 6,97 & 9,19 & 1,50 & 29,98 & 21,59 & 27,04 & 15,93 & 22,89 \\
\hline Par 02 & $0-5$ & 9,00 & 12,07 & 1,04 & 14,56 & 11,74 & 18,39 & 23,77 & 9,20 & 7,66 & 9,26 & 1,42 & 24,73 & 18,79 & 28,33 & 17,69 & 19,83 \\
\hline Par 03 & $0-5$ & 9,86 & 12,98 & 0,98 & 15,09 & 10,05 & 17,77 & 23,53 & 10,33 & 6,33 & 6,31 & 1,61 & 14,67 & 25,48 & 14,72 & 13,51 & 20,50 \\
\hline Par 04 & $0-5$ & 9,83 & 16,53 & 0,68 & 33,23 & 7,02 & 33,40 & 24,31 & 8,19 & 7,49 & 11,91 & 1,52 & 21,48 & 20,59 & 24,62 & 17,08 & 21,12 \\
\hline Par 01 & $5-15$ & 6,78 & 16,42 & 0,70 & 32,82 & 10,27 & 28,29 & 25,93 & 18,25 & 5,02 & 23,77 & 0,47 & 39,76 & 9,31 & 24,05 & 28,32 & 9,01 \\
\hline Par 02 & $5-15$ & 5,74 & 16,12 & 0,63 & 10,08 & 11,16 & 15,68 & 29,87 & 9,96 & 5,59 & 12,40 & 0,59 & 22,27 & 10,56 & 22,13 & 28,14 & 11,47 \\
\hline Par 03 & $5-15$ & 7,95 & 31,04 & 0,68 & 23,98 & 9,05 & 32,44 & 26,20 & 14,90 & 4,51 & 7,41 & 0,75 & 39,32 & 16,41 & 35,15 & 27,56 & 12,64 \\
\hline Par 04 & $5-15$ & 7,36 & 12,53 & 0,26 & 20,76 & 3,59 & 17,50 & 29,09 & 9,08 & 6,28 & 17,81 & 0,82 & 26,49 & 13,32 & 28,06 & 23,57 & 20,84 \\
\hline Par 01 & $15-25$ & 6,06 & 16,18 & 0,56 & 30,77 & 9,28 & 25,56 & 26,19 & 13,31 & 3,73 & 13,83 & 0,23 & 24,90 & 6,15 & 22,45 & 35,37 & 7,60 \\
\hline Par 02 & $15-25$ & 5,36 & 24,03 & 0,53 & 10,16 & 10,33 & 22,12 & 28,13 & 15,64 & 4,38 & 14,42 & 0,30 & 19,84 & 6,97 & 20,57 & 32,89 & 8,69 \\
\hline Par 03 & $15-25$ & 6,66 & 31,58 & 0,55 & 8,17 & 8,75 & 22,68 & 26,78 & 15,79 & 3,46 & 20,02 & 0,48 & 19,57 & 14,18 & 20,02 & 32,05 & 15,26 \\
\hline Par 04 & $15-25$ & 6,21 & 18,17 & 0,16 & 9,16 & 2,57 & 14,03 & 29,43 & 25,08 & 4,99 & 12,39 & 0,57 & 16,69 & 11,61 & 23,15 & 28,46 & 7,93 \\
\hline
\end{tabular}

$\mathbf{n}=12$ em cada parcela/profundidade. \% CV = Coeficiente de Variação.CV até 10\% pequena variabilidade; $10 \%$ a $20 \%$ média variabilidade; > 20\% alta variabilidade (Fonseca \& Martins, 1995). CTC $=$ Capacidade de troca de cátions $\left(\mathrm{Ca}^{+2}, \mathrm{Mg}^{+2}, \mathrm{~K}^{+}, \mathrm{Na}^{+}, \mathrm{H}^{+}\right.$e $\left.\mathrm{Al}^{+3}\right), \mathbf{S B}=$ Soma de bases $(\mathrm{Ca}, \mathrm{Mg}, \mathrm{KeNa}), \% \mathbf{V}=\mathrm{Percentagem} \mathrm{de}$ saturação de bases, $\% \mathbf{A l}=$ Toxidez do alumínio. 
Anexo G. Valores médios (Me) da Areia Grossa, Areia Fina, Silte e Argila do solo das parcelas amostradas em florestas secundárias nos municípios de Marituba e Bragança-PA, nas profundidades de $0-5 \mathrm{~cm}, 5-15 \mathrm{~cm}$ e $15-25 \mathrm{~cm}$.

\begin{tabular}{|c|c|c|c|c|c|c|c|c|c|c|c|c|c|c|c|c|c|}
\hline \multirow{3}{*}{ Parcelas } & \multirow{3}{*}{ Profun(cm) } & \multicolumn{8}{|c|}{ Marituba } & \multicolumn{8}{|c|}{ Bragança } \\
\hline & & \multicolumn{2}{|c|}{$\operatorname{Ar} \operatorname{Gros}(\%)$} & \multicolumn{2}{|c|}{$\operatorname{Ar} \operatorname{Fin}(\%)$} & \multicolumn{2}{|c|}{ Silte (\%) } & \multicolumn{2}{|c|}{ Argila (\%) } & \multicolumn{2}{|c|}{$\operatorname{Ar} \operatorname{Gros}(\%)$} & \multicolumn{2}{|c|}{$\operatorname{Ar}$ Fin $(\%)$} & \multicolumn{2}{|c|}{ Silte (\%) } & \multicolumn{2}{|c|}{ Argila (\%) } \\
\hline & & Me & $\% \mathrm{CV}$ & Me & $\% \mathrm{CV}$ & Me & $\% \mathrm{CV}$ & Me & $\% \mathrm{CV}$ & Me & $\% \mathrm{CV}$ & Me & $\% \mathrm{CV}$ & Me & $\% \mathrm{CV}$ & Me & $\% \mathrm{CV}$ \\
\hline Par 01 & $0-5$ & 60,61 & 7,05 & 21,83 & 12,10 & 9,73 & 16,44 & 7,83 & 28,29 & 52,02 & 6,91 & 31,41 & 9,91 & 7,76 & 15,82 & 8,83 & 24,60 \\
\hline Par 02 & $0-5$ & 53,88 & 8,95 & 26,12 & 10,93 & 12,32 & 20,44 & 7,65 & 24,09 & 43,62 & 3,85 & 33,98 & 5,40 & 14,32 & 11,61 & 8,08 & 13,81 \\
\hline Par 03 & $0-5$ & 64,85 & 9,49 & 18,05 & 22,02 & 11,07 & 12,05 & 6,03 & 41,96 & 47,16 & 6,74 & 33,48 & 9,29 & 11,33 & 11,78 & 8,05 & 14,76 \\
\hline Par 04 & $0-5$ & 60,65 & 7,81 & 21,68 & 12,17 & 11,87 & 17,09 & 5,80 & 31,11 & 54,23 & 4,93 & 23,71 & 9,34 & 10,49 & 10,81 & 11,62 & 12,26 \\
\hline Par 01 & $5-15$ & 52,65 & 9,21 & 25,08 & 9,08 & 10,68 & 21,28 & 11,62 & 29,91 & 49,33 & 7,75 & 30,34 & 16,31 & 10,22 & 37,41 & 10,10 & 20,72 \\
\hline Par 02 & $5-15$ & 48,94 & 9,85 & 27,73 & 8,55 & 11,34 & 32,91 & 12,00 & 34,02 & 42,10 & 3,77 & 34,52 & 4,04 & 14,88 & 10,47 & 8,49 & 15,87 \\
\hline Par 03 & $5-15$ & 60,04 & 8,86 & 19,42 & 19,10 & 10,66 & 18,12 & 9,91 & 27,54 & 44,46 & 6,35 & 34,11 & 9,76 & 12,68 & 20,82 & 8,79 & 13,64 \\
\hline Par 04 & $5-15$ & 56,46 & 6,17 & 22,06 & 11,34 & 12,79 & 16,35 & 8,65 & 37,01 & 48,78 & 5,87 & 26,44 & 5,90 & 11,53 & 11,49 & 13,34 & 12,13 \\
\hline Par 01 & $15-25$ & 47,93 & 9,73 & 25,13 & 11,53 & 12,69 & 19,81 & 14,26 & 18,77 & 44,42 & 5,48 & 32,32 & 15,55 & 10,51 & 20,68 & 12,77 & 22,15 \\
\hline Par 02 & $15-25$ & 43,44 & 7,56 & 28,13 & 5,13 & 13,75 & 33,83 & 14,69 & 24,06 & 38,67 & 5,38 & 35,29 & 4,37 & 15,01 & 11,12 & 11,04 & 14,56 \\
\hline Par 03 & $15-25$ & 54,72 & 8,56 & 20,26 & 14,58 & 12,46 & 21,79 & 12,56 & 30,29 & 40,96 & 7,13 & 34,19 & 6,69 & 13,67 & 16,93 & 11,18 & 12,33 \\
\hline Par 04 & $15-25$ & 48,47 & 7,08 & 22,91 & 11,10 & 17,33 & 19,28 & 11,28 & 27,52 & 45,59 & 4,85 & 26,95 & 5,42 & 11,44 & 11,59 & 16,03 & 13,91 \\
\hline
\end{tabular}


Anexo H. Matriz de presença e ausência das espécies presentes nos levantamentos realizados em Marituba e Bragança-PA

\begin{tabular}{|c|c|c|c|c|c|c|c|c|c|}
\hline \multirow{3}{*}{ Especie } & \multirow{3}{*}{$\begin{array}{c}\text { Código } \\
\text { Ana. } \\
\text { Agrup. }\end{array}$} & \multicolumn{8}{|c|}{ Parcelas } \\
\hline & & \multicolumn{4}{|c|}{ Marituba } & \multicolumn{4}{|c|}{ Bragança } \\
\hline & & M1 & M2 & M3 & M4 & B1 & B2 & B3 & B4 \\
\hline Abarema cochleata (Willd.) Barneby \& J.W.Grimes & Abarcoch & 0 & 0 & 0 & 0 & 0 & 1 & 1 & 1 \\
\hline Abarema jupumba (Willd.) Britton \& Killip & Abarjupu & 1 & 0 & 1 & 1 & 1 & 1 & 1 & 1 \\
\hline Alchorneopsis trimera Lanj. & Alchtrin & 0 & 1 & 0 & 0 & 0 & 0 & 0 & 0 \\
\hline Ambelania acida Aubl. & Ambeacid & 1 & 1 & 1 & 1 & 0 & 1 & 1 & 1 \\
\hline Ampelocera edentula Kuhlm. & Ampeeden & 1 & 0 & 0 & 0 & 0 & 0 & 0 & 0 \\
\hline Annona aff. excellens R. E. Fr. & Annoaff. & 0 & 0 & 0 & 0 & 0 & 1 & 0 & 0 \\
\hline Annona montana Macfad. & Annomont & 0 & 1 & 0 & 0 & 0 & 0 & 0 & 0 \\
\hline Annona paludosa Aubl. & Annopalu & 0 & 0 & 1 & 0 & 1 & 1 & 1 & 1 \\
\hline Apeiba albiflora Ducke & Apeialbi & 1 & 1 & 1 & 1 & 0 & 1 & 1 & 1 \\
\hline Aspidosperma auriculatum Markgr. (Pichon) & Aspiauri & 0 & 0 & 0 & 1 & 0 & 0 & 0 & 0 \\
\hline Aspidosperma rigidum $\mathrm{Rusby}$ & Aspirigi & 0 & 1 & 0 & 0 & 0 & 0 & 0 & 0 \\
\hline Batesia floribunda Benth. & Bateflor & 1 & 0 & 0 & 0 & 0 & 0 & 0 & 0 \\
\hline Bellucia grossularioides (L.) Triana & Bellglos & 1 & 0 & 0 & 0 & 0 & 1 & 1 & 0 \\
\hline Bombax faroense Ducke & Bombfaro & 0 & 0 & 0 & 0 & 0 & 0 & 1 & 0 \\
\hline Brosimum guianensis (Aubl.) Huber & Brosguia & 0 & 1 & 1 & 0 & 0 & 1 & 0 & 0 \\
\hline Brosimum lactescens (S.Moore) C.C.Berg & Broslact & 0 & 0 & 0 & 1 & 0 & 0 & 0 & 0 \\
\hline Brosimum parinarioides Ducke & Brospari & 0 & 0 & 0 & 1 & 0 & 0 & 0 & 0 \\
\hline Brosimum rubescens Taub. & Brosrube & 0 & 1 & 0 & 0 & 0 & 0 & 0 & 0 \\
\hline Byrsonima aerugo Sagot & Byrsaeru & 0 & 1 & 0 & 1 & 0 & 0 & 0 & 0 \\
\hline Byrsonima crispa A.Juss. & Byrscris & 0 & 0 & 0 & 1 & 1 & 0 & 0 & 0 \\
\hline Byrsonima densa (Poir.) DC. & Byrsdens & 0 & 1 & 0 & 0 & 1 & 1 & 1 & 1 \\
\hline Calophyllum brasiliense Cambess. & Calobras & 0 & 0 & 0 & 0 & 0 & 0 & 1 & 0 \\
\hline Calyptranthes gigantifolia $\mathrm{McV}$ augh & Calygiga & 0 & 0 & 0 & 1 & 0 & 0 & 0 & 0 \\
\hline Carapa guianensis Aubl. & Caraguia & 1 & 0 & 1 & 0 & 0 & 0 & 0 & 0 \\
\hline Caryocar glabrum (Aubl.) Pers. & Caryglab & 0 & 1 & 1 & 0 & 0 & 0 & 0 & 0 \\
\hline Caryocar villosum (Aubl.) Pers. & Caryvill & 0 & 0 & 0 & 1 & 0 & 0 & 0 & 0 \\
\hline Casearia acuminata DC. & Caseacum & 0 & 0 & 0 & 0 & 0 & 1 & 0 & 0 \\
\hline Casearia arborea (L.C.Rich.) Urban & Casearbo & 0 & 0 & 0 & 0 & 1 & 1 & 1 & 1 \\
\hline Casearia decandra Jacq. & Casedeca & 0 & 0 & 0 & 0 & 0 & 1 & 0 & 1 \\
\hline Casearia grandiflora Cambess. & Casegran & 0 & 0 & 0 & 0 & 1 & 1 & 0 & 1 \\
\hline Casearia spruceana Benth. ex Eichler & Casespru & 1 & 0 & 0 & 0 & 0 & 0 & 0 & 0 \\
\hline Cecropia obtusa Trécul & Cecrobtu & 1 & 1 & 0 & 1 & 0 & 0 & 0 & 0 \\
\hline Cecropia sciadophylla Mart. & Cecrscia & 1 & 1 & 1 & 1 & 0 & 0 & 0 & 0 \\
\hline Chaunochiton kapleri (Sagot ex Engl.) Ducke & Chaukapl & 0 & 1 & 0 & 0 & 0 & 0 & 0 & 0 \\
\hline Cheiloclinium cognatum (Miers) A.C.Sm. & Cheicogn & 0 & 0 & 0 & 0 & 0 & 0 & 1 & 0 \\
\hline Chimarrhis turbinata DC. & Chimturb & 0 & 0 & 0 & 1 & 0 & 0 & 0 & 0 \\
\hline Chrysophillum argenteum Jacq. & Chryarge & 0 & 0 & 0 & 0 & 1 & 0 & 0 & 0 \\
\hline Clusia amazonica Planch. \& Triana & Clusamaz & 0 & 0 & 0 & 0 & 0 & 0 & 1 & 0 \\
\hline Conceveiba guianensis Aubl. & Concguia & 0 & 0 & 1 & 0 & 0 & 0 & 0 & 0 \\
\hline Cordia bicolor DC. & Cordbico & 1 & 1 & 0 & 1 & 0 & 1 & 1 & 1 \\
\hline Cordia scabrifolia A.DC. & Cordscab & 1 & 0 & 0 & 0 & 0 & 0 & 0 & 0 \\
\hline
\end{tabular}


Continua...

Anexo H. Matriz de presença e ausência das espécies presentes nos levantamentos realizados em Marituba e Bragança-PA

\begin{tabular}{|c|c|c|c|c|c|c|c|c|c|}
\hline \multirow[t]{2}{*}{ Especie } & \multirow{2}{*}{$\begin{array}{c}\text { Código } \\
\text { Ana. } \\
\text { Agrup. }\end{array}$} & \multicolumn{8}{|c|}{ Parcelas } \\
\hline & & M1 & M2 & M3 & M4 & B1 & B2 & B3 & B4 \\
\hline Cordia sp. & Cordsp. & 0 & 1 & 0 & 0 & 0 & 0 & 0 & 0 \\
\hline Couepia bracteosa Benth. & Couebrac & 0 & 0 & 0 & 0 & 0 & 0 & 0 & 1 \\
\hline Couma guianensis Aubl. & Coumguia & 1 & 1 & 1 & 1 & 0 & 0 & 0 & 0 \\
\hline Couratari guianensis Aubl. & Courguia & 0 & 1 & 0 & 0 & 1 & 1 & 1 & 1 \\
\hline Couratari oblongifolia Ducke \& Knuth & Couroblo & 0 & 0 & 0 & 0 & 1 & 1 & 1 & 0 \\
\hline Coussarea paniculata (Vahl) Standl. & Couspani & 1 & 1 & 1 & 1 & 0 & 0 & 0 & 0 \\
\hline Croton matourensis Aubl. & Crotmato & 0 & 0 & 0 & 0 & 1 & 1 & 1 & 1 \\
\hline Cupania hirsuta Radlk. & Cupahirs & 0 & 0 & 0 & 0 & 1 & 1 & 1 & 1 \\
\hline Dendrobangia boliviana Rusby & Dendboli & 0 & 1 & 0 & 0 & 0 & 0 & 0 & 0 \\
\hline Dialium guianense (Aubl.) Sandwith & Dialguia & 0 & 0 & 0 & 0 & 1 & 0 & 0 & 0 \\
\hline Dimorphandra glabrifolia Ducke & Dimoglab & 0 & 0 & 0 & 1 & 0 & 0 & 0 & 0 \\
\hline Diospyros melinonii (Hierm.) A.C.Sm. & Diosmeli & 0 & 0 & 0 & 1 & 0 & 0 & 0 & 0 \\
\hline Diospyros praetermissa Sandwith & Diosplae & 0 & 0 & 0 & 0 & 0 & 1 & 0 & 0 \\
\hline Diploon venezuelanum Aubrév. & Diplguia & 0 & 0 & 1 & 0 & 0 & 1 & 1 & 1 \\
\hline Diplotropis guianensis Benth. & Diplvene & 0 & 0 & 0 & 1 & 0 & 0 & 0 & 0 \\
\hline Dipteryx odorata (Aubl.) Willd. & Diptodor & 1 & 0 & 0 & 1 & 0 & 1 & 0 & 0 \\
\hline Drypetes variabilis Uittien & Drypvari & 1 & 1 & 1 & 0 & 0 & 0 & 0 & 0 \\
\hline Duguetia stelechantha (Diels) R.E. Fr. & Dugustel & 0 & 0 & 0 & 1 & 0 & 0 & 0 & 0 \\
\hline Duroia guianensis & Duroguia & 0 & 0 & 0 & 0 & 0 & 0 & 0 & 1 \\
\hline Duroia sprucei Rusby & Durospru & 0 & 0 & 0 & 0 & 1 & 1 & 0 & 0 \\
\hline Emmotum fagifolium Ham. & Emmofagi & 0 & 0 & 0 & 1 & 0 & 1 & 1 & 0 \\
\hline Endicheria sp. & Endisp & 0 & 1 & 0 & 1 & 0 & 0 & 0 & 0 \\
\hline Erisma uncinatum Warm. & Erisunci & 0 & 1 & 1 & 1 & 0 & 0 & 0 & 0 \\
\hline Eschweilera amara (Aubl.) Ndz & Eschamar & 0 & 1 & 1 & 1 & 0 & 0 & 0 & 0 \\
\hline Eschweilera amazonica R.Knuth & Eschamaz & 0 & 0 & 0 & 0 & 1 & 1 & 1 & 1 \\
\hline Eschweilera apiculata (Miers) A.C.Sm. & Eschapic & 0 & 0 & 0 & 0 & 0 & 0 & 1 & 0 \\
\hline Eschweilera blanchetiana (O.Berg) Miers & Eschblan & 1 & 1 & 1 & 1 & 0 & 0 & 0 & 0 \\
\hline Eschweilera coriacea (DC.) S.A.Mori & Eschcori & 1 & 1 & 1 & 1 & 0 & 1 & 1 & 1 \\
\hline Eschweilera idatimon (Aubl.) Nied. & Eschidat & 0 & 0 & 0 & 0 & 0 & 1 & 0 & 0 \\
\hline Eschweilera micrantha (O.Berg) Miers & Eschmicr & 0 & 0 & 0 & 0 & 0 & 0 & 1 & 0 \\
\hline Eschweilera parvifolia Mart. ex DC. & Eschparv & 0 & 0 & 0 & 0 & 1 & 0 & 0 & 0 \\
\hline Eschweilera polyantha A.C.Sm. & Eschpoly & 0 & 1 & 1 & 1 & 0 & 0 & 0 & 0 \\
\hline Eugenia patrisii Vahl & Eugepatr & 1 & 0 & 0 & 0 & 0 & 0 & 0 & 0 \\
\hline Eugenia sp.1 & Eugesp1 & 0 & 0 & 0 & 0 & 1 & 1 & 0 & 0 \\
\hline Eugenia sp.2 & Eugesp2 & 0 & 0 & 0 & 0 & 1 & 1 & 1 & 0 \\
\hline Eugenia tapacumensis O. Berg & Eugetapa & 0 & 0 & 0 & 0 & 1 & 1 & 1 & 1 \\
\hline Ferdinandusa guianensis & Ferdguia & 0 & 0 & 0 & 1 & 0 & 0 & 0 & 0 \\
\hline Ferdinandusa paraensis Ducke & Ferdpara & 0 & 0 & 0 & 1 & 1 & 0 & 0 & 1 \\
\hline Ferdinandusa sp. & Ferdsp & 1 & 1 & 0 & 1 & 0 & 0 & 0 & 0 \\
\hline Geissospermum sericeum (Sagot) Benth. \& Hook.f. & Geisseri & 0 & 0 & 1 & 0 & 0 & 0 & 0 & 0 \\
\hline
\end{tabular}


Anexo H. Matriz de presença e ausência das espécies presentes nos levantamentos realizados em Marituba e Bragança-PA

\begin{tabular}{|c|c|c|c|c|c|c|c|c|c|}
\hline \multirow[t]{2}{*}{ Especie } & \multirow{2}{*}{$\begin{array}{c}\text { Código } \\
\text { Ana. } \\
\text { Agrup. }\end{array}$} & \multicolumn{8}{|c|}{ Parcelas } \\
\hline & & M1 & M2 & M3 & M4 & B1 & B2 & B3 & B4 \\
\hline Goupia glabra Aubl. & Goupglab & 1 & 1 & 1 & 1 & 0 & 0 & 0 & 0 \\
\hline Guarea kunthiana A.Juss. & Guarkunt & 1 & 0 & 0 & 0 & 0 & 0 & 0 & 0 \\
\hline Guatteria amazonica R.E.Fr. & Guatamaz & 0 & 0 & 0 & 0 & 0 & 0 & 0 & 1 \\
\hline Guatteria guianensis (Aubl.) R.E. Fr. & Guatguia & 0 & 0 & 0 & 1 & 0 & 0 & 0 & 0 \\
\hline Guatteria poeppigiana Mart. & Guatpoep & 1 & 1 & 1 & 1 & 0 & 1 & 1 & 1 \\
\hline Gustavia augusta $\mathrm{L}$. & Gustaugu & 0 & 0 & 0 & 0 & 1 & 0 & 1 & 0 \\
\hline Hebepetalum humiriifolium (Planch.) Benth. & Hebehumi & 1 & 1 & 0 & 1 & 0 & 0 & 0 & 0 \\
\hline Heisteria acuminata (Humb. \& Bonpl.) Engl. & Heisacum & 1 & 0 & 0 & 0 & 0 & 0 & 0 & 0 \\
\hline Heisteria sessilis Ducke & Heissess & 1 & 0 & 0 & 0 & 0 & 0 & 0 & 0 \\
\hline Heisteria sp. & Heissp & 0 & 1 & 0 & 0 & 0 & 0 & 0 & 0 \\
\hline Helicostylis sp. & Helisp & 0 & 0 & 0 & 0 & 0 & 1 & 0 & 0 \\
\hline Himatanthus sucuuba (Spruce ex Müll.Arg.) Woodson & Himasucu & 0 & 0 & 0 & 1 & 1 & 1 & 1 & 1 \\
\hline Hymenolobium excelsum Ducke & Hymeexce & 0 & 0 & 0 & 1 & 0 & 0 & 0 & 0 \\
\hline Inga alba (Sw.) Willd. & Ingaalba & 1 & 0 & 1 & 1 & 1 & 1 & 1 & 1 \\
\hline Inga auristellae Harms & Ingaauri & 1 & 0 & 0 & 0 & 0 & 0 & 0 & 0 \\
\hline Inga capitata Desv. & Ingacapi & 1 & 1 & 1 & 1 & 0 & 0 & 0 & 0 \\
\hline Inga cayennensis Sagot ex Benth. & Ingacaye & 0 & 0 & 0 & 1 & 1 & 0 & 0 & 0 \\
\hline Inga crassiflora Ducke & Ingacras & 1 & 0 & 0 & 0 & 0 & 0 & 0 & 0 \\
\hline Inga edulis Mart. & Ingaedul & 0 & 0 & 0 & 0 & 0 & 1 & 1 & 1 \\
\hline Inga gracilifolia Ducke & Ingagrac & 0 & 1 & 0 & 0 & 0 & 0 & 0 & 0 \\
\hline Inga heterophylla Willd. & Ingahete & 0 & 1 & 0 & 0 & 1 & 0 & 0 & 0 \\
\hline Inga macrophylla Humb. \&. Bonpl. ex Willd. & Ingamacr & 0 & 0 & 0 & 0 & 1 & 1 & 1 & 1 \\
\hline Inga paraensis Ducke & Ingapara & 0 & 0 & 0 & 0 & 1 & 0 & 1 & 1 \\
\hline Inga rubiginosa (Rich.) DC. & Ingarubi & 1 & 0 & 1 & 1 & 1 & 1 & 1 & 1 \\
\hline Inga sp.1 & Ingasp 1 & 1 & 1 & 0 & 1 & 0 & 0 & 0 & 0 \\
\hline Inga stipularis DC. & Ingastip & 1 & 0 & 1 & 0 & 0 & 0 & 1 & 0 \\
\hline Inga thibaudiana DC. & Ingathib & 0 & 0 & 1 & 1 & 0 & 0 & 0 & 0 \\
\hline Iryanthera juruensis Warb. & Iryajuru & 1 & 1 & 1 & 1 & 0 & 0 & 0 & 0 \\
\hline Iryanthera paraensis Huber & Iryapara & 0 & 1 & 0 & 0 & 0 & 0 & 0 & 0 \\
\hline Jacaranda copaia (Aubl.) D.Don & Jacacopa & 1 & 1 & 1 & 0 & 0 & 0 & 1 & 0 \\
\hline Lacistema aggregatum (Bergius) Rusby & Laciaggr & 0 & 0 & 0 & 0 & 0 & 1 & 1 & 1 \\
\hline Lacistema pubescens Mart. & Lacipube & 0 & 0 & 0 & 0 & 1 & 1 & 0 & 1 \\
\hline Lacmellea aculeata (Ducke) Monach. & Lacmscul & 1 & 1 & 1 & 1 & 1 & 1 & 0 & 0 \\
\hline Lacunaria jenmani (Oliv.) Ducke & Lacujenm & 1 & 0 & 1 & 1 & 0 & 1 & 0 & 0 \\
\hline Laetia procera (Poepp.) Eich. & Laetproc & 1 & 1 & 1 & 1 & 0 & 0 & 0 & 0 \\
\hline Lecythis idatimon Aubl. & Lecyidat & 0 & 0 & 0 & 1 & 0 & 0 & 1 & 0 \\
\hline Lecythis lurida (Miers) S.A.Mori & Lecyluri & 0 & 0 & 0 & 0 & 1 & 1 & 1 & 1 \\
\hline Lecythis micrantha $\mathrm{O}$. Berg & Lecymicr & 0 & 0 & 0 & 0 & 0 & 1 & 0 & 0 \\
\hline Lecythis usitata Miers & Lecyusit & 1 & 0 & 0 & 0 & 1 & 1 & 0 & 1 \\
\hline Licania blanchiiprance & Licablan & 1 & 1 & 1 & 0 & 0 & 0 & 0 & 0 \\
\hline Licania densiflora Kleinh. & Licacane & 0 & 0 & 0 & 0 & 0 & 1 & 0 & 1 \\
\hline
\end{tabular}


Anexo H. Matriz de presença e ausência das espécies presentes nos levantamentos realizados em Marituba e Bragança-PA

\begin{tabular}{|c|c|c|c|c|c|c|c|c|c|}
\hline \multirow{3}{*}{ Especie } & \multirow{3}{*}{$\begin{array}{c}\text { Código } \\
\text { Ana. } \\
\text { Agrup. }\end{array}$} & \multicolumn{8}{|c|}{ Parcelas } \\
\hline & & \multicolumn{4}{|c|}{ Marituba } & \multicolumn{4}{|c|}{ Bragança } \\
\hline & & M1 & M2 & M3 & M4 & B1 & B2 & B3 & B4 \\
\hline Licania heteromorpha Benth. & Licadens & 1 & 0 & 0 & 0 & 0 & 0 & 1 & 0 \\
\hline Licania lata J.F. Macbr. & Licahete & 0 & 1 & 1 & 0 & 0 & 0 & 0 & 0 \\
\hline Licania longistyla (Hook. f.) Fritsch & Licalata & 0 & 0 & 1 & 0 & 1 & 1 & 0 & 0 \\
\hline Licaria cannella (Meisn.) Kosterm & Licalogi & 1 & 1 & 1 & 1 & 0 & 0 & 0 & 0 \\
\hline Licaria multiflora (Kosterm.) Kosterm. & Licamult & 0 & 0 & 0 & 0 & 0 & 0 & 1 & 1 \\
\hline Lindackeria paraensis Kuhlm. & Lindpara & 0 & 0 & 0 & 0 & 0 & 1 & 1 & 0 \\
\hline Mabea caudata P. \& H. & Mabecaud & 1 & 1 & 1 & 1 & 0 & 0 & 0 & 0 \\
\hline Mabea paniculata Spruce ex Benth. & Mabepani & 1 & 1 & 1 & 1 & 1 & 0 & 0 & 0 \\
\hline Manilkara huberi (Ducke) A.Chev. & Manihube & 0 & 0 & 0 & 1 & 0 & 0 & 0 & 0 \\
\hline Manilkara paraensis (Huber) Standl. & Manipara & 0 & 0 & 0 & 1 & 0 & 0 & 0 & 0 \\
\hline Maprounea guianensis Aubl. & Maprguia & 0 & 0 & 0 & 0 & 1 & 1 & 1 & 1 \\
\hline Maquira guianensis Aubl. & Maquguia & 0 & 0 & 1 & 0 & 0 & 0 & 0 & 0 \\
\hline Maytenus myrsinoides Reissek & Maytmyrs & 0 & 0 & 0 & 0 & 0 & 0 & 1 & 0 \\
\hline Maytenus pruinosa Reissek & Maytprui & 0 & 0 & 0 & 0 & 0 & 0 & 1 & 0 \\
\hline Miconia eriodonta DC. & Micoerio & 0 & 0 & 0 & 0 & 0 & 1 & 0 & 0 \\
\hline Miconia surinamensis Gleason & Micosuri & 1 & 1 & 1 & 1 & 0 & 0 & 0 & 0 \\
\hline Micropholis guianensis & Micrguia & 1 & 1 & 1 & 0 & 0 & 0 & 0 & 0 \\
\hline Micropholis guyanensis (A. DC.) Pierre & Micrguya & 0 & 1 & 0 & 1 & 0 & 0 & 0 & 0 \\
\hline Micropholis venulosa (Mart. \& Eichler) Pierre & Micrvenu & 1 & 0 & 0 & 0 & 0 & 0 & 0 & 0 \\
\hline Minquartia guianensis Aubl. & Minqguia & 0 & 0 & 1 & 0 & 0 & 0 & 0 & 0 \\
\hline Mouriri apiranga Spruce ex Triana & Mourapir & 0 & 0 & 1 & 0 & 0 & 0 & 0 & 0 \\
\hline Mouriri sp. & Moursp & 0 & 0 & 1 & 0 & 0 & 0 & 0 & 0 \\
\hline Myrcia atramentifera Barb.Rodr. & Myrcatra & 0 & 0 & 1 & 0 & 1 & 1 & 1 & 1 \\
\hline Myrcia bracteata (Rich.) DC. & Myrcbrac & 0 & 0 & 0 & 0 & 1 & 1 & 1 & 1 \\
\hline Myrcia cf. tomentosa (Aubl.) DC. & Myrccf.t & 0 & 0 & 0 & 0 & 1 & 1 & 1 & 0 \\
\hline Myrcia deflexa DC. & Myrcdefl & 1 & 0 & 0 & 0 & 0 & 0 & 0 & 0 \\
\hline Myrcia sp.1 & Myrcsp & 0 & 0 & 1 & 0 & 1 & 1 & 1 & 1 \\
\hline Myrcia sp. 2 & Myrcsp 1 & 0 & 1 & 1 & 1 & 1 & 0 & 1 & 0 \\
\hline Myrcia sylvatica (G. Mey.) DC. & Myrcsp2 & 0 & 0 & 0 & 0 & 1 & 1 & 1 & 1 \\
\hline Myrciaria sp. & Myrcsylv & 0 & 0 & 0 & 0 & 0 & 0 & 1 & 0 \\
\hline Myrciaria tenella (DC.) O.Berg & Myrctene & 0 & 0 & 0 & 0 & 1 & 1 & 1 & 1 \\
\hline Nectandra sp. & Nectsp & 0 & 0 & 0 & 1 & 0 & 0 & 0 & 0 \\
\hline Neea glomeruliflora Heimerl & Neeaglom & 0 & 0 & 1 & 1 & 0 & 0 & 0 & 0 \\
\hline Neea guianensis & Neeaguia & 1 & 1 & 1 & 1 & 1 & 1 & 1 & 1 \\
\hline Neea oppositifolia Ruiz \& Pav. & Neeaoppo & 0 & 0 & 0 & 1 & 0 & 0 & 0 & 0 \\
\hline Ni nil Annon & Nini1A & 0 & 0 & 1 & 0 & 0 & 0 & 0 & 0 \\
\hline Ni ni2 Annon & Nini2A & 0 & 0 & 0 & 1 & 0 & 0 & 0 & 0 \\
\hline Ni ni3 & Nini3 & 0 & 0 & 0 & 1 & 0 & 0 & 0 & 0 \\
\hline Ni ni4 Sapo & Nini4S & 0 & 0 & 1 & 0 & 0 & 0 & 0 & 0 \\
\hline Ni ni5 Bragança & Nini5B & 0 & 0 & 0 & 0 & 0 & 0 & 1 & 0 \\
\hline Ni ni5 Marituba & Nini5M & 0 & 0 & 1 & 0 & 0 & 0 & 0 & 0 \\
\hline NI Ni6 & NINi6 & 0 & 0 & 0 & 0 & 0 & 0 & 1 & 0 \\
\hline
\end{tabular}


Anexo H. Matriz de presença e ausência das espécies presentes nos levantamentos realizados em Marituba e Bragança-PA

\begin{tabular}{|c|c|c|c|c|c|c|c|c|c|}
\hline \multirow{3}{*}{ Especie } & \multirow{3}{*}{$\begin{array}{c}\text { Código } \\
\text { Ana. } \\
\text { Agrup. }\end{array}$} & \multicolumn{8}{|c|}{ Parcelas } \\
\hline & & \multicolumn{4}{|c|}{ Marituba } & \multicolumn{4}{|c|}{ Bragança } \\
\hline & & M1 & M2 & $\mathbf{M 3}$ & M4 & B1 & B2 & B3 & B4 \\
\hline Ocotea canaliculata (Rich.) Mez & Ocotcana & 0 & 1 & 0 & 0 & 0 & 0 & 0 & 0 \\
\hline Ocotea costulata (Nees) Mez & Ocotcost & 0 & 0 & 1 & 1 & 0 & 0 & 0 & 0 \\
\hline Ocotea guianensis Aubl. & Ocotguia & 0 & 0 & 0 & 0 & 1 & 1 & 0 & 0 \\
\hline Ocotea sp.1 & Ocotsp 1 & 1 & 0 & 0 & 0 & 0 & 0 & 0 & 0 \\
\hline Ocotea sp.2 & Ocotsp 2 & 0 & 0 & 0 & 0 & 0 & 0 & 1 & 0 \\
\hline Ormosia discolor Spruce ex Benth. & Ormodisc & 0 & 0 & 0 & 0 & 0 & 0 & 0 & 1 \\
\hline Ormosia paraensis Ducke & Ormoflav & 0 & 0 & 0 & 1 & 1 & 1 & 1 & 1 \\
\hline Ormosiopsis flava (Ducke) Ducke & Ormopara & 1 & 0 & 0 & 0 & 1 & 0 & 0 & 0 \\
\hline Ouratea castaneaefolia (Endl.) DC. & Ouracast & 0 & 0 & 0 & 0 & 1 & 0 & 1 & 1 \\
\hline Palicourea guianensis Aubl. & Paliguia & 1 & 1 & 1 & 1 & 0 & 0 & 0 & 0 \\
\hline Parinari sp. & Paribarb & 0 & 0 & 0 & 1 & 0 & 0 & 0 & 0 \\
\hline Parinarium barbatum & Parisp & 0 & 0 & 1 & 0 & 0 & 0 & 0 & 0 \\
\hline Parkia multijuga Benth. & Parkmult & 1 & 0 & 1 & 0 & 0 & 0 & 0 & 0 \\
\hline Parkia paraensis Ducke & Parkpara & 1 & 0 & 0 & 0 & 0 & 0 & 0 & 0 \\
\hline Perebea guianensis Aubl. & Pereguia & 1 & 1 & 1 & 1 & 0 & 0 & 1 & 0 \\
\hline Phyllanthus nobilis (L.f.) Müll.Arg. & Phylnobi & 0 & 0 & 0 & 0 & 1 & 0 & 1 & 1 \\
\hline Pilocarpus sp. & Pilosp & 0 & 0 & 0 & 0 & 1 & 1 & 1 & 0 \\
\hline Piptadenia suaveolens Miq. & Piptsuav & 1 & 1 & 1 & 1 & 0 & 0 & 0 & 0 \\
\hline Pithecelobium racemosum Ducke & Pithrace & 0 & 1 & 0 & 0 & 0 & 0 & 0 & 0 \\
\hline Platonia insignis Mart. & Platinsi & 0 & 0 & 0 & 0 & 1 & 0 & 0 & 0 \\
\hline Pogonophora schomburgkiana Miers ex Benth. & Pogoscho & 0 & 0 & 0 & 0 & 1 & 1 & 0 & 0 \\
\hline Poraqueiba guianensis Aubl. & Poraguia & 0 & 1 & 1 & 1 & 0 & 0 & 0 & 0 \\
\hline Pourouma guianensis Aubl. & Poroguia & 1 & 1 & 1 & 1 & 0 & 0 & 0 & 0 \\
\hline Pourouma longipendula Ducke & Porolong & 1 & 1 & 1 & 1 & 0 & 0 & 0 & 0 \\
\hline Pourouma paraensis Huber & Poropara & 1 & 1 & 0 & 0 & 0 & 0 & 0 & 0 \\
\hline Pouteria bilocularis (H.Winkl.) Baehni & Poutbilo & 1 & 0 & 1 & 1 & 0 & 0 & 0 & 0 \\
\hline Pouteria caimito (Ruiz \& Pav.) Radlk. & Poutcaim & 0 & 1 & 1 & 1 & 0 & 0 & 0 & 0 \\
\hline Pouteria guianensis Aubl. & Poutguia & 1 & 1 & 1 & 1 & 0 & 1 & 1 & 1 \\
\hline Pouteria lasiocarpa (Mart.) Radlk. & Poutlasi & 0 & 0 & 1 & 0 & 0 & 0 & 0 & 0 \\
\hline Pouteria reticulata (Engl.) Eyma & Poutreti & 0 & 0 & 0 & 0 & 0 & 1 & 0 & 0 \\
\hline Pouteria torta (Mart.) Radlk. & Pouttort & 0 & 0 & 0 & 0 & 0 & 0 & 0 & 1 \\
\hline Pradosia praeato Ducke & Pradprae & 0 & 1 & 1 & 0 & 0 & 0 & 0 & 0 \\
\hline Protium opacum Swart & Protopac & 1 & 1 & 1 & 1 & 0 & 0 & 0 & 0 \\
\hline Protium pallidum Cuatrec. & Protpall & 1 & 1 & 1 & 1 & 0 & 0 & 1 & 1 \\
\hline Protium paniculatum Engl. & Protpani & 0 & 0 & 1 & 1 & 0 & 0 & 0 & 0 \\
\hline Protium pilosum (Cuatrec.) Daly & Protpilo & 0 & 1 & 0 & 0 & 0 & 0 & 0 & 0 \\
\hline Protium sp. & Protsp & 0 & 0 & 1 & 0 & 0 & 0 & 0 & 0 \\
\hline Protium spruceanum Huber. & Protspru & 1 & 1 & 1 & 1 & 0 & 0 & 0 & 0 \\
\hline Protium subserratum (Engl.) Engl. & Protsubs & 1 & 1 & 1 & 1 & 0 & 0 & 0 & 0 \\
\hline Protium trifoliolatum Engl. & Prottrif & 1 & 0 & 1 & 0 & 0 & 0 & 0 & 0 \\
\hline Pseudopiptadenia psilostachya (Benth.) G.P.Lewis \& L.Rico & Pseupsil & 0 & 0 & 1 & 1 & 0 & 0 & 0 & 0 \\
\hline Psidium guajava $\mathrm{L}$. & Psidguaj & 0 & 0 & 0 & 0 & 1 & 0 & 0 & 0 \\
\hline
\end{tabular}


Anexo H. Matriz de presença e ausência das espécies presentes nos levantamentos realizados em Marituba e Bragança-PA

\begin{tabular}{lccccccccc} 
& Código & \multicolumn{3}{c}{ Parcelas } \\
Ansecie & Ana. & Marituba & \multicolumn{4}{c}{ Bragança } \\
& Agrup. & M1 & M2 & M3 & M4 & B1 & B2 & B3 & B4
\end{tabular}

Psychotria racemosa Rich.

Pterocarpus amazonicus (Benth.) Amshoff

$\begin{array}{lllllllll}\text { Psycrace } & 0 & 0 & 0 & 0 & 0 & 0 & 1 & 1 \\ \text { Pteramaz } & 0 & 1 & 0 & 0 & 1 & 0 & 0 & 0 \\ \text { Qualalbi } & 1 & 0 & 1 & 0 & 0 & 0 & 0 & 0 \\ \text { Qualexim } & 1 & 1 & 1 & 1 & 0 & 0 & 0 & 0 \\ \text { Qualpara } & 1 & 0 & 0 & 0 & 0 & 0 & 0 & 0 \\ \text { Rheeacum } & 0 & 0 & 0 & 0 & 1 & 0 & 1 & 1 \\ \text { Richmacr } & 1 & 0 & 0 & 0 & 0 & 1 & 0 & 0 \\ \text { Rinoflav } & 1 & 0 & 0 & 0 & 0 & 0 & 0 & 0 \\ \text { Rinoguia } & 0 & 1 & 0 & 1 & 0 & 0 & 0 & 0 \\ \text { Rinorace } & 0 & 1 & 0 & 0 & 0 & 0 & 0 & 0 \\ \text { Saccamaz } & 0 & 0 & 0 & 1 & 1 & 1 & 1 & 1 \\ \text { saccguia } & 0 & 0 & 1 & 0 & 0 & 0 & 0 & 0 \\ \text { Sagorace } & 0 & 1 & 0 & 0 & 0 & 0 & 0 & 0 \\ \text { Sapisapo } & 0 & 0 & 0 & 0 & 1 & 0 & 0 & 1 \\ \text { Sapiscel } & 0 & 1 & 0 & 1 & 0 & 0 & 0 & 0\end{array}$

Qualea albiflora Warm.

Qualea eximia

Qualea paraensis Ducke

Rheedia acuminata (Ruiz \& Pav.) Pl.\& Tr.

Richardella macrophylla (Lam.) Aubrév.

Rinorea flavescens (Aubl.) Kuntze

Rinorea guianensis Aubl.

Rinorea racemosa (Mart.) Kuntze

Saccoglottis amazonica Mart.

Saccoglottis guianensis Benth.

Sagotia racemosa Baill.

Sapindus saponaria L.

Sapium scelerantum Ridley

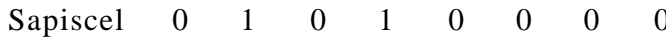

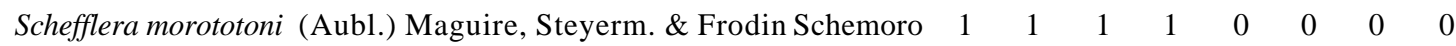

Sclerolobium chrysophyllum Poepp.

$\begin{array}{lllllllll}\text { Sclechry } & 1 & 0 & 0 & 0 & 1 & 1 & 1 & 1\end{array}$

Sclerolobium guianense Benth.

Sclerolobium paraense Huber

Simaba cedron Planch.

Simarouba amara Aubl.

Siparuna decipiens (Tul.) A.DC.

Sloanea froesii C.E.Sm.

Sloanea grandifolia Sm.

Sloanea guianensis (Aubl.) Benth.

Sterculia pilosa Ducke ex Engl.

Sterculia pruriens (Aubl.) K.Schum.

Stryphnodendron barbatimam Mart.

Stryphnodendron guianensis (Aubl.) Benth.

Stryphnodendron pulcherrimum (Willd.) Hochr.

Swartzia arborescens (Aubl.) Pittier

Symphonia globulifera L.f.

Tabebuia serratifolia (Vahl) Nichols.

Tachigali guianensis (Benth.) Zarucchi \& Herend.

Tachigali paniculata Aubl.

Tachigali sp.

Talisia carinata Radlk.

Talisia guianensis Aubl.

Talisia longifolia (Bth.)Radlk.

Tapirira guianensis Aubl.

Tapura singularis Ducke

$\begin{array}{lllllllll}\text { Scleguia } & 0 & 0 & 0 & 1 & 0 & 0 & 0 & 0\end{array}$

$\begin{array}{lllllllll}\text { Sclepara } & 1 & 0 & 0 & 1 & 1 & 1 & 1 & 1\end{array}$

$\begin{array}{lllllllll}\text { Simaamar } & 0 & 1 & 1 & 1 & 0 & 0 & 1 & 1\end{array}$

$\begin{array}{lllllllll}\text { Simacedr } & 0 & 0 & 1 & 1 & 0 & 0 & 0 & 0\end{array}$

$\begin{array}{lllllllll}\text { Sipadeci } & 1 & 0 & 0 & 1 & 0 & 0 & 0 & 0\end{array}$

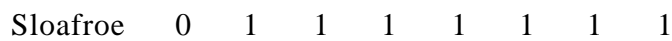

$\begin{array}{lllllllll}\text { Sloagran } & 0 & 0 & 0 & 1 & 0 & 1 & 0 & 1\end{array}$

$\begin{array}{lllllllll}\text { Sloaguia } & 0 & 0 & 0 & 0 & 1 & 0 & 0 & 0\end{array}$

$\begin{array}{lllllllll}\text { Sterpilo } & 1 & 1 & 1 & 1 & 0 & 0 & 0 & 0\end{array}$

$\begin{array}{lllllllll}\text { Sterprur } & 1 & 0 & 0 & 0 & 0 & 0 & 0 & 0\end{array}$

$\begin{array}{lllllllll}\text { Strybarb } & 0 & 0 & 0 & 0 & 0 & 1 & 1 & 1\end{array}$

$\begin{array}{lllllllll}\text { Stryguia } & 0 & 0 & 0 & 0 & 0 & 1 & 1 & 1\end{array}$

$\begin{array}{lllllllll}\text { Strypulc } & 0 & 1 & 0 & 0 & 0 & 0 & 0 & 0\end{array}$

$\begin{array}{lllllllll}\text { Swararbo } & 0 & 0 & 0 & 0 & 1 & 1 & 1 & 0\end{array}$

$\begin{array}{lllllllll}\text { Sympglob } & 1 & 1 & 1 & 1 & 0 & 0 & 1 & 0\end{array}$

$\begin{array}{lllllllll}\text { Tabeserr } & 0 & 0 & 0 & 0 & 1 & 1 & 1 & 1\end{array}$

$\begin{array}{lllllllll}\text { Tachguia } & 0 & 0 & 1 & 1 & 1 & 0 & 1 & 1\end{array}$

$\begin{array}{lllllllll}\text { Tachpani } & 0 & 1 & 1 & 1 & 0 & 0 & 0 & 0\end{array}$

$\begin{array}{lllllllll}\text { Tachsp } & 0 & 0 & 1 & 0 & 0 & 0 & 0 & 0\end{array}$

$\begin{array}{lllllllll}\text { Talicari } & 0 & 0 & 0 & 1 & 0 & 0 & 0 & 0\end{array}$

$\begin{array}{lllllllll}\text { Taliguia } & 0 & 0 & 0 & 0 & 1 & 1 & 1 & 1\end{array}$

$\begin{array}{lllllllll}\text { talilong } & 0 & 0 & 0 & 1 & 0 & 1 & 0 & 1\end{array}$

$\begin{array}{lllllllll}\text { Tapiguia } & 1 & 1 & 1 & 1 & 1 & 1 & 1 & 1\end{array}$

$\begin{array}{lllllllll}\text { Tapusing } & 0 & 0 & 1 & 0 & 1 & 1 & 0 & 0\end{array}$ 
Anexo H. Matriz de presença e ausência das espécies presentes nos levantamentos realizados em Marituba e Bragança-PA

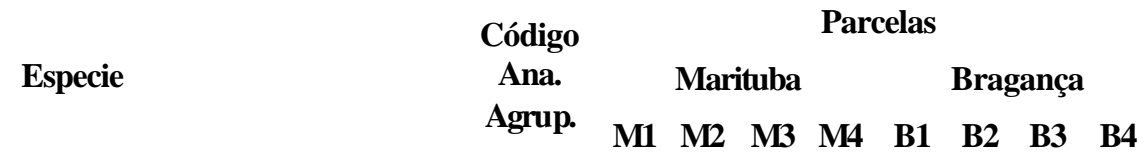

Terminalia amazonica (J.F.Gmel) Exell.

Theobroma speciosum Willd. ex Spreng.

Theobroma subincanum Mart.

Thyrsodium paraense Huber

Tovomita brevistaminea Engl.

Trattinickia rhoifolia Willd.

Trichilia lecointei Ducke

Vantanea guianensis Aubl.

Vantanea parviflora Lam.

Vatairea sericea (Ducke)Ducke

Vataireopsis speciosa Ducke

Virola calophylla (Spruce) Warb.

Virola cuspidata (Spruce ex Bentham) Warburg

Virola melinonii (Benoist) Smith

Virola michelii Heckel

Virola sp.

Virola surinamensis (Roland) Warburg

Vitex triflora Vahl.

Vochysia guianensis Aubl.

Vochysia inundata Ducke

Vochysia vismiaefolia Spruce ex Warm.

Vouacapoua americana Aubl.

Xylopia benthamii RE Fr.

Xylopia frutescens var frutescens Aubl.

\begin{tabular}{lllllllll} 
Termamaz & 1 & 1 & 0 & 0 & 1 & 0 & 0 & 1 \\
Theospec & 0 & 1 & 0 & 0 & 0 & 0 & 0 & 0 \\
Theosubi & 1 & 1 & 1 & 1 & 0 & 0 & 0 & 0 \\
Thyrpara & 1 & 1 & 1 & 1 & 0 & 1 & 1 & 0 \\
Tovobrev & 1 & 1 & 1 & 1 & 0 & 0 & 0 & 0 \\
Tratrhoi & 1 & 0 & 1 & 1 & 0 & 0 & 1 & 0 \\
Tricleco & 1 & 1 & 0 & 1 & 0 & 0 & 1 & 1 \\
Vantguia & 0 & 0 & 1 & 1 & 0 & 0 & 0 & 0 \\
Vantparv & 1 & 1 & 1 & 1 & 0 & 0 & 0 & 0 \\
Vataseri & 1 & 1 & 0 & 1 & 0 & 0 & 0 & 0 \\
Vataspec & 0 & 0 & 1 & 0 & 0 & 0 & 0 & 0 \\
Virocalo & 0 & 0 & 0 & 0 & 0 & 1 & 0 & 0 \\
Virocusp & 0 & 1 & 1 & 0 & 0 & 0 & 0 & 0 \\
Viromeli & 0 & 0 & 1 & 1 & 0 & 0 & 0 & 0 \\
Viromich & 0 & 1 & 1 & 1 & 0 & 0 & 0 & 0 \\
Virosp & 0 & 1 & 0 & 0 & 0 & 0 & 0 & 0 \\
Virosuri & 0 & 0 & 0 & 1 & 0 & 0 & 0 & 0 \\
Vitetrif & 0 & 0 & 0 & 0 & 0 & 1 & 0 & 0 \\
Vochguia & 1 & 1 & 0 & 1 & 0 & 0 & 1 & 0 \\
Vochinun & 0 & 1 & 0 & 0 & 0 & 0 & 1 & 1 \\
Vochvism & 0 & 1 & 1 & 1 & 0 & 0 & 0 & 0 \\
Vouaamer & 1 & 1 & 1 & 1 & 0 & 0 & 0 & 0 \\
Xylobent & 0 & 0 & 1 & 0 & 0 & 0 & 0 & 0 \\
Xylofrut & 0 & 0 & 0 & 0 & 0 & 1 & 0 & 0 \\
Xyloniti & 0 & 0 & 0 & 1 & 0 & 1 & 1 & 0 \\
Zantpent & 0 & 0 & 0 & 1 & 0 & 0 & 0 & 0 \\
Zantrhoi & 0 & 0 & 1 & 0 & 0 & 0 & 1 & 0 \\
\hline & & & & & & & &
\end{tabular}

Xylopia nitida Dun.

Zanthoxylum pentandra 


\section{REFERÊNCIAS BIBLIOGRÁFICAS}

ALLEN, J.C. Soil response to forest clearing in the United States and the tropics: geological and biological factors. Biotropica, v.17, p.15-27, 1985.

BAKKER, J.P.; OLFF, H.; WILLEMS, J.H.; ZOBEL, M. Why do we need permanent plots in the study of long-term vegetation dynamics? Journal of Vegetation Science, v.7, p.147156, 1996.

BARROS, P.L.C. de. Estudo fitossociológico de uma floresta tropical úmida no planalto de Curuá-Una, Amazônia brasileira. Curitiba, 1986. 146p. Tese (Doutorado) - Universidade Federal do Paraná.

BASTOS, T.X.; PACHECO, N.A. Características agroclimatológicas do Município de IgarapéAçu. In: SEMINÁRIO SOBRE MANEJO DA VEGETAÇÃO SECUNDÁRIA PARA A SUSTENTABILIDADE DA AGRICULTURA FAMILIAR DA AMAZÔNIA ORIENTAL, Belém, 1999. Anais. Belém: Embrapa Amazônia Oriental/CNPq 1999. p.51-58.

BERTANI, D.F. Análise da estrutura e dinâmica de uma comunidade de espécies arbóreas em um fragmento de floresta ribeirinha, Ipeúna, SP. Piracicaba, 2000. 70p. Dissertação (Mestrado) - Escola Superior de Agricultura “Luiz de Queiroz" Universidade de São Paulo.

BRASIL. Ministério de Minas e Energia. Departamento Nacional de Produção Mineral. PROJETO RADAM: Folha AS.22-Belém, geologia, geomorfologia, solos, vegetação e uso da terra. Rio de Janeiro, 1974. 276p.

BROWN, S.; LUGO, A. Tropical secondary forests. Journal of Tropical Ecology, v.6, p.1-32, 1990.

BUDOWSKI, G. Distribution of tropical American rain forest species in the light of successional processes. Turrialba, v.15, p.40-42, 1965.

CARVALHO, J.A.P. de. Structure and dynamics of a logged over Brazilian Amazonian rain forest. Oxford, 1992. 215 p. Thesis (Ph.D.) - University of Oxford. 
CLARK, D.B.; CLARK, D.A.; RICH, P.M. Comparative analysis microhabitat utilization by saplings of nine tree species in neotropical rain forest. Biotropica, v.25, n.4, p.397-407, 1993.

CORLETT, S. What is secondary forest? Short Communication. Journal of Tropical Ecology, v.10, p.445-447, 1994.

CRONQUIST, A. The evolution and classification of flowering plants. New York: The New York Botanical Garden, 1988. 555p.

CROW, T.R. A rain forest chronicle: a 30-year record of change in estructure and composition at El Verde, Puerto Rico. Biotropica, v.12, n.1, 1980, p.42-55.

DENICH, M. A Vegetação da Amazônia com ênfase na vegetação secundária. In: Pesquisas sobre utilização e conservação do solo na Amazônia Oriental. Belém: Ed. EMBRAPA Centro de Pesquisa do Tropico Úmido/Deutsche Gesellschaft für Technische Zusammenarbeit. 1986. p.43-69. (Documentos, 40).

DENICH, M. Estudo da importância de uma vegetação secundária nova para o incremento da produtividade do sistema de produção na Amazônia Oriental brasileira. Eschborn, 1991. 284p. Tese (Doutorado) - Deutsche Gesellschaft für Technische Zusammenarbeit.

DEPARTAMENTO NACIONAL DE METEOROLOGIA. Normas climatológicas (1961 a 1990). Brasília, 1992. 83p.

DINIZ, T.D.A.S. Caracterização climática da Amazônia Oriental. In: Pesquisas sobre utilização e conservação do solo na Amazônia Oriental. Belém: Ed. EMBRAPA Centro de Pesquisa do Tropico Úmido/Deutsche Gesellschaft für Technische Zusammenarbeit. 1986. p.3-13. (Documentos, 40).

EGLER, E.G.A. Zona bragantina no Estado do Pará. Revista Brasileira de Geografia. v.23, p.527-555, 1961.

EMPRESA BRASILEIRA DE PESQUISA AGROPECUÁRIA. Serviço Nacional de Levantamento e Conservação de Solos. Manual de métodos de análise de solos. Rio de Janeiro, pt.1: Análises físicas. v.1, 1979.

EMPRESA BRASILEIRA DE PESQUISA AGROPECUÁRIA. Serviço Nacional de Levantamento e Conservação de Solos. Caracterização físico-hídrica dos principais solos da Amazônia Legal: I - Estado do Pará. Belém, 1991. 228p. (Relatório técnico).

EMPRESA BRASILEIRA DE PESQUISA AGROPECUÁRIA - Centro Nacional de Pesquisa de Solos. Sistema brasile iro de classificação de solos. Brasília: Embrapa, Produção de Informação, 1999. 412p. 
EWEL, J. Tropical succession: manifold routs to maturity. Biotropica, v.12, p.2-7, 1980.

FASSBERNDER, H.W. Bases edafologicas de los sistemas de produccion agroforestales. Turrialba: CATIE, 1984. 192p.

FELFILI, M.F. Growth, recruitment and mortality in the Gama gallery forest in central Brazil over a six-year period (1985-1991). Journal of Tropical Ecology. V.11, p.67-83, 1995.

FELFILI, J.A.; VENTUROLI, F. Tópicos em análise de vegetação. Brasília. Comunicações Técnicas Florestais v.2, n.1, 24p. 2000.

FERREIRA, L.V.; PRANCE, G.T. Ecosystem recovery in terra firme forests after cutting and burning: a comparison on species richness, floristic composition and forest structure in the Jaú National Park, Amazonia. Botanical Journal of the Linnean Society, v.130, p.97-110, 1999.

FERREIRA, R.L.C.; SOUZA, A.L. de; JESUS, R.M. de. Taxa de crescimento de uma floresta secundária de transição. Revista Árvore, v.22, n.4, p.451-461, 1998.

FINA, B.G. Florística e fitossociologia em uma área de cerradão, município de Pirassununga, SP. Rio Claro, 1999. 90p. Dissertação (Mestrado) - Instituto de Biociências "Campus de Rio Claro" Universidade Estadual Paulista "Júlio de Mesquita Filho".

FINEGAN, B. Bases ecologicas de la silvicultura y la agroforesteria Turrialba. Costa Rica: CATIE, 1992. 153p.

FINEGAN, B.; CMACHO, M.; ZAMORA, N. Diameter increments patterns among 106 species in a logged and silviculurally treated Costa Rica rain forest. Forest Ecology and Management, v.121, p.159-176, 1999.

FROES, R.L. Observações sobre o tipo de vegetação de capoeira, conhecido na Ilha de Colares, por campina. Norte Agronômico. v.3, p.73-76, 1957.

FONSECA, J.S.; Martins, G.A. Curso de estatística. 5 ed. São Paulo: Atlas, 1994. 317p.

FURTINI NETO, A.E.; RESENDE, A.V. de; VALE, F.R. de; FAQUIN, V.; FERNANDES, L.A. Acidez do solo, crescimento e nutrição mineral de algumas espécies arbóreas, na fase de muda. Cerne, v.5, n.2, p.1-12, 1999.

GOMIDE, G.L.A.; FINEGAN, B.; SANQUETA, C.R.; Silva, J.N.M. Cambios en la estrutura, patrones de reclutamiento y mortalidad en dos bosques secundarios neotropicales durante la segunda fase de sucesión. In: SIMPOSIO INTERNACIONAL DA IUFRO: MANEJO INTEGRADO DE FLORESTAS ÚMIDAS NEOTROPICAIS POR INDUSTRIAS E COMUNIDADES, Belém, 2002. Belém: CIFOR; Embrapa Amazônia Oriental, 2002. p.124139. 
GREIG-SMITH, P. Ecological observations on degraded and secondary forest in Trinidad, British West Indics. General features of the vegetation. Journal of Ecology, v.40, p.283$315,1952$.

GUARIGUATA, M.R.; OTERTAG, R. Neotropical secondary Forest succession: changes in structural and functional characteristics. Forest Ecology and Management, v.148, p.185206, 2001.

GUNN, C.R. A nomenclator of legume (Fabaceae) genera. Washington: United States Department of Agriculture, 1983. 224p. (Technical Bulletin, 1680)

GUSMÃO, R.P. Diagnóstico Brasil: a ocupação do território e o meio ambiente-Mapas. Rio de Janeiro: IBGE, 1990. <http://www2.ibge.gov.br/pub/Cartas_e_ Mapas/Mapas_Tematicos>. (26 Jul. 2003)

HARDY, F. Soil and natural vegetation in Trinidad, W. I. Biotropica, v.10, n.1, p.70-71, 1978.

HARTSHORN, G.S. Tree falls and tropical forest dynamics. In: TOMLINSON, P.B.; ZIMMERMANN, M.H. (Ed.) Tropical tree as living systems. Cambridge: Cambridge University Press, 1978. p.617-638.

HERNANI, L.C.; SAKAI, F.; ISHIMURA, I.; LEPSCH, I.F. Influência de métodos de limpeza de terreno sob floresta secundária em Latossolo Amarelo do vale do Ribeira, SP.: I. Dinâmica de atributos químicos, físicos e produção de milho. Revista Brasileira de Ciência do Solo, v.11, n.2, p.205-214, 1987.

HIGUCHI, N.; SANTOS, J.; RIBEIRO, R. J.; FREITAS, J. V.; VIEIRA, G.; COIC, A.; MINETTE, L. J. Crescimento e incremento de uma floresta amazônica de terra-firme manejada experimentalmente. In: HIGUCHI, N.; FERRAZ, J.B.S.; ANTONY, F.; LUIZÃO, R.; BIOT, Y.; HUNTER, I.; PROCTOR, J.; ROSS, S. (Ed.). Biomassa e nutrientes florestais. Manaus: INPA/DFID, 1997, p.88-132. (Relatório final).

HOSOKAWA, R.T.; MOURA, J.B.; CUNHA, U.S. da. Introdução ao manejo e economia de florestas. Curitiba: Ed. UFPR, 1998. 162p.

HUBER, J. Matas e madeiras amazônicas. Boletim do Museu Paraense Emílio Goeldi, n.6, p.91-225, 1909.

INSTITUTO BRASILEIRO DE GEOGRAFIA E ESTATÍSTICA. Atlas nacional do Brasil. Brasília, 1992. de <http://www2.ibge.gov.br/pub/Cartas_e_Mapas/Mapas_Tematicos>. (26 Jul. 2003a)

INSTITUTO BRASILEIRO DE GEOGRAFIA E ESTATÍSTICA. Diagnóstico ambiental da Amazônia Legal. IBGE/DGC/DERNA-DEGEO-DECAR. Rio de Janeiro, 1997. <http://map.ibge.gov.br/website/amazonia/viewer.htm>. (26 Jul. 2003b). 
INSTITUTO DE DESENVOLVIMENTO ECONÔMICO-SOCIAL DO PARÁ. Diagnóstico do Município de Bragança. Belém: Coordenadoria de Documentação e Informação, 1998.

IVANAUSKAS, N.M. Estudo da vegetação na área de contato entre formações florestais em Gaúcha do Norte-MT. Campinas, 2002. 184p. Tese (Doutorado) - Instituto de Biologia, Universidade Estadual de Campinas.

IVANAUSKAS, N.M.; MONTEIRO, R.; RODRIGUES, R.R. Alterations following a fire in a forest community of Alto Rio Xingu. Forest Ecology and Management, v.184, p.239-250, 2003.

JARDIM, F.C.S.; ARAÚJO, M.M.; OLIVEIRA, F.A. Estrutura e sucessão em florestas secundárias no município de Marituba, Pará. Boletim da Faculdade de Ciências Agrárias do Pará, n.28, p.63-80, 1997.

JENNY, H. Comparison on soil nitrogen and carbon in tropical and temperate regions. Missori: Agricultural Experimental Station, 1961. 31p. (Research Bulletin, 765).

JOHNSON, M.C.; VIEIRA, I.C.G.; ZARIN, D.J.; FRIZANO, J.; JOHNSON, A.H. Carbon and nutrient storage in primary and secondary forests in eastern Amazônia. Forest Ecology and Management, v.147, p.245-252, 2001.

JORDAN, C.; GOLLEY, F.; HALL, Jerry.; HALL, Jan. Nutrient scavenging of rainfall by the canopy of an amazonian rain forest. Biotropica, v.12, n.1, p.61-66, 1980.

KIEHL, E.J. Manual de edafologia. São Paulo: Agronômica Ceres, 1979. 262p.

LANLY, J.P. Tropical forest resources. Rome: FAO, 1982, 116p. (FAO Forestry Paper, 30).

LIEBERMAN, D.; LIEBERMAN, M. Forest tree growth and dynamics at La Selva, Costa Rica (1969-1982). Journal of Tropical Ecology, v.3, n.4, p.334-358, 1987.

LIEBERMAN, D.; LIEBERMAN, M.; HARTSHORN, G.; PERALTA, R. Growth rate and age size relationships of lowland tropical wet forest tree in Costa Rica. Journal of Tropical Ecology, v.1, p.97-109, 1985.

LIMA, R.R. Os efeitos das queimadas sobre a vegetação dos solos arenosos da região da estrada de ferro de Bragança. Belém: IAN, 1954. 20p.

LONGHI, S.J. A estrutura de uma floresta natural de Araucaria angustifólia (Bert.) O. Ktze., Sul do Brasil. Curitiba, 1980. 198p. Dissertação (Mestrado) - Setor de Ciências Agrárias, Universidade Federal do Paraná.

MAGURRAN, A. Ecological diversity and its measurement. New Jersey: Princeton University Press, 1988. 179p. 
MANOKARAN, N.; KOCHUMMEN, K.M. Recruitment, growth and mortality of tree species in a lowland dipterocarp forest in Peninsular Malaysia. Journal of Tropical Ecology, v.3, n.4, p.315-330, 1987.

MARTINS, F.R. Atributos de comunidades vegetais. Quid, Teresina, v.9, n.1/2, p.12-17, 1990.

MARTINS, F.R.; Santos, F.A.M. dos. Técnicas usuais de estimativa da biodiversidade. Revista Holos, v. 1, p.236-267, 1999.

MARTINS, S.V.; RODRIGUES, R.R. Gap-phase regeneration in a semideciduous mesophytic forest, south-eastern Brazil. Plant Ecology, v.00, p.1-12, 2002.

MATHER, A.S. Global forest resources. Oregon: Timber Press, 1990. 314p.

MELLO, F.A.F.; SOBRINO, M.A.C.B.; SILVEIRA, R.I.; NETTO, A.C.; KIEL, J.C. Fertilidade do solo. Piracicaba: Nobel, 1989. 400p.

MENEZES, J.M.T. Desenvolvimento de sistemas agroflorestais em propriedades agrícolas no norte do Estado de Rondônia. Jaboticabal, 2003. 84p. Tese (Doutorado) - Faculdade de Ciências Agrárias e Veterinárias, Universidade Estadual Paulista "Júlio de mesquita Filho".

MIRANDA, I.S. Análise florística e estrutural da vegetação lenhosa do Rio Comemoração, Pimenta Bueno, Rondônia, Brasil. Acta Amazônica, v.30, n.3, p.393-422, 2000.

MUELLER-DOMBOIS, D.; ELLEMBERG, H. Aims and methods of vegetation ecology. New York: John Willey, 1974. 457p.

NUMATA, I. Avaliação da conversão de florestas para pastagem na Amazônia usando sensoriamento remoto e fertilidade do solo. São José dos Campos, 1999. 102p. Dissertação (Mestrado) - Instituto Nacional de Pesquisas Espaciais.

OLIVEIRA, A.A. de. Diversidade, estrutura e dinâmica do componente arbóreo de uma floresta de terra firme de Manaus, Amazonas. São Paulo, 1997. 188p. Tese (Doutorado) - Instituto de Biociências, Universidade de São Paulo.

OLIVEIRA, L.C. de. Dinâmica de crescimento e regeneração natural de uma floresta secundária no Estado do Pará. Belém, 1995. 136p. Dissertação (Mestrado) - Universidade Federal do Pará.

OLIVEIRA, L.C. de. Dinâmica de crescimento e regeneração natural de uma floresta secundária no Estado do Pará. In: ECOLOGY AND MANAGEMENT OF TROPICAL SECONDARY FOREST: SCIENCE PEOPLE AND POLICY, Turrialba, Costa Rica, 1997. Turrialba: CATIE/IUFRO/CIFOR/WWF/GTZ, 1997. p.69-87.

PANTOJA, F.B.C.; OLIVEIRA, V.C. de; COSTA, L.G.S.; VASCONCELOS, P.C.S. Estrutura de um trecho de floresta secundária de terra firme, no município de Benevides, Pará: Faculdade de Ciências Agrárias do Pará, 1997. 18p. (Informe Técnico, 24) 
PENTEADO, A.R. Problemas de colonização e de uso da terra na Região Bragantina do Estado do Pará. Belém: Universidade Federal do Pará, 1967. 488p. (Coleção Amazônia, Série José Veríssimo, 1).

PICKETT, S.T.A.; OSTFELD, R.S. The shifting paradigm in Ecology. In: KNIGHT, R.; BATES, S.F. (Ed.) A new century for natural resouces management. Washington: Island, 1995. p.261-278.

PICKETT, S.T.A.; WHITE, P.S. Patch dynamics: a synthesis. In: PICKETT, S.T.A.; WHITE, P.S. (Ed.) The ecology of natural disturbance and patch dynamics. New York: Academic press, 1985. p.372-384.

PIELOU, E.C. Ecological diversity. New York: John Wiley, 1975. 165p.

PIELOU, E.C. Mathematical diversity. New York: John Wiley, 1977. 385p.

PIRES, J.M.; SALOMÃO, R. de P. Dinâmica da diversidade arbórea de um fragmento de floresta tropical primária na Amazônia Oriental - 1.Período: 1956 a 1992. Boletim do

Museu Paraense Emílio Goeldi. Série Botânica, v.16, n.1, p.63-110, 2000.

PUTZ, F.E.; BROKAW, N.V.L. Sprouting of broken trees on Barro Colorado Island, Panama.

Ecology, v.70, n.2, p.508-512, 1989.

PUTZ, F.E.; BROKAW, N.V.L. Sprouting of broken trees on Barro Colorado Island, Panama.

Ecology, v.70, n.2, p.508-512, 1989.

RAIJ, B.Van. Fertilidade do solo e adubação. Piracicaba: Ceres, Potafos, 1991. 343p.

RAMOS, M.M. Regeneración natural y diversidad de especies arbóreas en selvas húmedas.

Boletim da Sociedade Botânica do México, n.54, p.179-224, 1994.

RIZZINI, C.T. Nota prévia sobre a divisão fitogeográfica florístico-sociológica do Brasil.

Separata da Revista Brasileira de Geografia, v.25, n.1, p.1-64, 1963.

RODRIGUES, R.R. Análise de um remanescente de vegetação natural às margens do rio Passa

Cinco, Ipeúna, SP. Campinas, 1991. 325p. Tese (Doutorado) - Universidade de Campinas.

RODRIGUES, R.R.; GANDOLFI, S. Restauração de florestas tropic ais: subsídios para uma definição metodológica e indicadores de avaliação de monitoramento, In: DIAS, L.E.; Mello, J.W.V. de. (Ed.). Recuperação de áreas degradadas . Viçosa: UFV, 1998. p.203-215.

SANCHEZ, P. Properties and management of soils in the tropics. New York: John Wiley, 1976. 619p.

SANTANA, J.A.S. Composição florística de uma vegetação secundária no nordeste paraense. Belém: Faculdade de Ciências Agrárias do Pará, 2000. 27p. (Informe Técnico, 26) SAS INSTITUTE. SAS/STAT guide, for personal computers: version 6. Cary, 1987. $1028 \mathrm{p}$. 
SHEPHERD, G.J. FITOPAC 1: manual do usuário. Campinas: Universidade Estadual de Campinas, 1995. 93p.

SILVA, S.B. Análise química de solos. Belém: Faculdade de Ciências Agrárias do Pará, 1991. 41p.(Informe Didático, 11).

SILVA, B.N.R.; CARVALHO, J.S. Os solos da Amazônia Oriental. Belém: EMBRAPA; CPATU; GTZ, 1986. 42p.

SILVA, J.N.M. The behaviour of the tropical rainforest of the brazilian Amazon after logging. Oxford, 1989. 302p. Thesis (Ph.D.) - University of Oxford.

SILVA, J.N.M.; LOPES , J.C.A. Inventário florestal contínuo em tropicais: a metodologia utilizada pela EMBRAPA-CPATU na Amazônia brasileira. Belém: EMBRAPA-CPATU, 1984. 36p. (Documento, 33).

SILVA, J.N.M.; CARVALHO, J.O.P.; LOPES, J.C.A; ALMEIDA, B.F.; COSTA, D.E.M.; OLIVEIRA, L.C.; VANKLAY, J.K.; SKOVSGAARD, J.P. Growth and yield of a tropical rain forest in the Brazilian amazon 13 years after loging. Forest Ecology and Management, v.71, p.267-274, 1995.

SMITH, J.; SABOGAL, C.; JONG, W.; KAIMOWITZ, D. Bosques secundarios como recurso para el desarrollo rural y la conservación ambiental en los trópicos de América Latina. Bogor: Center for International Forestry Research, 1997. 31p. (Occasional paper, 13).

SWAINE, M.D.; LIEBERMAN, D. The dynamics of tree populations in tropical forest. Journal of Tropical Ecology, v.3, n.4, p.ii-iii, 1987.

SWAINE, M.D.; LIBERMAN, D.; PUTZ, F.E. The dynamics of tree populations in tropical forests: a review. Journal of Tropical Ecology, v.3, n.4, p.359-366, 1987a.

SWAINE, M.D.; HALL, J.B.; ALEXANDER, I.J. Tree population dynamics at Kade, Ghana (1968-1982). Journal of Tropical Ecology, v.3, n.4, p.331-345, 1987 b.

TER BRAAK, C.J.F. Canonical Correspondence Analysis: a new eigenvector technique for multivariate direct gradient analysis. Ecology, v.67, n.5, p.1167-1179, 1986.

TRATADO DE COOPERACION AMAZÓNICA. Memorias del taller internacional sobre el estado actual y potencial de manejo y Desarrollo del bosque secundario tropical en América Latina. Pucallpa: Tratado de Cooperación Amazónica, 1997. 272p.

TRATADO DE COOPERACION AMAZÓNICA. Estrategia para implementar las recomendaciones de la propuesta de Pucallpa sobre el desarrollo sostenible del bosque secundario en la Región Amazónica. Caracas: Tratado de Cooperación Amazónica, 1999. $163 \mathrm{p}$. 
TOGNON, A.A.; DEMATTÊ, J.L.I.; DEMATTÊ, J.A.M. Teor e distribuição da matéria orgânica em latossolos das regiões da floresta amazônica e dos cerrados do Brasil central. Piracicaba. Scientia Agricola, v.55, n.3, p.343-354, 1998.

TOMÉ JUNIOR., J.B. Manual para interpretação de análise de solo. Guaíba: Agropecuária, 1997. 247p.

TUCKER, J.M.; BRONDIZIO, E.S.; MORAN, E.E. Rates of forest regrowth in eastern Amazônia: a comparison of Altamira and Bragantina regions, Pará State, Brazil. Interciencia, v.23, n.2, p.64-73, 1998.

UHL, C.; JORDAN, C.F. Succession and nutrient dynamics following forest cutting and burning in Amazonia. Ecology, v.65, n.5, p.1476-1490, 1984.

UHL, C.; CLARK, K.; MURPHY, H. Early plant succession after cutting and burning in the upper Rio Negro region of the Amazon basin. Journal of Ecology, v.69, p.631-649, 1981.

UHL, C.; CLARK, H.; CLARK, K.; MAQUIRINO, P. Successional peterns associated with slash-and-burn agriculture in the upper Rio Negro region of the Amazon Basin. Biotropica, v.14, n.4, p.249-254, 1982.

UHL, C.; BUSCHBACHER, R.; SERRÃO, E.A. Abandoned pastures in Eastern Amazonia. I. Patterns of plant succession. Journal of Ecology, v.76, p.663-681, 1988.

UNESCO. Ecossistemas de los bosques tropicales. Paris: UNESCO;PNUMA;FAO, 1978. p.204-264: Sucesiones secundarias.

VIDAL, E.J. Dinâmica de florestas manejadas e sob exploração convencional na Amazônia oriental. São Carlos, 2004. 148p. Tese (Doutorado) - Escola de Engenharia de São Carlos, Universidade de São Paulo.

VIDAL, E.J.; VIANA, V.M.; BATISTA, J.L.F. Crescimento de floresta tropical três anos após colheita de madeira com e sem manejo florestal na Amazônia oriental. Scientia Forestalis. v.61, p.133-143, 2002.

VIEIRA, I.C.G. Forest Succession after shifting cultivation in eastern Amazonia. Scotland, 1996. 639p. Thesis (Ph.D.) - Department of Biological and Molecular Sciences, University of Stirling.

VIEIRA, L.S.; VIEIRA, M.N.F. Manual de morfologia e classificação de solos. Belém: Faculdade de Ciências Agrárias do Pará, 1981. 580p.

VIEIRA, L.S.; SANTOS, W.H.P. dos; FALESI, J.C.; OLIVEIRA-FILHO, J.P.S. Levantamento e reconhecimento dos solos da Região Bragantina, Estado do Pará. Pesquisa Agropecuaia Brasileira, v.2, p.1-63, 1967. 
WEIDELT, H.J. Sustained yield management in moist tropical forest: opportunities and constrainst. Plant Research and Development, v.23, p.80-100, 1991. 